Universidade de São Paulo

Instituto de Fisica

\title{
Caracterização estrutural de peptideos melanotrópicos e suas interações com agregados anfifilicos: um estudo por fluorescência e ressonância paramagnética eletrônica
}

\section{Roberto Morato Fernandez}

Tese apresentada ao Instituto de Física da Universidade de São Paulo para obtenção do título de Doutor em Física.

\section{Banca Examinadora:}

M. Teresa Lamy Freund (Orientadora-IFUSP)
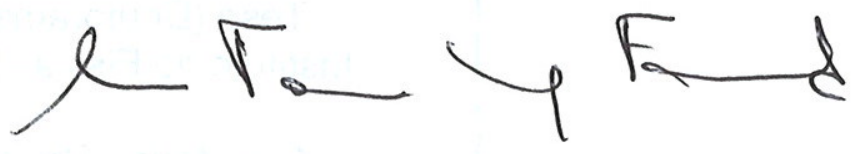

Sônia Renaux W. Louro (PUC-RJ)

Iouri Borissevitch (FFCLRP-USP)

Otaciro Rangel Nascimento (IFSC-USP)

INSTITUTO DE FISICA

Rosângela Itri (IFUSP)

Servị̧o de Biblioteca e lnformação

Tamb: $\quad 3626$

São Paulo

2002 


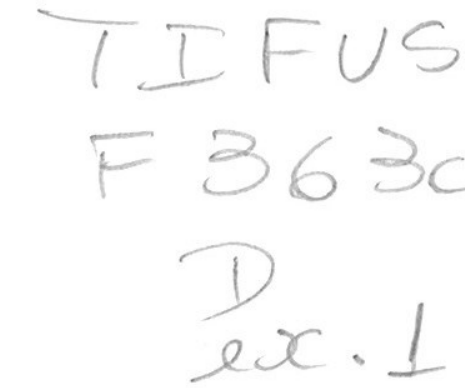

FICHA CATALOGRÁFICA

Preparada pelo Serviço de Biblioteca e Informação do Instituto de Física da Universidade de São Paulo

Fernandez, Roberto Morato

Caracterização Estrutural de Peptídeos Melanotrópicos e suas Interações com Agregados Anfifilicos: Um Estudo por Fluorescência e Ressonância Paramagnética Eletrônica. São Paulo 2002.

Tese (Doutoramento) - Universidade de São Paulo Instituto de Física - Departamento de Física Geral

Orientador: Profa. Dra. Maria Teresa Lamy-Freund Área de Concentração: Física

Unitermos: 1. Peptídeos Melanotrópicos;

2. Interação Peptídeo/Lipídeo;

3. Técnicas Espectroscópicas;

4. Propriedades Estruturais;

5. Hidratação. 
Universidade de São Paulo

Instituto de Física

Caracterização estrutural de peptideos

melanotrópicos e suas interações com agregados

anfifilicos: um estudo por fluorescência e

ressonância paramagnética eletrônica

Roberto Morato Fernandez

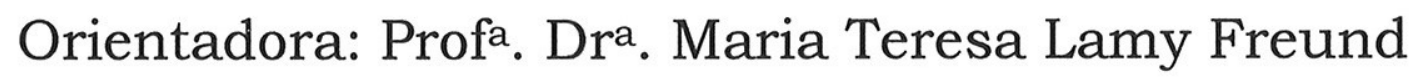

SBI-IFUSP

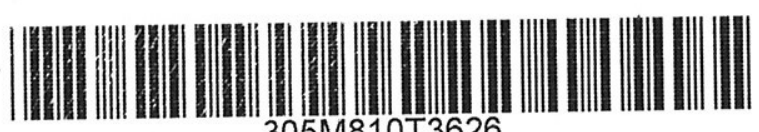

305M810T3626
Tese apresentada ao Instituto de Física da Universidade de São Paulo para obtenção do título de Doutor em Física.

INSTITUTO DE FÍSICA

Serviço de Biblioteoa e Informação

Tombo: $\frac{3626}{e x \cdot I_{\text {São Paulo }}}$

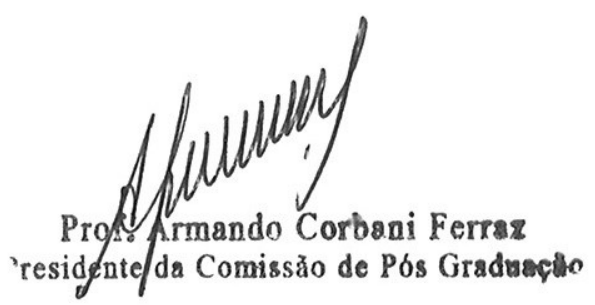

2002 


\section{Agradecimentos}

À Teresa, pela orientação e amizade presentes nestes quatro anos de trabalho. Pela disposição e satisfação em transmitir os conhecimentos cientificos e principalmente a sua compreensão humana.

Ao Amando Ito, pelos ensinamentos de teoria e prática em fluorescência e colaboração ao trabalho. Pelas discussões científicas na sala de Reuniões.

Aos meus colegas de sala, Karin e Rozane, pelas constantes discussões de RPE e realização de experimentos de RPE nas bandas L, Q e X; à Flávia, pelas discussões gerais de Física, e mais recentemente à Cássia, pelas discussões sobre o Triptofano, e ao Maeda pela amizade sempre presente.

Aos que disponibilizaram seus aparelhos para a realização de experimentos: Otaciro, da USP-São Carlos (RPE-bandas L e Q); ao Jack Freed, da Universidade de Cornell (RPE-250 GHz); e a Ana Castrucci, do IB da USP-São Paulo (potência biológica e resposta por lavagem).

Aos que colaboraram diretamente neste trabalho: Clóvis Nakaie, da UFESP, e Helgi Schiöth, da Universidade de Upsalla, pelo fornecimento dos peptídeos melanotrópicos e análogos.

Aos que sempre estiveram prontos e dispostos a socorrer nos experimentos: Márcia, Roberto (técnico), Karin e Rozane, pela ajuda na preparação de amostras e operação do RPE; Cássia, Marcelo e Eduardo, pela ajuda na operação dos fluorimetros estático e temporal; e ao Keith, pela ajuda na operação do RPE de $250 \mathrm{GHz}$.

À Carla, pelas discussões de grupo, apoio e interesse no trabalho.

À Nara e ao Márcio, pela grande amizade, carinho e estima.

À Silvana, Lorena, Suely, Tiago, Alessandro, Rafael, Fornés, Cássia, Flávia, Karin, Maeda, Marcelo, Eduardo, Jabá, Dirce, Ivone, Marcos, Carlão, Seu Wilson e o Silvio, pelo companheirismo, amizade e bate-papo. 
À Fapesp e ao CNPq pelo apoio financeiro.

À minha família, pelo carinho e apoio pessoal.

À todos que, direta ou indiretamente, contribuiram para o desenvolvimento deste trabalho. 


\section{Índice}

\section{Resumo}

Abstract

\section{Introdução}

1.1 Membranas biológicas 1

1.2 Estrutura físico-química dos fosfolipídeos 2

1.3 Membranas modelo 5

1.4 Hormônio estimulador do melanócito 6

$\begin{array}{ll}1.5 \text { Objetivos } & 7\end{array}$

2 Técnicas experimentais 9

$\begin{array}{ll}2.1 \text { Absorção óptica } & 10\end{array}$

2.1.1 A lei de Lambert-Beer 11

$\begin{array}{ll}2.2 \text { Espectroscopia de Fluorescência } & 12\end{array}$

$\begin{array}{ll}2.2 .1 \text { O fenômeno da fluorescência } & 14\end{array}$

2.2.2 Decaimento fluorescente $\quad 15$

2.2.3 Método de correlação temporal de fótons únicos 19

2.2.4 Triptofano como sonda fluorescente 20

2.3 Ressonância paramagnética eletrônica $\quad 21$

2.3.1 Largura de linha do espectro de RPE 25

2.3.2 Cálculo do tempo de correlação $\quad 30$

2.3.3 Parâmetro de ordem $\quad 32$

$\begin{array}{ll}\text { 2.3.4 Polaridade do meio } & 35\end{array}$

3 Materiais e métodos 36

3.1 Materiais 36

3.2 Métodos 39

4 Resultados e discussões $\quad 45$

4.1 Correlação entre alteração da fluidez e presença de água no 45 interior de bicamadas lipídicas: um estudo $\operatorname{com} \alpha-\mathrm{MSH}$

4.1.1 Marcadores de spin em bicamadas de DMPG puro: 46 desdobramento hiperfino isotrópico $a_{0}$ 
4.1.2 Mudanças nos valores de $a_{0}$ devido à presença do $\alpha$-MSH: 48 uma comparação com $\mathrm{Na}^{+}$e colesterol

4.1.3 Polaridade medida em amostras congeladas 55

4.1.4 Possiveis correlações entre as alterações na polaridade de bicamadas congeladas e mudanças na fluidez da membrana na fase gel

4.2 Propriedades térmicas e estruturais do complexo $\alpha-\mathrm{MSH} / \mathrm{DMPG}$ 62 4.2.1 A região de transição de bicamadas de DMPG

4.2.2 Espectros do 16-PCSL em bicamadas de DMPG à diferentes freqüências

4.2.3 Espectros do 16-PCSL em DMPG na presença do $\alpha$-MSH $\quad 70$

4.3 Análogos cíclicos do $\alpha$-MSH: interação com bicamadas lipídicas $\quad 74$

4.3.1 Coeficientes de extinção molar $\varepsilon$ do $\alpha$-MSH e seus análogos 74 cíclicos em solução aquosa

4.3.2 Fluorescência em solução aquosa

4.3.3 Fluorescência em sistema lipídico

4.3.4 Espectros de RPE do $\alpha$-MSH e análogos em dispersões de 90 DMPG

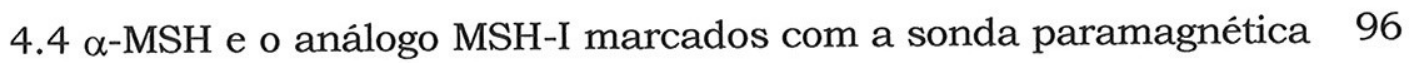
Toac: um estudo em solução

4.4.1 O Toac visto por RPE 96

4.4.2 O efeito supressor do Toac no Trp: um estudo por 100 fluorescência

4.4.3 Dependência do tempo de vida com o $\mathrm{pH}$

Anexo I - Modelo teórico para o espectro de ressonância magnética de movimento lento

A. 1 Considerações teóricas

A.2 Definição dos sistemas de coordenadas 


\section{Resumo}

Neste trabalho são apresentados vários estudos com o peptídeo melanotrópico catiônico $\alpha$ MSH (hormônio estimulador de melanócito) e análogos biologicamente mais ativos. Foram utilizadas as técnicas de fluorescência estática e resolvida no tempo, e RPE (ressonância paramagnética eletrônica). Com fluorescência, foi monitorado o aminoácido Trp (triptofano), presente em todos os peptídeos, e o aminoácido D-Nal (D-naphtyl alanine), presente nos análogos cíclicos aqui estudados, para a obtenção de informações estruturais. Com RPE, utilizou-se marcadores de spin incorporados a dispersões lipídicas aniônicas de DMPG (1,2-dimyristoyl-snglycero-3-phospho-rac-glycerol), para o estudo da estrutura dos agregados anfifilicos e da interação peptídeo/lipídio, e o aminoácido paramagnético Toac (2,2,6,6-tetramethylpiperidine-1-oxyl-4-amino4-carboxylic acid), ligado covalentemente ao $\alpha-\mathrm{MSH}$ e a seu análogo linear MSH-I $\left(\mathrm{Nle}^{4}, \mathrm{DPh} \mathrm{e}^{7}-\alpha-\right.$ $M S H)$, para o estudo comparativo da conformação destes peptídeos.

Com marcadores de spin, foi feito um estudo sobre modificações que o $\alpha$-MSH causa em vesículas de DMPG, correlacionando o aumento da concentração de moléculas de água, em toda a extensão da cadeia hidrocarbônica, com a diminuição da fluidez da bicamada lipídica. O perfil de polaridade da bicamada lipídica, medido em amostras congeladas, foi encontrado ser diferente do observado em lipídeos na fase fluida, particularmente na presença de moléculas polares.

É mostrado aqui que fosfolipídeos paramagnéticos, marcados no $16^{\circ}$ carbono da cadeia acila, incorporados em vesículas, monitoram a presença de duas populações, na chamada fase intermediária do DMPG (entre a fase gel e a líquido-cristal). A presença das duas populações fica evidente com a comparação dos espectros de RPE obtidos na presença e ausência de $\alpha$-MSH: o peptídeo parece fazer desaparecer um dos ambientes monitorados pelo marcador de spin.

As estruturas de análogos cíclicos do $\alpha-\mathrm{MSH}$, contendo, além do Trp, o fluoróforo D-Nal, foram estudadas em solução aquosa e em presença de vesículas de DMPG, e comparadas com a do peptídeo natural. Medidas de fluorescência do Trp indicam que, em meio aquoso, a estrutura dos análogos cíclicos (na região do Trp) está próxima da conformação adquirida pelo $\alpha$-MSH em bicamadas lipídicas, sugerindo que os peptídeos cíclicos encontram-se, em solução, em uma forma mais adequada para penetração na membrana. Comparando com resultados obtidos com $\alpha-\mathrm{MSH}$, nos peptídeos cíclicos, o Trp parece penetrar mais profundamente na membrana lipídica. O aminoácido D-Nal penetra na bicamada lipídica, tendo seu espectro de fluorescência, e tempo de vida do estado excitado, drasticamente alterados pela presença de vesículas de DMPG.

Tanto por RPE do Toac, como através da fluorescência do Trp, observa-se dependência da conformação do $\alpha$-MSH e MSH-I com o pH do meio, o que é atribuído a titulação de cadeias laterais dos peptídeos. A análise das curvas de titulação dos peptídeos $\alpha$-MSH e MSH-I, por fluorescência do Trp, sugere pequenas diferenças conformacionais entre estes dois peptídeos em meio aquoso, sendo maior o efeito observado em $\mathrm{pH}$ alcalino. Mostra também que as estruturas dos análogos marcados com a sonda paramagnética, em solução aquosa, são ligeiramente diferentes daquelas dos peptídeos originais, apesar de ter sido observado que a inserção do Toac em peptídeos melanotrópicos não altera a atividade biológica dos mesmos. 


\section{Abstract}

Some studies with the cationic melanotropic peptide $\alpha$-MSH ( $\alpha$-melanocyte stimulating hormone), and analogues biologically more active are presented here. Steady-state and time resolved fluorescence and EPR (electron paramagnetic resonance) have been used. Peptide structural information was obtained by the fluorescence spectroscopy of both the amino acid Trp (tryptophan), present in all the peptides monitored here, and that of D-Nal (D-naphtyl alanine), present only in cyclic analogues. EPR of spin labels incorporated in anionic lipid dispersions of DMPG (1,2-dimyristoyl-sn-glycero-3-phospho-rac-glycerol) has been used to study amphiphilic aggregate structure and peptide/lipid interaction. EPR was also applied to a comparative structural study of the paramagnetic amino acid Toac $(2,2,6,6-$ tetramethylpiperidine-1-oxyl-4-amino-4-carboxylic acid), covalently bound to $\alpha$-MSH and its linear analogue MSH-I (Nle $\left.{ }^{4}, \mathrm{DPhe}^{7}-\alpha-\mathrm{MSH}\right)$.

With spin labels incorporated into the bilayers, it is shown that there is a correlation between the packing of fluid DMPG membranes, caused by $\alpha-\mathrm{MSH} /$ lipid interaction, and the increase in bilayer interchain hydration. In frozen samples, alterations on the lipid bilayer polarity profile are shown to be different from those obtained at room temperature, particularly in the presence of polar molecules.

It is shown here that paramagnetic phospholipids labeled at the $16^{\text {th }}$ carbon of the acyl chain, incorporated in DMPG vesicles, monitor the presence of two distinct sites in the lipid bilayer intermediate phase (between the gel and liquid crystal phases). The presence of the two different spin populations is evident comparing the EPR spectra obtained in the presence and absence of $\alpha-\mathrm{MSH}$, as the peptide seems to make disappear one of the microenvironments monitored by the spin label.

The structures of cyclic analogues of $\alpha-\mathrm{MSH}$, containing both Trp and D-Nal fluorophores, have been studied in aqueous solution and in the presence of DMPG vesicles, and compared with that of the natural peptide. It seems that the cyclic analogues aqueous structures (around Trp) are more adequate for membrane penetration, as Trp fluorescence indicates that, in aqueous medium, the cyclic peptides are in a conformation similar to that acquired by $\alpha-\mathrm{MSH}$ in lipid bilayers. Trp in cyclic analogues was found to penetrate deeper in the bilayer than the fluorophore in the native peptide. The amino acid D-Nal penetrates in the lipid bilayer, having its fluorescent spectrum and excited state lifetime drastically changed.

Both the Toac EPR signal and the Trp fluorescence monitor the pH dependence of $\alpha$ MSH and MSH-I conformational structures, attributed to the titration of the side chains of some amino acids. The analysis of the titration curves of $\alpha-\mathrm{MSH}$ and MSH-I, by the Trp fluorescence, suggests small conformational differences between the two peptides in aqueous environment, more evident in alkaline medium. It shows also that the Toac labeled analogues, in aqueous medium, are structurally slightly different from the original peptides, although the insertion of Toac in melanotropic peptides does not alter their biological activity. 


\section{Introdução}

\subsection{Membranas biológicas}

(Voet\&Voet, 1995; Stryer, 1981; de Gennes, 1974)

Membranas biológicas são estruturas indispensáveis para os organismos vivos. São estas membranas que dão às células a capacidade de se separar do meio externo. A própria célula também contém membranas internas presentes nas organelas, tais como lisossomo ou mitocôndria, para separar compartimentos com diferentes funções fisiológicas. As membranas biológicas funcionam como uma barreira permeável altamente seletiva nos processos bioquímicos. Assim, uma célula pode se comunicar com o meio externo através de canais iônicos ou receptores específicos e portanto, as membranas têm um importante papel na comunicação biológica, necessária para manter a vida.

As membranas biológicas são compostas principalmente por lipídeos e proteinas. Entretanto, os lipídeos, em sua maioria fosfolipídeos, são os responsáveis pela formação espontânea de estrutura de bicamadas em meio aquoso, como mostra a Figura 1.1, devido ao caráter anfifilico dessas moléculas, ficando uma parte exposta à água (cabeça polar) e outra excluída pelo efeito hidrofóbico (cadeia hidrocarbônica). Macroscopicamente, estas bicamadas podem se agregar formando estruturas lamelares, separadas por camadas hidratadas da parte hidrofilica dos lipídeos. Elas podem se organizar em multicamadas planas (Figura 1.1a), ou camadas esféricas que podem ser vesículas multilamelares ou unilamelares (Figuras 1.1b e 1.1c, respectivamente).

A membrana lipídica é uma estrutura altamente estável. A estabilidade da bicamada é determinada por interações hidrofóbicas e forças atrativas de Van der Waals entre as cadeias hidrocarbônicas, e interações eletrostáticas e pontes de hidrogênio entre as cabeças polares e moléculas de água. Uma das características mais importantes das bicamadas fosfolipídicas é o seu comportamento térmico, sendo que o estudo de membranas lipídicas está intimamente relacionado ao estudo de cristais líquidos. Cristais líquidos são substâncias que apresentam um estado de agregação que é intermediário entre o sólido cristalino e o líquido amorfo (comportamento mesomórfico). Esse estado de agregação intermediário pode ocorrer por processos térmicos (termotrópico) ou pela influência de solventes (liotrópico), que é o caso das membranas lipídicas. Por apresentar estrutura lamelar, os lipídeos são classificados como cristais líquidos liotrópicos esméticos. 
a)

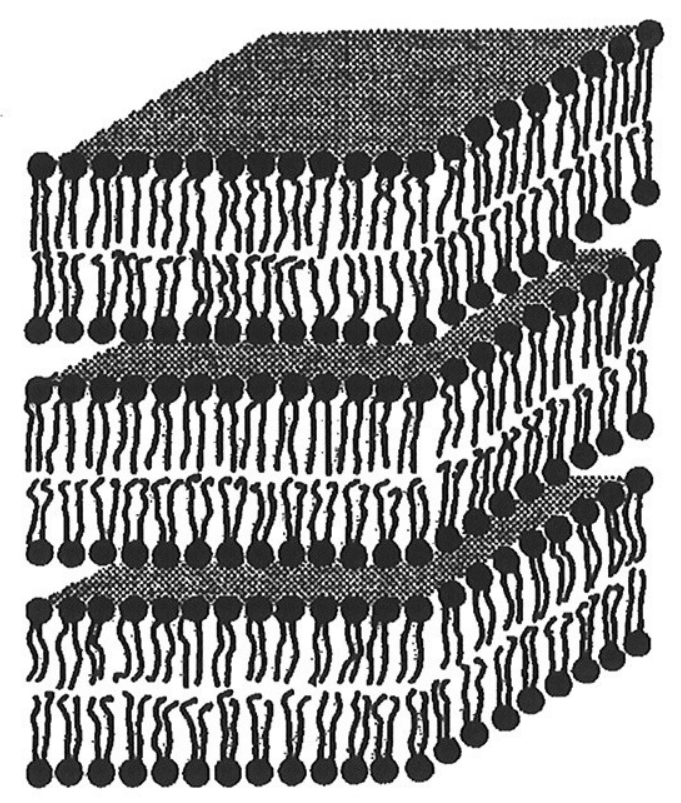

b)

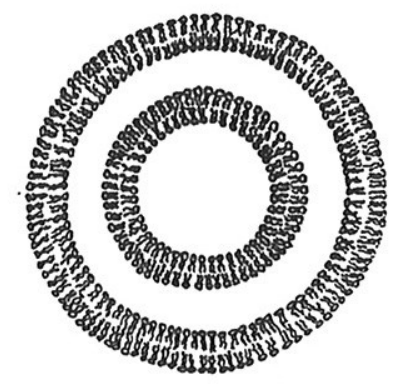

c)

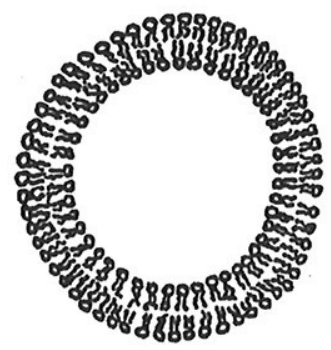

Figura 1.1 - Representação esquemática de bicamada lipídica em meio aquoso. Estrutura de bicamadas formando: a) multibicamadas planas, b) vesícula multilamelar, c) vesícula unilamelar.

\subsection{Estrutura físico-quimica dos fosfolipideos}

Os fosfolipídeos são moléculas que consistem de um grupo glicerol (um álcool com três carbonos), dois ácidos graxos (onde estão ligadas duas cadeias hidrocarbônicas, que normalmente contêm um número par de átomos de carbono, entre 14 e 24, podendo ter ligações saturadas ou insaturadas), e um grupo fosfato que pode ser esterificado com alcoóis, carregados eletricamente ou não (chamado de cabeça polar), tais como a colina, a etalonamina, a serina, o inositol, ou o glicerol. Um diagrama esquemático é mostrado na Figura 1.2a. A fórmula geral desse lipídeo é apresentado na Figura 1.2b. O fosfolipídeo é anfifilico, ou seja, a cabeça polar é hidrofilica enquanto as cadeias hidrocarbônicas são hidrofóbicas. 
a)

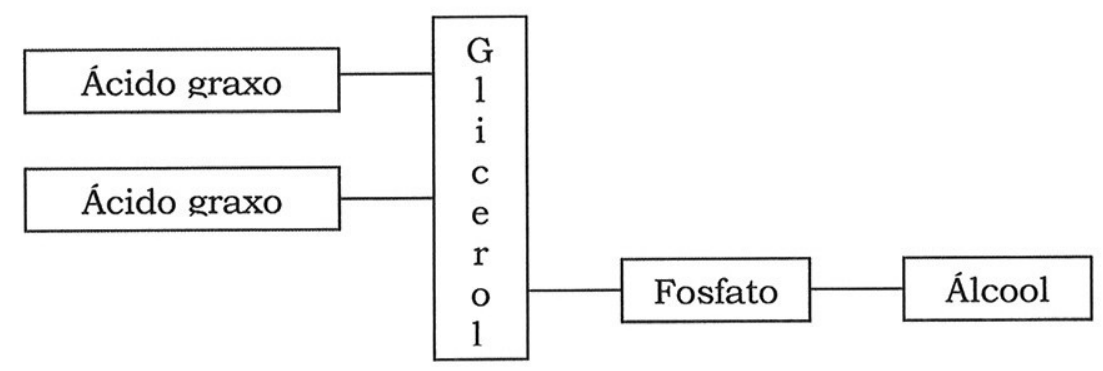

b)<smiles>[X]O[PH](=O)([O-])CC(COC([R])=O)OC([R])=O</smiles>

Figura 1.2 - a) Diagrama esquemático de um fosfolipídeo, e sua b) fórmula geral. $R_{1}, R_{2}$ e $X$ equivalem às cadeias hidrocarbônicas dos ácidos graxos e ao álcool, respectivamente.

As variações do tipo de álcool e carga a este associado, ligado ao grupo fosfato da cabeça polar, e o comprimento e saturação das cadeias hidrocarbônicas, são determinantes na capacidade de empacotamento das moléculas fosfolipídicas, e portanto, da fluidez da membrana, que é biologicamente importante. Por exemplo, certos processos de transporte através membrana e atividades enzimáticas podem ser interrompidas quando a viscosidade da bicamada é aumentada acima de um determinado nível. A fluidez da bicamada lipídica depende então, de sua composição. Porém, ela depende também da temperatura. Se a bicamada de uma membrana sintética, composta por um único tipo de fosfolipídeo, resfria abaixo de uma temperatura característica, denominada temperatura de transição principal $\mathrm{T}_{\mathrm{m}}$ (gel cristal-líquido), ela sofre uma mudança de fase, passando para uma fase gel, onde a bicamada encontra-se mais empacotada. Acima dessa temperatura $\left(T>T_{m}\right)$, na denominada fase líquido-cristalina, os lipídeos têm maior liberdade de movimento, conferindo à bicamada um aumento da fluidez (Figura 1.3). 


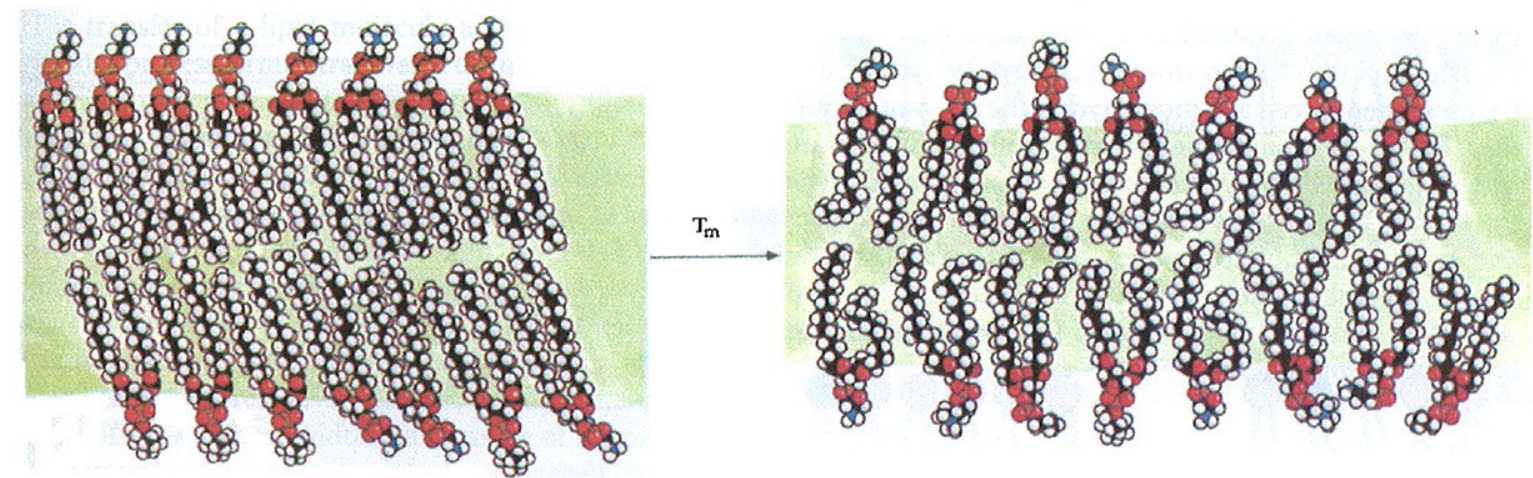

Figura 1.3 - Estrutura de bicamada lipídica composta por fosfatidilcolina e fosfatidiletalonamina na: a) fase gel (esquerda), formando um arranjo mais empacotado e; b) fase líquido-cristalina (direita), onde a membrana é mais fluida (Voet \& Voet, 1995, pág. 288).

O aumento da fluidez da bicamada acima da temperatura de transição de fase principal $\mathrm{T}_{\mathrm{m}}$ é decorrente de mudanças conformacionais das cadeias hidrocarbônicas dos fosfolipídeos. Na fase cristal-liquido, as cadeias hidrocarbônicas saturadas podem dobrar, adquirindo a conformação gauche (+ e -). Na fase gel, estas mesmas cadeias se esticam adquirindo a conformação all-trans. Essas conformações são mostradas na Figura 1.4. Em cadeias hidrocarbônicas insaturadas, a configuração das ligações duplas é quase sempre cis. O carbono da dupla ligação liga-se à cadeia hidrocarbônica formando um ângulo de 30\%, interferindo dessa maneira, na eficiência do empacotamento da bicamada lipídica.

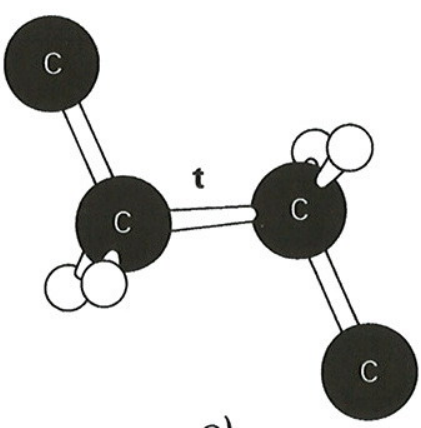

a)

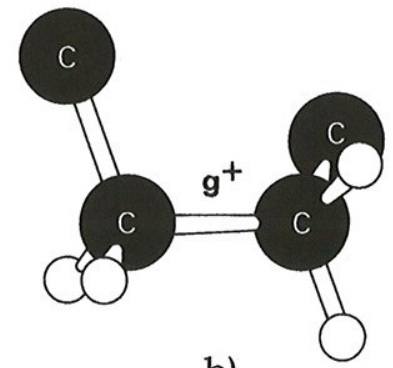

b)

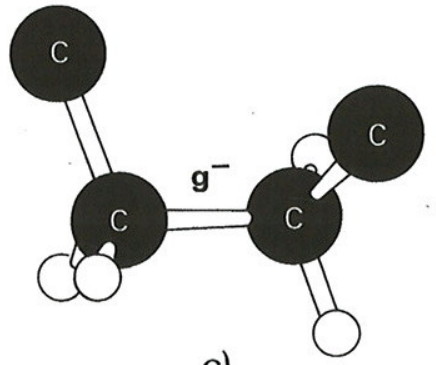

c)

Figura 1.4 - Conformação da ligação C — C em cadeias hidrocarbônicas: a) trans. Uma rotação de $120^{\circ}$ na ligação, no sentido horário, gera a b) conformação gauche ${ }^{+}$, e no sentido antihorário a c) conformação gauche- (Stryer, 1981, pág.226). 
Membranas biológicas não apresentam transição de fase a uma temperatura definida pois são compostas por vários tipos de lipídeos. Cada lipídeo possui uma temperatura de transição principal. Entretanto, é possível que em membranas biológicas encontre-se a coexistência de regiões mais rígidas (gel) e mais fluidas (cristal-líquido). Por exemplo, enquanto o DMPC (dimiristoil fosfatidilcolina), com 14 carbonos na cadeia hidrocarbônica, apresenta $\mathrm{T}_{\mathrm{m}}=23 \circ \mathrm{C}$, o DPPC (dipalmitoil fosfatidilcolina), com 16 carbonos, apresenta $T_{m}=41 \circ$ C. Essa grande diferença em $T_{m}$ resulta da estabilização da fase gel (dois carbonos a mais em cada cadeia) (Hauser, 1991). O estudo de membranas biológicas se torna bastante complexo, dada a grande variedade de seus componentes. Portanto, muitas pesquisas têm sido feitas em sistemas modelo, constituídos por um único tipo de fosfolipídeo, a fim de mimetizar as membranas biológicas e suas interações com moléculas. Uma vez que grande parte das moléculas se ligam às membranas, principalmente via atração eletrostática, neste trabalho foi estudado a interação de vesículas lipídicas negativamente carregadas com peptídeos catiônicos.

\subsection{Membranas modelo}

Membranas modelo, compostas por um único tipo de lipídeo, têm sido amplamente empregadas no estudo do comportamento térmico e outras características de bicamadas lipídicas. As membranas isoelétricas (zwitterionic) em $\mathrm{pH}$ fisiológico, tais como as compostas por fosfatidilcolina (PC) e a fosfatidiletalonamina (PE), têm sido muito investigadas, pois estes são os maiores componentes lipídicos em eritrócitos humanos depois do colesterol (Tanford, 1980). Entretanto, membranas negativamente carregadas, contendo o fosfatidilglicerol (PG), importantes para a atração de moléculas catiônicas, vem sendo estudadas na interação peptídeo/lipídeo (Biaggi et al., 1996 e 1997; Fernandez e Lamy-Freund, 2000; Turchiello et al., 2000).

O dimiristoil fosfatidilglicerol (DMPG, 1,2-dimyristoyl-sn-glycero-3-phospho glycerol) é um fosfolipídeo com duas cadeias saturadas de 14 carbonos cada e com um grupo glicerol ligado ao grupo fosfato na cabeça polar (ver Materiais e métodos, Fig. 3.1). Por ser negativamente carregado, o aumento da força iônica ou a diminuição do $\mathrm{pH}$, abaixo da região de titulação do grupo fosfato, reduzem a repulsão eletrostática entre as cabeças polares de PG, tornando a membrana mais estável na fase gel, onde a mobilidade das cadeias hidrocarbônicas tem seu efeito reduzido. O comportamento do DMPG tem sido estudado em função da força iônica (Riske et al, 1997 e 1999). Em baixa força iônica, a transição de fase gel - cristal-líquido deste lipídeo ocorre num 
intervalo de temperatura entre $\mathrm{T}_{\mathrm{m}}{ }^{\text {on }}=18 \circ \mathrm{C}$ e $\mathrm{T}_{\mathrm{m}}$ off $=35 \circ \mathrm{C}$, que marcam o início e o final da transição de fase, respectivamente (Riske et al., 2001).

A interação de peptídeos melanotrópicos, as melanotropinas, com membranas lipídicas de DMPG é um estudo que vem sendo desenvolvido no Grupo de Biofisica do IFUSP, onde a partição do peptídeo na água e na bicamada lipídica da membrana, bem como as modificações estruturais causadas pela interação peptídeo/membrana era assunto de nosso interesse (Ito et al., 1993; Macedo et al., 1996; Biaggi et al., 1996 e 1997).

\subsection{Hormônio estimulador do melanócito}

O tridecapeptídeo linear hormônio estimulador do melanócito ( $\alpha-\mathrm{MSH}$; Ac-Ser1Tyr2-Ser3-Met4-Glu5-His6-Phe7-Arg8-Trp9-Gly10-Lys'11-Pro12-Val13-NH2 ${ }^{1}$ ) (ver Materiais e métodos, Fig. 3.2), derivado do hormônio precursor pro-opiomelanocortina (POMC), é um hormônio fisiologicamente relevante na regulagem do escurecimento da pele em muitos vertebrados (Hadley et al., 1993). Além disso, este peptídeo está presente numa série de processos, tais como, crescimento fetal, termoregulação, aprendizado , memória, obesidade (por exemplo, ver Vaudry e Eberly, 1993). Nos valores de pH fisiológico, $\alpha-\mathrm{MSH}$ é aproximadamente monovalente, com o resíduo positivo Arg localizado na seqüência mínima requerida para estimular melanócitos, Ac-His 6 -Phe7Arg8-Trp9- $\mathrm{NH}_{2}$ (Castrucci et al., 1989; Hruby et al., 1987). Devido à conservação dessa seqüência em muitas espécies, ela é denominada sítio ativo primário ou "seqüência mensageira". Estudos com espectroscopia fuorescente usando o resíduo $\operatorname{Trp}^{9}$ como sonda, e ressonância paramagnética eletrônica (RPE) de marcadores de spin incorporados em vesículas lipídicas, mostram que o peptídeo catiônico interage fortemente com micelas e vesículas aniônicas. Essa interação se deve primeiramente à atração eletrostática, seguida de uma penetração parcial do peptídeo no núcleo hidrofóbico (Ito et al., 1993; Macêdo et al., 1996; Biaggi et al., 1996 e 1997), contrariamente aos resultados encontrados em vesículas com carga total nula (zwitterionic vesicles), onde não é possivel monitorar interação com o $\alpha$-MSH. Em geral, quando a membrana se encontra no estado líquido cristalino (fase fluida), o $\alpha$ MSH aumenta o empacotamento lipídico em todas as profundidades da bicamada. Já no estado gel, a interação lipídeo-peptídeo altera diferentemente as diversas regiões da bicamada, como será mostrado aqui. 


\subsection{Objetivos}

No presente trabalho, é discutido o efeito do peptídeo melanotrópico $\alpha$-MSH sobre a hidratação e fluidez de membranas lipídicas de DMPG, com o objetivo de encontrar possiveis alterações na barreira hidrofóbica da membrana causadas pela interação lipídeo/peptídeo. Para estudar a hidratação em bicamadas lipídicas foram usados marcadores de spin, e observado a variação do desdobramento hiperfino isotrópico em várias profundidades da membrana. $O$ efeito que o peptídeo melanotrópico causa na fluidez de bicamadas lipídicas aniônicas de DMPG é correlacionado às variações que ocorrem no perfil de polaridade da membrana. Os valores da polaridade local foram estimados em altas temperaturas, com o lipídeo na fase liquido cristalina, pelo desdobramento hiperfino isotrópico $a_{0}$, e em amostras congeladas, pela medida da componente $z$ do tensor hiperfino, $A_{z z}$. A confiabilidade das medidas do desdobramento hiperfino isotrópico é discutida, considerando a dificuldade em separar os efeitos de polaridade e mobilidade na temperatura ambiente (Griffith et al., 1974). Embora a componente $z$ do tensor hiperfino possa ser avaliada em amostras congeladas, sem influência dos movimentos da sonda, o efeito de moléculas interagentes ( $\alpha-\mathrm{MSH}, \mathrm{Na}^{+}$e colesterol) sobre o perfil de polaridade de bicamadas de DMPG mostrou ser distinto em temperatura ambiente e em amostras congeladas. Essas diferenças são discutidas em relação às variações que as moléculas causam na fluidez da membrana, nas fases gel $\left(T<T_{m}^{o n}\right)$ e líquido-cristalina $\left(T>T_{m}{ }^{o f f}\right)$. É mostrado que os resultados obtidos com amostras congeladas podem ser correlacionados com aqueles obtidos com o lipídeo na fase gel.

Dando prosseguimento ao estudo da interação peptídeo/lipídeo, discutiremos o efeito que o $\alpha$-MSH tem na região de transição entre as fases gel e líquido-cristalina do DMPG (fase intermediária), e compararemos com o aumento da força iônica, que aparentemente faz desaparecer esta fase. O efeito do $\alpha$-MSH na fase intermediária de bicamadas de DMPG é analisado pelos espectros de RPE do marcador de spin 16PCSL obtidos em diferentes freqüências de ressonância.

Paralelo a esse estudo, iniciamos um trabalho de caracterização espectroscópica de análogos cíclicos derivados do $\alpha-\mathrm{MSH}$, em solução aquosa e em presença de bicamadas lipídicas aniônicas. A motivação desse estudo resulta da identificação de novos receptores da melanocortina (MC3-R, MC4-R e MC5-R) (Schiöth et al., 1997 e 1998, e referências lá citadas). A fim de entender as regras fisiológicas desses novos receptores, tem-se procurado potentes agonistas e antagonistas seletivos a eles. Tal procura levou ao desenvolvimento de análogos cíclicos em que a 
substituição da Phe, no sítio ativo primário do $\alpha-\mathrm{MSH}$, por um volumoso aminoácido aromático fluorescente, gerou potentes antagonistas seletivos aos receptores melanocórticos (Hruby et al., 1995; Schiöth et al., 1997 e 1998; Kask et al., 1998). Sabendo que os peptídeos melanocórticos interagem com receptores proteicos específicos, os análogos cíclicos podem ser usados para elucidar as regras funcionais dos diferentes receptores da melanocortina. Além disso, esses novos antagonistas podem ser seletivos a um determinado receptor devido as suas diferenças nas estruturas primárias, o que lhes confere diferentes conformações. Neste trabalho, através das diferenças observadas entre os tempos de vida no estado excitado dos fluoróforos presentes nos peptídeos, infere-se qualitativamente sobre a estrutura conformacional do $\alpha$-MSH e seus análogos cíclicos, nos meios aquoso e lipídico.

Uma outra parte deste trabalho é dedicada aos peptídeos melanotrópicos marcados com uma sonda paramagnética estável, o Toac (2,2,6,6-tetramethyl piperidine-1-oxyl-4-amino-4-carboxilic acid) (Nakaie et al., 1981; Toniolo et al., 1995 e 1998; Hanson et al., 1996), cuja característica favorável é ser um aminoácido que se liga no esqueleto peptídico. $\mathrm{O}$ centro paramagnético $\mathrm{N}-\mathrm{O}$ faz parte de um anel rígido onde também está o carbono $\mathrm{C}_{\alpha}$ pertencente à cadeia, e portanto a mobilidade da cadeia peptídica pode ser monitorada. A inserção desta sonda nos peptídeos melanotrópicos sem alterar suas propriedades biológicas (Barbosa et al., 1999; Nakaie et al., 2001), vem contribuir para o estudo conformacional dos peptídeos melanotrópicos pela técnica de ressonância paramagnética eletrônica. $\mathrm{O} \alpha-\mathrm{MSH}$ e seu análogo linear MSH-I possuem cinco grupos protonáveis: Tyr, Glu, His, Arg e Lys. Por grupo protonável entenda-se, um aminoácido que pode ganhar ou perder um hidrogênio $(\mathrm{H})$, em sua cadeia lateral polar descarregada ou não, dependendo da concentração de $\mathrm{H}^{+}$disponivel (o valor de pH da solução). Assim, serão mostrados aqui os efeitos que esses grupos protonáveis têm sobre a conformação do $\alpha$-msh e seu análogo linear MSH-I em solução aquosa, através de medidas de fluorescência do Trp resolvida no tempo e RPE do Toac. 


\section{Técnicas experimentais}

As técnicas experimentais utilizadas no estudo da interação de membranasmodelo são técnicas espectroscópicas. Empiricamente, um experimento espectroscópico é bastante simples. Deixa-se incidir uma radiação eletromagnética de certo comprimento de onda $\lambda$ (ou freqüência $v=c / \lambda$ ) sobre a amostra, e então, medese algumas propriedades da radiação que emerge desta. Uma das propriedades mais simples é a fração da radiação incidente absorvida ou dissipada pela amostra. Também pode-se examinar a radiação emitida pela amostra em outros comprimentos de onda que os usados na excitação. Os diversos comprimentos de onda usados em espectroscopia de moléculas biológicas são sumarizados na Tabela 2.1, assim como as energias correspondentes aos fótons envolvidos (que vai de $10^{7} \mathrm{eV}$, algumas ordens de grandeza maior do que a mais forte ligação química covalente, até menos que $10^{-4} \mathrm{eV}$, muito menor que a energia térmica, que é aproximadamente $2,6 \mathrm{x} 10^{-2} \mathrm{eV}$ à temperatura ambiente). Técnicas espectroscópicas mostram alterações nas distribuições de cargas e spins (que têm propriedades elétricas e magnéticas) de moléculas expostas à luz.

Tabela 2.1 - Regiões do espectro eletromagnético biologicamente usadas (Cantor e Schimmel, 1980, pág. 350).

\begin{tabular}{|c|c|c|c|}
\hline $\begin{array}{l}\text { Comprimento de } \\
\text { onda típico }(\mathrm{cm})\end{array}$ & $\begin{array}{l}\text { Energia aproximada } \\
\qquad(\mathrm{eV})\end{array}$ & $\begin{array}{c}\text { Região } \\
\text { espectroscópica }\end{array}$ & $\begin{array}{l}\text { Técnicas e } \\
\text { aplicações }\end{array}$ \\
\hline $10-11$ & $1,3 \times 10^{7}$ & Raio- $\gamma$ & Mössbauer \\
\hline $10-8$ & $1,3 \times 10^{4}$ & Raio-X & Difração de raio-X \\
\hline $10-5$ & $1,3 \times 10$ & UV no vácuo & Espectro eletrônico \\
\hline \multirow[t]{2}{*}{$3 \times 10^{-5}$} & 4,3 & UV próximo & Espectro eletrônico \\
\hline & En. lig. $C-C(3,6)$ & & \\
\hline $6 \times 10^{-5}$ & $2,2 \times 10^{2}$ & visivel & Espectro eletrônico \\
\hline \multirow[t]{2}{*}{$10-3$} & $1,3 \times 10^{-1}$ & IR & Espectro vibracional \\
\hline & RT à temp. amb. & & \\
\hline $10-2$ & $1,3 \times 10^{-2}$ & IR distante & Espectro vibracional \\
\hline $10-1$ & $1,3 \times 10^{-3}$ & microonda & Espectro rotacional \\
\hline $10^{0}$ & $1,3 \times 10^{-4}$ & microonda & RPE \\
\hline 10 & $1,3 \times 10^{-5}$ & radio freqüência & $\mathrm{RMN}$ \\
\hline
\end{tabular}




\subsection{Absorção Óptica}

(Cantor e Schimmel, 1980)

O processo de absorção de luz visível ou ultravioleta por amostras biológicas é um processo no qual uma certa distribuição de cargas elétricas dentro de uma molécula é alterada quando esta é exposta à luz (por simplicidade, vamos considerar aqui somente o campo elétrico oscilante $\boldsymbol{E}$, embora tratamentos mais rigorosos incluem os efeitos magnéticos também). A distribuição de cargas da molécula pode ser descrita numa expansão de multipólos ao invés de considerar cada carga individual. $\mathrm{Na}$ aproximação de primeira ordem, o termo mais importante é o dipólo elétrico $\mu$, que em mecânica qüântica, é descrito pelo operador $\underline{\boldsymbol{\mu}}=\sum_{i} e_{i} \underline{\mathbf{r}}_{i}$. Considerando as posições dos núcleos fixas, a energia de interação entre a molécula e a luz será dada apenas pela parte eletrônica da função de onda, por $\underline{\mathbf{V}}(t)=\underline{\mu} \cdot \mathbf{E}_{0} e^{i \varpi t}$. Quando luz de uma determinada freqüência é absorvida por uma molécula, esta pode ser excitada para um dos muitos níveis vibracionais-rotacionais de estados eletrônicos de maior energia que o seu estado inicial. Se $h v$ é a energia da luz, a transição eletrônica de um particular estado $a$ com energia $E_{a}$, para um estado $b$ com energia $E_{b}$ na molécula, será induzida somente quando a energia da luz for aproximadamente igual a separação de energia entre os dois estados $\left(E_{b}-E_{a}\right)$ (para maior rigor, ver discussão da regra de ouro de Fermi, em Bransden, 1996).

$$
h v=E_{b}-E_{a}
$$

A taxa em que a energia é removida da luz dependerá do número de transições de absorção $a \rightarrow b$ estimulada pela luz, do número de transições de emissão $b \rightarrow a$, e da energia por transição $h v$. Dessa forma, a intensidade de absorção depende da magnitude do dipólo elétrico de transição $\left\langle S_{b}\right.$, vib, rot $\left./ \underline{\mu} / S_{a}\right\rangle$, onde $S_{b}$, vib, rot é a função de onda de um particular estado vibracional-rotacional de $S_{b}$ ocupado, e $S_{a}$ é a função de onda do estado inicial.

Muitas macromoléculas possuem ligações entre átomos do tipo $\sigma$ (onde a densidade eletrônica está concentrada ao redor dos núcleos dos átomos que se ligaram) e $\pi$ (quando existe mais de uma covalência entre dois átomos, sendo uma sigma), sendo esta última considerada uma combinação de orbitais $2 p$. Assim, os 
cromóforos $^{1}$ constituintes de uma proteina podem sofrer transições fracas do tipo $n \pi^{*}$, em torno de $220 \mathrm{~nm}$, e transições fortes do tipo $\pi \pi^{*}$, em torno de $195 \mathrm{~nm}$, provenientes do grupo amida. Entretanto, as cadeias laterais dos aminoácidos fenilalanina (Phe), tirosina (Tyr) e triptofano (Trp), podem sofrer transições $\pi \pi^{*}$ em bandas de energia logo abaixo de $300 \mathrm{~nm}$, sendo importantes para o estudo de moléculas biológicas. É interessante ressaltar que fatores como o efeito do solvente, heterogeneidade do estado e movimento molecular, podem contribuir para o alargamento da banda espectral desses aminoácidos.

\subsubsection{A lei de Lambert-Beer}

A Figura 2.1.1 apresenta o diagrama esquemático de uma medida de absorção de luz. Uma luz incidente com intensidade $I_{0}$ e comprimento de onda $\lambda$ atinge uma solução contendo uma certa quantidade de moléculas absorvedoras (com concentração $\mathrm{C}$ em mol/1). A luz, que não é absorvida pela amostra, após atravessar um caminho óptico $l(\mathrm{em} \mathrm{cm})$, emerge com intensidade $I$.

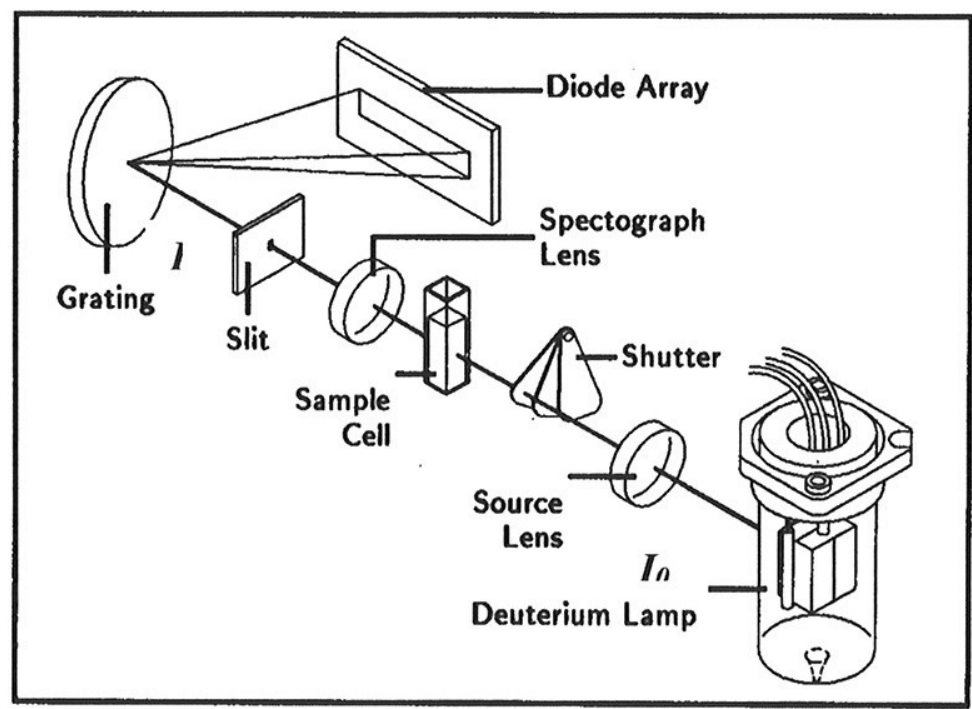

Figura 2.1.1 - Diagrama esquemático do espectrofotômetro HP 8452-A (ver seção 3.2).

A fração de luz absorvida (-dI /I) por uma camada delgada $d l$ da amostra é proporcional ao número de moléculas absorvedoras,

$$
-d I / I=C \cdot \varepsilon^{\prime} \cdot d l
$$

${ }^{1}$ Cromóforos são grupos funcionais de poucos átomos com um espectro de absorção eletrônica característico (van Holde, 1998). 
onde $\varepsilon$ 'é uma constante de proporcionalidade chamada coeficiente de extinção molar, que depende da luz absorvida. Integrando a equação acima (de $I_{0}$ a $I$ para a intensidade da luz, e de $O$ a $l$ para o caminho percorrido na amostra), temos:

$$
\ln \left(I_{0} / I\right)=C \cdot \varepsilon^{\prime} \cdot l
$$

Mudando o logaritmo para a base dez, temos a forma conhecida da lei de Lambert-Beer:

$$
A(\lambda) \equiv \log \left(I_{0} / I\right)=C . \varepsilon(\lambda) . l
$$

onde $\varepsilon=\varepsilon^{\prime} \cdot \log e$. A quantidade $A$ é chamada absorbância ou (algumas vezes) densidade óptica. Normalmente, os valores de absorbância medidos são obtidos no intervalo de 0,1 a 2. Assim, pequenos valores de $A$ indicam que só uma pequena fração da luz incidente foi absorvida. Valores grandes indicam que só uma pequena fração da luz atingiu o detector.

Para estimar as intensidades de absorção associadas com as transições, é necessário avaliar o dipólo elétrico de transição $\left\langle S_{b}\right.$, vib rot $\left./ \underline{\mu} / S_{a}\right\rangle$, que está correlacionado ao parâmetro empírico $\varepsilon$. No caso de moléculas com mais de um cromóforo, que interagem eletronicamente, a absorção depende da distância e da orientação relativa entre os cromóforos.

\subsection{Espectroscopia de Fluorescência}

(Lakowicz, 1999 e van Holde, 1998)

A fluorescência se baseia na emissão de radiação eletromagnética (fótons) devido à transição eletrônica entre o estado excitado singleto e o estado fundamental (retorno de um elétron de um nivel de mais alta energia para um nível de mais baixa energia), sendo que a orientação do spin do elétron desexcitado tem direção oposta ao elétron do orbital de mais baixa energia. A banda de emissão fluorescente em geral é deslocada, em relação à banda de absorção, para comprimentos de onda maiores devido à perda de energia no estado excitado entre um maior nivel vibracional e o nível vibracional fundamental desse mesmo estado. Além disso, a fluorescência do nível vibracional fundamental do primeiro estado excitado singleto para algum nivel vibracional do estado fundamental também promove o deslocamento dessa banda de emissão fluorescente. 
A fluorescência pode ser subdividida, de acordo com a forma de detecção, em duas técnicas: a espectroscopia de fluorescência estática e a de resolução temporal. Um espectro de emissão fluorescente é um gráfico da intensidade fluorescente versus o comprimento de onda $(\mathrm{nm})$ ou número de onda $\left(\mathrm{cm}^{-1}\right)$. Alguns espectros de emissão, tais como o do perileno (ver Fig. 2.2.1), podem apresentar niveis de energia vibracional do estado fundamental, assim como espectros de absorção podem refletir níveis vibracionais de estados eletronicamente excitados.

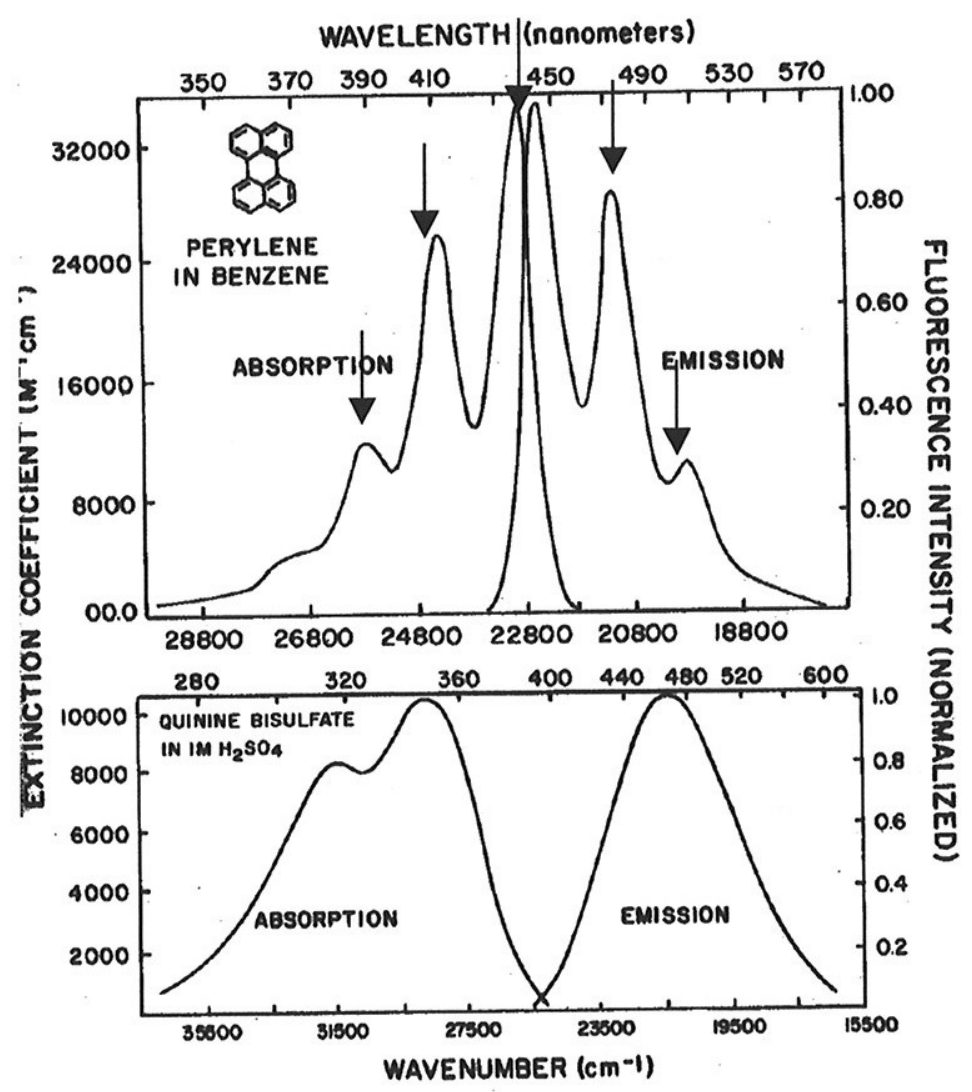

Figura 2.2.1 - Espectro de absorção e emissão fluorescente do perileno e da quinina. As setas indicam niveis vibracionais (Lakowicz, 1999, pág. 4).

A fluorescência ocorre tipicamente em moléculas aromáticas e ligações peptídicas. Os tempos de vida de algumas substâncias fluorescentes (fluoróforos), de importante interesse biológico, podem ser usados para a determinação de processos dinâmicos, tais como mudanças conformacionais, protonação, efeitos de solvente, e processos de transferência de energia doador/aceitador. 


\subsubsection{O fenômeno da fluorescência}

Na seção anterior foi discutida o processo de absorção de luz por uma molécula, excitada de um estado fundamental para um nível singleto de maior energia. A transição eletrônica nesse processo ocorre em 10-15 s. Por ocorrer num tempo bastante curto em relação a um deslocamento significante do núcleo, esta transição é considerada vertical (Princípio de Franck-Condon). Após isso, na desexcitação da molécula, a energia absorvida é perdida sob a forma de calor, através dos níveis vibracionais de todos os estados singletos excitados até atingir o nível vibracional fundamental do primeiro estado singleto (conversão interna). Nesse processo, que tem um tempo de vida da ordem de 10-12 s, ocorre um rearranjo da densidade eletrônica devido a colisões da molécula com o solvente. A molécula, agora no mais baixo nivel vibracional do primeiro estado singleto, pode retornar ao estado fundamental de três maneiras: pela emissão de um fóton (fluorescência), sem emissão de um fóton (transição não-radiativa), e pela conversão ao primeiro estado tripleto (cruzamento inter-sistema). Esses três processos, com tempo de vida da ordem de 10-8 s, competem entre si, sendo que o de menor tempo prevalecerá.

Para moléculas em que prevalece a fluorescência, é possivel estudar processos dinâmicos (como por exemplo, mudanças conformacionais) que ocorrem durante o tempo de vida do estado excitado da molécula. Se a transição ao estado tripleto ocorre, devido à mudança da direção do spin eletrônico, a molécula pode fosforescer ou sofrer uma transição não-radiativa para o estado fundamental. Como essa transição é proibida, o tempo de vida pode ser muitas vezes maior que o de fluorescência, podendo chegar a valores da ordem de $10^{2}$ s. A emissão do fóton, em ambos os processos de fluorescência e fosforescência, é tão rápida quanto a absorção, aproximadamente $10^{-15} \mathrm{~s}$.

Esses processos podem ser melhor entendidos no esquema apresentado na Figura 2.2.2. As linhas horizontais representam niveis vibracionais dos vários estados eletrônicos apresentados (estado fundamental, primeiro estado tripleto, primeiro estado singleto e segundo estado singleto), e todos os processos ocorrem em uma distância internuclear de equilíbrio do estado fundamental. 


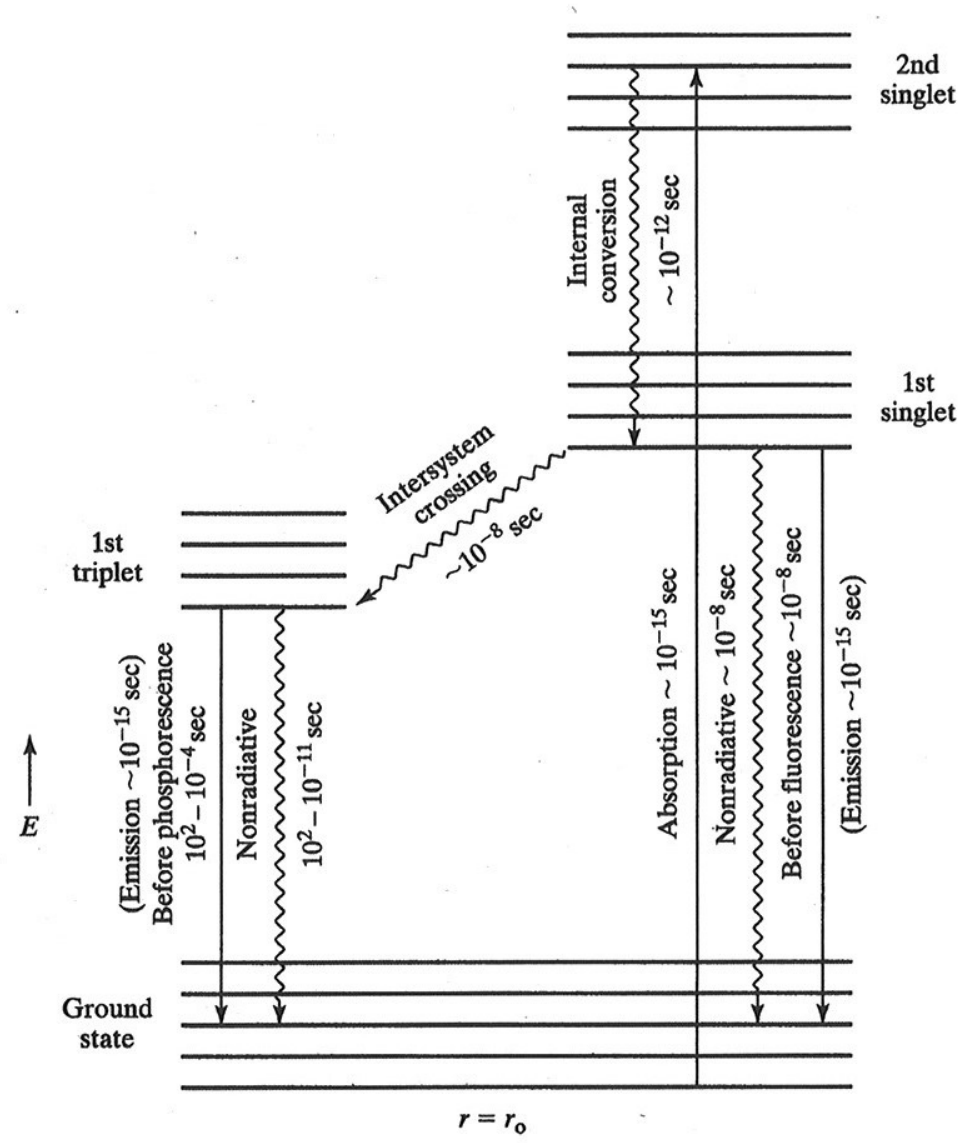

Figura 2.2.2 - Diagrama esquemático dos processos de absorção, fluorescência e fosforescência, e seus tempos de vida. (van Holde, 1998, pág. 454).

Como já mencionado, medidas de fluorescência podem ser classificadas em dois tipos: no regime estacionário e resolvida no tempo. No regime estacionário, a amostra é excitada com um feixe contínuo de luz, em um particular comprimento de onda, e a intensidade ou o espectro de emissão fluorescente são obtidos (Figura 2.2.1). Na medida resolvida no tempo, um pulso de luz bastante curto, tipicamente menor que o tempo de vida do estado excitado da amostra, é usado para medir o decaimento da intensidade fluorescente. Embora essas medidas sejam distintas, existe uma relação entre elas. A observação no regime estacionário é simplesmente uma média do fenômeno resolvido no tempo sobre o decaimento da intensidade da amostra.

\subsubsection{Decaimento fluorescente}

O tempo de vida do estado excitado, medido pelo decaimento da emissão fluorescente de uma substância, geralmente representa a quantidade média de tempo que a molécula permanece no estado excitado antes de retornar para o estado 
fundamental. Medidas do tempo de vida são freqüentemente necessárias em espectroscopia de fluorescência. Esse parâmetro pode dar indicações sobre, por exemplo, a taxa de transferência de energia, a taxa de reação no estado excitado, assim também como detalhes sobre as interações dos fluoróforos com sua vizinhança. Medidas do tempo de vida fluorescente são tipicamente da ordem de nanosegundos, fazendo-se necessário o uso de dispositivos eletrônicos de alta velocidade.

Existem dois métodos de detecção amplamente usados para medir tempos de vida fluorescentes: o método de pulsos e o método harmônico ou de modulação de fases. Por ser o método de pulsos usado em nossos experimentos, limitaremos nossa discussão a este método. A amostra é excitada com um curto pulso de luz, e a emissão fluorescente é medida em função do tempo. O número de moléculas perdendo um quantum de energia no tempo $d t$ será proporcional ao número de moléculas $N$ no estado excitado e à taxa de decaimento radiativo $\Gamma$ (pela emissão fluorescente) e não radiativo $k_{n r}$, conforme esquematizado na Figura 2.2.3.

$$
-\frac{d N(t)}{d t}=\left(\Gamma+k_{n r}\right) N(t)
$$

Seja a população inicial $N(t)$ de fluoróforos em $t=0$ igual a $N_{0}$. Integrando ambos os lados temos,

$$
\begin{aligned}
\ln N(t)-\ln N_{0} & =\ln N(t) / N_{0}=-\left(\Gamma+k_{n r}\right) t \\
N(t) & =N_{0} e^{-\left(\Gamma+k_{n r}\right) t}
\end{aligned}
$$

O tempo de vida $\tau$ é definido como o tempo necessário para a população inicial $N_{o}$ decair para $N(t)=N_{o} /$ e. Isto ocorre quando $t=1 /\left(\Gamma+k_{n r}\right)=\tau$.

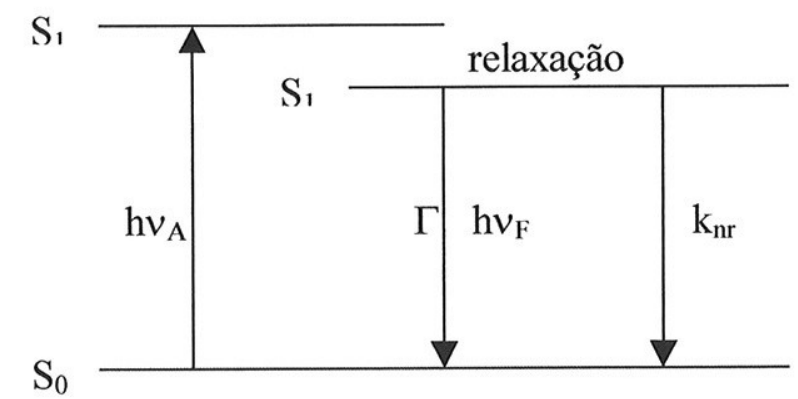

Figura 2.2.3 - Diagrama esquemático apresentando os niveis fundamental $\left(\mathrm{S}_{0}\right)$ e excitado $\left(\mathrm{S}_{1}\right)$, e as taxas de emissão fluorescente $(\Gamma)$ e de decaimento não radiativo $\left(\mathrm{k}_{\mathrm{nr}}\right)$. 
Quando nenhum outro processo compete com a fluorescência $\left(k_{n r}=0\right)$, o tempo de vida é $\tau=1 / A$, onde A é o coeficiente de Einstein da emissão espontânea, proporcional ao número de moléculas emitindo fótons. Nesse caso, o tempo de vida é denominado tempo de vida intrínseco $\tau_{0}$. A razão entre o tempo de vida e o tempo de vida intrínseco é chamado rendimento quântico $Q$, que é a razão entre o número de fótons emitidos e absorvidos.

$$
Q=\frac{\tau}{\tau_{0}}=\frac{\Gamma}{\Gamma+k_{n r}}
$$

Esse parâmetro pode dar informações sobre mudanças no ambiente molecular do cromóforo, como por exemplo, o deslocamento da fase aquosa para a fase lipídica da membrana.

O tempo de vida também pode ser considerado uma média dos tempos que um fluoróforo permanece no estado excitado após sua excitação. Isto pode ser visto calculando o tempo médio $\langle t>$, que é obtido pela média de $t$ sobre a intensidade de decaimento do fluoróforo:

$$
\langle t\rangle=\frac{\sum_{i} t_{i} N_{i}(t)}{\sum_{i} N_{i}(t)}
$$

Para um grande número de fluoróforos e pequenos intervalos de tempo, essa soma fica,

$$
\langle t\rangle=\frac{\int_{0}^{\infty} t N(t) d t}{\int_{0}^{\infty} N(t) d t}=\frac{\int_{0}^{\infty} t e^{-t / \tau} d t}{\int_{0}^{\infty} e^{-t / \tau} d t}=\tau
$$

e assim, para um decaimento exponencial, o tempo médio <t> que um fluoróforo permanece no estado excitado é igual ao tempo de vida $\tau$.

A equação (2.2.5) só é válida para decaimentos mono-exponenciais. Para decaimentos multi-exponenciais, o tempo de vida médio pode ser calculado por uma função complexa de parâmetros descrevendo o decaimento real da seguinte maneira: 


$$
\tau=\langle t\rangle=\frac{\sum_{i} \alpha_{i} \tau_{i}{ }^{2}}{\sum_{i} \alpha_{i} \tau_{i}}
$$

onde $\alpha_{\mathrm{I}}$ é um fator pré-exponencial que representa a contribuição percentual para o decaimento resolvido no tempo da componente com tempo de vida $\tau_{\mathrm{i}}$. Tal comportamento pode ser atribuído à presença de mais de um fluoróforo na amostra analisada, ou simplesmente a diferentes conformações apresentadas por um mesmo fluoróforo. Nesses casos, a intensidade fluorescente $\mathrm{I}(\mathrm{t})$ pode ser ajustada por uma soma de decaimentos mono-exponenciais individuais:

$$
I(t)=\sum_{i} \alpha_{i} e^{-t / \tau_{i}}
$$

O significado dos fatores pré-exponenciais $\alpha_{i}$ é diferente para uma mistura de fluoróforos e para um fluoróforo apresentando um decaimento complexo. Para o último caso, geralmente assume-se que o fluoróforo tem a mesma taxa de decaimento radiativo em cada ambiente. Nesse caso, os valores de $\alpha_{i}$ representam a fração de moléculas em cada conformação. Entretanto, o significado de $\alpha_{i}$ é mais complexo para uma mistura de fluoróforos. Nesse caso, $\alpha_{\mathrm{i}}$ depende do rendimento quântico e intensidade de cada fluoróforo.

Decaimentos não exponenciais são normalmente observados por fluoróforos que sofrem supressão por transferência de energia ${ }^{2}$ ou processos de relaxação através do solvente. Os espectros de emissão fluorescente de muitos fluoróforos são também sensiveis à polaridade do solvente onde estes se encontram. Solventes polares tendem a deslocar o espectro de emissão para comprimentos de onda maiores (red shift), e que freqüentemente são acompanhados por uma diminuição do rendimento quântico do fluoróforo. Contrariamente, solventes apolares deslocam o espectro de emissão para comprimentos de onda menores (blue shift).

\footnotetext{
${ }^{2}$ Transferência de energia fluorescente é a transferência de energia de um estado excitado de um doador para um aceitador, sem o aparecimento de um fóton, resultante da interação dipólo-dipólo entre o doador e o aceitador. A taxa de transferência de energia depende da extensão da sobreposição do espectro de emissão do doador com o espectro de absorção do aceitador, da orientação relativa entre os dipólos de transição do doador e aceitador, e a distância entre essas moléculas.
} 


\subsubsection{Método de correlação temporal de fótons únicos}

Medidas de fluorescência resolvidas no tempo podem ser obtidas pelo método de correlação temporal de fótons únicos (time-correlated single-photon couting, TCSPC). Nesse método, os fótons são contados e correlacionados temporalmente em relação ao pulso de excitação, através de conversor de tempo-amplitude (time-to-amplitude converter, TAC). A amostra é repetitivamente excitada por um pulso de luz que é monitorado por uma fotomultiplicadora, para iniciar uma rampa de voltagem no TAC. A rampa de voltagem termina quando o primeiro fóton da amostra é detectado. $\mathrm{O}$ TAC fornece um pulso de saída cuja voltagem é proporcional ao tempo entre o iníco e o fim de cada evento. Um analisador multicanal converte a tensão em canal de tempo. A soma sobre todos os pulsos gera um histograma de probabilidades de contagens por canal de tempo, levando à representação do decaimento temporal da amostra.

Normalmente, existem três curvas associadas ao decaimento da intensidade fluorescente. Estas são os dados medidos $N\left(t_{k}\right)$, a resposta do instrumento $L\left(t_{k}\right)$, e a curva de decaimento calculada $N_{c}\left(t_{k}\right)$. A resposta do instrumento, na maioria das vezes chamada de sinal da lâmpada, é obtida pela solução pura em que foi diluída a macromolécula, e representa a resposta do instrumento para uma amostra de tempo de vida igual a zero. A curva calculada representa a convolução do sinal da lâmpada com o sinal medido, e o tempo de decaimento é o valor de $\tau$ que melhor se ajusta ao dados experimentais, que pode ser obtido pelo método dos minimos quadrados,

$$
\chi^{2}=\sum_{k=1}^{n} \frac{1}{\sigma_{k}^{2}}\left[N\left(t_{k}\right)-N_{c}\left(t_{k}\right)\right]^{2}
$$

onde $n$ é o número de canais e $\sigma_{\mathrm{k}}$ é o desvio padrão que, na estatística de Poisson, é a raiz quadrada do número de fótons, $\sigma_{k}=\left[N\left(t_{k}\right)\right]^{1 / 2}$. A incerteza relativa nos dados diminui quando o número de fótons aumenta. Essa dependência com a quantidade de pontos é eliminada com o uso do $\chi^{2}$ reduzido,

$$
\chi_{R}^{2}=\frac{\chi^{2}}{n-p}
$$

onde $p$ é o número de parâmetros, e $n$ - $p$ é o número de graus de liberdade. Assim, um aumento na quantidade de parâmetros a serem ajustados, diminui o valor de $\chi_{R^{2}}$. 
Geralmente, pode-se combinar experimentos a fim de melhorar um dado conjunto de parâmetros ajustados. Por exemplo, se medirmos o decaimento em vários comprimentos de onda de emissão, então podemos obter um único conjunto de tempos que melhor se ajuste as curvas de decaimento medidas. Essas curvas são então analisadas simultaneamente para determinar os valores de $\tau_{i}$ e $\alpha_{i}(\lambda)$. Os valores de $\tau_{i}$ são assumidos serem independentes do comprimento de onda de emissão. Nesse caso, denominado análise global, o cálculo de $\chi \mathrm{R}^{2}$ fica:

$$
\chi_{R}^{2}=\frac{1}{n-p} \sum_{\lambda} \sum_{k=1}^{n} \frac{\left[I_{c}^{\lambda}\left(t_{k}\right)-I^{\lambda}\left(t_{k}\right)\right]^{2}}{I^{\lambda}\left(t_{k}\right)}
$$

\subsubsection{Triptofano como sonda fluorescente}

Na grande maioria dos casos, o aminoácido triptofano (Trp) cumpre o papel de sonda fluorescente adequada, pois é um componente natural de peptídeos e proteínas. A fluorescência do triptofano origina-se de transições envolvendo o anel indol, presente na estrutura do aminoácido. Cálculos de estrutura eletrônica do grupo indol mostram a ocorrência de dois primeiros estados excitados bastante próximos, de modo que na banda de absorção observada em $280 \mathrm{~nm}$, estão envolvidas duas transições. Os momentos de dipolos dessas transições apresentam orientações diferentes no anel indol. Diversas características da estrutura eletrônica típicas do anel indol são mantidas no triptofano.

A posição espectral da emissão fluorescente depende fortemente da polaridade do meio em que se encontra o triptofano. Em meio apolar, os efeitos de relaxação através do solvente são menores que os verificados em meio polar. Dessa forma, o máximo de emissão fluorescente fica deslocado para energias maiores, ou comprimento de ondas menores.

Cabe citar também que a cinética de decaimento da fluorescência do triptofano oferece outro conjunto de parâmetros empregados na análise do meio no qual se insere o aminoácido. Apesar das semelhanças espectrais com moléculas derivadas do indol, como o N-acetil-triptofano-amida (NATA) e o 3-metilindol, a cinética de decaimento do triptofano apresenta características bem distintas. Em lugar do decaimento monoexponencial das outras duas moléculas, o triptofano pode apresentar dois tempos de vida em pH's alcalinos, sendo comum a observação de decaimento triexponencial quando ele faz parte de peptídeos e proteínas (Szabo e Rayner, 1980; 
Chang et al., 1983). Supõe-se que processos de transferência de elétrons entre o anel e grupos amina ou carboxila promovam desexcitação e que os mesmos dependam da disposição espacial do anel em relação a estes grupos (Petrich et al., 1983). Dessa forma, assume-se que o decaimento multi-exponencial da fluorescência do Trp é atribuído a diferentes estruturas da cadeia peptídica nas vizinhanças desse resíduo.

\subsection{Ressonância paramagnética eletrônica}

(Bales, 1989; Marsh, 1981 e 1989; Atherton, 1993)

Diferente das outras técnicas apresentadas nos itens anteriores, a ressonância paramagnética eletrônica (RPE) é uma técnica que permite observar moléculas com elétrons desemparelhados, cujo momento de dipólo magnético eletrônico total é diferente de zero, sem alterar ou destruir essas moléculas. A essas moléculas com elétrons desemparelhados chamamos de radical livre. Apesar de muitas das biomoléculas não possuirem radical livre, estas têm sido estudadas por RPE pela incorporação de estruturas com radical livre estável, denominadas marcadores de spin e utilizadas para detectar mudanças na conformação de macromoléculas e agregados moleculares tais como membranas, e estudar propriedades do meio, tais como polaridade, viscosidade e anisotropia.

Um orbital eletrônico preenchido por dois elétrons de spins opostos possui momento magnético eletrônico total nulo. No caso do radical livre, este possui momento magnético diferente de zero. Na ausência de campo magnético externo os momentos magnéticos eletrônicos dos radicais livres são aleatoriamente orientados e estão no mesmo estado de energia. Se um campo magnético externo é aplicado, os momentos magnéticos eletrônicos tenderão a se alinhar com o campo, seguindo as leis de quantização do spin eletrônico, expressos pelo número quântico $m_{S}$, com valores iguais a $-1 / 2$ e $+1 / 2$. Neste caso, existem somente duas possiveis direções de alinhamento. Uma, no mesmo sentido do campo magnético (que é a condição de energia mais estável), e outra em direção oposta. Assim, o campo magnético separa o sistema de spins em dois grupos com uma diferença de energia $\Delta \mathrm{E}$.

Se introduzirmos agora, um campo magnético oscilante de freqüência igual à separação dos níveis de energia, os elétrons entram em ressonância com o campo de radiação e absorvem energia, resultando numa transição de energia. Ou seja, alguns elétrons que estão acoplados ao campo de radiação absorvem energia, e mudam de um nivel de menor energia para um de maior energia, e vice-versa. Assim, quanto maior é a diferença de energia $\Delta \mathrm{E}$ promovida pelo campo magnético externo, maior é a 
freqüência de ressonância do campo de radiação. Na prática alguns valores de freqüência são usados por RPE, dentre os quais, usamos o de $9 \mathrm{GHz}$ (Banda-X), 35 $\mathrm{GHz}$ (Banda-Q), 1,3 GHz (Banda-L), e a freqüência de $250 \mathrm{GHz}$.

Consideremos agora a interação do núcleo com o elétron desemparelhado. $\mathrm{O}$ núcleo também possui momento magnético nuclear, que por sua vez produz um campo magnético local sobre o elétron. A esta interação entre o núcleo e o elétron denomina-se interação hiperfina. O campo magnético total sobre o radical livre agora é a soma entre o campo nuclear e o campo externo aplicado. No caso do radical nitróxido, que é um marcador de spin amplamente utilizado no estudo de membranas lipídicas, a interação hiperfina é principalmente com o núcleo do $\mathrm{N}$ que tem spin nuclear igual a 1 . Nesse caso, cada um dos niveis de energia do spin do elétron (para $m_{S}=-1 / 2$ e $\left.+1 / 2\right)$ pode se desdobrar em três niveis de energia, resultante da quantização da componente $z$ do spin nuclear, e caracterizado pelo seu número quântico $m_{I}$, com valores iguais a $-1,0,+1$. A transição entre esses níveis ocorre segundo regras de seleção específicas, e só é permitida quando $\Delta m_{S}= \pm 1$ e $\Delta m_{I}=0$. Assim, o desdobramento hiperfino do $\mathrm{N}$ promove o aparecimento de três linhas no espectro de RPE. O espectro de RPE consiste na medida da primeira derivada da intensidade de absorção da energia em função do campo magnético externo aplicado, e é através da forma, largura e intensidade que uma linha hiperfina é caracterizada, além da seperação entre as linhas.

Podemos construir a hamiltoniana de spin $\mathcal{H}$ para um elétron desemparelhado, considerando apenas as interações Zeeman (devido ao campo magnético externo $\boldsymbol{H}$ ) e hiperfina (devido ao campo nuclear):

$$
\mathcal{H}=\beta \boldsymbol{H} \cdot \boldsymbol{g} \cdot \mathbf{S}+\boldsymbol{I} \cdot \boldsymbol{A} \cdot \mathbf{S}
$$

onde $\beta$ é o magneton de Bohr, $\boldsymbol{H}$ é o campo magnético externo aplicado, $\boldsymbol{S}$ e $\boldsymbol{I}$ são os operadores momento angular do spin do elétron desemparelhado e do núcleo, respectivamente, e $\boldsymbol{g}$ e $\boldsymbol{A}$ são os tensores de 2a ordem relacionados às interações Zeeman e hiperfina, e freqüentemente são escritos no sistema de eixos molecular. O valor de $g$ possui dependência orientacional e reflete características da estrutura eletrônica, ao passo que o desdobramento hiperfino $A$, também anisotrópico, resulta da interação entre os spins do elétron e dos núcleos vizinhos, indicando características da estrutura hiperfina. Ambos os tensores revelam a anisotropia espacial da molécula. A Figura 2.3.1 apresenta a anisotropia do espectro de um radical nitróxido num monocristal. O campo magnético é aplicado nas três direções do 
sistema de eixos do radical nitróxido. O eixo $\mathrm{x}$ foi escolhido ao longo da ligação N-O do grupo nitróxido, o eixo $z$ ao longo do orbital $2 \mathrm{p}-\pi$ do elétron desemparelhado do radical livre, e o eixo y perpendicular aos outros dois eixos.

Os espectros da Figura 2.3.1 (a), b), e (c) mostram que as três linhas do desdobramento hiperfino do nitrogênio e a posição sobre a qual cada espectro é centrado dependem do eixo em que o campo magnético é aplicado. Na Figura 2.3.1 (d) e (e), os espectros são típicos de movimento lento (espectro de pó) e movimento rápido, relativos à freqüência do campo de radiação. No primeiro caso, o espectro consiste de uma combinação de espectros dos três eixos principais e todas as orientações intermediárias. No segundo caso, o espectro aparece de radicais livres "tombando" rápido e isotropicamente num solvente de baixa viscosidade. As flutuações térmicas promediam a anisotropia dos termos da Hamiltoniana, e os valores de $g$ e $A$ são as médias dos valores nas três direções: $g_{0}=\left(g_{z z}+g_{y y}+g_{z z}\right) / 3$ e $a_{0}=\left(A_{z z}+A_{y y}+A_{z z}\right) / 3$, resultando num espectro isotrópico, independente da orientação do campo magnético aplicado. A Tabela 2.3.1 apresenta os valores principais dos tensores $\boldsymbol{g}$ e $\boldsymbol{A}$ de um radical nitróxido do tipo doxil. As componentes $A_{x x}$ e $A_{y y}$ do tensor hiperfino são muito diferentes em relação a $A_{z z}$, o que confere ao nitróxido uma simetria quase axial, contrário ao tensor $\boldsymbol{g}$, cujas componentes são: $g_{x x}>g_{y y}>g_{z z}$.

Como podemos observar, a anisotropia dos tensores $\boldsymbol{g}$ e $\boldsymbol{A}$ é fundamental para a análise do espectro de RPE. Se o movimento é mais rápido do que a escala de tempo de RPE, o espectro consistirá de três linhas finas com a mesma altura (Fig. 2.3.1 (e)). À medida que o movimento se torna mais lento, as linhas hiperfinas começam a alargar sem alterar sua posição inicial, e segue até o deslocamento das linhas e posterior distorção de suas formas de linha, que é o limite do espectro imobilizado (Fig. 2.3.1 (d)). Se o movimento é rápido, porém anisotrópico, então, usando um sistema de coordenadas apropriado, é possivel determinar a orientação angular do radical nitróxido relativa à superficie da membrana, bem como sua velocidade de movimento. A primeira está relacionada com o parâmetro de ordem da molécula, e a segunda com os tempos de correlação rotacional, que serão discutidos adiante. É possivel distinguir o sinal de RPE em quatro regiões distintas de mobilidade, relacionadas ao tempo de correlação $\tau$ (ver seção 2.3.2): 


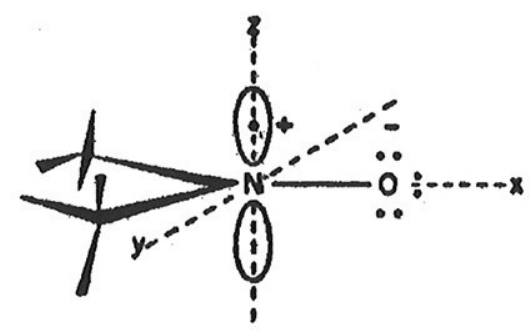

(a)

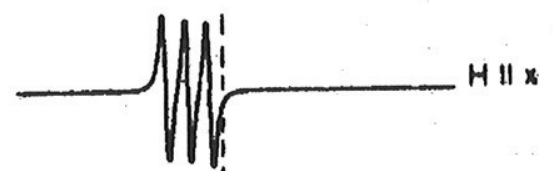

(b)

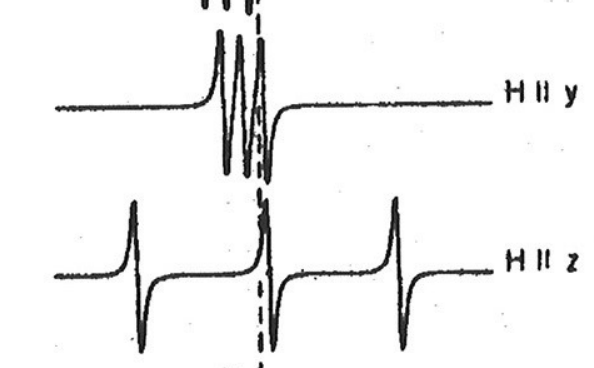

(c)

(d)

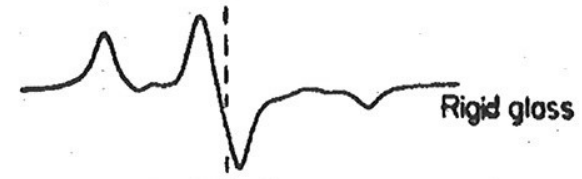

(e)

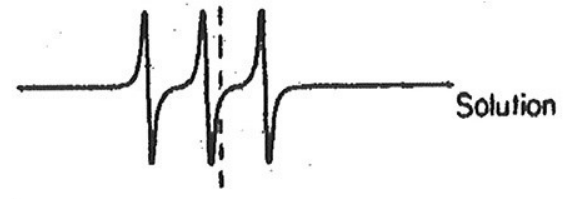

$50 G$

Figura 2.3.1 - Esquema do radical nitróxido e seus espectros de RPE em diferentes condições: como impureza em um cristal diamagnético com $H$ paralelo ao eixo-x (a), eixo-y (b) e eixo $z$ (c); em solução congelada (d) e em solução de baixa viscosidade (e) (Marsh, 1981, pág. 68).

$\tau<10^{-11} \mathrm{~s}-\mathrm{a}$ anisotropia do sistema é promediada. O espectro é isotrópico, ou seja, apresenta três linhas de igual intensidade, e os valores de $\boldsymbol{g}$ e $\boldsymbol{A}$ são os valores médios ( $g_{0}$ e $A_{0}$, respectivamente).

10-11 $\mathrm{s}<\tau<3 \times 10^{-9} \mathrm{~s}-$ é a região denominada movimento rápido (motional narrowing), em que o alargamento diferencial das três linhas hiperfinas dá informações sobre a velocidade de movimento da molécula, e onde será desenvolvido uma teoria para a forma e largura de linha, discutida a seguir.

$3 \times 10^{-9}<\tau<10^{-7} \mathrm{~s}-$ nessa região, chamada de movimento lento, além das linhas se alargarem, sua posição também é alterada. Um tratamento teórico mais sofisticado é necessário para análise desses espectros, como o desenvolvido por J.H. Freed (Schneider e Freed, 1989). 
$\tau>10^{-7} \mathrm{~s}-$ o espectro é a soma de todos os sinais correspondentes à molécula em todas as orientações relativas ao campo magnético aplicado. É um típico espectro de pó, em que as moléculas estão imóveis para a RPE.

Tabela 2.3.1 - Valores principais dos tensores $\boldsymbol{g}$ e $\boldsymbol{A}$ do nitróxido em um monocristal.

\begin{tabular}{lcccccc}
\hline & $\mathrm{A}_{\mathrm{xx}}(\mathrm{G})$ & $\mathrm{A}_{\mathrm{yy}}(\mathrm{G})$ & $\mathrm{A}_{z z}(\mathrm{G})$ & $\mathrm{g}_{\mathrm{xx}}$ & $\mathrm{g}_{\mathrm{yy}}$ & $\mathrm{g}_{z z}$ \\
$\begin{array}{l}\text { Doxil - } \\
\text { cadeia alifática }^{\mathrm{a}}\end{array}$ & 5,9 & 5,4 & 32,9 & 2,0088 & 2,0058 & 2,0021 \\
\hline
\end{tabular}

a (Marsh, 1981, pág. 69)

\subsubsection{Largura de linha do espectro de $R P E$}

Efeitos dinâmicos induzidos por rotação molecular normalmente são caracterizados pelo aumento da largura de linha, do qual se pode obter o tempo de correlação $\tau$ do movimento. Para radicais nitróxidos com movimento rápido $\left(\tau_{\mathrm{c}}<10^{-9} \mathrm{~s}\right)$ num meio isotrópico, pode-se determinar o tempo de relaxação, usando a teoria de perturbação dependente do tempo. Para tempos de correlação maiores que $10^{-9} \mathrm{~s}$, deve-se aplicar uma outra teoria a fim de resolver a hamiltoniana da equação (2.16). Neste regime de movimento lento, o sistema deve ser tratado pela equação de Liouville estocástica, onde os graus de liberdade dos spins estão acoplados à orientação da molécula através da parte anisotrópica do sistema afetando a evolução temporal dos spins (Schneider e Freed, 1989).

A teoria para a análise dos espectros de RPE para movimento rápido se baseia nas equações de Bloch, através da relaxação de um conjunto de spins não interagentes num campo magnético estático $H_{0}$ aplicado no eixo-z. Na condição de equilíbrio térmico, uma magnetização líquida $M_{z}$ é observada. No plano-xy não há magnetização, pois não existe coerência das fases dos diferentes spins. Entretanto, se uma perturbação dependente do tempo, por exemplo um campo girante $H_{1}$, é aplicada perpendicular ao campo magnético estático, o momento magnético $\mu$ precessionará produzindo uma magnetização girante no plano- $x y$, devido à coerência de fase, como mostra a Figura 2.3.2. Depois a perturbação é removida, o momento magnético $\mu$ retorna à sua posição inicial, paralela ao eixo- $z$, e a magnetização no plano- $x y$ volta a ser nula. Esses dois processos podem ser caracterizados por decaimentos exponenciais. A relaxação do sistema para a magnetização do eixo- $z$ é chamada de relaxação longitudinal, ou spin-rede, com tempo característico $T_{1}$. Já a perda de 
coerência entre as fases dos spins no plano- $x y$ é chamada de relaxação transversal ou spin-spin, com tempo característico $T_{2}$.

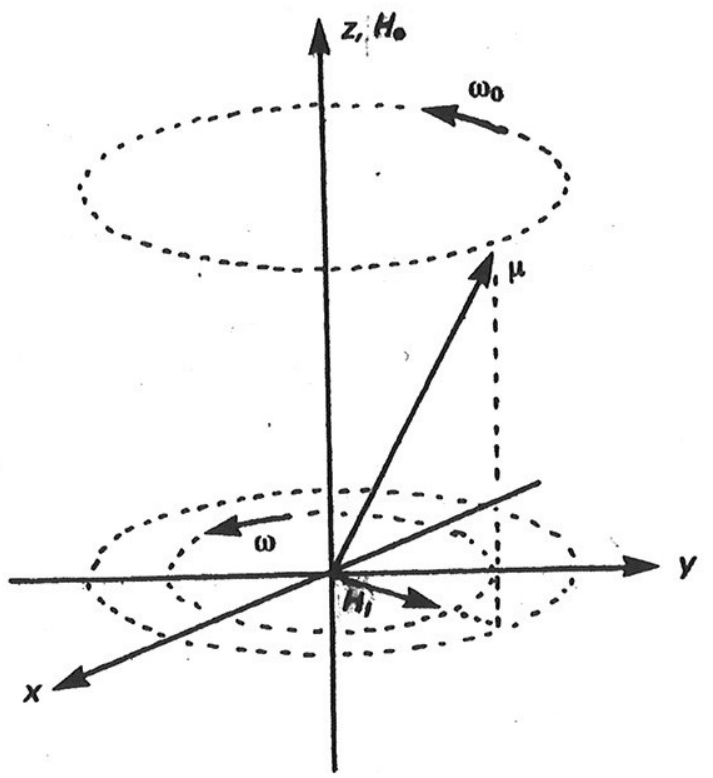

Figura 2.3.2 - Precessão do momento magnético de spin pela aplicação de um campo magnético $H_{1}$, girando no plano-xy com uma determinada freqüência $\omega$ (Atherton, 1993, pág. 13).

As equações de movimento para as componentes da magnetização (equações de Bloch) são:

$$
\begin{aligned}
& \frac{d M_{z}}{d t}=\gamma(\mathbf{H} \times \mathbf{M})_{z}+\frac{M_{0}-M_{z}}{T_{1}} \\
& \frac{d M_{x}}{d t}=\gamma(\mathbf{H} \times \mathbf{M})_{x}-\frac{M_{x}}{T_{2}} \\
& \frac{d M_{y}}{d t}=\gamma(\mathbf{H} \times \mathbf{M})_{y}-\frac{M_{y}}{T_{2}}
\end{aligned}
$$

onde $\gamma$ é a razão giromagnética (que para o caso de spin eletrônicos é substituída por $\left.g \mu_{B}\right)$, e $\boldsymbol{H}$ é o campo magnético total dado por

$$
\mathbf{H}=\hat{\mathbf{i}} H_{1} \cos \omega t+\hat{\mathbf{j}} H_{1} \sin \omega t+\hat{\mathbf{k}} H_{0}
$$


Substituindo a equação (2.3.3) em (2.3.2) e fazendo uma mudança de coordenadas para um referencial girante sobre o eixo- $z$ com freqüência $\omega$, a solução das equações (2.3.2) é simplificada. Se tomarmos uma solução estacionária, em que $\omega=\omega_{0}$, que é a freqüência de Larmor, dada por $\omega_{0}=\gamma H_{0}$, as equações de movimento são facilmente resolvidas. Retornando ao sistema de coordenadas do campo magnético estático (referencial de laboratório), as expressões para as componentes da magnetização ficam:

$$
\begin{aligned}
M_{z} & =\frac{\bar{M}\left\{\left(1 / T_{2}\right)^{2}+\left(\omega_{0}-\omega\right)^{2}\right\}}{\gamma H_{1}} \\
M_{x} & =\bar{M}\left\{\left(\omega_{0}-\omega\right) \cos \omega t+1 / T_{2} \sin \omega t\right\} \\
M_{y} & =\bar{M}\left\{\left(\omega_{0}-\omega\right) \sin \omega t-1 / T_{2} \cos \omega t\right\}
\end{aligned}
$$

onde

$$
\bar{M}=\frac{\gamma H_{1} M_{0}}{\gamma^{2} H_{1}^{2}\left(T_{1} / T_{2}\right)+\left(1 / T_{2}\right)^{2}+\left(\omega_{0}-\omega\right)^{2}}
$$

Em experimentos de RPE, é normal o uso de radiação linearmente polarizada, da forma $H_{x}=2 H_{1} \cos \omega t$ e $H_{y}=O$. Considerando $H_{x}$ a parte real de um campo complexo $H_{c}=2 H_{1} e^{i^{\omega} t}$, e escrevendo a magnetização proporcional ao campo por um fator denominado susceptibilidade magnética $\chi$, temos:

$$
M_{x}=2 H_{1} \chi^{\prime} \cos \omega t+2 H_{1} \chi^{\prime \prime} \sin \omega t
$$

Comparando a equação acima com (2.3.4), obtemos as componentes da susceptibilidade complexa,

$$
\begin{aligned}
& \chi^{\prime}=\frac{1}{2}\left\{\frac{\gamma M_{0}\left(\omega_{0}-\omega\right)}{\gamma^{2} H_{1}^{2}\left(T_{1} / T_{2}\right)+\left(1 / T_{2}\right)^{2}+\left(\omega_{0}-\omega\right)^{2}}\right\} \\
& \chi^{\prime \prime}=\frac{1}{2}\left\{\frac{\gamma M_{0}\left(1 / T_{2}\right)}{\gamma^{2} H_{1}^{2}\left(T_{1} / T_{2}\right)+\left(1 / T_{2}\right)^{2}+\left(\omega_{0}-\omega\right)^{2}}\right\}
\end{aligned}
$$

onde a parte imaginária $\chi$ " está relacionada com a transferência de energia do campo eletromagnético à amostra, ou seja, a absorção da radiação. Assim, a absorção é 
também proporcional à magnetização fora de fase e portanto, a forma de linha do espectro de RPE é uma função equivalente à parte imaginária da equação (2.3.7). Essa função é máxima quando $\omega=\omega_{0}$ e decresce para $H_{1}$ e $T_{1}$ grandes (saturação). Se restringirmos $H_{1}$ a valores pequenos, que é usual em RPE, então o termo $\gamma^{2} H_{1}^{2}\left(T_{1} / T_{2}\right)$ pode ser desprezado comparado com $\left(1 / T_{2}\right)^{2}$, e assim podemos escrever uma função dependente da freqüência para a forma de linha

$$
f(\omega)=A \frac{\gamma M_{0}\left(1 / T_{2}\right)}{\left(1 / T_{2}\right)^{2}+\left(\omega_{0}-\omega\right)^{2}}
$$

onde $A$ é uma constante de proporcionalidade. A função $f(\omega)$ é equivalente à função lorentziana, centrada em $\omega_{0}=\gamma H_{0}$ e com largura de linha dada por $\left(1 / T_{2}\right)$. Esse resultado é um caso particular de uma teoria mais geral, denominada teoria de resposta linear. Assim, a resposta de qualquer sistema dinâmico a uma pequena perturbação periódica sempre pode ser descrita em termos de uma função resposta complexa, onde a parte imaginária está relacionada à potência absorvida e freqüentemente tem a forma lorentziana, e a parte real associada à dispersão. Esta última é equivalente à parte real da equação (2.3.7), e o seu uso tem sido pouco aplicado em experimentos de RPE.

Até agora, foi desenvolvida uma teoria clássica para a largura de linha de espectros de RPE, relacionada ao tempo de relaxação transversal $T_{2}$, sem mostrar as causas desse alargamento, embutidas fenomenologicamente. A seguir, daremos algumas indicações do que depende a largura de linha. Para isso, faz-se necessário o uso do formalismo quântico da matriz densidade e a teoria de Redfield (Redfield, 1965). Atravês do cálculo dos elementos da matriz densidade, usando uma função de correlação temporal, a expressão para $T_{2}$ fica:

$$
\frac{1}{T_{2}}=\left(\frac{g \beta}{\hbar}\right)^{2}\left\{\overline{H_{z}^{2}} \tau_{C}+\frac{\tau_{C}}{2} \frac{\overline{H_{x}^{2}}+\overline{H_{y}^{2}}}{1+\omega_{o}^{2} \tau_{C}^{2}}\right\}
$$

onde $\tau_{\mathrm{C}}$ é o tempo de correlação característico da molécula paramagnética. Essa expressão vale para a região de motional narrowing, onde a mobilidade da molécula é da ordem de $\tau_{\mathrm{C}} \leq 10^{-9} \mathrm{~s}$. O primeiro termo, chamado de secular, indica flutuações na componente $z$ do campo aplicado, que não induzem transições entre níveis de energia dos spins. O segundo termo, não-secular, está ligado a flutuações no plano-xy que 
podem induzir transições, e portanto depende de $\mathrm{T}_{1}$. Se desprezarmos a contribuição do termo não-secular, e associarmos as flutuações em $\mathrm{H}_{z}$ às flutuações na freqüência de ressonância, $\omega=g \beta H_{z} / \hbar$ (efeito Zeemann), então podemos reescrever a equação acima como:

$$
\frac{1}{T_{2}} \approx \overline{\Delta \omega^{2}} \tau_{C}
$$

Assim, qualquer processo dinâmico que altere a freqüência de ressonância irá causar alargamento da linha de absorção. Devido às anisotropias dos tensores $\mathbf{g}$ e $\mathbf{A}$ (Fig. 2.3.1), a freqüência de absorção, e portanto a largura de linha, será sensível à difusão rotacional das moléculas paramagnéticas.

De acordo com a Eq. 2.3.1 a freqüência de ressonância é dada por:

$$
\omega=g \frac{\mu_{B} H_{o}}{\hbar}+a \frac{m_{I}}{\hbar}
$$

onde $\mathrm{m}_{\mathrm{I}}$ são os autovalores do operador de spin nuclear I. O fator-g e o desdobramento hiperfino a variam, portanto $\overline{\Delta \omega^{2}}$ é:

$$
\overline{\Delta \omega^{2}}=\overline{\Delta g^{2}}\left(\frac{\mu_{B} H_{o}}{\hbar}\right)^{2}+2 \overline{\Delta g \Delta a} \frac{\mu_{B} H_{o}}{\hbar^{2}} m_{I}+\overline{\Delta a^{2}} \frac{1}{\hbar^{2}} m_{I}^{2}
$$

Usando a Eq. 2.3.12, podemos reescrever a Eq. 2.3.10:

$$
\frac{1}{T_{2}}=A+B m_{I}+C m_{I}^{2}
$$

onde A, B, C dependem dos valores médios das anisotropias dos tensores $\mathbf{g}$ e $\mathbf{A}$. Fica claro, então, que o alargamento é diferencial para cada linha correspondente a $\mathrm{m}_{\mathrm{I}}$. No caso do nitróxido $\mathrm{m}_{\mathrm{I}}=+1,0,-1$, como visto na Fig. 2.3.1. Os valores médios da Eq. 2.3.12 podem ser escritos em termos dos produtos internos dos tensores $\mathbf{g}$ e $\mathbf{A}$ : 


$$
\begin{aligned}
& A=\frac{2}{15}\left(\frac{\mu_{B} H_{o}}{\hbar}\right)^{2}\left(g^{o}: g^{o}\right) \tau_{C} \\
& B=\frac{4}{15} \frac{\mu_{B} H_{o}}{\hbar}\left(g^{o}: A^{o}\right) \tau_{C} \\
& C=\frac{2}{15} \frac{1}{\hbar^{2}}\left(A^{o}: A^{o}\right) \tau_{C}
\end{aligned}
$$

onde os termos $\mathrm{T}^{\mathrm{o}}: \mathrm{T}^{\circ}$ (To sendo a parte anisotrópica dos tensores $\mathrm{T}=\mathbf{g}$ ou $\mathbf{A}$ ) representam uma soma dos produtos dos elementos de matriz dos tensores $\mathbf{g}$ e $\mathbf{A}$. O termo A alarga as três linhas igualmente, devido à diferença entre $g_{\min }$ e $g_{\max }$. O termo $\mathrm{C}$ adiciona um alargamento simétrico com relação à $\mathrm{m}_{\mathrm{I}}=0$, dependendo de $a_{\min } \mathrm{e} a_{\max }$. O termo misto B alarga as linhas diferentemente. Dependendo do sinal de B, o pico mais largo será o referente à $\mathrm{m}_{\mathrm{I}}=+1$ ou -1 .

\subsubsection{Cálculo do tempo de correlação}

Os tempos de correlação paralelo e perpendicular ao eixo principal de rotação de um marcador de spin são calculados a partir das larguras de linha de seu espectro (Bales, 1989 e Marsh, 1989), considerando que o movimento do marcador esteja no regime de "motional narrowing", isto é $10^{-11}<\tau_{c}<3 \times 10^{-9} \mathrm{~s}$.

Primeiro obtém-se a largura de linha lorentziana calculada a partir da largura de linha total e do valor médio das larguras gaussianas, obtidas do programa LOWFIT (ajusta cada linha hiperfina a uma função soma de gaussianas e lorentzianas, que é a representação da função de Voigt, ver Bales, 1989). Em princípio a largura gaussiana é um parâmetro de cada marcador, não devendo depender da temperatura, do solvente ou de $\mathrm{m}_{\mathrm{l}}$, e portanto tomamos um valor médio dos ajustes do LOWFIT a diversas temperaturas e condições. $\Delta \mathrm{H}_{\mathrm{pp}}^{\mathrm{L}}(0)$ é calculada da seguinte forma:

$$
\Delta H_{p p}^{L}(0)=\Delta H_{p p}^{o}(0)\left\{1-\left(\frac{<\Delta H_{p p}^{G}>}{\Delta H_{p p}^{o}(0)}\right)^{2}\right\}
$$

onde os indices superiores L,G e 0 referem-se às larguras lorentziana, gaussiana e total, respectivamente, e o termo entre parênteses refere-se a $M_{I}=O$. Assumindo-se que o alargamento das linhas é dado por (2.3.9), os coeficientes dessa equação podem ser escritos a partir de parâmetros espectrais, como: 


$$
\begin{aligned}
A & =\Delta H_{p p}^{L}(0) \\
B & =\frac{1}{2} \Delta H_{p p}^{L}(0)\left[\sqrt{\frac{V_{p p}(0)}{V_{p p}(+1)}}-\sqrt{\frac{V_{p p}(0)}{V_{p p}(-1)}}\right] \\
C & =\frac{1}{2} \Delta H_{p p}^{L}(0)\left[\sqrt{\frac{V_{p p}(0)}{V_{p p}(+1)}}+\sqrt{\frac{V_{p p}(0)}{V_{p p}(-1)}}-2\right]
\end{aligned}
$$

$V_{p p}\left(M_{I}\right)$ á a altura do pico correspondente à $M_{I}$, usada no lugar das larguras de linha pois $\Delta H^{2}\left(M_{I}\right) \cdot V_{p p}\left(M_{I}\right)=$ área do espectro. Introduzindo uma correção devida ao fato de não termos somente larguras Lorentzianas envolvidas:

$$
\begin{aligned}
& \mathrm{B}_{\text {corr }}=\mathrm{S}\left(\chi_{0}\right) \mathrm{B} \\
& \mathrm{C}_{\text {corr }}=\mathrm{S}\left(\chi_{0}\right) \mathrm{C}
\end{aligned}
$$

onde

$$
\mathrm{S}\left(\chi_{\mathrm{o}}\right)=\frac{1+1.78 \chi_{\mathrm{o}}+1.85 \chi_{\mathrm{o}}^{2}}{1+2.08 \chi_{\mathrm{o}}}, \quad \chi_{\mathrm{o}}=\frac{\left\langle\Delta \mathrm{H}_{\mathrm{pp}}^{\mathrm{G}}\right\rangle}{\Delta \mathrm{H}_{\mathrm{pp}}^{\mathrm{L}}(0)}
$$

Dada a dependência do tempo de relaxação com a freqüência, podemos calcular os tempos de correlação rotacional através de uma função de autocorrelação. Assumindo um modelo de difusão rotacional browniano, podemos calcular os tempos de correlação $\tau_{L K}$ através dos autovalores da equação de difusão. Para a modulação das interações hiperfina e Zeeman, é necessário $L=2$ termos. Para difusão rotacional anisotrópica são necessários dois tempos de correlação rotacional independentes para descrever o alargamento da linha hiperfina. A partir dos parâmetros $\mathrm{B}_{\mathrm{cor}}$ e $\mathrm{C}_{\mathrm{cor}}$, calculamos os tempos de correlação $\tau_{20}$ e $\tau_{22}$,

$$
\begin{aligned}
\tau_{20} & =c_{1}\left(C_{\text {cor }}+c_{2} B_{\text {cor }}\right) \\
\tau_{22} & =b_{1}\left(B_{\text {cor }}+b_{2} C_{\text {cor }}\right)
\end{aligned}
$$

onde $c_{1}, c_{2}, b_{1}$ e $b_{2}$ são parâmetros que dependem do eixo preferencial de rotação do marcador em questão. Para marcadores cujo eixo principal de rotação é o x, como é o caso do dcat1, $c_{1}=-2,85 n s, c_{2}=1,447, b_{1}=1,28 n s$ e $b_{2}=1$,912. Para marcadores com movimento principal em torno do eixo-z (16-PCSL, 16-MESL e 16-SASL), $c_{1}=1,16 \mathrm{~ns}$, $c_{2}=-0,0316, b_{1}=-0,437 n s$ e $b_{2}=0,988$ (Marsh, 1989). Para rotação anisotrópica axial, 
podemos determinar tempos de correlação sobre os eixos de simetria molecular $(\tau / /)$ e perpendicular a ele $\left(\tau_{\perp}\right)$. Assim, os tempos de correlação paralelo e perpendicular são dados por:

$$
\begin{aligned}
\tau_{\perp} & =\tau_{20} \\
\tau_{/ /} & =\frac{2 \tau_{20} \tau_{22}}{3 \tau_{20}-\tau_{22}}
\end{aligned}
$$

\subsubsection{Parâmetro de ordem}

Um parâmetro que pode ser calculado a partir da anisotropia do tensor $\boldsymbol{A}$ é o parâmetro de ordem $\mathbf{S}$ da membrana que mede a distribuição angular média do eixo $z$ do nitróxido com relação à normal à superfície da bicamada lipídica. Tomando como exemplo um caso particular, quando ambos o orbital p- $\pi$ da cadeia acila e o campo magnético $H$ forem paralelos à normal à bicamada, então $A_{/ /}=A_{z z}$. Se o campo $H$ for perpendicular à normal à superficie e o movimento nesse plano for rápido, podemos escrever $A_{\perp}=\left(A_{x x}+A_{y y}\right) / 2$. Porém, se a cadeia forma um ângulo $\theta_{3}$ com a normal à bicamada, conforme indica a Figura 2.3.3, $A_{/ /}$será menor do que $A_{z z}$ devido às contribuições de $A_{x x}$ e $A_{y y}$, e $A_{\perp}$ será maior do que $\left(A_{x x}+A_{y y}\right) / 2$ devido à contribuição de $A_{z z}$.

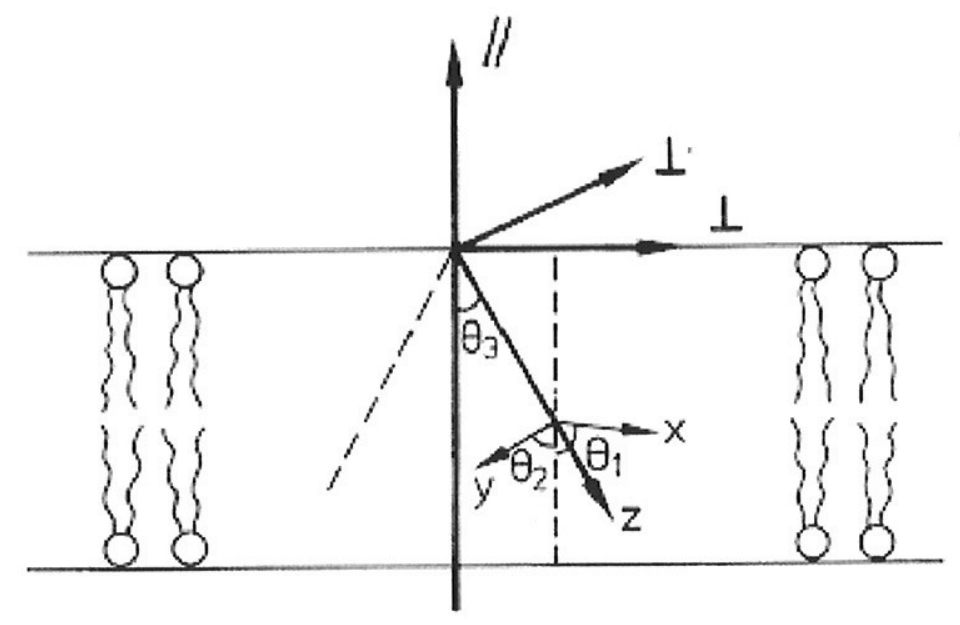

Figura 2.3.3 - Orientação dos eixos do nitróxido com relação a normal à superficie da bicamada. Os eixos $\mathbf{x}, \mathbf{y}, \mathbf{z}$ do radical livre formam ângulos $\theta_{1}, \theta_{2}, \theta_{3}$ em relação a normal à bicamada.

O parâmetro de ordem efetivo $S_{\text {eff }}$ é dado pela expressão, 


$$
S_{\text {eff }}=\frac{A_{/ /}-A_{\perp}}{A_{Z Z}-\left(A_{X X}-A_{Y Y}\right) / 2} \frac{a_{o}(\text { cristal })}{a_{0}(\text { bicamada })}
$$

onde $2 A_{/ /}$é o desdobramento hiperfino máximo (ver Figs. 2.3.4 e 4.1.1), e $a_{0}$ (cristal) é o desdobramento hiperfino isotrópico dado por $a_{0}=1 / 3\left(A_{x x}+A_{y y}+A_{z z}\right)$, onde $A_{x x}, A_{y y} \mathrm{e}$ $A_{z z}$ são os valores do tensor $\boldsymbol{A}$ para o monocristal (ver Tabela 2.3.1). Os valores de $a_{0}$ (bicamada) e de $A_{\perp}$ (Griffith e Jost, 1976; Gaffney, 1976) podem ser calculados de uma aproximação dada por:

$$
\begin{aligned}
& a_{0}(\text { bicamada })=\frac{1}{3}\left(A_{/ /}+2 A_{\perp}\right) \\
& A_{\perp}=A_{\min }+1,4\left[1-\frac{A_{/ /}-A_{\min }}{A_{z z}-\left(A_{x x}+A_{y y}\right) / 2}\right]
\end{aligned}
$$

onde $A_{\min }$ é a medida do desdobramento hiperfino mínimo (ver Figs. 2.3.4 e 4.1.1). Na Figura 2.3.4 são apresentados alguns espectros de RPE, de movimento rápido, com o parâmetro de ordem variando de $1 \mathrm{a} 0$. Também são apresentados os desdobramentos hiperfinos máximo e mínimo. Para altos valores de parâmetros de ordem, o desdobramento mínimo é pouco resolvido enquanto que para baixos valores os dois desdobramentos se superpõem. 

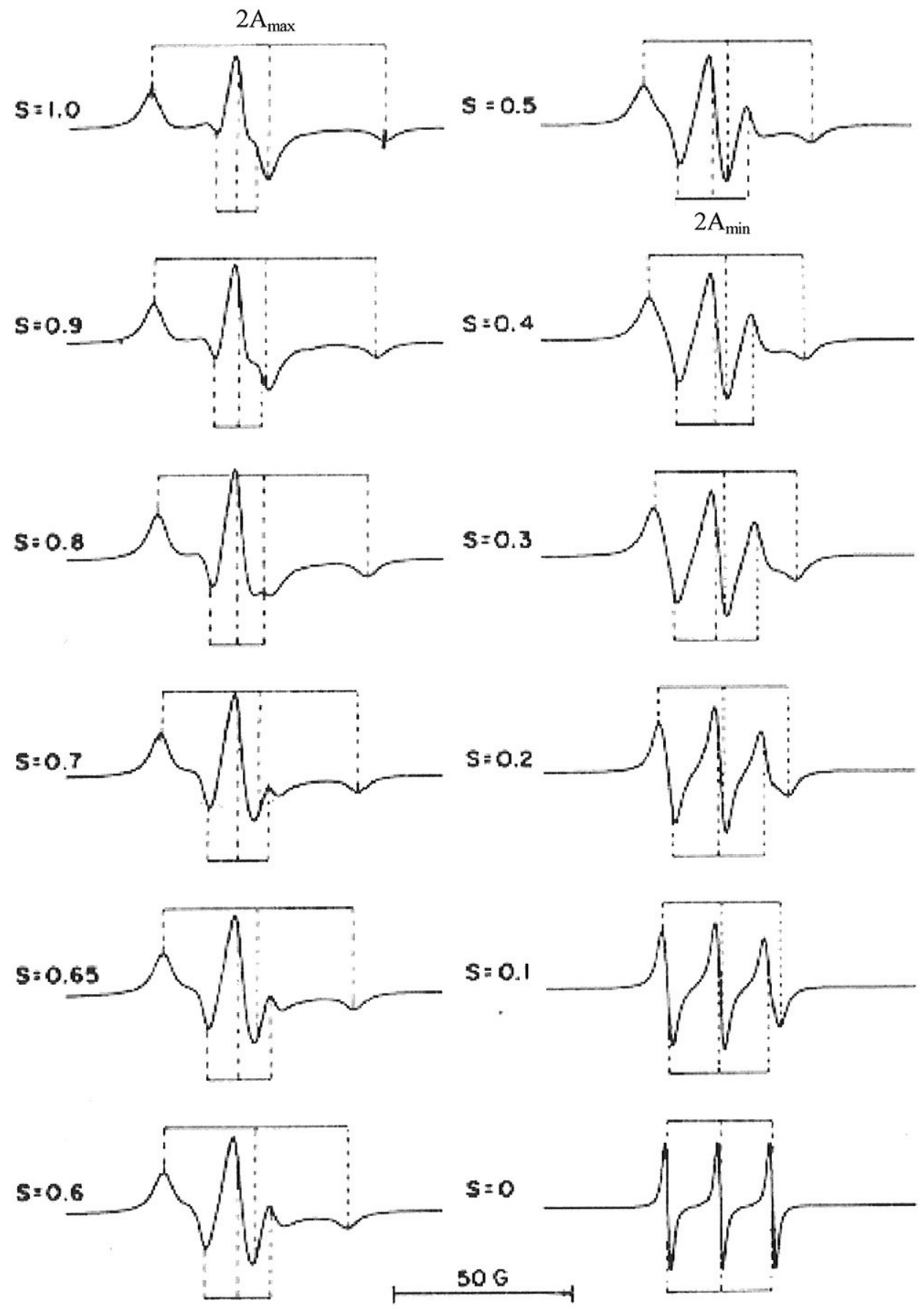

Figura 2.3.4 - Espectros de RPE de amostras aleatoriamente orientadas com diferentes valores do parâmetro de ordem. As linhas pontilhadas indicam os desdobramentos máximo $2 A_{\max } \mathrm{e}$ minimo $2 A_{\min }$ (Griffith e Jost, 1976). 


\subsubsection{Polaridade do meio}

A polaridade do meio no qual encontra-se o radical nitróxido afeta os tensores $\mathbf{g}$ e A, pois altera a distribuição da nuvem eletrônica ao redor do núcleo de nitrogênio. $\mathrm{O}$ grupo nitróxido pode assumir duas configurações eletrônicas, como visto abaixo (Grifith et al., 1974):

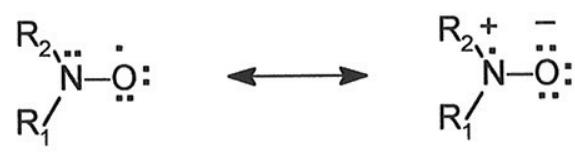

Solventes polares tendem a estabilizar a segunda estrutura, que por apresentar maior densidade de spin no nitrogênio possui um desdobramento hiperfino maior. Dessa forma, medidas do desdobramento hiperfino médio, $a_{0}$, e do valor médio do tensor-g, $g_{o}$, são uma medida da polaridade do meio, como está mostrado na tabela abaixo, obtida para o di-t-butil-nitróxido (DTBN) a 23 ○C (Griffith et al., 1974):

Tabela 2.3.1 - Valores de $a_{0}$ e go de alguns solventes (Griffith et al., 1974).

\begin{tabular}{lll}
\hline solvente & $a_{o}(\mathrm{G})$ & $g_{o}$ \\
\hline Hexano & 15.10 & 2.0061 \\
Etanol & 16.06 & 2.0059 \\
Água & 17.16 & 2.0056 \\
\hline
\end{tabular}

O cálculo de $a_{0}$ a partir dos espectros de RPE é confiável somente quando o movimento é muito rápido. No caso isotrópico, a distância medida entre os picos é o próprio valor médio $a_{0}$, enquanto que em movimentos bastante anisotrópicos, consegue-se medir $A_{/ /}$e $A_{\perp}$ com precisão. Em espectros que representam marcadores com pouca mobilidade, $a_{0}$ só pode ser obtido com a simulação dos espectros. 


\section{Materiais e métodos}

\subsection{Materiais}

Anfifilicos e marcadores de spin.. O sal de sódio do fosfolipídeo DMPG (1,2-dimyristoylsn-glycero-3-phospho-rac-glycerol, lote no 140PG-115) e os marcadores de spin $\boldsymbol{n}$-PCSL (1-palmitoyl-2-(n-doxyl stearoyl)-sn-glycero-3-phosphocholine; $\boldsymbol{n}=5,9,12$, ou 16) e $\boldsymbol{n}$ MESL ( $\boldsymbol{n}$-methyl ester stearic acid spin label; $\boldsymbol{n}=5,12$ ou 16) foram comprados da Avanti Polar Lipids (Birmingham, AL, USA). O marcador 10- e 14-PCSL foi gentilmente doado por A. Watts, da University of Oxford, UK. O colesterol e os marcadores de spin 5-, 12- e 16-SASL (5-, 12-, ou 16-doxyl stearic acid spin label) foram comprados da Sigma Chemical Co. (St. Louis, MO, USA).

Tampão, sal e base. O tampão Hepes (4-(2-hydroxyethyl)-1-piperizineethanesulfonic acid) foi comprado da Sigma Chemical Co. (St. Louis, MO, USA). O sal NaCl (cloreto de sódioe a base $\mathrm{NaOH}$ (hidróxido de sódio) foram compradas da Casa Americana (São Paulo, SP).

Peptídeos melanotrópicos. O $\alpha$-MSH ( $\alpha$-melanocyte stimulating hormone) foi comprado da Sigma Chemical Co. (St. Louis, MO, USA). O mesmo peptídeo, seu análogo linear biologicamente mais ativo (aqui chamado de MSH-I), e análogos cíclicos (HS-014, HS024, HS-032 e HS-053) foram sintetizados pelo grupo do Dr. Helgi B. Schiöth da Uppsala University, SW. Todos esses peptídeos tem um grupo acetil no terminal-N e um grupo amida no terminal-C. O $\alpha$-MSH marcado com a sonda paramagnética Toac (acetil-Toac ${ }^{0}-\alpha-\mathrm{MSH}$ ), onde Toac é o amino ácido 2,2, 6, 6-tetramethylpiperidine-1-oxyl-4amino-4-carboxylic acid, e seu análogo MSH-I marcado (acetil-Toac ${ }^{0}-\left[\mathrm{Nle}^{4}, \mathrm{D}-\mathrm{Phe}^{7}\right] \alpha-$ MSH) foram sintetizados pelo Dr. Clóvis R. Nakaie da Universidade Federal de São Paulo.

A Figura 3.1 mostra esquematicamente o fosfolipídeo DMPG, os marcadores de spin 5-PCSL, 12-SASL e 16-MESL, e o colesterol. A Figura 3.2 apresenta a estrutura primária do hormônio estimulador do melanócito. A composição dos análogos cíclicos e linear do $\alpha-\mathrm{MSH}$ é apresentada na Tabela 3.1. Nesta, também são indicados os valores das cargas de cada resíduo e a carga líquida desses análogos em pH neutro. A figura 3.3 mostra a estrutura primária do análogo cíclico HS-024 (ver Tabela 3.1). 
<smiles>CCCCCCCCCCCCCCCCCCCCCCC(=O)OCC(COP(=O)([O-])OCC(O)CO)OC(=O)CCCCCC</smiles><smiles>CCCCCCCCCCCCCCCCCCC1(CCCCCCCCCCCC)OCC(C)(C)N1OC(=O)CCCC1(CCCCCC)OCC(C)(C)N1O</smiles><smiles>CCC1(CCCCCCCCCCCCCCC(=O)OC)OCC(C)(C)N1O</smiles><smiles>CC(C)CCCC(C)C1CCC2C3CC=C4CC(O)CCC4(C)C3CCC12C</smiles>

Figura 3.1 - Representação esquemática da molécula de DMPG, dos marcadores de spin 5PCSL, 12-SASL, 16-MESL e do colesterol. O marcador $n$-MESL diferencia-se do $n$-SASL na cabeça polar em que a terminação $\mathrm{OH}$ é metilada pelo $\mathrm{CH}_{3}$. 


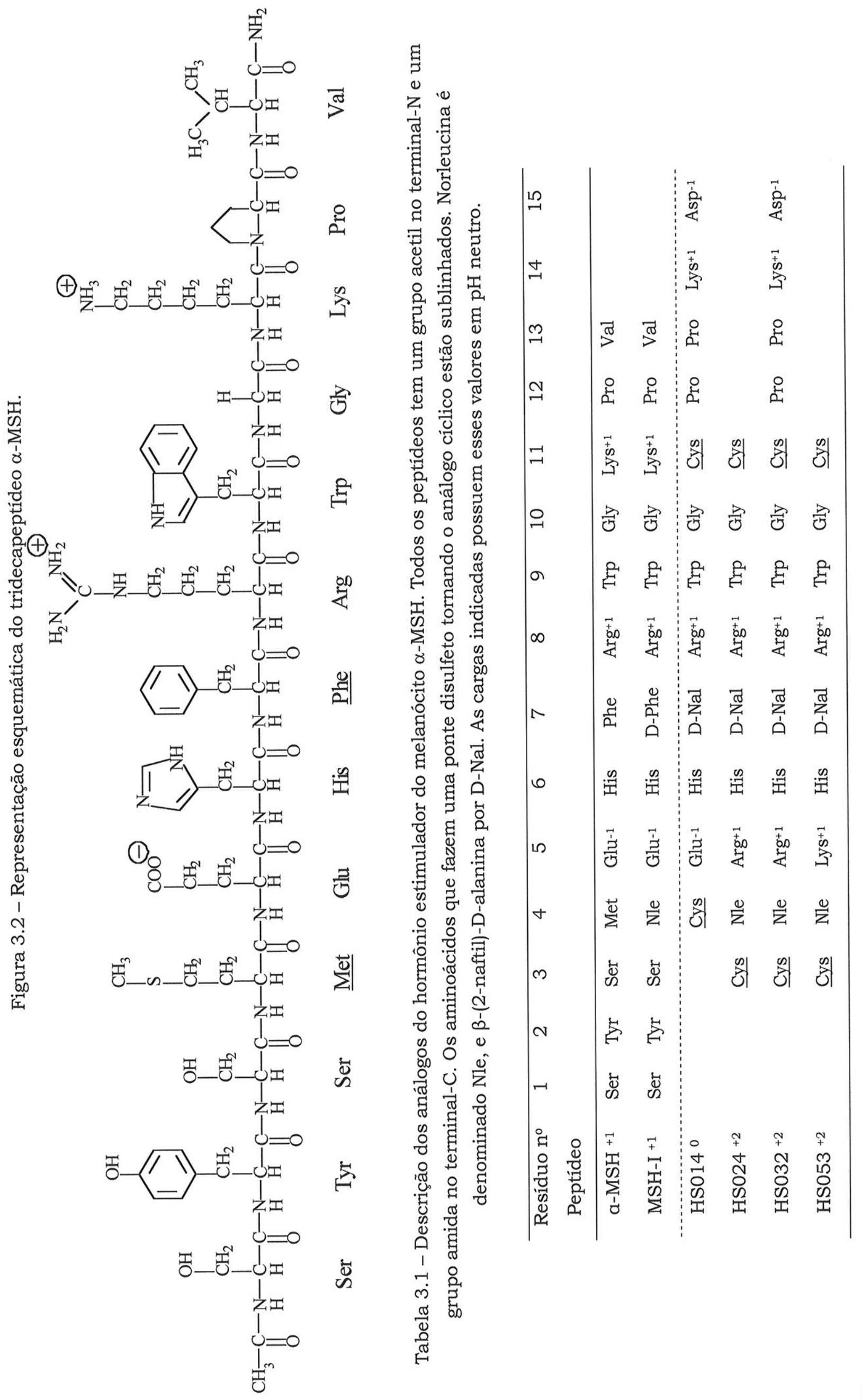




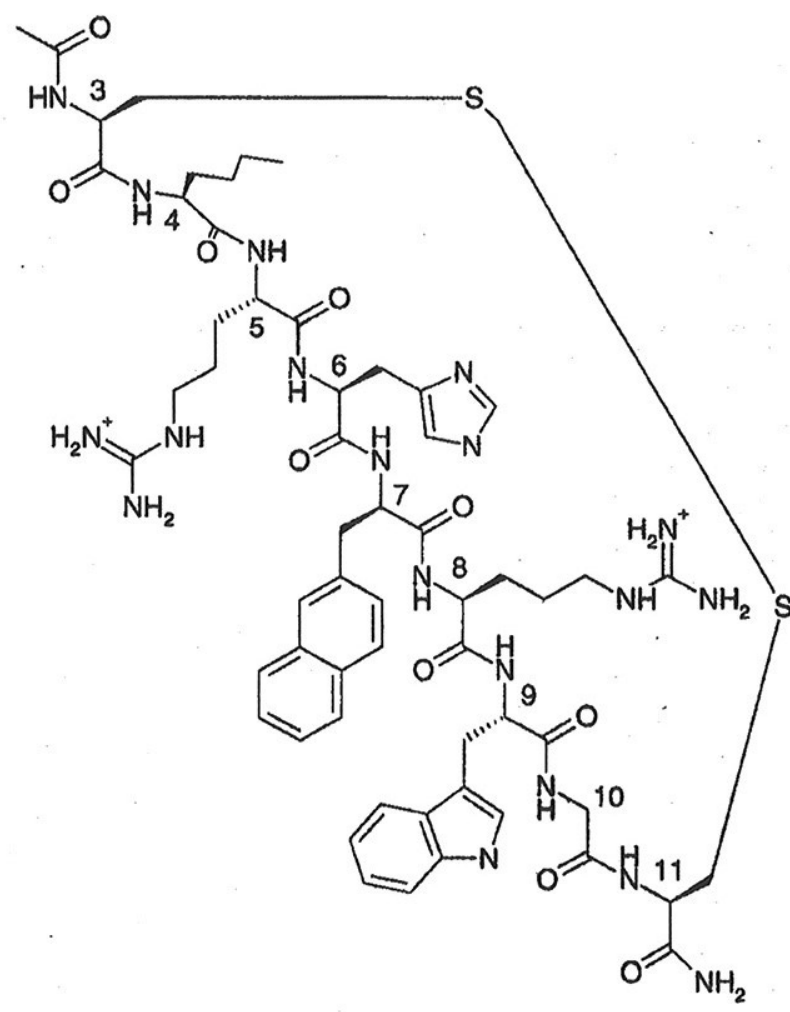

Figura 3.3 - Estrutura primária do análogo cíclico HS-024. Os resíduos estão enumerados de acordo com a seqüência do $\alpha-\mathrm{MSH}$ (ver Tabela 3.1, Kask et al., 1998).

\subsection{Métodos}

Preparação da dispersão lipídica. Um filme foi formado de uma solução de DMPG e marcador de spin $\left(0,2 \mathrm{~mol} \%\right.$, relativo ao lipídeo, para o anfifilico marcado no $16^{\circ}$ carbono, e 0,6 mol \% para os outros marcadores, que são as concentrações máximas de marcadores de spin que não apresentam interação de troca) em clorofórmio, seco sob um fluxo de $\mathrm{N}_{2}$ e mantido a uma pressão reduzida por um tempo não inferior a 2 h, para remover todos os traços do solvente orgânico. Lipossomos foram preparados pela adição da solução tampão desejada, com ou sem peptídeo, colesterol ou sal, seguida pela agitação por um minuto, acima da temperatura de transição de fase. A concentração final de DMPG foi 10 mM. Se não mencionado, a solução tampão usada foi $10 \mathrm{mM}$ Hepes $+2 \mathrm{mM} \mathrm{NaCl}$, ajustada com $\mathrm{NaOH}$ para $\mathrm{pH} 7,4$.

Preparação dos peptídeos melanotrópicos. Para as medidas espectroscópicas, soluções estoques dos peptídeos $\left(5.10^{-3} \mathrm{M}\right)$ foram preparadas à temperatura ambiente em solução aquosa (10 mM HEPES + $2 \mathrm{mM} \mathrm{NaCl}$, ajustada com $\mathrm{NaOH}$ para pH 7,4) e 
diluídas para a concentração final desejada (se não mencionada ao contrário, a concentração usada foi $\left.5 \cdot 10^{-5} \mathrm{M}\right)$.

Ajuste do $p H$. O tampão HEPES é um ácido (HA) fraco possui um $p K=7,55$, ou seja, em $\mathrm{pH}=7,55$ metade do tampão encontra-se na sua forma ionizada (A-, base conjugada do ácido) e metade na sua forma normal.

$$
\mathrm{HA} \Leftrightarrow \mathrm{H}^{+}+\mathrm{A}^{-}
$$

A separação nestas duas formas depende do pH (concentração de $\mathrm{H}^{+}$, em mol/1) da solução, e é bem descrita pela equação de Henderson-Hasselbalch,

$$
p H=p K+\log \frac{\left[A^{-}\right]}{[H A]}
$$

proveniente da constante dissociação $K$ do ácido $\left(K=\left[A^{-}\right] \cdot\left[H^{+}\right] /[H A]\right)$. A equaçao indica que o pK de uma substância é numericamente igual ao pH da solução quando as concentrações molares de um ácido e sua base conjugada são iguais. Essa região de $\mathrm{pH}$ é denominada região tamponante.

O HEPES dissolvido em água pura (10 mM) apresenta um $\mathrm{pH}$ da ordem de 5,6. A fim de mudar o $\mathrm{pH}$ para valores próximos do $\mathrm{pH}$ físiológico $(7,4)$, foi necessário a adição de hidróxido de sódio $(\mathrm{NaOH})$. Essa quantidade de base gerou uma força iônica de 4 mM (o tampão HEPES agora tem 4 mM de íons $\mathrm{Na}^{+}$em solução). A leitura do pH foi feita com um medidor de pH Metler Toledo. Nos experimentos de variação de pH da solução utilizou-se $\mathrm{HCl}$ para abaixar o $\mathrm{pH}$ ou $\mathrm{NaOH}$ para aumentá-lo.

Espectroscopias ópticas e fluorescentes. Medidas de absorção óptica foram realizadas com um espectrofotômetro HP 8452 A, em cubetas de quartzo com caminho óptico de $1 \mathrm{~cm}$. Para experimentos de fluorescência estática foi usado um espectrômetro Jobin Yvon-Spex, mod. Fluorolog 3, com aberturas das fendas de excitação e emissão de 1 $\mathrm{mm}$ e $2 \mathrm{~mm}$ respectivamente, e o comprimento de onda de excitação foi ajustado para $296 \mathrm{~nm}$.

Os experimentos com resolução temporal foram realizados usando um equipamento baseado no método de correlação temporal de fótons únicos (ver seção 2.2.3). A fonte de excitação utilizada foi um laser de titânio-safira Spectra Physics, mod. Tsunami 3950, pré estimulada por um laser de argônio Spectra Physics, mod. 2060. A taxa de repetição dos pulsos de 5 ps de largura, foi ajustada para $800 \mathrm{kHz}$ 
através do selecionador de pulsos Spectra Physics, mod. 3980. O laser foi ajustado para fornecer um comprimento de onda de $888 \mathrm{~nm}$. Um gerador de terceiro harmônico de cristal de borato de bário (BBO) Spectra Physics, mod. GWN-23PL, produziu um pulso de excitação de $296 \mathrm{~nm}$ que foi dirigido para um espectrômetro Edinburgh, mod. FL900. O comprimento de onda de emissão foi selecionado por um monocromador, e os fótons emitidos foram detectados a $90^{\circ}$ do feixe de excitação por uma fotomultiplicadora multicanal Hamamatsu, mod. R3809U. A largura total na meia altura (full width half maximum - FWHM) da resposta do instrumento foi de 50 ps e a resolução instrumental foi de $12 \mathrm{ps} /$ canal para escala tempo de 50 ns (usado em amostras com tempo de vida curto) e de 48 ps/canal para 200 ns (usado em amostras com tempo de vida longo). Um software fornecido pela Edinburgh Instruments foi usado para analisar as curvas de decaimento, e a qualidade dos ajustes foi verificada pelo método dos mínimos quadrados e/ou função de autocorrelação residual. Os espectros de decaimento associados (decay-associated spectra, DAS) foram gerados por uma análise global do conjunto de dados obtidos em diferentes comprimentos de onda de emissão, usando um software de análise da Edinburgh Instruments.

Espectroscopia de RPE. Banda-X. Os espectros de RPE foram obtidos com um espectrômetro Bruker EMX. Uma amplitude de modulação de campo de $1 \mathrm{G}$ e uma potência de microondas de $5 \mathrm{~mW}$ foram usadas. A freqüência de microondas usada foi da ordem de 9,4 GHz. A temperatura foi controlada para um desvio máximo de $0,2 \circ \mathrm{C}$ com um controlador de temperatura Bruker BVT-2000. A temperatura foi monitorada através de um termopar Fluke $51 \mathrm{~K} / \mathrm{J}$ colocado acima da cavidade. O campo magnético foi medido com um gaussímetro Bruker ER 035 NMR. Todos os dados são médias dos resultados de pelo menos três experimentos, e as incertezas são os desvios padrões. Quando não mostrados, as incertezas são menores que o tamanho dos simbolos.

Bandas $Q e L$. Os espectros em Banda-Q e Banda-L foram obtidos em um espectrômetro Varian E 109 (São Carlos, SP, Prof.Dr. Otaciro R. Nascimento). A temperatura da amostra foi mantida e controlada por uma unidade de fluxo de nitrogênio da Varian. Uma amplitude de modulação entre 1,25 e 1,6 G e uma potência de microondas de $10 \mathrm{~mW}$ foram utilizadas. A freqüência de microondas usada foi de $35 \mathrm{GHz}$ para a Banda-Q e de 1,28 GHz para a Banda-L.

As linhas do espectro de RPE de sondas mais móveis, marcadas no $16^{\circ}$ carbono da cadeia acila, em altas temperaturas, foram ajustadas cada uma a uma função soma de gaussianas e lorentzianas (Halpern et al., 1993). Essa função soma é uma 
aproximação de uma convolução gaussiana-lorentziana, a função de Voigt (Bales, 1989). O desdobramento hiperfino isotrópico, $a_{0}$, foi obtido calculando-se a metade da diferença dos campos ressonantes das linhas de alto e baixo campo. Para espectros altamente anisotrópicos obtidos pelo 5-PCSL e 5-SASL, incorporados na fase líquido cristalina de vesículas de DMPG, o desdobramento hiperfino isotrópico foi calculado pela equação (2.3.22).

Os parâmetros de ordem efetivos $S_{\text {eff }}$ foram calculados através da expressão (2.3.21). Valores muito similares do parâmetro de ordem foram obtidos usando a expressão melhorada, sugerida por Marsh e Schorn (Marsh e Schorn, 1998).

Simulação dos espectros de RPE. Para análise dos espectros de RPE nós usamos o programa NLSL (ajuste não linear por minimos quadrados) desenvolvido por Freed e co-autores (Schneider e Freed, 1989; Budil et al., 1996). Como discutido na literatura (Ge and Freed, 1999, e referências lá citadas), a melhor simulação do espectro (MOMD, ordem microscópica e desordem macroscópica) é fortemente dependente dos parâmetros iniciais. Portanto, a análise dos mínimos quadrados não é automática, mas requer a "intuição" do usuário (Benatti et al., 2001). Considerando que as variações do valor de $g$ com a polaridade local do marcador é muito pequena, as componentes do tensor $\boldsymbol{g}$ foram mantidas como sendo $g_{x x}=2,0089, g_{y y}=2,0058$ e $g_{z z}=$ 2,0021 (Earle et al., 1994; Ge e Freed, 1999). O tensor desdobramento hiperfino $\boldsymbol{A}$ foi considerado axial, onde $A_{x x}=A_{y y}=A_{\perp}$, e os valores $A_{\perp}$ e $A_{z z}$ variaram dentro de um intervalo razoável (Earle et al., 1994). Não foi usado os valores de $A_{z z}$ obtidos de amostras congeladas, porque temos indicações que o desdobramento hiperfino obtido nessas condições não é idêntico àqueles obtidos em altas temperaturas. Os parâmetros do alargamento não homogêneo gaussiano usados nas simulações foram gibo $=0,82 ;$ gib2 $=0,16$. Os tempos de correlação rotacional $\left(\tau_{\perp}\right.$ e $\left.\tau_{/ /}\right)$foram calculados baseados nos melhores resultados obtidos dos valores principais do tensor de difusão rotacional axialmente simétrico $\left(R_{\perp}\right.$ e $R_{/ /} ; \tau=1 / 6 R$; os valores de $\tau_{/ /}$obtidos foram bastante pequenos, quase fora da sensibilidade do ajuste, e por isso não serão indicados na Tabela 4.1.1). Para o tensor de difusão, o eixo de simetria é o eixo do segmento da cadeia, $z^{\prime}$ (o referencial molecular, ver Schneider e Freed, 1989). O ângulo entre o eixo molecular $z^{\prime}$ e o eixo magnético $z^{\prime \prime \prime}$ (por convenção, definido paralelo ao orbital $2 \mathrm{p}_{z}$ do átomo de $\mathrm{N}$ ), o ângulo de difusão $\beta$ foi variado, sem no entanto melhorar a simulação, e portanto $\beta$ foi mantido nulo (ver discussões em Ge e Freed, 1993; 1999). A orientação microscópica do marcador de spin é caracterizada pelo parâmetro $S_{20}$, relacionada à amplitude de movimento rotacional. Isto é, a medida da extensão do 
alinhamento do eixo molecular $z^{\prime}$ com relação ao eixo diretor local $z^{\prime \prime}$, definido como sendo normal a bicamada (Schneider e Freed, 1989; Ge e Freed, 1999). Como não existe uma indicação clara do espectro ser composto por duas populações distintas, nós optamos usar o ajuste de um único sinal (um sítio), mesmo que esses ajustes não reproduzam perfeitamente os espectros experimentais.

Para os experimentos em que foram analisadas as três bandas simultaneamente, o mesmo conjunto de parâmetros escolhidos para um sítio simulou razoavelmente bem os espectros obtidos nas diferentes freqüências (ver Tabela 4.2.1). As componentes do tensor $\boldsymbol{g}$ permaneceram com os mesmos valores que os anteriormente citados. O tensor desdobramento hiperfino $\boldsymbol{A}$ também foi considerado axial. O alargamento não homogêneo gaussiano ( $g i b O$ e gib2) teve seu valor modificado, nas diferentes bandas usadas, devido à dependência deste parâmetro com o potencial diretor (Budil et al., 1996). Os valores dos tempos de correlação rotacional perpendicular e paralelo ( $\tau_{\perp}$ e $\left.\tau_{\lambda}\right)$ foram escolhidos pela observação do espectro obtido na banda-X. Os ângulos de difusão $(\alpha, \beta$ e $\gamma$ ) foram mantidos nulos (ver discussão do parágrafo anterior). Os coeficientes do potencial diretor $\left(c_{20}\right.$ e $\left.c_{22}\right)$ foram escolhidos negativos por melhor simularem os espectros. Toda essa teoria de alargamento de linha de espectros de RPE com movimento lento (do qual este programa de simulação é baseado) é apresentada no Anexo I.

Titulação do $\mathrm{pH}$ em moléculas. A equação de Henderson-Hasselbalch descreve muito bem a titulação do pH de sítios individuais. Entretanto, para uma molécula com vários sítios tituláveis interagindo entre si, a curva de protonação total pode ser bastante complexa. Neste caso, essa curva pode ser descrita por uma soma ponderada das curvas de Henderson-Hasselbalch correspondente a cada um dos sítios individuais não interagentes. A probabilidade de protonação $<x>$ de um sítio isolado é dada por:

$$
<x>=\frac{10^{p K-p H}}{1+10^{p K-p H}}
$$

A equação acima é algebricamente equivalente à equação de Henderson-Hasselbalch e descreve uma curva sigmoidal. Nessa equação, entretanto, essa probabilidade de protonação foi normalizada para 1. A probabilidade de protonação total média é a soma ponderada das curvas de Henderson-Hasselbalch individuais dos $N$ sítios tituláveis interagentes presentes na molécula. 


$$
<X>=\sum_{i}^{N} a_{i} \frac{10^{p K_{i}-p H}}{1+10^{p K_{i}-p H}}
$$

onde $a_{i}$ é a contribuição de cada curva de Henderson-Hasselbalch individual. 


\section{Resultados e discussões}

Os resultados obtidos serão apresentados da seguinte maneira: na seção 4.1, o efeito da polaridade na fluidez de bicamadas lipídicas aniônicas promovido pelo $\alpha$ MSH é discutido, e comparado com o colesterol e íns de $\mathrm{Na}^{+}$. A seguir, na seção 4.2, são discutidas as propriedades estruturais do complexo $\alpha-\mathrm{MSH} / \mathrm{DMPG}$, na região de transição de fase, monitoradas pelo marcador de spin 16-PCSL. Na seção 4.3, é feito um estudo dos análogos cíclicos, derivados dos peptídeos melanotrópicos, em solução aquosa e em presença de vesículas de DMPG. Na última seção é discutido as modificações estruturais que o Toac (Fig. 4.4.1) causa nos peptídeos melanotrópicos.

\subsection{Correlação entre alteração da fluidez e presença de água no interior de bicamadas lipidicas: um estudo com $\alpha$-MSH}

Sabe-se que a água pode atravessar membranas biológicas e, particularmente, bicamadas fosfolipídicas (Lawaczeck, 1979, e referências lá citadas). Entretanto, a porção de água e a extensão de sua presença ao longo da bicamada lipídica ainda gera controvérsias. Enquanto difração de nêutrons e raios-X, e ressonância magnética nuclear de prótons indicam que praticamente não existe água a partir do grupo carbonil em direção ao interior da bicamada fosfolipídica, (Winner e White, 1992; Volke e Pampel, 1995; Zhou et al., 1999), sondas fluorescentes e paramagnéticas, incorporadas em membranas, podem detectar moléculas de água no interior da bicamada (Griffith et al., 1974; Fretten et al., 1980; Harris et al., 1983; Subczynski et al., 1994; Ho et al., 1995; Ge e Freed, 1998). Essas técnicas espectroscópicas indicam que a barreira hidrofóbica da membrana depende da presença de duplas ligações e moléculas hidrofóbicas, como o colesterol e carotenóides. $\mathrm{O}$ aumento da hidrofobicidade da membrana foi relacionada à redução da permeação de pequenas moléculas polares, sugerindo ser relevante para aspectos funcionais de membranas biológicas.

Considerando que o peptídeo é um grande cátion, e que seu efeito sobre a polaridade da membrana poderia ser principalmente relacionado à presença de íns na superficie da membrana, as alterações causadas pelo $\alpha$-MSH sobre os perfis de polaridade e fluidez de bicamadas de DMPG são comparadas com aquelas causadas pelo cátion $\mathrm{Na}^{+}$. Colesterol também é usado aqui como referência de molécula hidrofóbica que penetra completamente no interior da bicamada. 
Foi mostrado que a magnitude do desdobramento hiperfino isotrópico do nitrogênio ( $a_{0}$; um terço do traço do tensor hiperfino) depende de muitos fatores que aumentam a densidade de spin eletrônico desemparelhado no nitrogênio, como a polaridade do solvente, a presença de campos elétricos, ou complexos de transferência de elétrons (Griffith et al., 1974; Schwartz et al., 1997). Para marcadores dentro de bicamadas lipídicas, existem fortes indicações que o aumento em $a_{0}$ está principalmente relacionada às pontes de hidrogênio da água-nitróxido (Griffith et al., 1974). Dessa maneira, a extensão da presença de água dentro da bicamada pode ser estimada pela magnitude do desdobramento hiperfino isotrópico do nitrogênio (ver Materiais e métodos).

Alternativamente, a análise de espectros de RPE de marcadores de spins em diferentes solventes mostrou que existe uma correlação linear entre o valor de $a_{0}$ e a componente $z$ do tensor hiperfino $\left(A_{z z}\right)$, que pode ser diretamente medida em amostras congeladas (Griffith et al., 1974). Baseado nas medidas de $A_{z z}$, foi mostrado que ambos, o colesterol e os carotenóides polares, que penetram completamente na membrana lipídica, causam um aumento na polaridade da bicamada em regiões próximas à superficie da membrana, e dramaticamente aumentam a barreira hidrofóbica no centro da bicamada de membranas lipídicas saturadas (Subczynski et al., 1994; Wisniewska e Subczynski, 1998). Entretanto, para o $\alpha$-MSH interagindo com vesículas de DMPG, é mostrado aqui que não existe uma correlação linear entre $a_{0}$ e a componente $z$ do tensor hiperfino $\left(A_{z z}\right)$.

\subsubsection{Marcadores de spin em bicamadas de DMPG puro: desdobramento hiperfino isotrópico $a_{0}$}

A Figura 4.1.1 mostra os sinais de RPE de marcadores fosfolipídicos (PCSL), incorporados em vesículas de DMPG a $35 \circ \mathrm{C}$, acima da temperatura de transição gelcristal-liquido da membrana (entre 18 e 35 oC, Riske et al., 2001). O radical nitróxido do marcador de spin está ligado em cinco posições diferentes, a saber, no $5^{\circ}, 10^{\circ}, 12^{\circ}$, $14^{\circ}$ e $16^{\circ}$ átomo de carbono da cadeia acila. Seus diferentes espectros mostram o gradiente de flexibilidade em direção ao centro da membrana (Hubbel e McConnell, 1971): a taxa e amplitude de movimento aumentam na seguinte ordem, 5-PCSL < 10PCSL $<12$-PCSL $<14-P C S L<16-$ PCSL $^{3}$. O desdobramento hiperfino isotrópico $a_{0}$ do nitrogênio pode ser bem determinado em espectros típicos de sondas com bastante

\footnotetext{
${ }^{3}$ Embora o DMPG possua catorze carbonos na cadeia acila, o espectro do 16-PCSL é típico de um marcador mais móvel que o 14-PCSL, mostrando uma maior mobilidade no final da cadeia.
} 
ordem e/ou movimento rápido, onde os valores de $A_{\max }$ e $A_{\min }$ podem ser precisamente medidos (ver seção 2.3.3) tal como o 5-PCSL a altas temperaturas (Fig. 4.1.1a). Para espectros de RPE relativamente isotrópicos, na região do motional narrowing, como aquele obtido com o 16-PCSL, $a_{0}$ pode ser diretamente medido como indicado na Figura 4.1.1e, ou também pode ser obtido pelo ajuste das três linhas hiperfinas pela função de Voigt, (ver seção 3.2). A dificuldade em obter valores confiáveis de $a_{0}$ de sinais obtidos pelos marcadores 10 e 12-PCSL (Fig. 4.1.1b e 4.1.1c) é evidente, quer seja pelas medidas de $A_{\max }$ e $A_{\min }$ que são bastante inexatas, ou pela medida direta de $a_{0}$ por apresentar um sinal fora da região de motional narrowing. Embora o sinal do 14-PCSL seja típico de movimento rápido, o valor de $a_{0}$ apresentou variação com a temperatura, o que não é esperado para o parâmetro hiperfino isotrópico 4 .

Além disso, a presença do $\alpha$-MSH e do colesterol diminuem a mobilidade do lipídeo, fazendo com que a medida de $a_{0}$ obtida pelo 14-PCSL seja menos confiável. Assim, na fase fluida do DMPG, a polaridade foi monitorada somente nas regiões do $5^{\circ}$ e $16^{\circ}$ carbono da cadeia lipídica. É importante notar que não é possível medir $a_{0}$ a baixas temperaturas, com o lipídeo na fase gel.

\footnotetext{
${ }^{4}$ Espera-se que os valores de $\mathrm{a}_{\mathrm{o}}$ sejam pouco dependentes da temperatura. Medidas do desdobramento hiperfino isotrópico, do marcador de spin derivado do ácido esteárico (SASL), foram feitas em meio aquoso (dados não mostrados). Os valores de $\mathrm{a}_{\mathrm{o}}$ puderam ser bem determinados com um desvio menor que $0,3 \%$ entre 20 e $50{ }^{\circ} \mathrm{C}$. Entretanto, dentro da bicamada lipídica, o mesmo pode não ocorrer.
} 


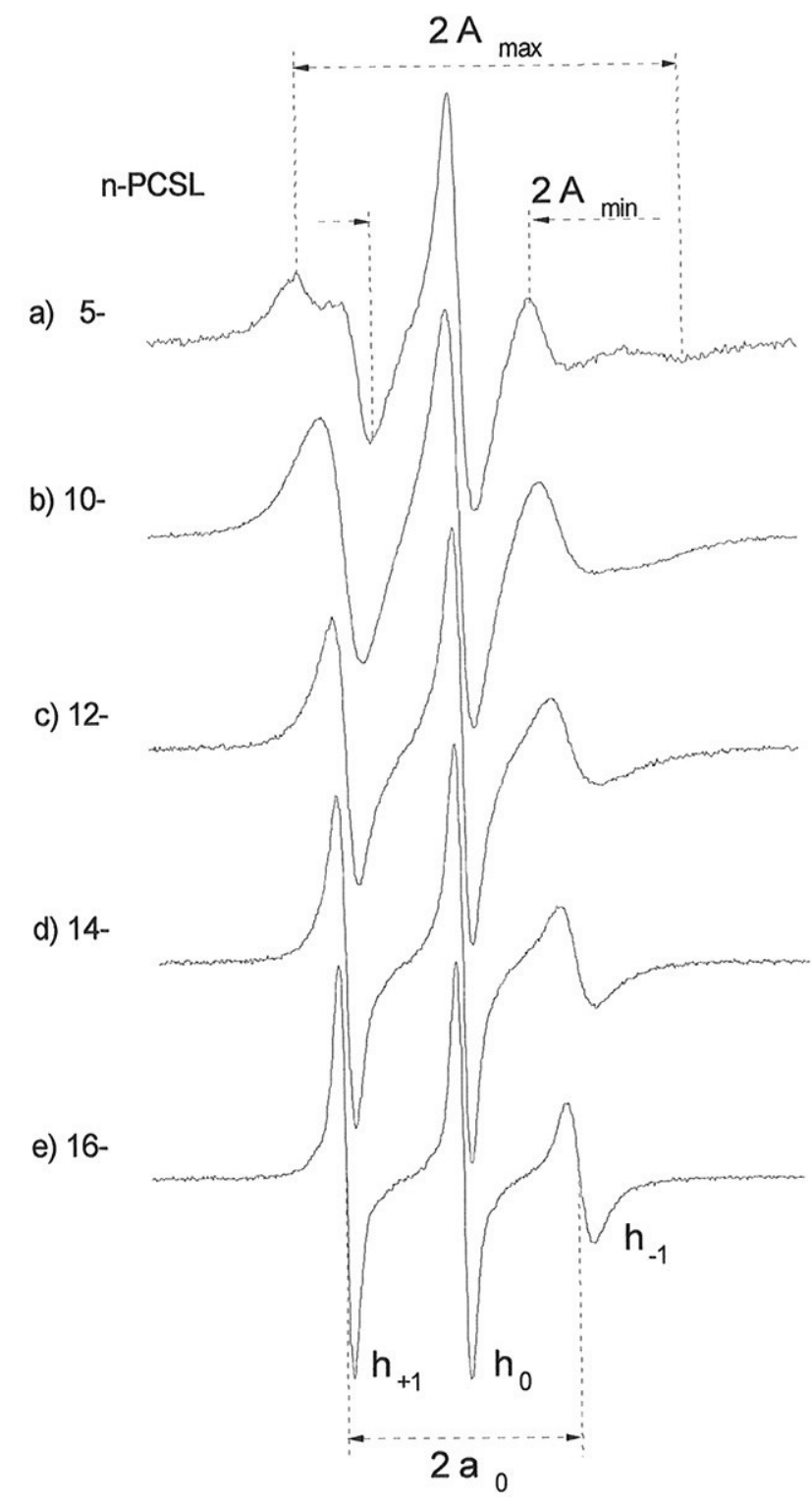

Figura 4.1.1 - Espectro de RPE em banda X (9 GHz) do n-PCSL em dispersões de $10 \mathrm{mM}$ de DMPG a $35{ }^{\circ} \mathrm{C}$. Largura total do espectro $100 \mathrm{G}$. Os desdobramentos hiperfinos externo e interno $\left(A_{\max }\right.$ e $A_{\min }$ ), o desdobramento hiperfino isotrópico $\left(a_{0}\right)$ e as amplitudes das três linhas hiperfinas do nitrogênio $\left(h_{+1}, h_{0}\right.$ e $h_{1}$ correspondendo a $M_{I}=+1,0,-1$, respectivamente) estão indicados.

\subsubsection{Mudanças nos valores de $a_{0}$ devido à presença do $\alpha$-MSH: uma comparação com $\mathrm{Na}^{+}$e colesterol}

Em geral os marcadores fosfolipídicos são os mais usados em membranas, por apresentarem um grupo polar que permanece bem ancorado na superficie da 
bicamada. Entretanto, resultados obtidos com o SASL também serão apresentados por serem amplamente usados na literatura para medir a barreira hidrofóbica dos lipídeos (Subczynski et al., 1994; Wisniewska e Subczynski, 1998). Além do mais, pode ser interessante saber se a cabeça polar do marcador tem alguma influência sobre a monitoração da estrutura da bicamada e polaridade. Como discutido antes (Biaggi et al., 1997), o ácido esteárico está em sua maioria neutro (protonado) em dispersões de DMPG, pH 7,4, com baixa força iônica, e na fase cristal-líquido do lipídeo penetra mais profundamente na bicamada que o PCSL.

A Figura 4.1.2 mostra os valores de $a_{0}$ medidos nos espectros do 5-PCSL (a) e 5SASL (b), em diferentes temperaturas acima da $\mathrm{T}_{\mathrm{m}}{ }^{\text {ff }}$ do DMPG, na presença de $1 \mathrm{mM}$ de $\alpha$-MSH (10 mol \% relativo à concentração do DMPG), $100 \mathrm{mM}$ de $\mathrm{NaCl}$ e $3 \mathrm{mM}$ de colesterol (30 mol \% relativo ao DMPG, completamente incorporado na vesícula lipídica). Para comparação, os efeitos causados sobre a fluidez da membrana de DMPG, na posição do $5^{\circ}$ carbono, também são mostrados (Fig. 4.1.2c e 4.1.2d). O parâmetro de ordem efetivo, $S_{\text {eff, }}$ (ver seção 2.3.3) contém contribuições de ordem e mobilidade, embora a contribuição principal para o $S_{\text {eff }}$ seja a amplitude de movimento do segmento da cadeia acila (Schindler e Seelig, 1973). Os efeitos obtidos pelo $\alpha$-MSH, $\mathrm{NaCl}$ e colesterol, sobre a polaridade $\left(a_{0}\right)$ e fluidez $\left(h_{-1} / h_{0}\right)$ da membrana de DMPG, no centro da bicamada, são mostrados na Figura 4.1.3, baseado nos espectros obtidos com o 16-PCSL e 16-SASL. O parâmetro $h_{1} / h_{0}$ é a razão entre as amplitudes das linhas correspondendo aos números quânticos nucleares do nitrogênio $M_{I}=-1$ e $M_{I}=O$ (ver Fig. 4.1). A razão $h_{1} / h_{0}$, em geral, aproxima-se da unidade quando a viscosidade monitorada pelo marcador diminui ${ }^{5}$. Como mostrado antes, ambos $\alpha$-MSH (Biaggi et al. 1996; 1997) e colesterol (Schreier-Muccilo et al., 1973) aumentam o empacotamento da membrana na fase líquido cristalina, tanto próximo à superficie (o $S_{\text {eff }}$ do marcador no $5^{\circ}$ carbono aumenta, Fig. 4.1.2c e 4.1.2d) quanto no centro da bicamada (a razão $h_{-1} / h_{0}$ do marcador no 160 diminui, Fig. 4.1.3c e 4.1.3d), enquanto o $\mathrm{NaCl}$ praticamente não causa nenhum efeito sobre a fluidez da membrana.

\footnotetext{
${ }^{5}$ Tempos de correlação rotacional (Marsh, 1989) não foram calculados porque os espectros obtidos na presença de colesterol e $\alpha$-MSH não puderam ser perfeitamente ajustados pela função de Voigt (Bales, 1989).
} 


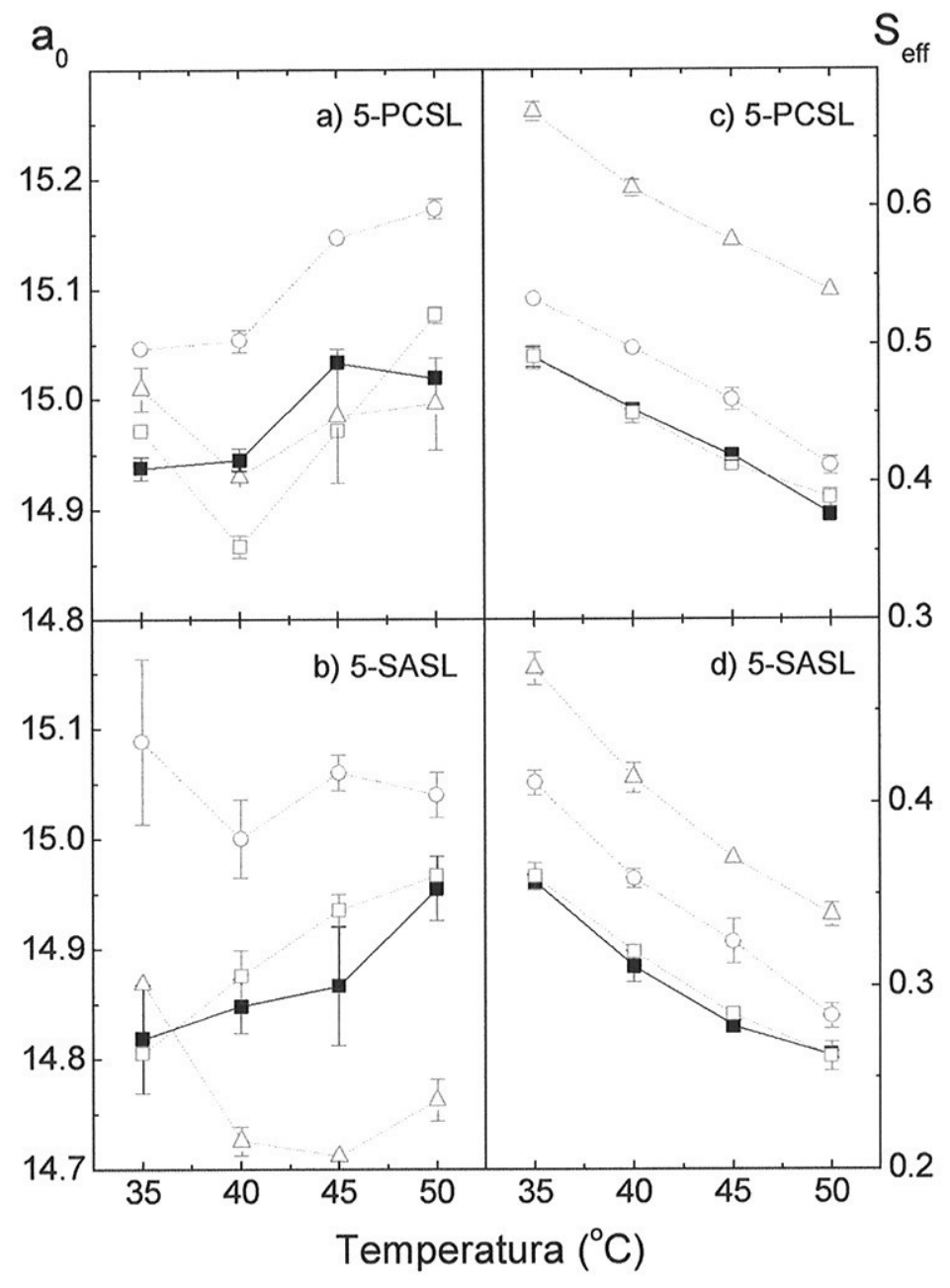

Figura 4.1.2 - Dependência do desdobramento hiperfino isotrópico $\left(a_{0}\right)$ (a e b) e parâmetro de ordem efetivo ( $S_{\text {eff }}$ (c e d) com a temperatura, medidos no espectro de RPE de anfifilicos (PCSL e SASL) marcados no $5^{\circ}$ átomo de carbono da cadeia acila, em dispersões de $10 \mathrm{mM}$ de DMPG puro ( $\square$, linha sólida), e com a adição de $10 \mathrm{~mol} \%$ de $\alpha-\mathrm{MSH}(O$, linha tracejada), $30 \mathrm{~mol} \%$ de colesterol ( $\Delta$, linha tracejada) e $100 \mathrm{mM}$ de $\mathrm{NaCl}(\square$, linha tracejada). As linhas que conectam os simbolos servem somente para auxílio visual. 


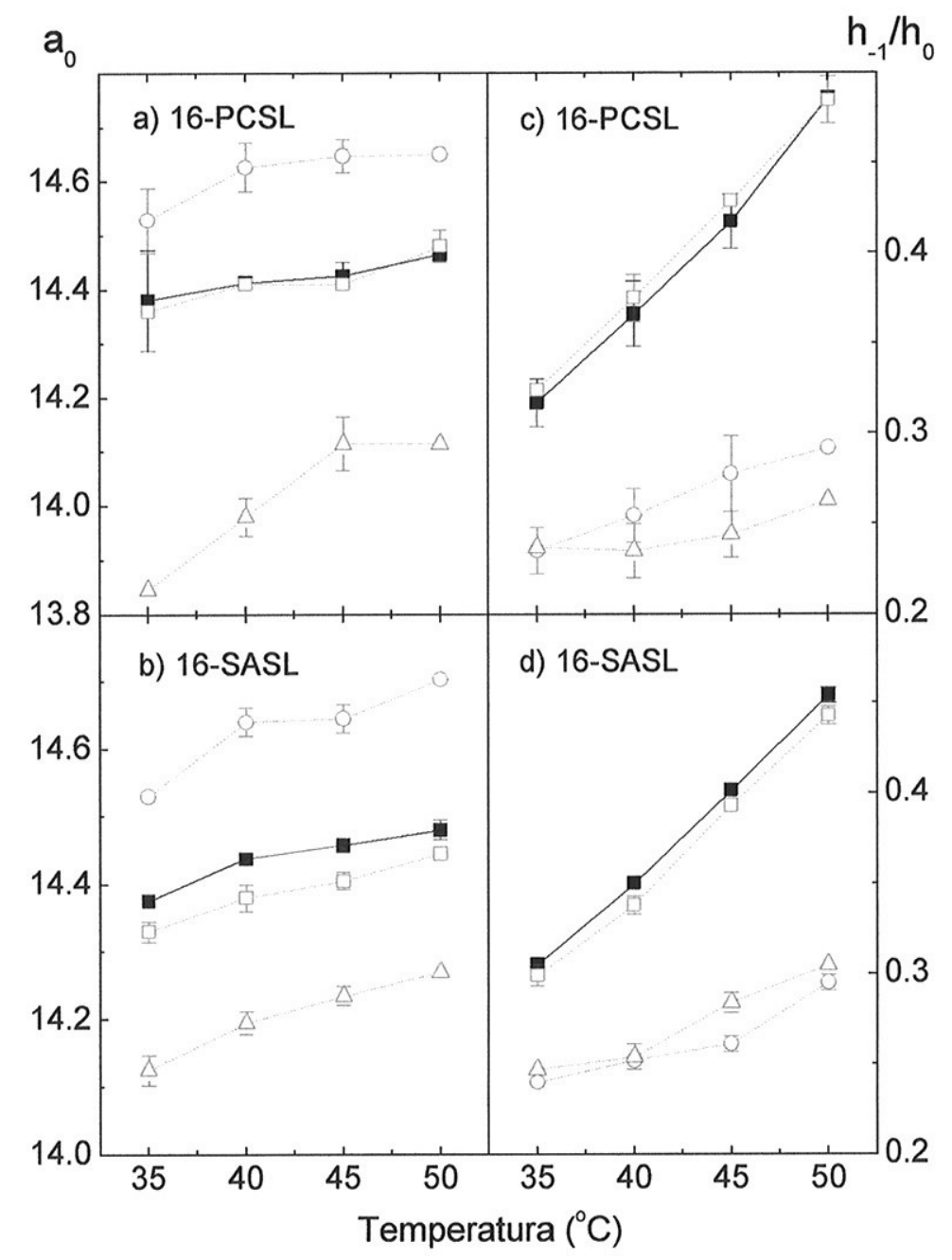

Figura 4.1.3 - Dependência do desdobramento hiperfino isotrópico $\left(a_{0}\right)$ (a e b) e da razão entre as amplitudes das linhas de campo alto e central $\left(h_{1} / h_{0}\right)$ (c e d) com a temperatura, medidos no espectro de RPE de anfifilicos (PCSL e SASL) marcados no $16^{\circ}$ átomo de carbono da cadeia acila, em dispersões de $10 \mathrm{mM}$ de DMPG puro ( $\square$, linha sólida), e com a adição de $10 \mathrm{~mol} \%$ de $\alpha$-MSH (O, linha tracejada), $30 \mathrm{~mol} \%$ de colesterol $(\Delta$, linha tracejada) e $100 \mathrm{mM}$ de $\mathrm{NaCl}(\square$, linha tracejada). As linhas que conectam os símbolos servem somente para auxílio visual.

Em dispersões de DMPG puro, o perfil de polaridade é evidente, se compararmos os dados mostrados na Fig. 4.1.2a ou 4.1.2b (回) com aqueles na Fig. 4.1.3a ou 4.1.3b (घ): os anfifilicos marcados no $5^{\circ}$ carbono mostram um desdobramento hiperfino isotrópico (em torno de 14,9 G) maior que aqueles marcados no $16^{\circ}$ carbono (aproximadamente 14,4 G). (O desdobramento hiperfino isotrópico dos marcadores solúveis em água 5-, 12- e 16-SASL, em meio aquoso, é 15,78 \pm 0,01 G). Como mencionado antes, os espectros de RPE marcados no $5^{\circ}$ carbono indicam que os marcadores fosfolipídicos estão localizados numa posição mais próxima à superficie, 
na fase líquido cristalina do DMPG, que os derivados do ácido esteárico. Isto pode ser visto pelos maiores valores de $S_{\text {eff }}$ obtidos pelo 5-PCSL ( $\square$ na Fig. 4.1.2c) quando comparado com o 5-SASL ( $\square$ na Fig. 4.1.2d). Da mesma maneira, os valores de $a_{0}$ obtidos pelo 5-PCSL são um pouco maiores que o 5-SASL (ver $\square$ na Fig. 4.1.2a e 4.1.2b). Possivelmente devido a uma maior flutuação vertical do final da cadeia acila (Feix et al., 1984; Ellena et al., 1988), os parâmetros do 16-PCSL e 16-SASL ( $a_{0}$ na Fig. 4.1.3a e 4.1.3b; $h_{-1} / h_{0}$ na Fig. 4.1.3c e 4.1.3d) indicam que ambos os marcadores, em média, monitoram a mesma região em bicamadas de DMPG na fase fluida.

Como esperado, os dois parâmetros, $S_{\text {eff }}$ e $h_{-1} / h_{o}$, que monitoram a fluidez lipídica próximo à superficie da bicamada e no centro, respectivamente, mostram uma considerável dependência com a temperatura (Fig. 4.1.2c e 4.1.2d; Fig. 4.1.3c e 4.1.3d). É interessante notar que os valores de $a_{0}$ praticamente não variam com a temperatura, embora haja um pequeno desvio devido à dificuldade de eliminação completa das contribuições de ordem e mobilidade nas medidas hiperfinas na fase liquido cristalina da membrana (os valores médios mostrados na Tabela 4.1.1 foram calculados entre $40-50 \circ \mathrm{C}$ ). Mesmo assim, algumas conclusões relativas ao perfil de polaridade da bicamada são apresentadas. Considerando que o aumento de a está relacionado a um aumento na polaridade local, é evidente que o peptídeo catiônico, que interage na superficie da membrana, parcialmente penetrando na bicamada (Macêdo et al., 1996; Biaggi et al., 1997), aumenta a polaridade da membrana nas micro-regiões monitoradas pelos marcadores 5- e 16-PCSL, e 5- e 16-SASL. O efeito de blindagem eletrostática na superficie da vesícula, gerado pelo íon monovalente de $\mathrm{Na}^{+}$, parece não alterar significativamente nem o perfil de polaridade $\left(a_{0}\right)$ nem o perfil de fluidez $\left(h_{1} / h_{0}, S_{e f f}\right)$ do DMPG, enquanto que o colesterol causa uma considerável diminuição na polaridade da membrana no centro da bicamada (no 16-PCSL e 16SASL) e também na posição onde o 5-SASL está localizado. Em regiões próximas à superficie, monitoradas pelo 5-PCSL, o colesterol parece não alterar o grau de hidrofobicidade.

É interessante notar que, embora o $\alpha$-MSH e colesterol aumentem o empacotamento da membrana, suas diferentes formas de interagir com a bicamada de DMPG são refletidas nas alterações distintas que as duas moléculas causam na polaridade da bicamada. Os diferentes comportamentos da bicamada de DMPG na presença do $\alpha$-MSH e colesterol são melhores evidenciados pelos parâmetros obtidos com as simulações teóricas (Tabela 4.1.1) do espectro de RPE do 5-PCSL e 12-PCSL incorporados nas bicamadas (Fig. 4.1.4). (A simulação do 16-PCSL, altamente isotrópico, foi obtida com diferentes conjuntos de parâmetros que igualmente se 
ajustavam ao sinal experimental, não sendo possivel obter uma melhor informação). Embora as simulações teóricas dos sinais na Fig. 4.1.4 não reproduzam com detalhes os espectros, algumas tendências são evidentes.

Tabela 4.1.1 - Parâmetros obtidos do ajuste dos mínimos quadrados não linear ${ }^{1}$ dos espectros de RPE do 5- e 12-PCSL em dispersões de DMPG a $45^{\circ} \mathrm{C}$, na ausência e presença do $\alpha-\mathrm{MSH}^{2} \mathrm{e}$ colesterol $^{3}$. Os espectros teóricos e experimentais são mostrados na Fig. 4.1.4.

\begin{tabular}{|c|c|c|c|c|c|c|c|}
\hline & $\begin{array}{l}A_{\perp} \\
(G)\end{array}$ & $\begin{array}{l}A_{z z} \\
(G)\end{array}$ & $\begin{array}{l}a_{0}{ }^{4} \\
(G)\end{array}$ & $\begin{array}{c}\tau_{\perp} \\
\text { (ns) }\end{array}$ & $\mathrm{S}_{20}$ & $\begin{array}{c}a_{0}^{5} \\
(\exp .)(G)\end{array}$ & $\begin{array}{l}\text { Seff } 6 \\
\text { (exp.) }\end{array}$ \\
\hline \multicolumn{8}{|l|}{ 5-PCSL } \\
\hline DMPG & 5,12 & 34,85 & 15,03 & 1,05 & 0,32 & $15,00 \pm 0,05$ & 0,42 \\
\hline$+\alpha-\mathrm{MSH}^{2}$ & 5,12 & 35,40 & 15,21 & 1,48 & 0,35 & $15,12 \pm 0,06$ & 0,46 \\
\hline+ Chol. $^{3}$ & 5,12 & 34,85 & 15,03 & 1,63 & 0,46 & $14,97 \pm 0,03$ & 0,57 \\
\hline \multicolumn{8}{|l|}{ 12-PCSL } \\
\hline DMPG & 5,10 & 33,36 & 14,52 & 1,05 & 0,06 & - & - \\
\hline$+\alpha-\mathrm{MSH}$ & 5,10 & 33,63 & 14,61 & 1,52 & 0,09 & - & - \\
\hline + Chol. & 5,10 & 32,15 & 14,12 & 2,15 & 0,14 & - & - \\
\hline
\end{tabular}

1Para discussão do programa de simulação usado, e parâmetros espectrais,ver seção 3.2.

2 Concentração total da amostra é de $10 \mathrm{~mol} \%$ relativo ao DMPG.

3 Concentração na bicamada é de $30 \mathrm{~mol} \%$ relativo ao DMPG.

$4 \mathrm{a}_{\mathrm{o}}=\left(2 \mathrm{~A}_{\perp}+\mathrm{A}_{\mathrm{zz}}\right) / 3$

5Valores médios de 40 - 50 ○C (Fig. 4.1.2a).

6Da Fig. 4.1.2c.

i) Nas simulações do 5-PCSL, os valores de $A_{z z}$ encontrados para as amostras de DMPG e DMPG + colesterol foram bastante similares, e menores que o DMPG + $\alpha$ MSH. Isto está de acordo com o maior valor de $a_{0}$ obtido experimentalmente para a última amostra (Fig. 4.1.2a). (Os valores experimental e teórico são mostrados na Tabela 4.1.1). ii) Na posição do $5^{\circ}$ carbono, o colesterol claramente aumenta a ordem da bicamada $\left(S_{20}\right)$ e o tempo de correlação rotacional $\left(\tau_{\perp}\right)$, assim como o $\alpha-\mathrm{MSH}$, porém com valores menores que o colesterol. (Os parâmetros de ordem experimentais $S_{\text {eff }}$, mostrados na Fig 4.1.2c, também são apresentados na Tabela 4.1.1. Como esperado, eles são maiores que os valores teóricos de $S_{20}$, porque em $S_{\text {eff }}$ está incorporado ordem e mobilidade). iii) A simulação do 12-PCSL permite-nos concluir que existe um aumento (diminuição) no desdobramento hiperfino $A_{z z}$ na presença do $\alpha-M S H$ (colesterol). Este resultado concorda com o aumento (diminuição) de $a_{0}$ monitorado pelo 16-PCSL e 16-SASL (Fig. 4.1.3a e 4.1.3b), indicando que o $\alpha$-MSH (colesterol) está diminuindo (aumentando) a hidrofobicidade no centro da lamela. iv) Embora o 
colesterol cause um aumento muito maior em $S_{20}$ e $\tau_{\perp}$ que o $\alpha$-MSH, na região monitorada pelo 12-PCSL, as duas moléculas aumentam a ordem da bicamada e diminuem a taxa de movimento.

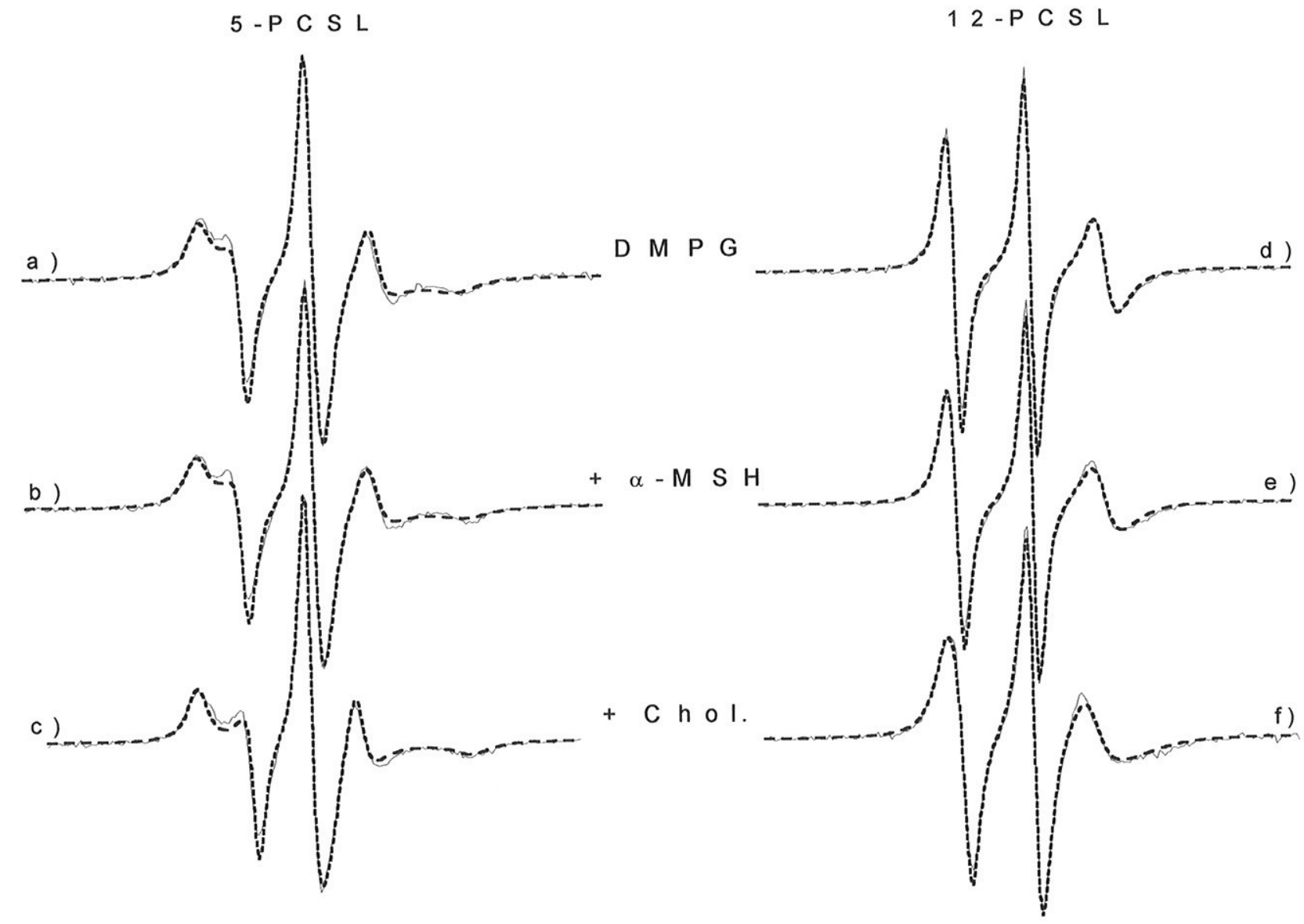

Figura 4.1.4 - Espectro de RPE do 5- PCSL (a, b e c) e 12-PCSL (d, e e f) incorporados em vesículas de DMPG na fase fluida $\left(45^{\circ} \mathrm{C}\right.$ ), na ausência (a e d) e presença de $10 \mathrm{~mol} \%$ de $\alpha$ MSH (b e e) e $30 \mathrm{~mol} \%$ de colesterol (c e f). As simulações dos espectros (ver texto) são mostradas em linha tracejada. Os parâmetros espectrais resultantes do ajuste são dados na Tabela 4.1.1.

Supondo que o perfil de polaridade da bicamada é principalmente determinado pela extensão de penetração da água na membrana (Griffith et al., 1974), a diminuição na fluidez da membrana causada pelo peptídeo melanotrópico poderia ser parcialmente atribuída ao aumento da concentração de água na região das cadeias acilas. Isto estaria de acordo com sugestões anteriores de que os peptídeos induzem a penetração de água na região da cadeia hidrocarbônica (Jacobs e White, 1989). Os 
dados aqui apresentados indicam que o $\alpha$-MSH diminui a barreira hidrofóbica da bicamada lipídica de lipídeos de DMPG na fase fluida. Ainda mais, embora o peptídeo penetre na bicamada só até uma certa profundidade, ele parece estabilizar a presença de moléculas de água ao longo de toda a cadeia hidrocarbônica. Contrariamente, a penetração do colesterol dentro da bicamada, uma molécula altamente hidrofóbica, não altera significantemente a hidrofobicidade na região da bicamada monitorada pelo 5-PCSL, mas torna a membrana significantemente menos polar no centro da bicamada.

\subsubsection{Polaridade medida em amostras congeladas}

O perfil de polaridade de bicamadas lipídicas tem sido bastante discutido baseado na componente $z$ do desdobramento hiperfino $\left(A_{z z}\right)$, medido em amostras congeladas (Griffith et al., 1974; Ge e Freed, 1993; Subczynski et al., 1994; Wisniewska e Subczynski, 1998). A grande vantagem desse método é que o valor medido de $A_{\max }$ é o próprio valor de $A_{z z}$, completamente independente do movimento do marcador. A Figura 4.1.5a mostra os parâmetros hiperfinos diretamente medidos do espectro de RPE de amostras de DMPG congeladas $(-150 \circ \mathrm{C})$, obtidos com marcadores do tipo PCSL em seis diferentes posições da cadeia acila, no $5^{\circ}, 9^{\circ}, 10^{\circ}, 12^{\circ}, 14^{\circ}$ e $16^{\circ}$ átomo de carbono.

Os valores de $A_{z z}$ dos marcadores fosfolipídicos em vesículas congeladas de DMPG puro indicam um leve gradiente de polaridade em direção ao centro da bicamada: $2 A_{z z}$ varia de $(69,67 \pm 0,16) \mathrm{G}$ no 5 -PCSL para $(66,65 \pm 0,25) \mathrm{G}$ no $16-\mathrm{PCSL}$ (Fig. 4.5a) (o valor de $2 A_{z z}$ encontrado em fase aquosa foi de aproximadamente 72,5 G; Subczynski et al., 1994). Esses valores são similares aos obtidos com o SASL em DMPG (Fig. 4.1.5b) e em membranas de DMPC (Subczynski et al., 1994). É importante notar que as variações sobre o perfil de polaridade de amostras congeladas de DMPG, na presença de diferentes moléculas interagentes (Fig. 4.1.5a), não são idênticas às obtidas das medidas de $a_{0}$ (Figs. 4.1.2a e 4.1.3a), com o lipídeo na fase líquido cristalina. Por exemplo, nas regiões monitoradas pelo 5- e 16-PCSL, onde os valores de $a_{o}$ na fase fluida da membrana de DMPG puderam ser calculados, nenhuma alteração significativa foi monitorada pelo parâmetro $A_{z z}$ em amostras congeladas (Fig. 4.1.5a). Entretanto, o $\alpha$-MSH aumentou a polaridade da bicamada de amostras congeladas nas regiões monitoradas pelos marcadores 9-, 10-, 12- e 14-PCSL (Fig. 4.1.5a). 


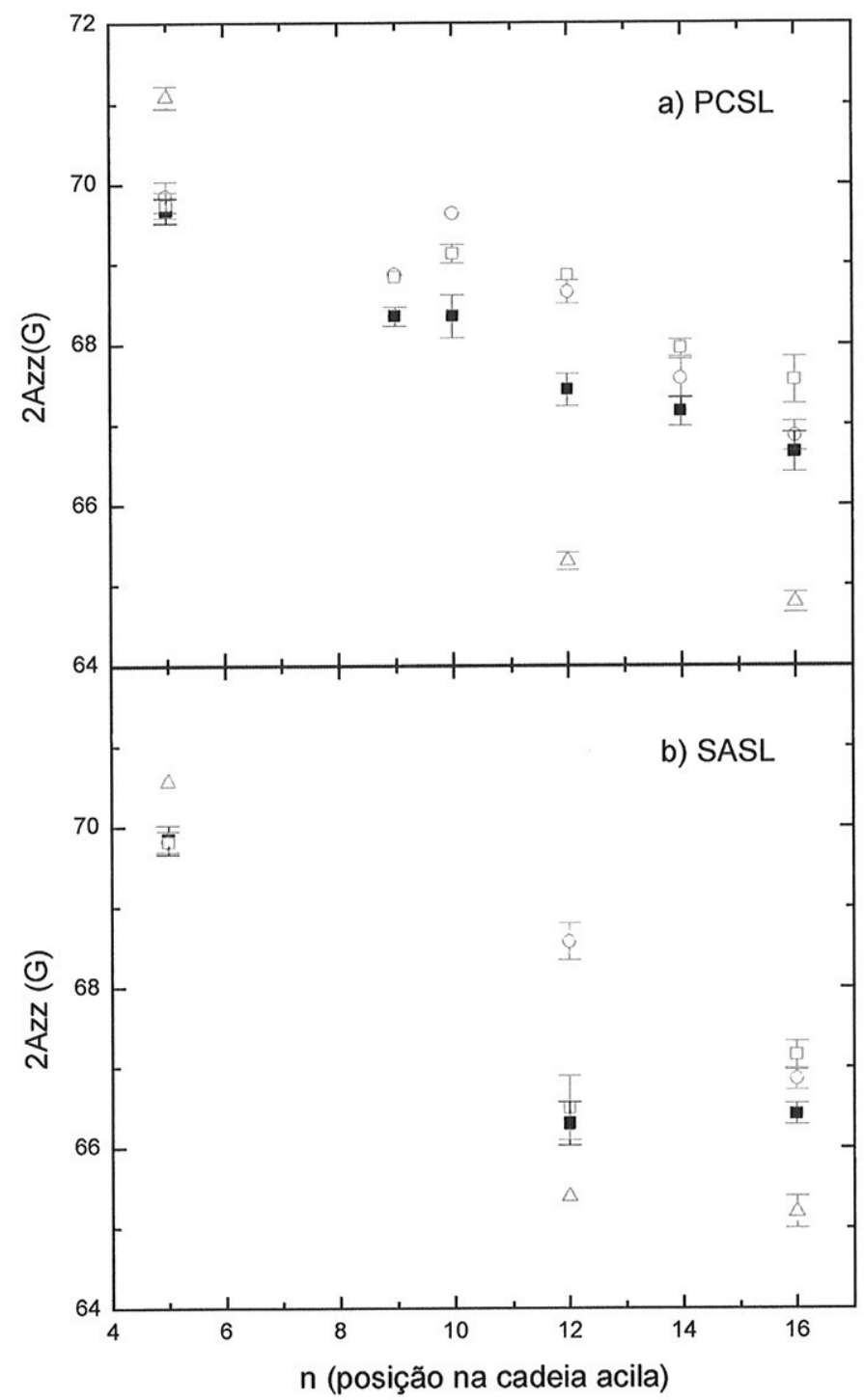

Figura 4.1.5 - Componente $z$ do desdobramento hiperfino $\left(A_{z z}\right)$, medida a $-150{ }^{\circ} \mathrm{C}$, como função da posição do nitróxido em anfifilicos (n-PCSL e n-SASL) em dispersões de $10 \mathrm{mM}$ de DMPG puro (घ), e com a adição de $10 \mathrm{~mol} \%$ de $\alpha$-MSH (O), $30 \mathrm{~mol} \%$ de colesterol $(\Delta)$ e $100 \mathrm{mM}$ de $\mathrm{NaCl}$ ( $\square$ ).

Os resultados obtidos com $\mathrm{NaCl}$ são ainda mais surpreendentes: $\mathrm{O}$ sal quase não tem efeito algum à temperatura ambiente (Figs. 4.1.2a e 4.1.3a), mas aumenta significantemente a polaridade da bicamada em amostras congeladas, monitorada pelos fosfolipídeos na região do 90 e $16^{\circ}$ átomos de carbono da cadeia. Todavia, mesmo que os efeitos gerados pelo $\alpha$-MSH e $\mathrm{Na}^{+}$não sejam idênticos nas diferentes posições da cadeia acila, ambos os cátions diminuem a barreira hidrofóbica da bicamada em membranas congeladas. Isto indica que a presença de íons na superficie da vesícula 
estabiliza as moléculas de água no interior da bicamada. É importante ter em mente que isto é específico para amostras congeladas, enquanto que na fase fluida da membrana de DMPG o efeito do $\mathrm{NaCl}$ sobre a polaridade parece não ser relevante (Figs. 4.1.2a e 4.1.3a).

O aumento nos valores de $A_{z z}$ dos marcadores de spin incorporados em amostras congeladas também foi observado na presença de gramicidina A (GA) (Ge e Freed, 1993). Considerando que a GA é um pentadecapeptídeo hidrofóbico, que penetra completamente na bicamada lipídica, foi sugerido que, em geral, as proteinas de membrana e peptídeos aumentam a penetração de água dentro da bicamada (Ge e Freed, 1993).

O efeito do colesterol no centro da bicamada de amostras congeladas é similar ao observado em temperatura ambiente, com o esteróide causando um grande aumento na hidrofobicidade da membrana (diminuição de $A_{z z}$ ). Entretanto, o aumento da polaridade da bicamada em regiões próximas de sua superficie (monitorada pelo 5PCSL) só é evidente em amostras congeladas. Um efeito similar também é observado com o marcador derivado do ácido esteárico (Fig. 4.1.5b), e foi bem documentado por Subczynski et al. (1994), com marcadores derivados do ácido esteárico em diferentes sistemas lipídicos saturados 6 .

A variação dos valores de $\mathrm{A}_{\mathrm{zz}}$ devido à presença do $\alpha-\mathrm{MSH}, \mathrm{Na}^{+}$e colesterol, monitorada pelos marcadores de spin derivados do ácido esteárico (Fig. 4.1.5b), não foi muito bem comprendida. Embora os efeitos observados sobre o perfil de polaridade da bicamada de DMPG sejam qualitativamente similares aos obtidos com marcadores fosfolipídicos (Fig. 4.1.5a), eles são diferentes em magnitude. É importante notar que mesmo em bicamadas de DMPG puro, o comportamento dos dois tipos de marcadores, SASL e PCSL, não é idêntico: no $5^{\circ}$ e $16^{\circ}$ carbono os valores $A_{z z}$ são bastante similares, mas o valor de $A_{z z}$ obtido pelo 12-PCSL (Fig. 4.1.5a) é significantemente maior que o obtido pelo 12-SASL (Fig. 4.1.5b). Contrariamente aos marcadores fosfolipídicos, que são bem ancorados na superficie da membrana, os marcadores derivados do ácido esteárico podem apresentar deslocamentos verticais na transição de fase, ou em presença de moléculas interagentes (Turchiello et al., 2000). Mais ainda, a presença de moléculas carregadas na superficie da vesícula poderia aumentar o valor do $\mathrm{pH}$ local induzindo uma desprotonação do ácido esteárico, afetando assim sua posição vertical na bicamada (Ptak et al., 1980).

\footnotetext{
${ }^{6}$ É importante mencionar que a relação linear empírica obtida por Griffith et al. (1974), relacionando a constante hiperfina isotrópica com a componente $\mathrm{z}$ do tensor hiperfino, obtida com o marcador de spin em solução, $\left(\mathrm{a}_{\mathrm{o}}=0,0426 \mathrm{~A}_{\mathrm{zz}}+0,349\right.$, em Gauss), não se ajusta aos dados aqui apresentados, mesmo para marcadores de spin incorporados em membranas de DMPG puro.
} 


\subsubsection{Possiveis correlações entre as alterações na polaridade de bicamadas congeladas e mudanças na fluidez da membrana na fase gel}

É interessante comparar as alterações que o $\alpha$-MSH causa sobre o gradiente de polaridade do DMPG, medidas através dos valores de $A_{z z}$ em amostras congeladas, com as mudanças devido à interação peptídeo-lipídeo na fluidez de vesículas de DMPG no estado gel (mais empacotado). A razão para se fazer isto é que a membrana congelada está num estado mais próximo da fase gel, obtido a baixas temperaturas, do que a estrutura na fase líquido cristalina obtido a altas temperaturas7. Entretanto, é importante ter em mente que o processo de congelamento pode levar a outros arranjos estruturais do sistema peptídeo-lipídeo.

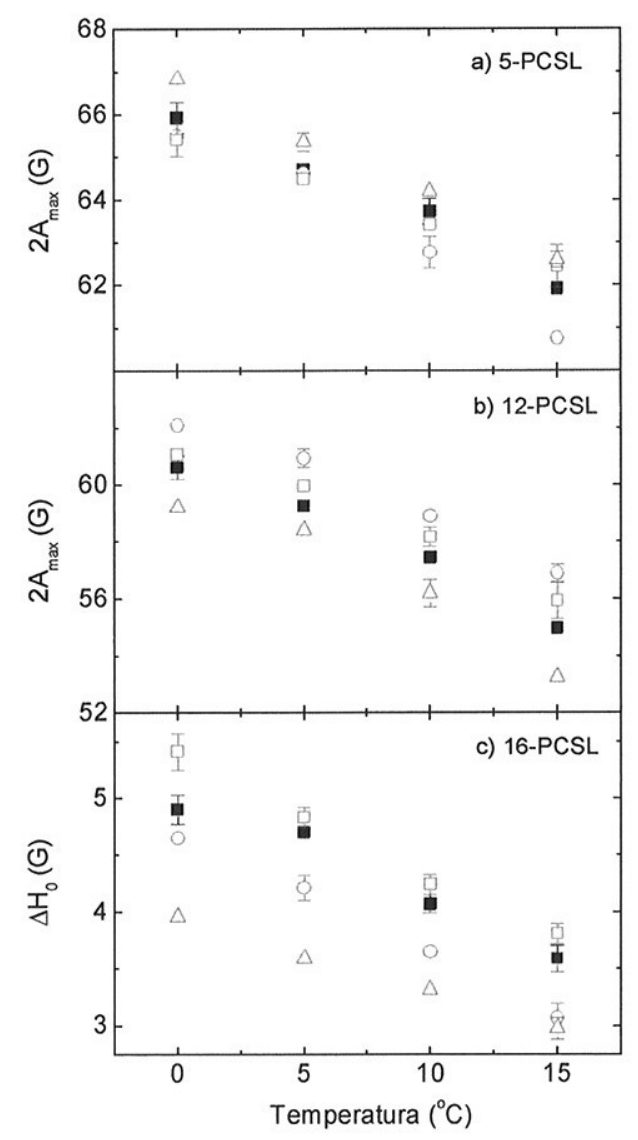

Figura 4.1.6 - Dependência do desdobramento hiperfino externo $\left(A_{\max }\right)$ (a e b) e da largura de linha do campo central $\left(\Delta H_{0}\right)$ (c) com a temperatura medidos nos espectros de RPE do n-PCSL em dispersões de $10 \mathrm{mM}$ de DMPG (曰, linha sólida), e com a adição de $10 \mathrm{~mol} \%$ de $\alpha$ - MSH (O), $30 \mathrm{~mol} \%$ de colesterol $(\Delta)$ e $100 \mathrm{mM}$ de $\mathrm{NaCl}$. ( $\square$ ).

\footnotetext{
${ }^{7}$ Amostras congeladas $\left(-150^{\circ} \mathrm{C}\right)$ geraram o mesmo sinal de RPE quando preparadas de diferentes maneiras: i) a amostra a temperatura ambiente é rapidamente introduzida na cavidade ressonante a $-150^{\circ} \mathrm{C}$; ii) a amostra é equilibrada a $5^{\circ} \mathrm{C}$ (fase gel) antes de ser resfriada a $-150{ }^{\circ} \mathrm{C}$. Este último, é consistente com a estrutura da bicamada congelada ser mais similar ao empacotamento na fase gel que no estado líquido cristalino.
} 
A Figura 4.1.6 mostra os valores de $A_{\max }$ obtidos com o 5- e 12-PCSL, e a largura de linha do campo central $\left(\Delta H_{0}\right)$ do 16-PCSL, (a medida de $A_{\max }$ é bastante questionável para marcadores altamente móveis), para temperaturas abaixo da transição gel - cristal-líquido. Os dois parâmetros espectrais, $A_{\max }$ e $\Delta H_{0}$, mostram uma forte dependência com a temperatura, indicando que eles estão monitorando principalmente o empacotamento da bicamada lipídica. Eles tornam-se menores quando a temperatura e a mobilidade do marcador aumenta, como uma indicação de um microambiente menos viscoso ${ }^{8}$. Embora não mostrados, os resultados obtidos com o 9- e 10-PCSL são bastante similares aos obtidos com o 12-PCSL, mostrando que o $\alpha$ MSH causa um significativo aumento no empacotamento da bicamada de DMPG na fase gel nas regiões monitoradas por aqueles três marcadores (aumento de $A_{\max }$ mostrado na Fig. 4.1.6b, ou na largura de linha, $\Delta H_{0} e \Delta H_{+1}$, relativo às linhas de campo central e baixo, não mostradas aqui). Contrariamente, é interessante notar que a interação peptídeo-lipídeo leva a uma pequena diminuição no empacotamento da bicamada na posição do $5^{\circ}$ carbono da cadeia ( $A_{\max }$ diminui, Fig. 4.1.6a) e nas regiões monitoradas pelo 16- e 14-PCSL (dados não mostrados) ( $\Delta H_{0}$ diminui, Fig. 4.1.6c; ou $h_{+1} / h_{0}$ aumenta, não mostrado). Assim, o efeito do peptídeo na fluidez da membrana de DMPG na fase gel é muito diferente do obtido na fase líquido cristalina. Embora a correlação entre as alterações no empacotamento na fase gel e a polaridade em amostras congeladas não seja direta, é interessante notar que o efeito rigidificante do peptídeo em certos microambientes na fase gel (na região do 90 ao $12^{\circ}$ carbono) está relacionado a um aumento de concentração de água nessas regiões em amostras congeladas.

Diferente dos resultados obtidos com o DMPG na fase fluida (Fig. 4.1.2c e 4.1.3c), na fase gel, os íons de sódio causam algum efeito na estrutura da membrana, embora não muito grande. Com excessão do 5-PCSL' , todos os outros marcadores (9-, 10-, 12-, 14- e 16-PCSL) indicam que a presença de $\mathrm{Na}^{+}$aumenta um pouco o empacotamento lipídico, monitorado por $A_{\max }$ ou pelas larguras de linha, medidas diretamente no espectro de RPE (a Fig. 4.1.6 mostra os resultados obtidos com o 5-, 12- e 16-PCSL). Esse resultado poderia ser interpretado como conseqüência da blindagem eletrostática do $\mathrm{Na}^{+}$na superficie da bicamada, levando a uma maior aproximação dos grupos polares do DMPG, e conseqüentemente aproximando as cadeias hidrocarbônicas. Entretanto, uma vez mais, a correlação dos resultados

\footnotetext{
${ }^{8}$ Foi mostrado por transferência de saturação de RPE que o parâmetro $A_{\max }$ em temperaturas baixas até $0{ }^{\circ} \mathrm{C}$, é mais sensível aos movimentos do marcador que às mudanças de polaridade (Johnson, 1981).

${ }_{9}$ As pequenas alterações observadas com o 5-PCSL podem ser devido à baixa sensibilidade de RPE convencional para movimentos lentos deste marcador.
} 
obtidos na fase gel com aqueles em amostras congeladas poderiam indicar que existe uma associação entre o efeito de empacotamento local e o aumento da presença de moléculas de água dentro da membrana.

$\mathrm{Na}$ fase liquido cristalina, a interação peptídeo-bicamada foi justificada considerando que o $\alpha$-MSH penetra parcialmente na bicamada lipídica, aumentando o empacotamento da membrana, e estabilizando a presença de um maior número de moléculas de água ao longo da cadeia hidrocarbônica. A interação do peptídeo com o lipídeo na fase gel parece ser mais complexa. O aumento no empacotamento da bicamada nas regiões monitoradas pelo 9- e 12-PCSL poderia ser um indicativo da presença do peptídeo catiônico na superfice aniônica de membranas de DMPG, diminuindo a repulsão eletrostática entre os grupos polares, e causando um aumento no empacotamento da membrana. Isto está de acordo com a redução da fluidez causada pela presença de íons de sódio. Entretanto, a presença de $\mathrm{Na}^{+}$, diferente do $\alpha-$ MSH, diminui a fluidez da bicamada em todas as profundidades, enquanto que o peptídeo aumenta a mobilidade/desorganização da cadeia no centro da membrana, monitorado pelo 14- e 16-PCSL. Considerando a possivel correlação entre os resultados da fase gel e de amostras congeladas, poder-se-ia especular que a presença do peptídeo na superfície da membrana estabiliza as moléculas de água só até uma certa profundidade da bicamada, tornando essa região mais empacotada e polar, porém com algum espaço entre as cadeias hidrocarbônicas quando comparadas com bicamadas lipídicas puras. Dessa maneira, próximo ao centro da bicamada, onde o número de moléculas de água não foi alterado pela presença do peptídeo, os segmentos de cadeia poderiam ter mais mobilidade e/ou menos ordem.

O efeito do colesterol em aumentar a fluidez da bicamada na fase gel, devido à perturbação que a molécula causa no empacotamento do lipídeo (Schreier-Muccilo et al., 1973), monitorado pelo 12- e 16-PCSL (Fig. 4.1.6b e 4.1.6c), pode estar relacionado a uma diminuição na polaridade no centro da bicamada congelada (ver os valores de $A_{z z}$ para o 12- e 16-PCSL na Fig. 4.1.5a, e também para o 12- e 16- SASL na Fig. 4.1.5b). Assim, a presença do colesterol, que é altamente hidrofóbico, dentro da membrana lipídica, tanto tornando mais rígido o estado fluido como diminuindo a organização na fase gel, promove um aumento considerável da hidrofobicidade no centro da bicamada. Entretanto, o aumento na polaridade (concentração de moléculas de água) observada em amostras congeladas de DMPG na presença do colesterol, próximo à superficie da bicamada (aumento do parâmetro $A_{z z}$ no 5-PCSL e 5-SASL, ver Fig. 4.1.5a e 4.1.5b, e Subczynski et al., 1994 para outros sistemas lipídicos), pode estar relacionado ao aumento no empacotamento observado com o 5-PCSL na fase gel 
do lipídeo (Fig. 4.1.6a). Parece possivel que, na fase gel, a incorporação do colesterol na membrana induza um efeito à parte nos grupos polares, permitindo a penetração de mais moléculas de água (monitoradas em amostras congeladas), causando um aumento na polaridade local e microviscosidade na região do $5^{\circ}$ carbono. 


\subsection{Propriedades térmicas e estruturais do complexo $\alpha$-MSH/DMPG}

(Trabalho em colaboração com a Dra. Karin A. Riske e o Prof. Dr. Otaciro R. Nascimento)

A seguir, será discutido a presença de uma região de transição de fase, denominada fase intermediária (Riske et al., 2001), em bicamadas lipídicas de DMPG, com baixa e alta concentração de sal. Concomitantemente, discutiremos uma característica particular monitorada pelo 16-PCSL em dispersões de DMPG em baixa força iônica nesta região de transição. Além disso, analisaremos o efeito do $\alpha$-MSH na estrutura das bicamadas lipídicas.

No DMPG, a região de temperatura entre o início da transição gel-fluido, transição principal, $\mathrm{T}_{\mathrm{m}}{ }^{\mathrm{n}}$, e o seu final, $\mathrm{T}_{\mathrm{m}}{ }^{\text {off, }}$ é caracterizada por baixa turbidez da amostra e alta viscosidade (Heimburg e Biltonen, 1994; Riske et al., 1997). Na fase gel a bicamada lipídica está altamente empacotada, quando comparada com a fase cristal-líquido, apresentando menor área superficial por cabeça polar de lipídeo, sendo que as cadeias acilas apresentam-se extremamente ordenadas e muito próximas umas das outras, favorecendo as interações atrativas de van der Waals. A espessura da bicamada lipídica é maior na fase gel do que na fase líquido cristalina, e também ligeiramente maior é a densidade de membrana (para caracterização de lipídeos ver, por exemplo, Gennis, 1989).

Ao longo do trabalho desenvolvido no nosso grupo, foi mostrado que a região de baixo espalhamento de luz, entre $\mathrm{T}_{\mathrm{m}}$ on e $\mathrm{T}_{\mathrm{m}}$ off, está também relacionada com várias características especiais da dispersão lipídica, como, por exemplo, menor intensidade de espalhamento de raio $\mathrm{X}$ de baixo ângulo, alta condutividade elétrica, alta repulsão entre as vesículas, alto módulo do potencial eletrostático de superficie da vesícula, um perfil complexo de absorção de calor, medido por calorimetria diferencial de varredura (DSC), e uma transição gradual das cadeias hidrocarbônicas, monitorada por marcadores de spin e fluorescentes incorporados na bicamada lipídica (Riske et al., 1997, 1999 e 2001). Foi sugerido, baseado nos vários resultados experimentais já obtidos, que a brusca diminuição de espalhamento de luz em $\mathrm{T}_{\mathrm{m}}{ }^{\text {on }}$ esteja relacionada com um aumento do potencial eletrostático de superficie das vesículas de DMPG. Para que exista este aumento, é necessário que o grau de ionização dos lipídeos cresça, o que só é possivel se houver uma diminuição da constante de ligação $\mathrm{Na}^{+}-\mathrm{PG}^{-}$ em $\mathrm{T}_{\mathrm{m}}{ }^{\text {on }}$. Esta ionização das cabeças polares, acarretando forte repulsão eletrostática entre os lipídeos, dispararia o processo de fusão das cadeias hidrocarbônicas, que só estaria terminado em $\mathrm{T}_{\mathrm{m}}$ off. A fase intermediária, para temperaturas entre $\mathrm{T}_{\mathrm{m}}$ on $\mathrm{e} \mathrm{T}_{\mathrm{m}}$ off, seria caracterizada por um empacotamento muito peculiar, provavelmente com a 
coexistência de domínios mais rígidos com domínios fluidos, de alta curvatura, acarretando baixos contrastes, tanto óptico como de raio X. Para temperaturas acima de $\mathrm{T}_{\mathrm{m}}$ off a bicamada se reorganizaria em uma fase fluida convencional (Riske et al., 2001).

\subsubsection{A região de transição de bicamadas de DMPG}

A Figura 4.2.1 compara os espectros de RPE, em diferentes temperaturas, obtidos com marcadores de spin, incorporados em bicamadas de DMPG, com o grupo nitróxido ligado no $14^{\circ}$ e $16^{\circ}$ carbono da cadeia hidrocarbônica fosfolipídica, 14-PCSL e 16-PCSL, respectivamente. Os pontos onde começa $\left(\mathrm{T}_{\mathrm{m}}{ }^{\text {on }}\right)$ e termina $\left(\mathrm{T}_{\mathrm{m}}{ }^{\text {off }}\right)$ a fase intermediária (Riske et al., 2001) são indicados na figura. Os espectros obtidos com o 14-PCSL (Fig. 4.2.1a), e aqueles gerados por anfifilicos marcados em outras posições da cadeia acila (do $5^{\circ}$ ao 140 carbono, resultados não mostrados) podem ser atribuídos a marcadores de spin monitorando um único domínio, cuja fluidez varia com a temperatura. Entretanto, esta suposição não é necessariamente correta, porque em uma determinada temperatura da fase intermediária, podem existir regiões de membrana estruturalmente diferentes (Riske et al., 2001), sendo que os marcadores de spin podem estar particionados, em sua maioria, em um destes dominios, ou mesmo podem monitorar diferentes regiões, sem, no entanto, terem sinais de RPE muito bem resolvidos no espectro. Isto pode acontecer devido às similaridades entre os sinais, ou à rápida troca entre os marcadores nas distintas regiões, na escala de tempo de RPE, conseqüentemente promediando os diferentes sinais de RPE. Assim, foi muito interessante encontrar espectros gerados pelo 16-PCSL incorporados em bicamadas de DMPG, que apresentam características atípicas na região de alto campo, em temperaturas entre $\mathrm{T}_{\mathrm{m}}$ on $\mathrm{e} \mathrm{T}_{\mathrm{m}}$ off, que podem ser atribuídas à presença de dois sinais de RPE (Fig.4.2.1b). 

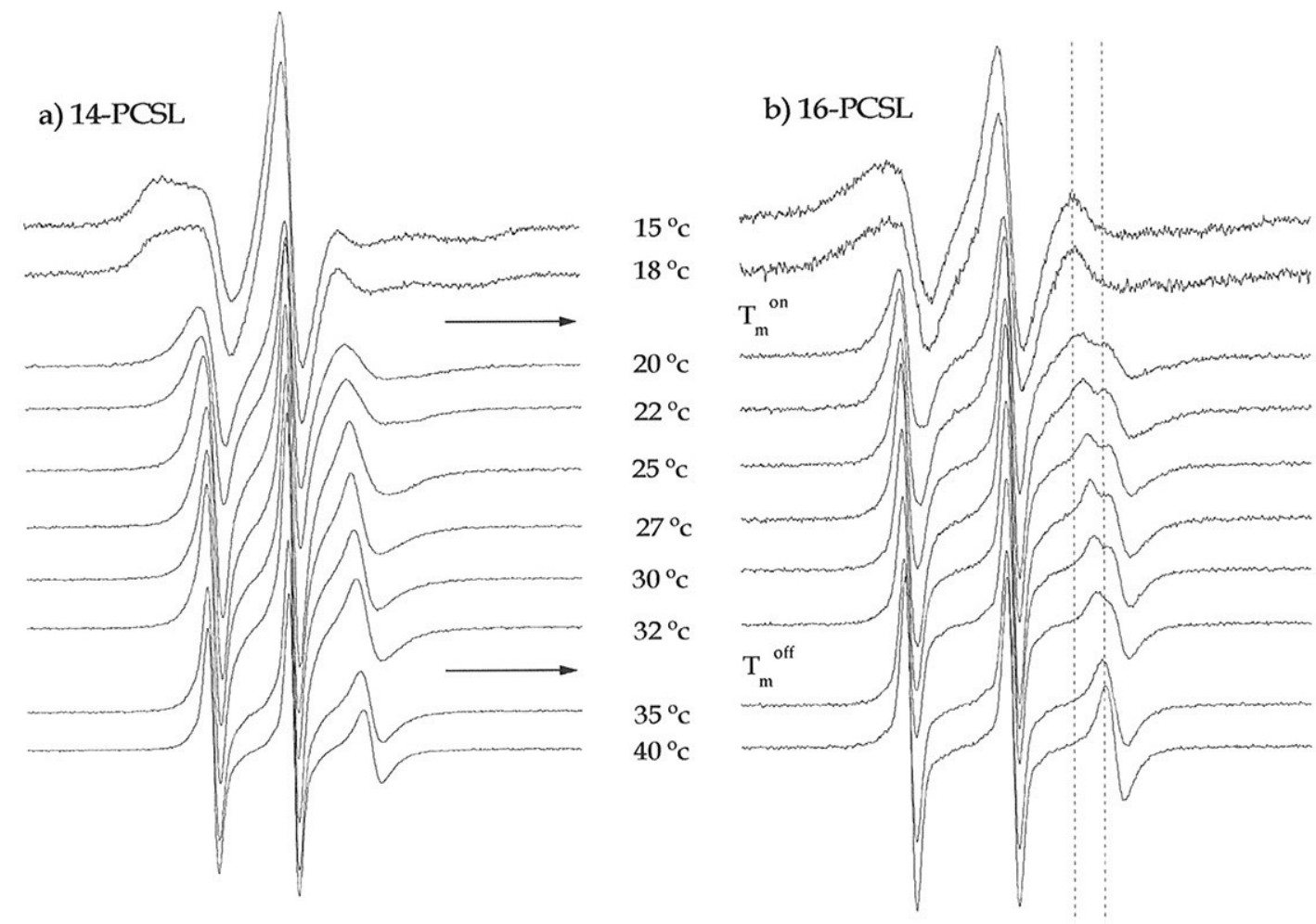

Figura 4.2.1 - Espectros de RPE, banda X, do 14-PCSL (a) e 16-PCSL (b) incorporados em dispersões de DMPG com baixa força iônica e pH neutro, a diferentes temperaturas.

Os espectros de ambos 14-PCSL e 16-PCSL podem ser analisados pela razão entre as alturas das linhas de campo central e baixo $\left(h_{0} / h_{+1}\right)$, um parâmetro empírico que tende à unidade quando a mobilidade do marcador de spin aumenta, para um sinal de RPE. Na Figura 4.2.2, os dados obtidos com os dois marcadores incorporados em DMPG, à baixa força iônica, são comparados com aqueles obtidos com os mesmos marcadores, porém em dispersões lipídicas em alta força iônica (acrescentando-se 100 $\mathrm{mM}$ de $\mathrm{NaCl}$ ). Como mostrado antes (Riske et al., 2001), com o 14-PCSL (Fig. 4.2.2a), em dispersões de DMPG em baixa força iônica, existe uma abrupta diminuição da viscosidade da bicamada em $\mathrm{T}_{\mathrm{m}}$ on, seguida por um intervalo de aproximadamente 15 ${ }^{\circ} \mathrm{C}$ de mobilidade intermediária, antes que a fase fluida seja atingida. Este resultado é diferente do encontrado em dispersões lipídicas com 100 mM de $\mathrm{NaCl}$ (Fig. 4.2.2a), em que a viscosidade sofre uma redução muito mais acentuada, porém é consistente com a presença de uma extensa região de transição, entre as fases gel e fluida, para a bicamada de DMPG em baixa concentração de sal (Riske et al., 2001). Para uma melhor visualização da fase intermediária, a razão $h_{0} / h_{+1}$ é mostrada em função de (T - 


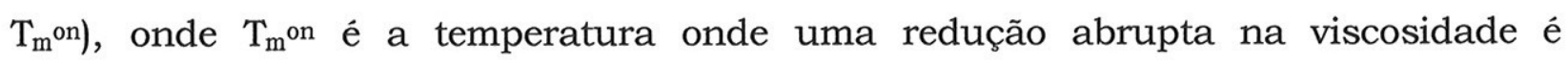
observada. Com o 16-PCSL incorporado em bicamadas de DMPG em alta força iônica (Fig. 4.2.2b), existe uma diminuição abrupta na viscosidade na transição gel-fluida, possivelmente mais acentuada do que a observada com o 14-PCSL (Fig. 4.2.2a). Em geral, quanto mais no interior está o nitróxido, maior é o contraste entre as mobilidades das fases gel e fluida. É interessante notar que, para dispersões de DMPG em baixa força iônica, o 16-PCSL também monitora os 15 ○C de fase intermediária, porém mostra uma queda menos acentuada na viscosidade em $\mathrm{T}_{\mathrm{m}}{ }^{\text {n }}$ (Fig. 4.2.2b), quando comparado com o fosfolipídeo marcado no 140 carbono (Fig. 4.2.2a).
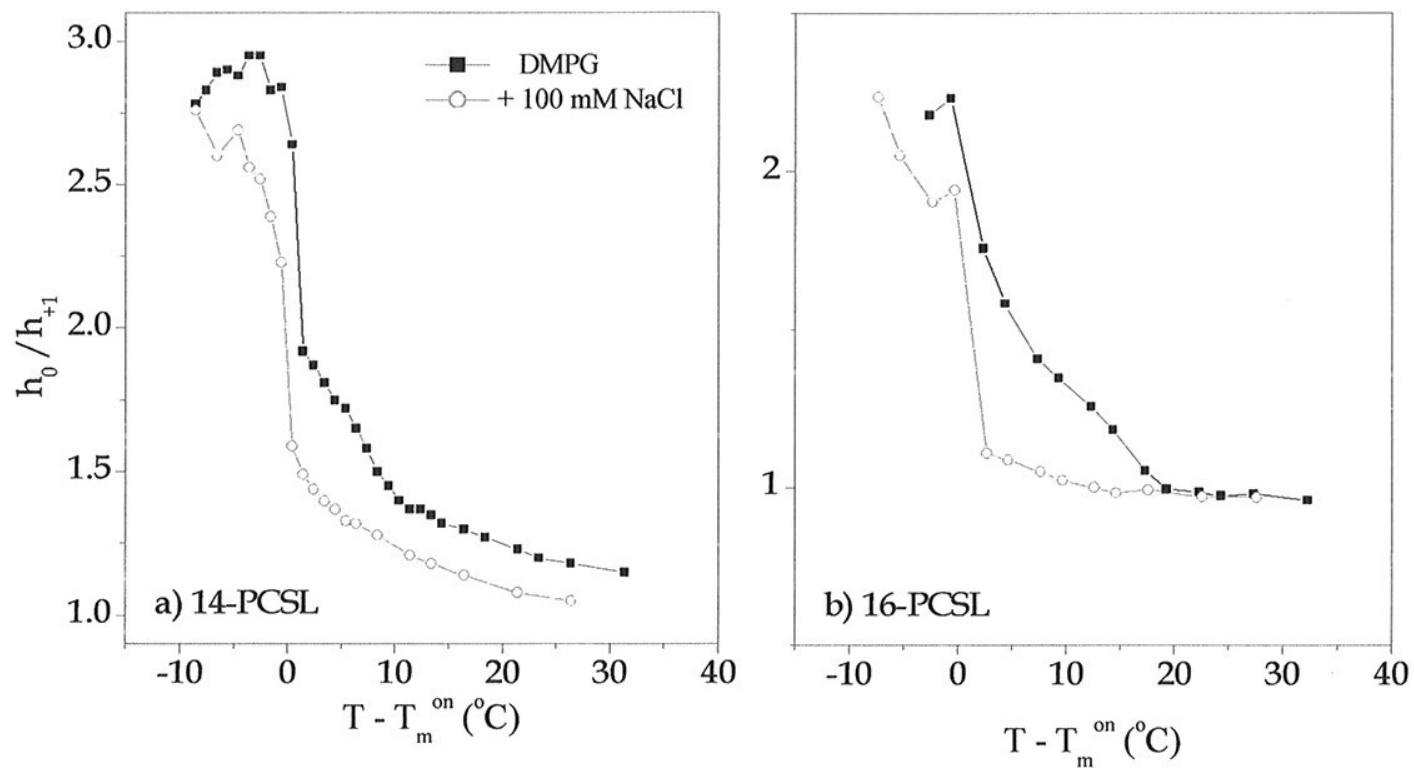

Figura 4.2.2 - Dependência da razão entre as alturas das linhas de campo central e baixo $\left(h_{0} / h_{+1}\right)$ do 14-PCSL (a) e 16-PCSL (b) em dispersões de DMPG em diferentes forças iônicas.

Em dispersões de DMPG em baixa força iônica, para temperaturas entre $\mathrm{T}_{\mathrm{m}}{ }^{\text {on }} \mathrm{e}$ $\mathrm{T}_{\mathrm{m}}$ off, o duplo pico na posição de alto campo, também pode ser visto no espectro de RPE do ácido esteárico marcado no $16^{\circ}$ carbono (16-SASL), mas não é evidente com o metil ester do ácido esteárico (16-MESL), como mostrado na Figura 4.2.3 para dispersões lipídicas à 25 oC. Como discutido antes (Turchiello et al., 2000), esses três marcadores de spin estão localizados em diferentes posições verticais na bicamada de DMPG, com o PCSL bem ancorado na superficie, o SASL numa posição ligeiramente mais profunda (em sua maioria neutro, em bicamadas de DMPG em baixa força iônica, Biaggi et al., 1996), e o MESL, com sua cabeça hidrofóbica, em uma posição da 
bicamada mais profunda ainda. Assim, esta característica atípica na posição de alto campo parece estar somente presente nos espectros de RPE de nitróxidos localizados em uma certa profundidade da membrana. As diferentes posições verticais da membrana dos três marcadores também podem ser inferidas pelos diferentes desdobramentos hiperfinos isotrópicos $\left(a_{0}\right)$ medidos nos espectros de RPE (gráfico inserido na Fig.4.2.3), refletindo as diferentes polaridades sentidas pelos marcadores. Como discutido antes (Fernandez e Lamy-Freund, 2001), a somente pode ser medido com exatidão em sinais de RPE no regime de motional narrowing (Marsh, 1981). Para o 16-PCSL em DMPG, a necessária baixa ordem e alta mobilidade somente é encontrada em temperaturas maiores que $40{ }^{\circ} \mathrm{C}$, onde os valores de $a_{0}$ são praticamente independentes da temperatura (gráfico inserido na Fig. 4.2.3).

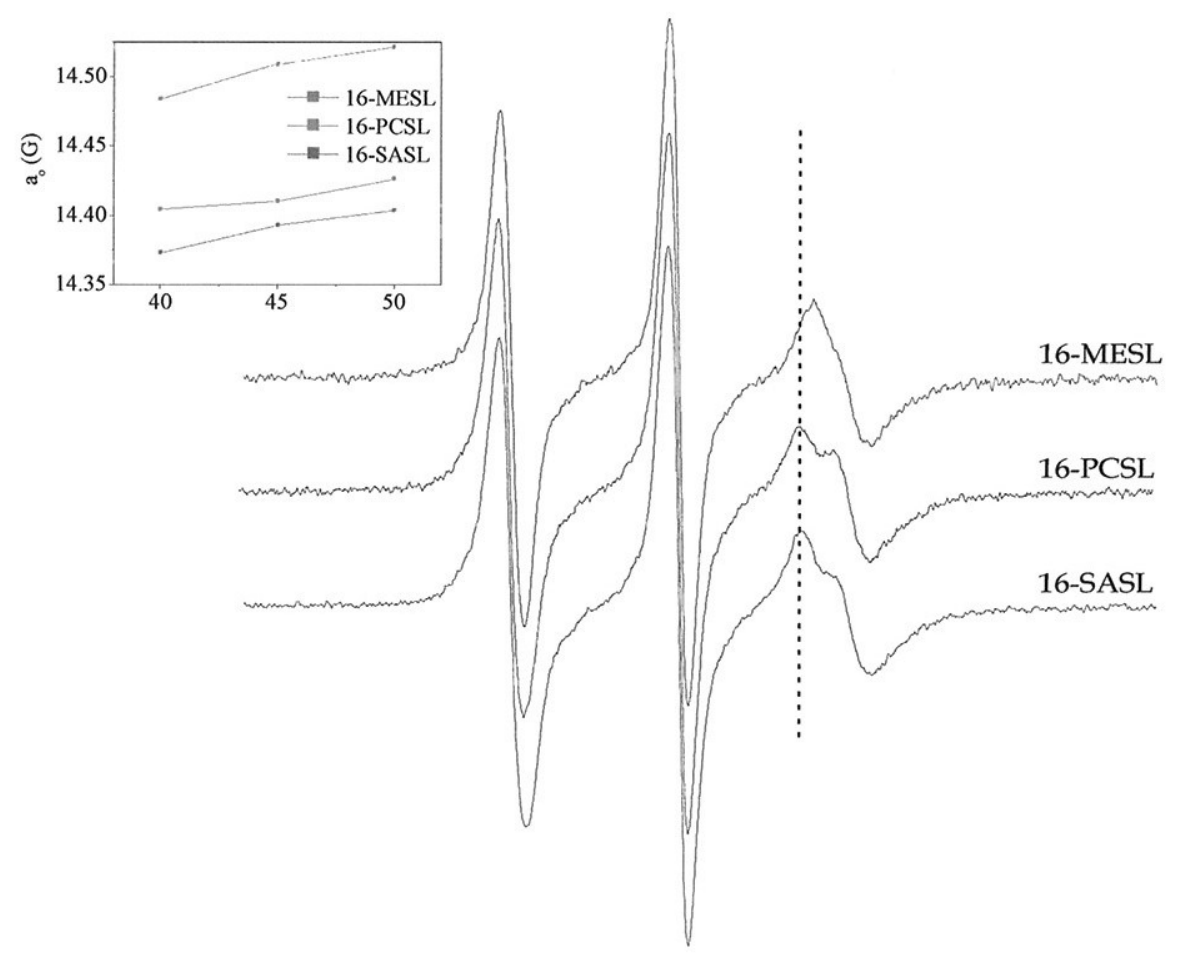

Figura 4.2.3 - Comparação entre os espectros do 16-PCSL, 16- SASL e 16-MESL, banda X, em dispersões de DMPG em baixa força iônica à $25^{\circ} \mathrm{C}$.

Considerando que a polaridade da bicamada diminui da superficie para o centro, e que um maior valor de $a_{0}$ significa uma maior presença de moléculas de água, pode-se concluir que o nitróxido no 16-PCSL e 16-SASL monitoram, em média, microregiões bastante similares na bicamada, com o PCSL em uma posição menos 
profunda, evidenciada pelo maior valor de $a_{0}$. O 16-MESL está monitorando uma região mais próxima à superficie da bicamada, como indicado pelo seu maior valor de $a_{0}$, e menor mobilidade (resultados não mostrados), quando comparado com o 16PCSL e16-SASL (gráfico inserido na Fig. 4.2.3) ${ }^{10}$. Assim, a presença do duplo pico na posição de alto campo parece estar fortemente relacionada à posição vertical do nitróxido na bicamada, quando é monitorado com o 16-PCSL e 16-SASL.

\subsubsection{Espectros do 16-PCSL em bicamadas de DMPG a diferentes freqüências}

Com o objetivo de obter informação adicional sobre o espectro gerado pelo 16PCSL na fase intermediária do DMPG, os sinais de RPE foram obtidos em duas outras freqüências, 1,3 e $35 \mathrm{GHz}$, denominadas bandas $\mathrm{L}$ e $\mathrm{Q}$, respectivamente. Como o desdobramento hiperfino é praticamente independente da freqüência de RPE usada, e os valores $g$ são fortemente dependentes (Atherton, 1993), a idéia era a separação dos dois possiveis sinais presentes nos espectros do 16-PCSL em temperaturas entre $\mathrm{T}_{\mathrm{m}}$ on e $\mathrm{T}_{\mathrm{m}}$ off. Para comparação, os espectros de RPE do 16-PCSL obtidos nas três bandas, em bicamadas de DMPG com baixa e alta concentração de sal, são mostrados na Figura 4.2.4, com os lipídeos nas fases intermediária $(25 \circ \mathrm{C})$ e fluida $(40 \circ \mathrm{C})$. Em altas temperaturas, na fase fluida, o sinal de RPE é quase independente da concentração de ions $\mathrm{Na}^{+}$, como foi mostrado antes (Fernandez e Lamy-Freund, 2001). Em bicamadas de DMPG com alta concentração de sal, condição em que parece não existir a fase intermediária (ver Fig. 4.2.2a e b), os espectros do 16-PCSL obtidos nas três freqüências, à $25 \circ \mathrm{C}$, também são típicos de um único sinal, provavelmente relacionados ao marcador de spin em um único ambiente.

É interessante notar que os possiveis dois sinais apresentados pelos espectros do 16-PCSL em DMPG em baixa força iônica, na fase intermediária, não são bem definidos em nenhuma das freqüências usadas (bandas L, X e Q). No espectro da banda $\mathrm{L}$, à $25{ }^{\circ} \mathrm{C}$, os dois picos podem ser vistos nas posições de baixo e alto campo, e na banda $\mathrm{Q}$, somente na posição de campo central. A fim de extrair mais informações sobre os sinais do 16-PCSL, os espectros obtidos à $25{ }^{\circ} \mathrm{C}$ foram simulados (Figura 4.2.5a), primeiramente assumindo o marcador em um único sítio, usando os mesmos parâmetros para as três bandas (Tabela 4.2.1), como discutido em Materiais e métodos. Foi muito interessante simular os espectros de RPE, nas três bandas,

\footnotetext{
${ }^{10}$ Quando marcado no $5^{\circ}$ e $12^{\circ}$ carbono, foi mostrado que o MESL monitora uma região mais profunda da bicamada de DMPG, que o PCSL (Turchiello et al., 2000). Considerando que o DMPG tem duas cadeias com 14 carbonos, no 16-MESL o nitróxido parece ter atravessado o centro da bicamada e estar posicionado na monocamada adjacente, numa posição menos profunda que o nitróxido do 16-PCSL e 16-SASL.
} 
razoavelmente bem como um único sinal. Entretanto, os dois picos, presentes em diferentes posições de campo para as três bandas, são dificeis de simular, particularmente a linha de campo central em banda Q. Simulações com dois sítios para o espectro de 16-PCSL em DMPG também foram feitas nas três bandas (Figura 4.2.6), e nenhuma melhora nos ajustes mostrados na Fig. 4.2.5a foi obtida. Isto pode estar relacionado às limitações nas simulações teóricas, particularmente à impossibilidade de simular simultaneamente dois sítios com diferentes valores de $g_{0}$.
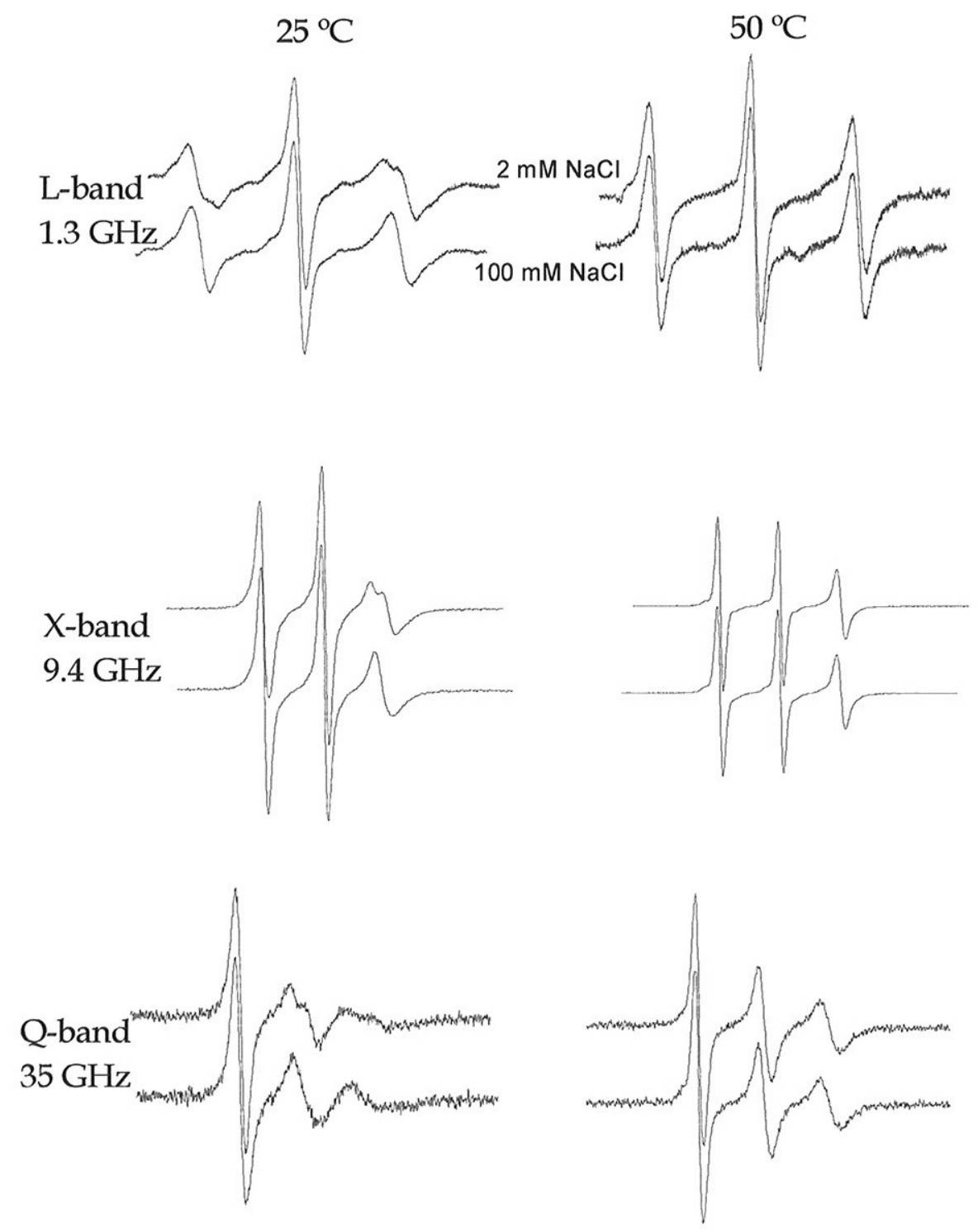

Figura 4.2.4 - Espectros do 16-PCSL em bicamadas de DMPG (50 mM) com baixa e alta força iônica, à 25 e $50^{\circ} \mathrm{C}$, nas bandas $\mathrm{L}, \mathrm{X}$ e Q. 
Apesar de sabermos de possiveis problemas envolvidos nesta metodologia (ver seção 4.1.3), os valores dos elementos de matriz da diagonal principal do tensor desdobramento hiperfino $\mathbf{A}$ foram determinados pela simulação dos espectros, na banda-X, de amostras congeladas de DMPG. Nestas amostras, onde em princípio não deve existir movimento dos lipídeos, os parâmetros associados à difusão rotacional do nitróxido do marcador de spin foram ajustados de maneira que o movimento fosse quase nulo. Além disso, os coeficientes do potencial de orientação (c20, c22, c40, ...) foram considerados nulos. Uma vez obtida as componentes do tensor $\mathbf{A}$, os valores encontrados foram utilizados para simular espectros com movimento nas diversas bandas estudadas. Os valores negativos dos coeficientes do potencial diretor (ver Anexo I) poderiam ser interpretados como sendo indicativos de uma dobra no final da cadeia acila do marcador de spin (Mingtao e Freed, 1999). Isto é razoável, considerando que o DMPG, que possui 14 carbonos em sua cadeia, é menor que a cadeia do marcador, composta por 18 carbonos, possuindo o anel polar doxil ligado ao final da cadeia, no $16^{\circ}$ carbono. A variação nos valores do alargamento não homogêneo gaussiano devido à mudança da freqüência de ressonância utilizada era esperada, uma vez que o termo responsável pelo alargamento de linha é introduzido no modelo de maneira fenomenológica (Schneider e Freed, 1989).

A variação nas componentes do tensor de difusão rotacional (rprp e rpll), que estão correlacionadas aos tempos de correlação rotacional $\tau_{/ /}$e $\tau_{\perp}(\tau=1 / 6 . \log R)$, alteram principalmente a altura das 1a e 2a linhas (aumento de rprp aumenta altura da linha e conseqüentemente reduz sua largura) de espectros de RPE. O aumento no alargamento de linha não homogêneo (gibO e gib2) possui influência sobre a forma das linhas (principalmente sobre a $1^{\text {a }}$ e a $2^{\text {a }}$ ) que as torna mais alargadas e ligeiramente assimétricas. O aumento no coeficiente de primeira ordem do potencial diretor $c_{20}$ promove uma mudança na forma da 1a linha de aproximadamente simétrica para um pico aparentemente composto, seguida de um aumento na altura da 2a linha. A diminuição de $c_{20}$ promove o aumento da altura da 1a linha e redução da $2^{\mathrm{a}}$.

Como mencionado na seção 3.2, o programa de simulação adota o modelo de ordem microscópica com desordem macroscópica (MOMD), isto é, o caso em que existem domínios com ordem local descrito pelo potencial diretor (ver Anexo I), porém os eixos diretores locais são isotropicamente distribuídos uma vez que não existe ordem macroscópica.

Como dito acima, nas simulações de dois sítios dos espectros do DMPG, nas três bandas (Fig. 4.2.6), os coeficientes do potencial diretor também assumiram valores negativos para os dois sítios, o que dá uma indicação de que a cadeia acila do 
marcador poderia estar dobrada. O tensor hiperfino $\mathbf{A}$ foi determinado pela medida do desdobramento máximo hiperfino de cada um dos possiveis sítios do espectro obtido na banda L e considerando este como o desdobramento hiperfino isotrópico a 0 . Assim, da mesma maneira que a simulação com um sitio, as simulações obtidas com dois sítios também ajustaram-se razoavelmente bem com os espectros experimentais, sem no entanto definir os detalhes específicos de cada banda. Portanto, somente baseado nas simulações dos espectros é impossivel dizer se o espectro é resultante de marcadores em um sítio, ou da coexistência de marcadores em dois sítios.

\subsubsection{Espectros do 16-PCSL em DMPG na presença do $\alpha$-MSH}

Os espectros do 16-PCSL em DMPG com baixa força iônica, na fase intermediária, em presença do $\alpha-\mathrm{MSH}$, nas bandas $\mathrm{L}, \mathrm{X}$ e Q, são apresentrados na Figura 4.2.5b. Este peptídeo é sabido enrijecer a bicamada lipídica na fase fluida (ver seção 4.1.2). Na fase intermediária, em todas as freqüências usadas, o $\alpha-\mathrm{MSH}$ modifica o sinal de RPE. É interessante notar que nas bandas L e X, a interação deste peptídeo com a bicamada lipídica faz desaparecer um dos picos da linha de campo alto. Na banda $\mathrm{Q}$ a presença do $\alpha$-MSH elimina o segundo pico na linha central (ver linhas tracejadas na Fig. 4.2.5.

A coincidência da posição de um pico obtido em presença de $\alpha$-MSH (bandas X e L, campo alto e banda Q, campo central) e um dos picos observados em DMPG puro levou-nos a efetuar subtrações nas três bandas avaliadas (Fig. 4.2.5c). É surpreendente que nas três bandas a subtração do espectro de 16-PCSL em DMPG do espectro obtido em presença do peptídeo, gerou espectros tipicos de marcador em um sítio com alta mobilidade, porém com um desdobramento hiperfino proveniente de uma região mais polar que o encontrado com o $\alpha$-MSH. Portanto, parece que o sinal apresentado pelo 16-PCSL em DMPG é um sinal composto, sendo que a presença do peptídeo inibiria a presença de uma das populações. Tanto o espectro do 16-PCSL em DMPG $+\alpha$-MSH como o espectro resultante da subtração foram bastante bem simulados como sinais únicos, como mostra a Fig. 4.2.5. Os parâmetros das simulações estão apresentados na Tabela 4.2.1. 


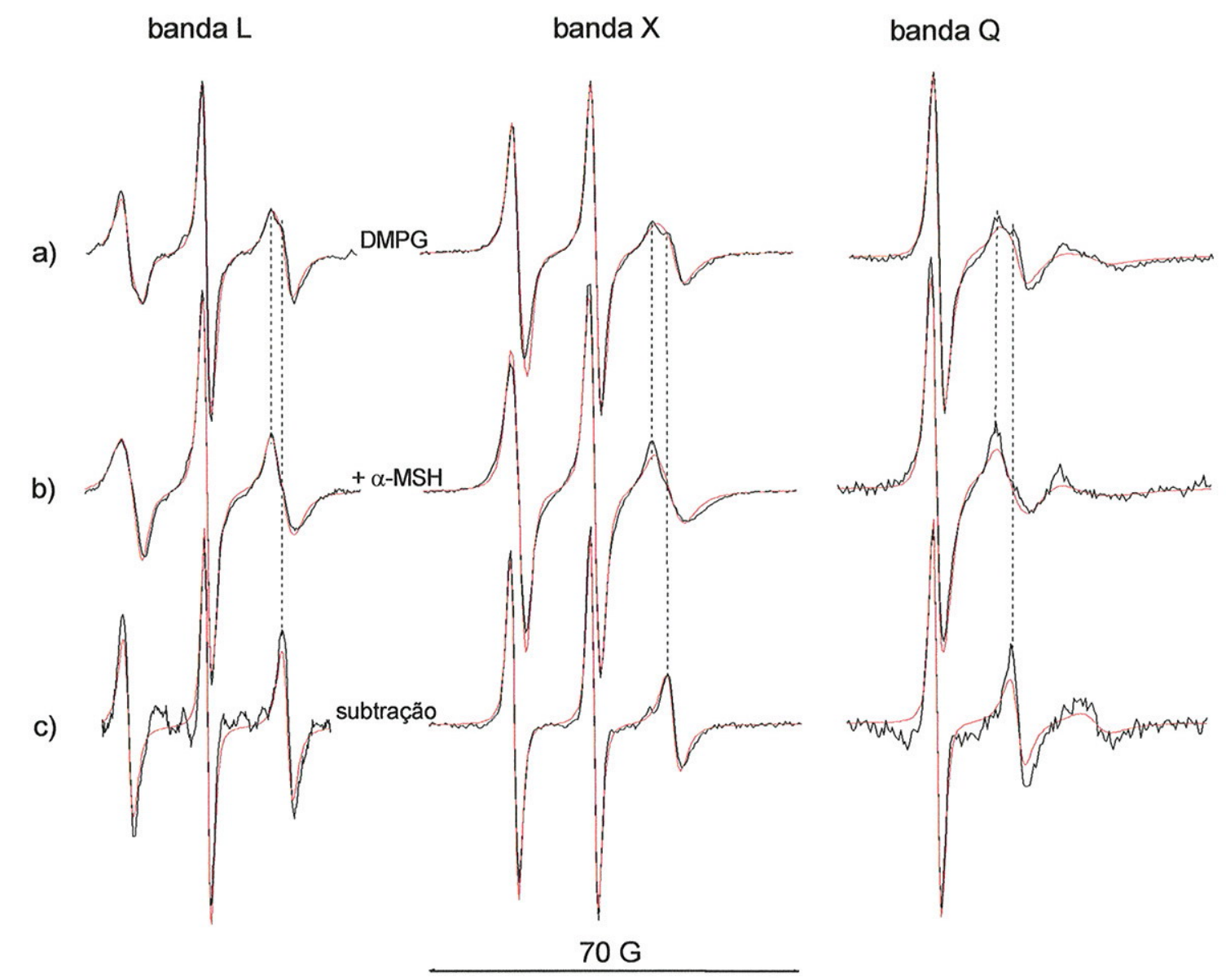

Figura 4.2.5 - Espectros do 16-PCSL em bicamadas de DMPG (50 mM) em baixa força iônica à $25^{\circ} \mathrm{C}$, nas bandas L, X e Q, na ausência (a) e presença do $\alpha$-MSH (b), e do espectro diferença (c). As simulações, indicadas na cor vermelha, representam espectros teóricos correspondendo a marcadores de spin em um único microambiente. Os parâmetros espectrais resultantes do ajuste são dados na Tabela 4.2.1.

O sinal obtido em presença do peptídeo a $25{ }^{\circ} \mathrm{C}$ é bastante assimétrico, de forma mais evidente no terceiro pico, semelhante ao observado em espectros de 14PCSL na fase intermediária (Fig. 4.2.1a). Como dito antes, o sinal resultante da subtração tem um caráter bem móvel e um alto valor de desdobramento hiperfino $\left(\mathrm{a}_{0}=\right.$ 15,03 G). Esse valor de $a_{0}$ corresponderia ao centro paramagnético localizado na posição do quinto carbono da cadeia acila (Fernandez e Lamy-Freund, 2000). 
Tabela 4.2.1 - Parâmetros obtidos do ajuste não linear de mínimos quadrados ${ }^{1} \operatorname{dos}_{\text {espectros }}$ de RPE do 16-PCSL em dispersões de DMPG (50 mM) em baixa força iônica à $25^{\circ} \mathrm{C}$, na ausência e presença do $\alpha-\mathrm{MSH}$, e do espectro sutraído. Os espectros teóricos e experimentais são mostrados na Fig. 4.2.5.

\begin{tabular}{|c|c|c|c|c|c|c|c|c|c|}
\hline & \multicolumn{3}{|c|}{ DMPG } & \multicolumn{3}{|c|}{$+\alpha-\mathrm{MSH}^{2}$} & \multicolumn{3}{|c|}{ Subtração } \\
\hline$A_{\perp}(G)$ & \multicolumn{3}{|c|}{5,1} & \multicolumn{3}{|c|}{5,1} & \multicolumn{3}{|c|}{5,3} \\
\hline$A_{z z}(G)$ & \multicolumn{3}{|c|}{33} & \multicolumn{3}{|c|}{33} & \multicolumn{3}{|c|}{34,4} \\
\hline$a o^{3}(\mathrm{G})$ & \multicolumn{3}{|c|}{14,40} & \multicolumn{3}{|c|}{14,40} & \multicolumn{3}{|c|}{15,00} \\
\hline$a o^{4}(\exp )(\mathrm{G})$ & \multicolumn{3}{|c|}{14,40} & \multicolumn{3}{|c|}{14,60} & \multicolumn{3}{|c|}{-} \\
\hline$\tau_{\perp}(\mathrm{ns})$ & \multicolumn{3}{|c|}{0,63} & \multicolumn{3}{|c|}{1,13} & \multicolumn{3}{|c|}{0,68} \\
\hline$\tau_{/ /}(\mathrm{ns})$ & \multicolumn{3}{|c|}{0,17} & \multicolumn{3}{|c|}{0,003} & \multicolumn{3}{|c|}{0,80} \\
\hline $\mathrm{c}_{20}$ & \multicolumn{3}{|c|}{$-0,80$} & \multicolumn{3}{|c|}{$-0,60$} & \multicolumn{3}{|c|}{0,12} \\
\hline $\mathrm{c}_{22}$ & \multicolumn{3}{|c|}{$-0,20$} & \multicolumn{3}{|c|}{0,08} & \multicolumn{3}{|c|}{0,20} \\
\hline gibo5 & 1,16 & 1,65 & 4,93 & 0,28 & 1,03 & 0,97 & 0,70 & 1,00 & 0,83 \\
\hline$g i b 2^{5}$ & 0,44 & $-0,22$ & $-3,92$ & 1,56 & 0,41 & 2,55 & 0,39 & $-0,78$ & 0,51 \\
\hline
\end{tabular}

${ }_{1}^{1}$ Para discussão do programa de simulação usado, e parâmetros espectrais,ver seção 3.2.

2 Concentração total da amostra é de $10 \mathrm{~mol} \%$ relativo ao DMPG.

$3 a_{0}=\left(2 \mathrm{~A}_{\perp}+\mathrm{A}_{z z}\right) / 3$

4 Valores médios de $40-50 \circ \mathrm{C}$ (Fig. 4.1.3a).

5 Os valores dos alargamentos não homogêneo gaussiano referem-se às bandas L, X e Q, respectivamente.

Entretanto, espectros de marcadores com o radical nitróxido na posição do quinto carbono, em bicamadas de DMPG, sentem uma microviscosidade reduzida, devido ao perfil de mobilidade de bicamadas lipídicas (Biaggi et al., 1997; Riske et al., 1997; Fernandez \& Lamy-Freund, 2001). É mais provável, portanto, que esse sinal de grande polaridade e mobilidade esteja associado a marcadores localizados em uma região com um empacotamento bem mais frouxo, muito distinto do esperado em bicamadas lipídicas, que permitiria um alto grau de liberdade de movimento e a entrada de moléculas de água, que aumentariam a polaridade interna. Recentemente, foi observado que o valor de $a_{0}$ do marcador 16-SASL é consideravelmente maior quando inserido em micelas $\left(a_{0}=15,0 \mathrm{G}\right)$ do que em bicamadas $\left(a_{0}=14,2 G\right)$ (Benatti et al., 2001), indicando que, à medida que o raio de curvatura do agregado anfifilico cresce, ocorre uma maior penetração de água no interior da região hidrofóbica, ou o nitróxido apresenta uma maior amplitude de movimento, tendo acesso a regiões de polaridades maiores.

A hipótese da existência de dois sinais fica muito reforçada, uma vez que os espectros resultantes das subtrações nas três bandas possuem as mesmas 
características, isto é, alta polaridade $\left(a_{0} \sim 15 G\right)$ e mobilidade. Além disso, a proporção das duas populações obtidas das subtrações é praticamente igual nas três bandas (65 $\%$ do sinal mais imobilizado e $35 \%$ do sinal mais móvel). Seria altamente improvável que essa alta correlação entre as componentes subtraídas fosse um acaso.

Com os dados obtidos até o presente momento, a hipótese da existência de dois sinais parece ser a mais adequada, embora o problema não esteja ainda elucidado. Podemos especular que a presença dos dois sinais seja causada por um empacotamento não usual da membrana de DMPG na fase intermediária. Esse empacotamento peculiar da região de transição pode ser causado, por exemplo, pela existência de regiões de altíssima curvatura, impostas à membrana devido à coexistência de domínios de diferentes empacotamentos e mesmo de diferentes densidades superficiais de carga. As regiões curvas teriam características de empacotamento semelhantes às encontradas em agregados micelares, ou seja, uma alta fluidez que permitiria o acesso do marcador a meios de polaridade mais altas, devido à grande amplitude do movimento, e, talvez, uma maior entrada de moléculas de água mesmo numa região mais interna. O peptídeo poderia preferir localizar-se nessas regiões, que por apresentarem uma maior área por cabeça polar, permitiriam uma maior penetração de regiões hidrofóbicas. A presença do peptídeo na região curva poderia alterar o sinal dessa população de marcadores 16-PCSL ou expulsar o marcador desta região. O outro sinal não seria então muito alterado pela presença do peptídeo, já que o peptídeo preferiria as regiões de maior curvatura.

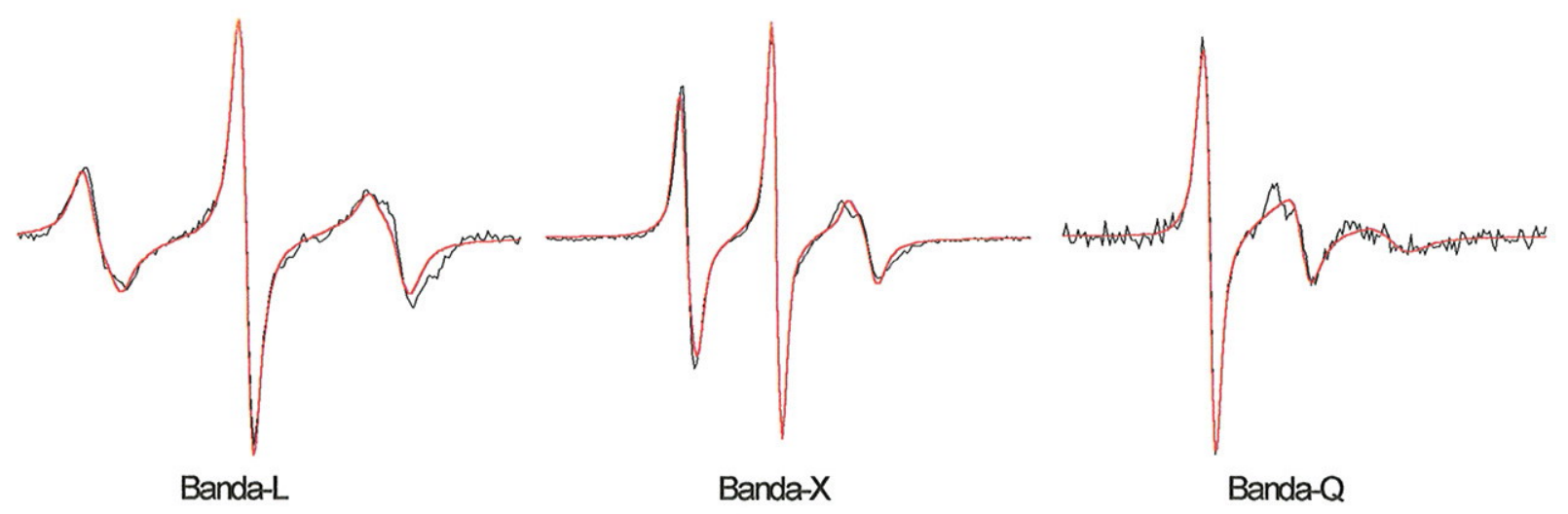

Figura 4.2.6 - Espectros do 16-PCSL em bicamadas de DMPG (50 mM) em baixa força iônica à $25^{\circ} \mathrm{C}$, nas bandas L, X e Q. As simulações, indicadas na cor vermelha, representam espectros teóricos correspondendo a marcadores de spin em dois microambientes. 


\subsection{Análogos cíclicos do $\alpha$-MSH: interação com bicamadas lipídicas}

(Trabalho em colaboração com o Dr. Helgi Schiöth e o Prof. Dr. Amando S. Ito)

Recentemente foram descobertos novos receptores do hormônio estimulador do melanócito ( $\alpha-\mathrm{MSH})$, sem no entanto, conhecer suas regras fisiológicas (Schiöth, 1997). Isto têm levado muitos pesquisadores ao desenvolvimento de substâncias seletivas para estes receptores, com o objetivo de elucidar tais regras. Análogos cíclicos com a presença de um volumoso aminoácido (neste caso aqui, o D-Nal) no lugar da $\mathrm{Phe}^{7}$, têm sido usados para determinar as regras funcionais destes novos receptores (Hruby et al., 1995; Schiöth et al., 1997 e 1998; Kask et al., 1998). Nesse sentido, é de grande importância caracterizar este aminoácido e avaliar sua influência na estrutura dos análogos cíclicos. A seguir, vamos apresentar os resultados de vários tipos de análogos cíclicos contendo o D-Nal, em solução aquosa e em presença de vesículas aniônicas de DMPG.

\subsubsection{Coeficientes de extinção molar $\varepsilon$ do $\alpha$-MSH e seus análogos cíclicos em solução aquosa}

O peptídeo natural $\alpha$-MSH tem em sua estrutura primária o fluoróforo triptofano (Trp) (ver Tabela 3.1). Através da medida de absorbância à temperatura ambiente, o valor do coeficiente de extinção molar $\varepsilon$ encontrado (determinado através da equação 2.1.4) para o comprimento de onda $280 \mathrm{~nm}$, em solução aquosa, foi de aproximadamente 5700 (M.cm)-1 (ver seção 3.2). Para os demais análogos (HS-014, HS024, HS-032 e HS-053, cuja característica comum é a substituição do resíduo 7 do $\alpha$ MSH pelo $\beta$-(2-naphthyl)-D-alanine, aqui chamado D-Nal, ver Tabela 3.1), que contêm dois resíduos cisteína (Cys) ligados, conferindo a estes uma estrutura cíclica, e além disso dois cromóforos (Trp e D-Nal), $\varepsilon$ foi de aproximadamente 8000 (M.cm)-1 em 280 nm. A medida de absorbância em $280 \mathrm{~nm}$ para o Boc-D-Nal (D-Nal isolado) também foi obtida e resultou num valor $\varepsilon=4200(\mathrm{M} . \mathrm{cm})^{-1}$.

O valor de $\varepsilon$ em $280 \mathrm{~nm}$ do resíduo Trp do $\alpha$-MSH indica que este não se altera drasticamente quando comparado com o do Trp puro, ou melhor dizendo, com o NATA11. Os demais peptídeos cíclicos (HS-014, HS-024, HS-032 e HS-053) apresentaram coeficientes de extinção em $280 \mathrm{~nm}$ menores que a soma dos coeficientes de extinção individuais de cada cromóforo (NATA e Boc-D-Nal) livre da

\footnotetext{
${ }^{11}$ Embora não mostrado, o valor de $\varepsilon$ encontrado para o NATA, nas mesmas condições experimentais, foi de aproximadamente $5800(\mathrm{M} . \mathrm{cm})^{-1}$.
} 
cadeia peptídica. Portanto, ou o D-Nal no esqueleto peptídico absorve menos e/ou Trp e D-Nal interagem eletronicamente devido à proximidade dos dois cromóforos, alterando o espectro de absorção. A Figura 4.3.1 apresenta os espectros de absorção dos peptídeos acima mencionados. Medidas de absorbância também poderiam ter sido obtidas em $230 \mathrm{~nm}$, uma vez que o sinal nesse comprimento de onda é mais intenso. Entretanto, como muitos solventes e ligações peptídicas absorvem nessa região, esse comprimento de onda não é utilizado para obtenção das medidas a serem usadas na calibração da concentração de peptídeos.

As medidas de absorbância dos análogos cíclicos indicaram que a concentração dos peptídeos analisados era a mesma (aproximadamente $50 \mu \mathrm{M}$ ), entretanto estas não puderam revelar possiveis diferenças estruturais em solução aquosa (cada um desses conjuntos apresentou praticamente o mesmo espectro de absorção, ver Fig. 4.3.1).

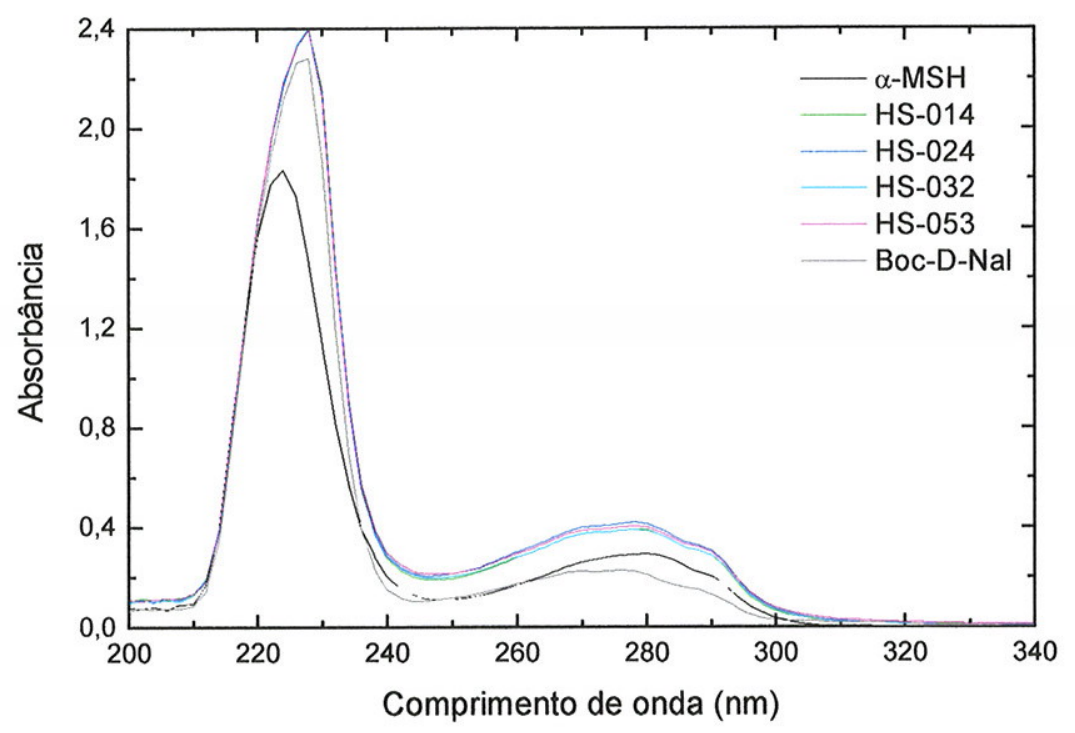

Figura 4.3.1 - Espectros de absorção do peptídeo melanotrópico $\alpha$-MSH, seus análogos cíclicos e do Boc-D-Nal ( $\left.5 \times 10^{-5} \mathrm{M}\right)$ em tampão HEPES, com caminho óptico de $1 \mathrm{~cm}$ obtidos à temperatura ambiente.

\subsubsection{Fluorescência em solução aquosa}

Devido a sua grande ocorrência em peptídeos e proteínas, o aminoácido aromático Trp tem sido extensivamente investigado como uma sonda fluorescente intrínseca, podendo fornecer informações a respeito da estrutura dessas substâncias. Além disso, um estudo mais detalhado das propriedades espectroscópicas do anel indol vem sendo realizado (Szabo e Rayner, 1980; Chang et al., 1983; Petrich et al., 
1983) e tem estimulado vários outros estudos. Neste trabalho, as características fluorescentes do $\alpha$-MSH e de seus análogos cíclicos (HS-014, HS-024, HS-032 e HS053) em solução aquosa, à temperatura ambiente, foram investigadas. $\mathrm{O} \alpha-\mathrm{MSH}$ em solução aquosa apresenta intensidade máxima de emissão fluorescente próximo ao comprimento de onda $357 \mathrm{~nm}$, característico da exposição do resíduo Trp a um ambiente polar, de acordo com resultados prévios de fluorescência em melanotropinas (Lakowicz, 1999; Ito et al. 1993). Para os análogos cíclicos, a máxima emissão fluorescente foi encontrada próxima a $347 \mathrm{~nm}$ (Fig. 4.3.2). O deslocamento para um comprimento de onda menor se deve à presença do D-Nal, que quando isolado, emite fluorescência máxima em torno de $334 \mathrm{~nm}$. As formas dos espectros de fluorescência dos análogos cíclicos são semelhantes entre si.

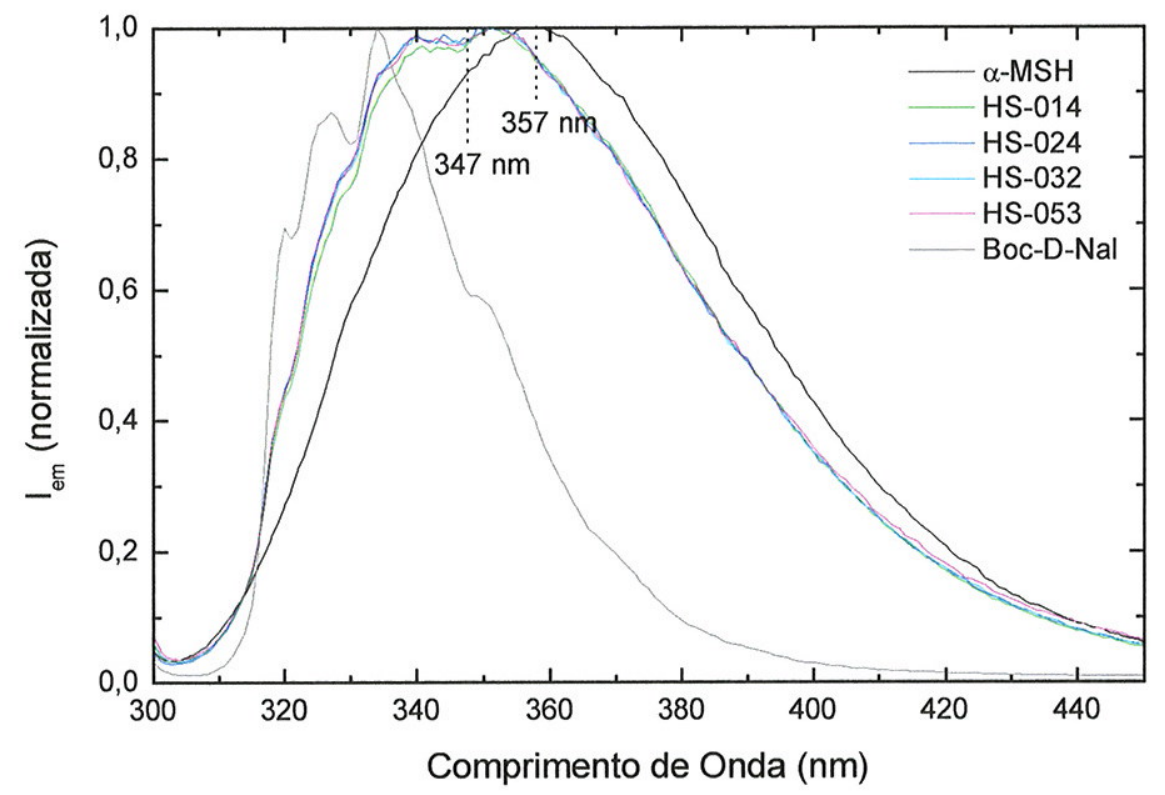

Figura 4.3.2 - Intensidades normalizadas da emissão fluorescente obtidas à temperatura ambiente, do $\alpha$-MSH, seus análogos cíclicos e do Boc-D-Nal ( $\left.5 \times 10^{-5} \mathrm{M}\right)$ em tampão HEPES; excitação=296 nm; caminho óptico $=1 \mathrm{~cm}$; abertura das fendas: exc. $=1 \mathrm{~mm}$, em. $=2 \mathrm{~mm}$.

O espectro de fluorescência desses análogos cíclicos pode ser composto com uma determinada porcentagem das emissões do Trp e D-Nal em solução aquosa. A Figura 4.3.3 mostra um exemplo de composição espectral, onde o HS-024, excitado em 296 nm, é reproduzido com o sinal do $\alpha$-MSH mais o sinal do Boc-D-Nal, excitados também no mesmo comprimento de onda. Como a absorção e emissão do Trp e D-Nal presentes nos análogos cíclicos ocorrem em diferentes comprimentos de onda, as 
contribuições de ambos os fluoróforos, Trp e D-Nal, na composição do espectro, dependem fortemente do comprimento de onda de excitação. A composição dos espectros de fluorescência dos análogos cíclicos também foi feita pela adição do NATA (Trp livre de uma cadeia peptídica) ao Boc-D-Nal. Nesse caso, a contribuição do D-Nal foi ligeiramente maior que no caso anterior.

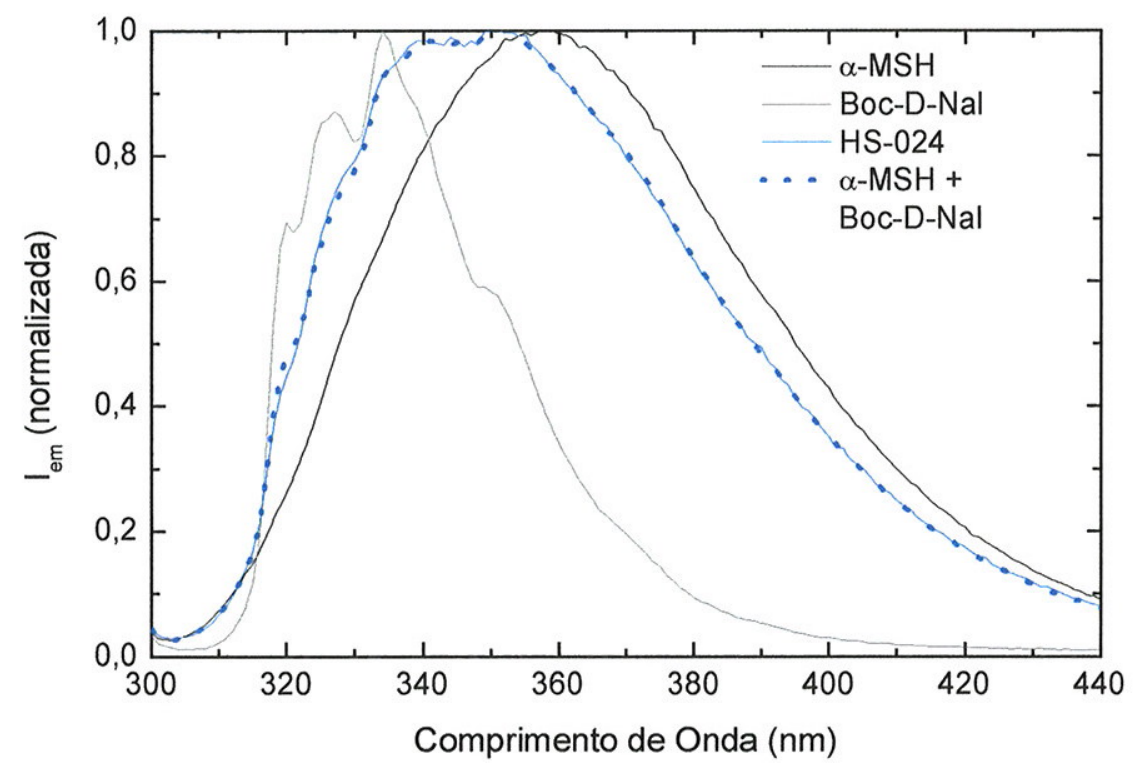

Figura 4.3.3 - Comparação entre os espectros de emissão fluorescente do análogo HS-024 e o composto a partir do $\alpha$-MSH e do Boc-D-Nal (para os parâmetros experimentais ver Fig. 4.3.2).

Como a sensibilidade da técnica de fluorescência no regime estacionário não resolveu possiveis diferenças nas estruturas dos peptídeos cíclicos em solução aquosa, utilizou-se a técnica de fluorescência com resolução temporal, para observar o decaimento das intensidades fluorescentes desses mesmos peptídeos. Através dessas curvas de decaimento foi possivel identificar nos peptídeos cíclicos um tempo de decaimento bastante longo, proveniente do D-Nal, quando comparado com o $\alpha-\mathrm{MSH}$ (onde somente o Trp é monitorado), que possue tempo de decaimento curto para o comprimento de onda de emissão de $355 \mathrm{~nm}$, conforme indica a Figura 4.3.4.

Também foram observadas diferenças entre os análogos cíclicos. O decaimento do HS-024, HS-032 e HS-053 é bastante similar. Porém, o análogo HS-014 inicialmente decai um pouco mais lento, decaindo no final a uma taxa semelhante aos demais cíclicos (devido ao tempo longo do D-Nal). Também é observado que estes peptídeos cíclicos decaem inicialmente mais rápido que o $\alpha-\mathrm{MSH}$. As diferenças no decaimento dos peptídeos podem estar associadas a modificações estruturais, sendo 
que os tempos de vida do estado excitado podem ser determinados por convolução multi-exponencial. Por serem biologicamente mais importantes na interação com receptores, será dada especial atenção aos análogos cíclicos HS-032 e HS-053 (Schiöth, comunicação pessoal).

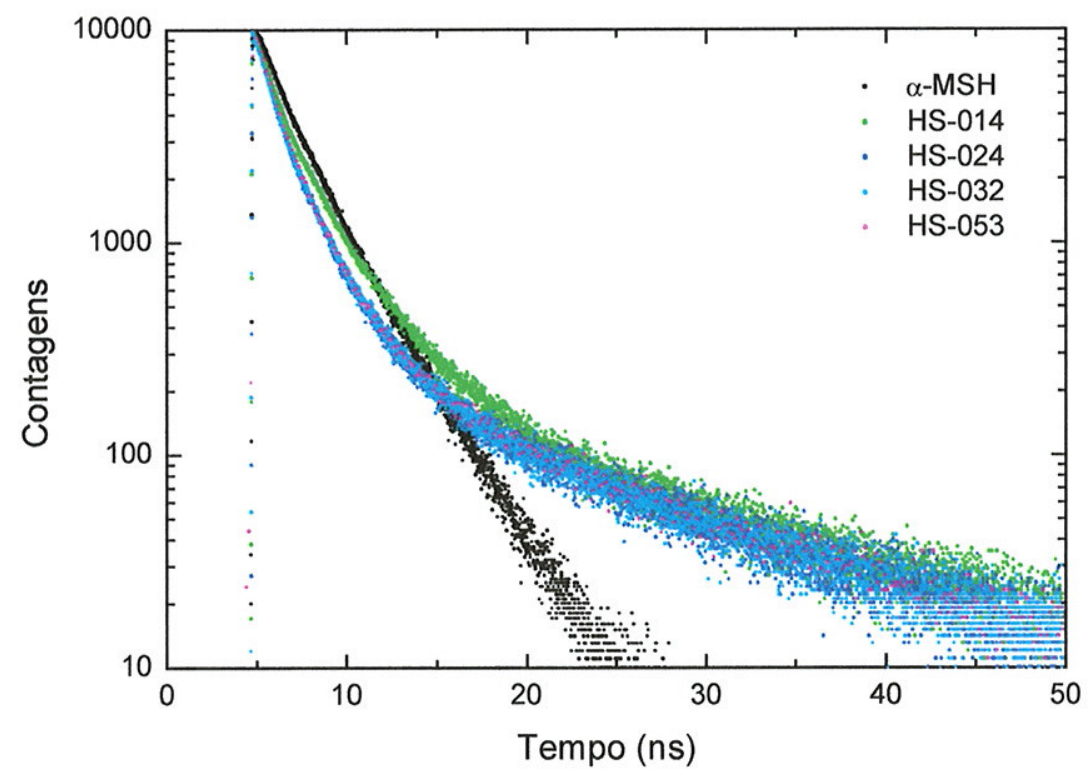

Figura 4.3.4 - Curvas de decaimento da fluorescência do $\alpha$-MSH e seus análogos cíclicos (5 x 10-5 M) em solução aquosa, no comprimento de onda de emissão $355 \mathrm{~nm}$. $\lambda_{\text {exc }}=296 \mathrm{~nm}$.

Para o $\alpha$-MSH (que contêm apenas o Trp como resíduo fluorescente) o decaimento de fluorescência é bem descrito por uma função multi-exponencial e pode ser ajustado com três tempos de vida. Esses tempos de vida acredita-se serem originários da fluorescência de diferentes rotâmeros do anel indol em torno da ligação $\mathrm{C}_{\alpha}-\mathrm{C}_{\beta}$ da cadeia lateral (Szabo e Rayner, 1980; Willis e Szabo, 1992; Ross et al., 1992). As curvas de decaimento dos peptídeos cíclicos HS-032 e HS-053 (que contêm os resíduos Trp e D-Nal) foram ajustadas com quatro tempos de vida, sendo um tempo bastante longo proveniente do $\mathrm{D}-\mathrm{Nal}$ e os outros três que atribuímos ao Trp. O decaimento do NATA e Boc-D-Nal (onde, respectivamente, Trp e D-Nal estão livres) em solução aquosa, foram ajustados por funções mono-exponenciais (ver Tabelas 4.3.1, 4.3.2 e 4.3.3).

O decaimento do estado excitado do $\alpha$-MSH, HS-032 e HS-053 foi obtido em vários comprimentos de onda de emissão, no intervalo de 325 a $380 \mathrm{~nm}$. Com o objetivo de melhorar a resolução dos tempos de vida encontrados no ajuste, nos vários 
comprimentos de onda, foi feita uma análise global (seção 2.2.3). Dessa maneira, foi possivel encontrar um único conjunto de tempos para todos os comprimentos de onda medidos. Os tempos de vida do Trp no $\alpha$-MSH e nos análogos cíclicos HS-032 e HS053, obtidas nesta análise, à temperatura de $10 \mathrm{oC}$, variam muito pouco entre si (Tabela 4.3.1). No entanto, a porcentagem relativa de cada componente varia consideravelmente, resultando em $u m<\tau>$ semelhante para os dois análogos cíclicos e significativamente menor do que o obtido para o $\alpha$-MSH $(<\tau\rangle^{\alpha-M S H}>\langle\tau>$ HS-032, HS-053) (eq. 2.2.6). À $25 \circ \mathrm{C}$ e $40 \circ \mathrm{C}$ (Tabelas 4.3 e 4.4, respectivamente), $\tau_{1}$ varia bastante $\left(\tau_{1}^{\mathrm{HS}-053>}\right.$ $\left.\tau_{1}{ }^{\mathrm{HS}-032}>\tau_{1}{ }^{\alpha}-\mathrm{MSH}\right)$, sendo que os tempos das componentes $\tau_{2}$ e $\tau_{3}$ praticamente não variam. Contudo, como antes, $\left.\langle\tau\rangle^{\alpha_{-} \text {MSH }}\right\rangle\langle\tau\rangle$ HS-032, HS-053. Esses resultados parecem indicar que a presença do D-Nal (nos peptídeos HS-032 e HS-053) e/ou a estrutura cíclica dos peptídeos, somente promovem algum efeito no tempo longo do Trp $\left(\tau_{1}\right)$, quando o peptídeo possui uma determinada mobilidade, decorrente do aumento da temperatura. O decaimento do estado excitado das outras duas componentes $\tau_{2}$ e $\tau_{3}$ do Trp não é sensível a algum eventual efeito térmico observável. Portanto, a presença do D-Nal nos peptídeos cíclicos não parece estar suprimindo a fluorescência do Trp, mas alterando o equilibrio entre os possiveis rotâmeros do Trp, de tal maneira que o seu $<\tau>$ diminui. É interessante notar que os valores de $<\tau>$ do Trp para os dois peptídeos cíclicos são idênticos, apesar dos tempos de vida do rotâmero $1\left(\tau_{1}\right)$ serem diferentes.

Nas três temperaturas, o tempo de vida do D-Nal é maior para o HS-053 comparado com o HS-032, sendo que os valores obtidos com os peptídeos são muito menores do que os obtidos para o Boc-D-Nal em solução aquosa (aproximadamente 40 \%). Este resultado sugere uma forte supressão do D-Nal pelo Trp, sendo que para confirmação, é necessário o estudo de outros peptídeos que contenham o D-Nal e não contenham um possivel supressor, como o Trp. A menor supressão da fluorescência do D-Nal no HS-032, sugere que, neste peptídeo em solução aquosa, o D-Nal e o Trp estejam ligeiramente mais afastados espacialmente.

A partir das percentagens relativas, obtidas pela análise global do ajuste multiexponencial dos vários comprimentos de onda medidos, foi possivel associar um espectro de emissão fluorescente para cada uma das componentes dos tempos de vida. A esses espectros associados dá-se o nome de espectros associados ao decaimento (DAS, decay-associated spectra) (Knutson et al., 1983). Espectros associados típicos são mostrados nas Figuras 4.3.7, 4.3.8 e 4.3.9. A contribuição percentual $(\%)$ de cada uma das componentes dos tempos de vida foi calculada pela área integrada da componente espectral. Também foi obtido o comprimento de onda 
onde a intensidade é máxima $\left(\lambda_{\text {máx }}\right)$. Os valores destes parâmetros (\% e $\lambda_{\text {máx }}$ ) para as três componentes temporais do $\alpha$-MSH são apresentados na Tabela 4.3.4. Quando a temperatura do $\alpha$-MSH é aumentada (Figs. 4.3.7 a a 4.3.7c), a contribuição do espectro associado a $\tau_{2}$ aumenta, ao passo que a do tempo longo $\left(\tau_{1}\right)$ diminui (Tabela 4.3.4). O espectro associado ao tempo curto $\left(\tau_{3}\right)$ não sofre mudança considerável com a temperatura. Fica evidente que, em solução aquosa, para os peptídeos cíclicos, a conformação do Trp que predomina é aquela associada a $\tau_{2}$ (Figuras 4.3.8a, b, c e 4.3.9a, b, c), enquanto que no $\alpha$-MSH predomina a associada a $\tau_{1}$.

\subsubsection{Fluorescência em sistema lipidico}

Os parâmetros de fluorescência dos espectros de emissão no regime estacionário do peptídeo melanotrópico $\alpha$-MSH (carga +1$)$, e de seus análogos cíclicos (carga +2), em dispersões lipídicas de DMPG (carregadas negativamente) foram monitorados, e comparados com os valores obtidos de duas outras amostras utilizadas como padrão: o NATA e o Boc-D-Nal. Os experimentos foram realizados em três temperaturas. Numa delas, a membrana lipídica está na fase gel $(10 \circ \mathrm{C})$, e nas outras duas a membrana se encontra na fase intermediária $\left(25^{\circ} \mathrm{C}\right)$ e fluida $\left(40{ }^{\circ} \mathrm{C}\right)$, respectivamente (Riske et al., 2001). Na relação peptídeo/lipídeo usada (5 x 10-5 M de peptídeo, $1 \mathrm{mM}$ de lipídeo), os peptídeos catiônicos devem estar quase totalmente associados às bicamadas lipídicas aniônicas (Ito et al., 1993).

$\mathrm{O}$ espectro de emissão fluorescente do $\alpha-\mathrm{MSH}$, gerado pelo resíduo Trp, quando este se encontra no complexo com vesículas de DMPG a uma razão de lipídeo/peptídeo (L/P) de 20:1, apresentou um deslocamento do máximo do espectro da fluorescência para comprimentos de ondas menores ("blue shift"), de $357 \mathrm{~nm}$ para aproximadamente $342 \mathrm{~nm}$, e um aumento da intensidade. A mudança da posição de máximo se deve, provavelmente, à entrada do resíduo Trp em um ambiente mais hidrofóbico, tal como o encontrado na fase lipídica de membranas. O aumento da intensidade fluorescente resulta, provavelmente, da redução de processos de decaimento não radiativos, relacionados com interações com o solvente (Ito et al., 1993 e referências lá citadas). É interessante notar que, em presença de DMPG o espectro de emissão fluorescente dos análogos cíclicos (HS-032 e HS-053) é semelhante ao espectro do D-Nal livre em solução aquosa ou em etanol. Isto indica que, em ambiente hidrofóbico, predomina a fluorescência do D-Nal quando comparada à do Trp. Nenhuma diferença significativa foi observada entre os dois peptídeos cíclicos estudados. 
O Boc-D-Nal em água ou etanol tem espectros muito semelhantes (ver figura inserida na Fig. 4.3.5). Além disso, não é observada variação da intensidade com o aumento de temperatura em etanol. Entretanto, quando o meio é polar, como a água, o aumento de temperatura favorece os processos de relaxação através do solvente, diminuindo a intensidade de fluorescência.

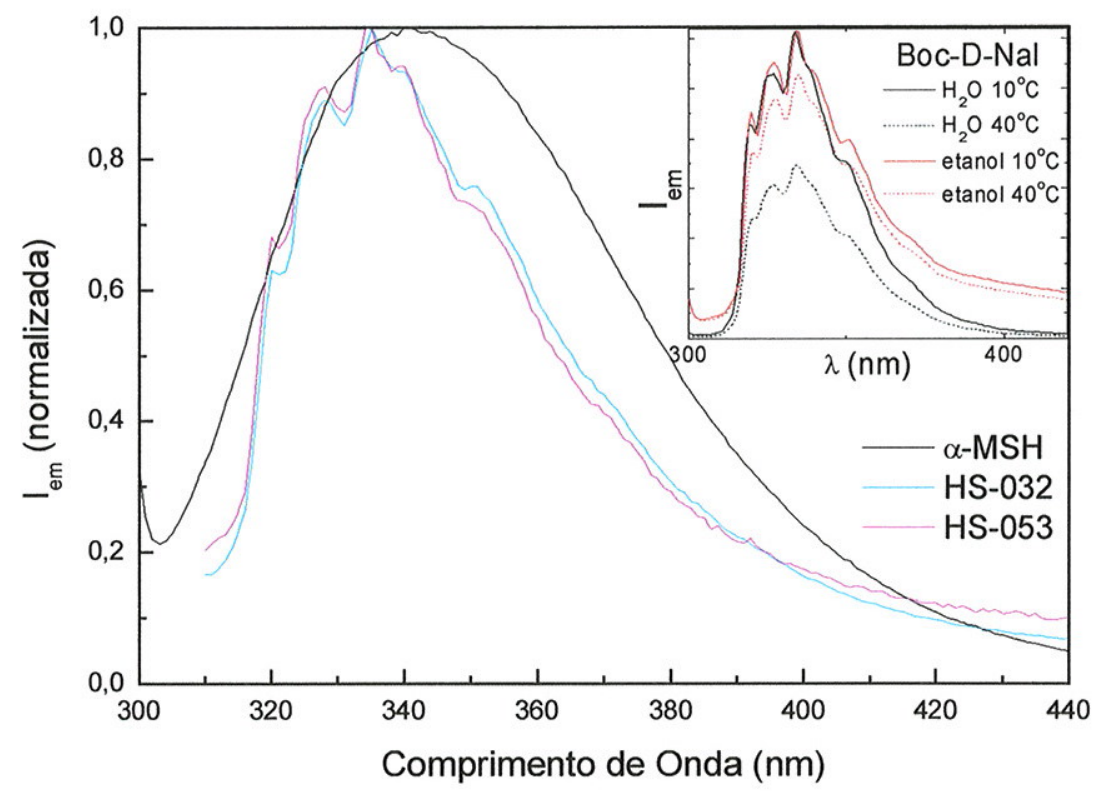

Figura 4.3.5 - Intensidades normalizadas da emissão fluorescente do $\alpha$-MSH, HS-032 e HS-053 em $1 \mathrm{mM}$ de DMPG à $25^{\circ} \mathrm{C}$. A figura inserida mostra espectros do Boc-D-Nal em água e etanol à 10 e $40^{\circ} \mathrm{C}$ (para parâmetros experimentais ver Fig. 4.3.2).

As curvas de decaimento fluorescente do $\alpha-\mathrm{MSH}, \mathrm{HS}-032$ e HS-053 em presença de DMPG, também foram obtidas, nas mesmas condições experimentais mencionadas em solução aquosa (Figura 4.3.6).

$\mathrm{Na}$ presença de vesículas, os fluoróforos contidos no $\alpha$-MSH, HS-032 e HS-053 permanecem muito mais tempo em seus estados excitados (comparar a escala de tempo das Figs. 4.3.4 e 4.3.6). Isto deve estar associado a uma redução da taxa de decaimento não-radiativo devido à redução da polaridade do meio (ambiente hidrofóbico), sendo, portanto, uma forte indicação de que tanto o Trp como o D-Nal penetram na bicamada lipídica. 


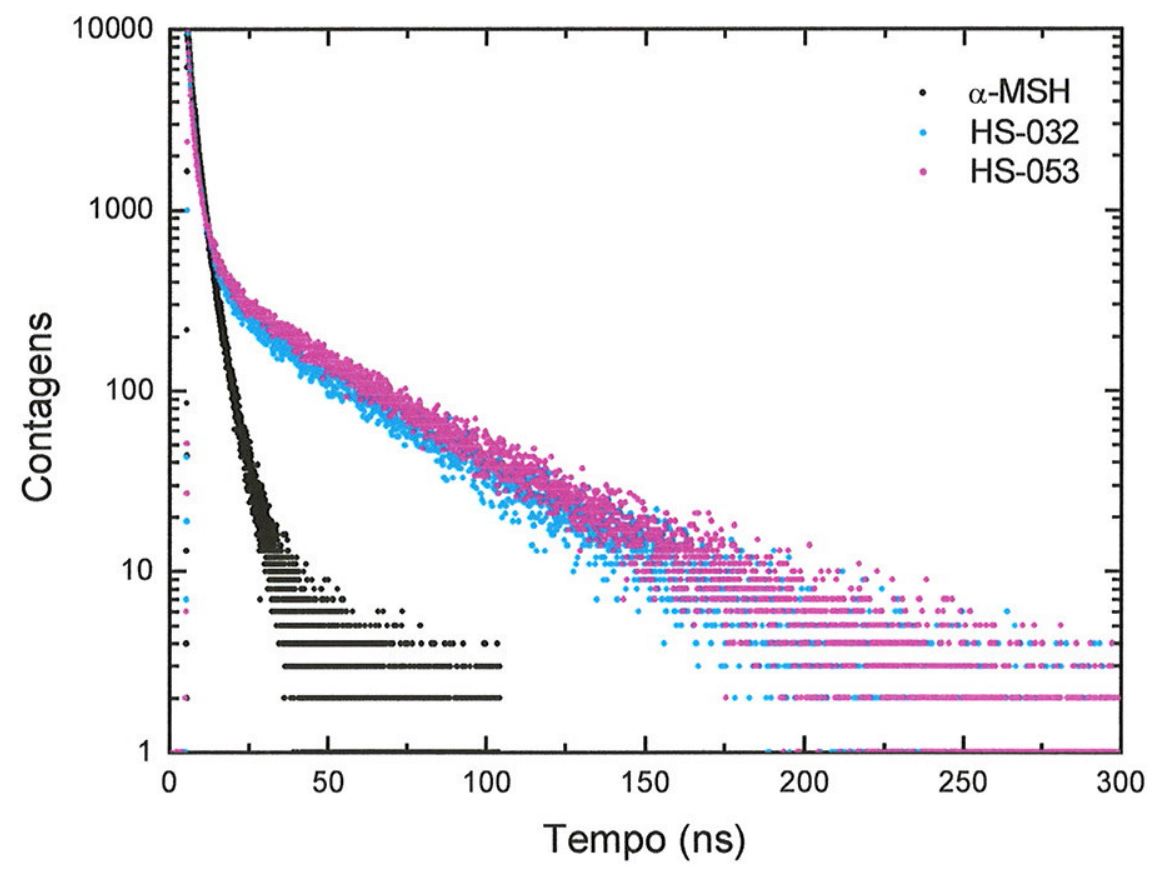

Figura 4.3.6 -Curvas de decaimento fluorescente do $\alpha$-MSH, HS-032 e HS-053 (5 x 10-5 M) em presença de DMPG a $25^{\circ} \mathrm{C}$, no comprimento de onda $355 \mathrm{~nm}, \lambda_{\text {exc }}=296 \mathrm{~nm}$.

Da mesma maneira que na seção anterior, as curvas de decaimento de fluorescência foram ajustadas por uma função multi-exponencial (ver Materiais e métodos), e os valores dos tempos de vida foram obtidos pela análise global. Os tempos de vida do $\alpha$-MSH e seus análogos cíclicos em presença de DMPG, às temperaturas de $10{ }^{\circ} \mathrm{C}, 25{ }^{\circ} \mathrm{C}$ e $40{ }^{\circ} \mathrm{C}$, são apresentados nas Tabelas 4.3.1, 4.3.2 e 4.3.3. Como anteriormente mencionado, o conjunto de tempos apresentado nessas tabelas, para cada peptídeo, é um conjunto que satisfaz os ajustes no intervalo de comprimento de onda de emissão de 325 a $380 \mathrm{~nm}$. O decaimento do $\alpha-\mathrm{MSH}$ praticamente não varia com o comprimento de onda de emissão, sendo que o decaimento dos peptídeos cíclicos, onde Trp e D-Nal coexistem, tem uma certa dependência com o comprimento de onda de emissão (dados não mostrados). 
Tabela 4.3.1 - Tempos de vida do estado excitado (ns) do $\alpha$-MSH e de seus análogos cíclicos (HS-032 e HS-053), em solução aquosa e em presença de DMPG à temperatura de $10^{\circ} \mathrm{C}$.

\begin{tabular}{ccccccc}
\hline & \multicolumn{2}{c}{$\alpha-$ MSH } & \multicolumn{2}{c}{ HS-032 } & \multicolumn{2}{c}{ HS-053 } \\
& solução & DMPG & solução & DMPG & solução & DMPG \\
\hline$\tau_{0}$ & & & 22,11 & 50,37 & 22,21 & 53,85 \\
$\tau_{1}{ }^{\mathrm{a}}$ & 4,04 & 6,05 & 4,07 & 9,07 & 4,17 & 15,03 \\
$\tau_{2}{ }^{\mathrm{a}}$ & 1,99 & 2,65 & 1,89 & 2,85 & 1,85 & 3,50 \\
$\tau_{3}{ }^{\mathrm{a}}$ & 0,27 & 0,54 & 0,31 & 0,70 & 0,32 & 1,02 \\
$<\tau>\mathrm{b}$ & 3,31 & 3,91 & 2,68 & 3,75 & 2,66 & 5,89 \\
\hline
\end{tabular}

a $\tau_{1}, \tau_{2}$ e $\tau_{3}$ referem-se respectivamente aos tempos longo, intermediário e curto do Trp.

b $\mathrm{O}$ tempo de vida médio $<\tau>$ foi calculado a partir das componentes do Trp obtidas pela análise global. $\tau_{\mathrm{NATA}}=3,43$ ns e $\tau_{\text {Boc-D-Nal }}=38,08 \mathrm{~ns}$; em água destilada (constante dielétrica $\varepsilon \approx 80,0$ ). $\tau_{\mathrm{NATA}}=4,21 \mathrm{~ns}$ e $\tau_{\mathrm{Boc}-\mathrm{D}-\mathrm{Nal}}=25,93$; em etanol (constante dielétrica $\varepsilon \approx 24,3$ ).

Tabela 4.3.2 - Tempos de vida do estado excitado (ns) do $\alpha$-MSH e de seus análogos cíclicos (HS-032 e HS-053), em solução aquosa e em presença de DMPG à temperatura de $25^{\circ} \mathrm{C}$.

\begin{tabular}{ccccccc}
\hline & \multicolumn{2}{c}{$\alpha-$ MSH } & \multicolumn{2}{c}{ HS-032 } & \multicolumn{2}{c}{ HS-053 } \\
& solução & DMPG & solução & DMPG & solução & DMPG \\
\hline$\tau_{0}$ & & & 16,45 & 41,90 & 17,15 & 43,97 \\
$\tau_{1}{ }^{\mathrm{a}}$ & 2,92 & 5,14 & 3,66 & 6,05 & 4,34 & 13,14 \\
$\tau_{2}{ }^{\mathrm{a}}$ & 1,60 & 2,19 & 1,60 & 2,04 & 1,64 & 2,84 \\
$\tau_{3}{ }^{\mathrm{a}}$ & 0,27 & 0,49 & 0,31 & 0,46 & 0,37 & 0,91 \\
$<\tau>\mathrm{b}$ & 2,37 & 2,90 & 2,03 & 2,85 & 2,03 & 4,22 \\
\hline
\end{tabular}

a $\tau_{1}, \tau_{2}$ e $\tau_{3}$ referem-se respectivamente aos tempos longo, intermediário e curto do Trp.

b O tempo de vida médio $<\tau>$ foi calculado a partir das componentes do Trp obtidas pela análise global.

Tabela 4.3.3 - Tempos de vida do estado excitado (ns) do $\alpha$-MSH e de seus análogos cíclicos (HS-032 e HS-053), em solução aquosa e em presença de DMPG à temperatura de $40^{\circ} \mathrm{C}$.

\begin{tabular}{ccccccc}
\hline & \multicolumn{2}{c}{$\alpha-\mathrm{MSH}$} & \multicolumn{2}{c}{ HS-032 } & \multicolumn{2}{c}{ HS-053 } \\
& solução & DMPG & solução & DMPG & solução & DMPG \\
\hline$\tau_{0}$ & & & 12,68 & 32,89 & 13,32 & 35,12 \\
$\tau_{1}{ }^{\mathrm{a}}$ & 2,19 & 4,20 & 3,70 & 6,09 & 4,33 & 9,98 \\
$\tau_{2}{ }^{\mathrm{a}}$ & 1,36 & 1,71 & 1,33 & 1,78 & 1,31 & 2,25 \\
$\tau_{3}{ }^{\mathrm{a}}$ & 0,27 & 0,39 & 0,29 & 0,41 & 0,33 & 0,80 \\
$<\tau>$ b & 1,70 & 2,18 & 1,59 & 2,35 & 1,58 & 3,19 \\
\hline
\end{tabular}

a $\tau_{1}, \tau_{2}$ e $\tau_{3}$ referem-se respectivamente aos tempos longo, intermediário e curto do Trp.

b O tempo de vida médio $<\tau>$ foi calculado a partir das componentes do Trp obtidas pela análise global. $\tau_{\mathrm{NATA}}=2,08 \mathrm{~ns}$ e $\tau_{\mathrm{Boc}-\mathrm{D}-\mathrm{Nal}}=33,61 \mathrm{~ns}$; em água destilada (constante dielétrica $\varepsilon \approx 80,0$ ).

$\tau_{\mathrm{NATA}}=2,08 \mathrm{~ns}$ e $\tau_{\mathrm{Boc}-\mathrm{D}-\mathrm{Nal}}=22,21 \mathrm{~ns}$; em etanol (constante dielétrica $\varepsilon \approx 24,3$ ). 
As componentes espectrais relativas aos tempos de vida de ambos os resíduos fluorescentes dos peptídeos cíclicos em ambiente lipídico (Figs. 4.3.8d a 4.3.8f), praticamente não variam com a temperatura, independente da fase em que a membrana se encontra. Contrário a esse comportamento e similar ao observado no $\alpha-$ MSH em solução aquosa, o espectro associado ao tempo $\tau_{1}$ do Trp presente nestes peptídeos em meio aquoso diminui sua porcentagem com o aumento de temperatura, enquanto que a contribuição do tempo curto praticamente não se altera (Figs. 4.3.8a a 4.3.8c). Além disso, comparando o $\alpha$-MSH e os peptídeos cíclicos em solução aquosa, verifica-se que o último favorece a contribuição da componente de tempo intermediário do Trp (ver Tabelas 4.3.4 e 4.3.6). Em presença de DMPG, o D-Nal aumenta bastante sua contribuição relativa, e diminui a contribuição do Trp nesse peptídeo. Como mencionado anteriormente, o aumento no tempo de vida do $\mathrm{D}-\mathrm{Nal}$ pode ser atribuído a uma maior penetração na membrana lipídica.

Nas Tabelas 4.3.1, 4.3.2 e 4.3.3 ficam explícitos os significativos aumentos dos três tempos de vida do Trp em presença de DMPG, para os três peptídeos. Os resultados evidenciam a penetração do Trp na bicamada lipídica, nas três temperaturas estudadas, portanto, com a membrana nas diferentes fases. É interessante notar que, na bicamada lipídica, o Trp nos peptídeos cíclicos apresenta tempos de vida bastante maiores do que os apresentados pelo fluoróforo em $\alpha-\mathrm{MSH}$, sendo que os tempos relativos ao HS-053 são ainda bem maiores do que os do HS032. Este resultado sugere que para o análogo HS-053 o Trp penetra mais profundo na bicamada, portanto em um ambiente mais hidrofóbico (ver perfil de hidrofobicidade do DMPG no ítem 4.1.3).

É interessante também o grande aumento do tempo de vida do D-Nal para os peptídeos cíclicos em DMPG (aproximadamente 1,5 vezes) ${ }^{12}$. Os resultados sugerem que o D-Nal também penetra na bicamada lipídica, tendo o tempo de vida do estado excitado muito aumentado, provavelmente devido à diminuição da interação com moléculas de água. Outro fator que deve estar contribuindo é a redução da supressão da fluorescência do D-Nal pelo Trp no interior da membrana. Similar ao observado com o Trp, o D-Nal no peptídeo HS-053 parece penetrar mais fundo na membrana do que no análogo HS-032: no primeiro peptídeo, as diferenças entre os tempos de vida em solução e na bicamada lipídica são maiores (Tabelas 4.3.1, 4.3.2 e 4.3.3).

\footnotetext{
${ }^{12}$ Não vamos comparar este resultado com a diminuição do tempo de vida do Boc-D-Nal em etanol relativo ao fluoróforo em meio aquoso. Isto porque achamos que o efeito em etanol pode ser um efeito específico deste solvente, e estudos em outros solventes são necessários.
} 
Similarmente ao que foi feito em solução aquosa, os espectros associados ao decaimento, bem como a contribuição percentual de cada uma das componentes dos tempos de vida e o comprimento de onda do máximo foram obtidos (Tabelas 4.3.5, 4.3.7 e 4.3.9). Isto nos leva a supor que as modificações estruturais devidas às diferenças nos peptídeos são muito mais expressivas em DMPG do que em solução aquosa.

Os espectros associados do $\alpha$-MSH em DMPG (Fig. 4.3.7d a 4.3.7f), mostram que as componentes relativas a $\tau_{2}$ e $\tau_{3}$ aumentam com a temperatura, enquanto que $\tau_{1}$ diminui bastante sua contribuição, similar ao que ocorre no $\alpha$-MSH em solução aquosa. Entretanto, as contribuições das componentes relativas aos tempos intermediário $\left(\tau_{2}\right)$ e curto $\left(\tau_{3}\right)$ (Tabela 4.3.5) são mais favorecidas quando o Trp se encontra na fase lipídica (comparar com Tabela 4.3.4), seja nas fases gel, intermediária ou líquido-cristalina da membrana.
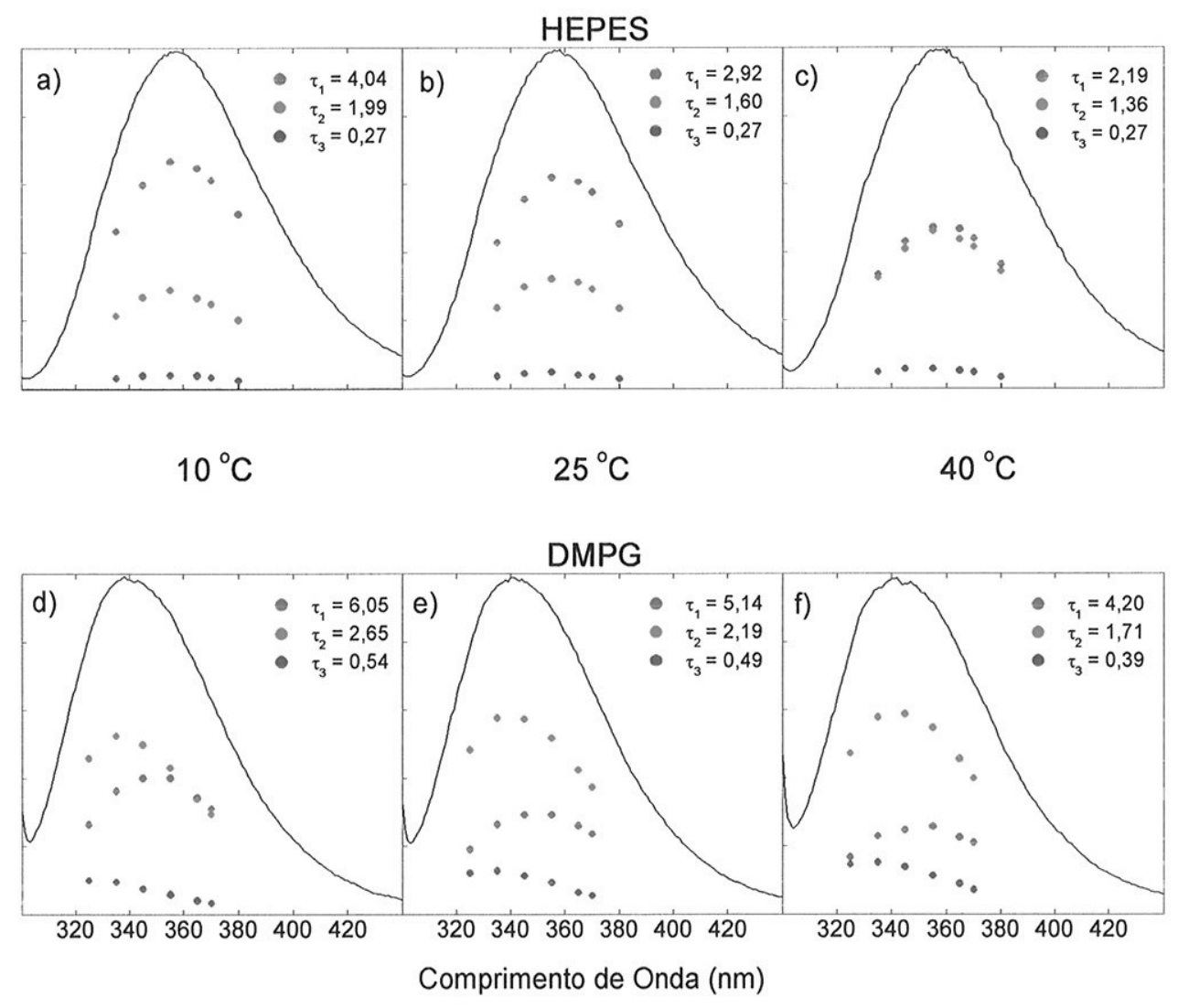

Figura 4.3.7 - Espectros de emissão associados ao decaimento do $\alpha$-MSH em solução aquosa (a, b, c) e em presença de vesículas de DMPG (d, e, f) obtidos a $10^{\circ} \mathrm{C}$ (a e d), $25^{\circ} \mathrm{C}$ (b e e) e 40 ${ }^{\circ} \mathrm{C}$ (c e f), relativos aos tempos longo $\tau_{1}(\ominus)$, intermediário $\tau_{2}(\ominus)$ e curto $\tau_{3}(\ominus)$. O espectro no regime estacionário $(-)$ também é apresentado. 
Tabela 4.3.4 - Comprimento de onda de máxima intensidade $\lambda_{\max }(\mathrm{nm})$ e contribuição percentual (\%) da área integrada das componentes espectrais dos tempos de vida do Trp presente no $\alpha$-MSH em solução aquosa, obtidos a $10^{\circ} \mathrm{C}, 25^{\circ} \mathrm{C}$ e $40^{\circ} \mathrm{C}$, pela análise global de um conjunto de dados no intervalo de 325 a $380 \mathrm{~nm}$.

\begin{tabular}{|c|c|c|c|c|c|c|}
\hline & \multicolumn{2}{|c|}{$10^{\circ} \mathrm{C}$} & \multicolumn{2}{|c|}{$25^{\circ} \mathrm{C}$} & \multicolumn{2}{|c|}{$40^{\circ} \mathrm{C}$} \\
\hline & $\lambda_{\max }$ & $\%$ & $\lambda_{\max }$ & $\%$ & $\lambda_{\max }$ & $\%$ \\
\hline$\tau_{1}{ }^{a}$ & 358,9 & 67,61 & 358,9 & 63,08 & 358,9 & 48,34 \\
\hline$\tau_{2}{ }^{a}$ & 353,2 & 28,75 & 356,0 & 32,56 & 356,0 & 46,12 \\
\hline$\tau_{3} \mathrm{a}$ & 353,2 & 3,64 & 350,4 & 4,36 & 350,4 & 5,54 \\
\hline
\end{tabular}

a $\tau_{1}, \tau_{2}$ e $\tau_{3}$ referem-se respectivamente aos tempos longo, intermediário e curto do Trp.

Tabela 4.3.5 - Comprimento de onda de máxima intensidade $\lambda_{\max }(\mathrm{nm})$ e contribuição percentual (\%) da área integrada das componentes espectrais dos tempos de vida do Trp presente no $\alpha-\mathrm{MSH}$ em presença de vesículas de DMPG, obtidos a $10^{\circ} \mathrm{C}, 25^{\circ} \mathrm{C}$ e $40^{\circ} \mathrm{C}$, pela análise global de um conjunto de dados no intervalo de 325 a $380 \mathrm{~nm}$.

\begin{tabular}{|c|c|c|c|c|c|c|}
\hline & \multicolumn{2}{|c|}{$10^{\circ} \mathrm{C}$} & \multicolumn{2}{|c|}{$25^{\circ} \mathrm{C}$} & \multicolumn{2}{|c|}{$40^{\circ} \mathrm{C}$} \\
\hline & $\lambda_{\max }$ & $\%$ & $\lambda_{\max }$ & $\%$ & $\lambda_{\max }$ & $\%$ \\
\hline$\tau_{1}{ }^{a}$ & 348,9 & 40,88 & 348,9 & 30,05 & 348,9 & 25,97 \\
\hline$\tau_{2}{ }^{a}$ & 337,5 & 51,10 & 340,4 & 58,44 & 343,2 & 59,89 \\
\hline$\tau_{3}{ }^{a}$ & 326,2 & 8,02 & 331,9 & 11,51 & 331,9 & 14,14 \\
\hline
\end{tabular}

a $\tau_{1}, \tau_{2}$ e $\tau_{3}$ referem-se respectivamente aos tempos longo, intermediário e curto. 

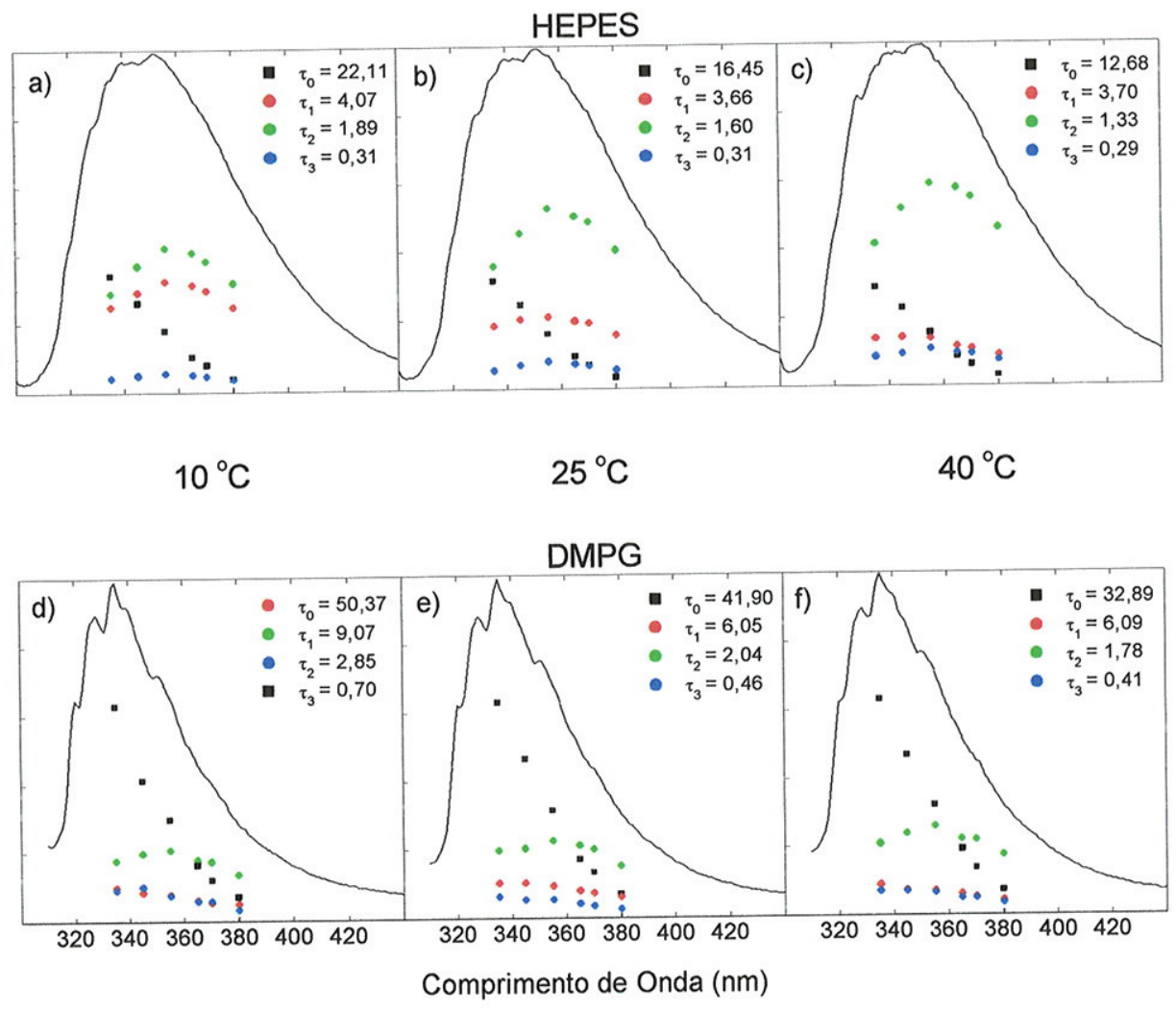

Figura 4.3.8 - Espectros de emissão associados ao decaimento do análogo cíclico HS-032 em solução aquosa (a, b, c) e em presença de vesículas de DMPG (d, e, f) obtidos a $10{ }^{\circ} \mathrm{C}$ (a e d), 25 ${ }^{\circ} \mathrm{C}$ (b e e) e $40^{\circ} \mathrm{C}$ (c e f), relativos aos tempos longo $\tau_{1}(\ominus)$, intermediário $\tau_{2}(\ominus)$ e curto $\tau_{3}(\ominus)$ do Trp, e ao tempo $\tau_{0}$ do D-Nal $(\square)$. O espectro no regime estacionário $(-)$ também é apresentado.

Tabela 4.3.6 - Comprimento de onda de máxima intensidade $\lambda_{\max }(\mathrm{nm})$ e contribuição percentual (\%) da área integrada das componentes espectrais dos tempos de vida do Trp e D$\mathrm{Nal}$ presentes no HS-032 em solução aquosa, obtidos a $10^{\circ} \mathrm{C}, 25^{\circ} \mathrm{C}$ e $40^{\circ} \mathrm{C}$, pela análise global de um conjunto de dados no intervalo de 330 a $380 \mathrm{~nm}$.

\begin{tabular}{|c|c|c|c|c|c|c|}
\hline & \multicolumn{2}{|c|}{$10^{\circ} \mathrm{C}$} & \multicolumn{2}{|c|}{$25^{\circ} \mathrm{C}$} & \multicolumn{2}{|c|}{$40^{\circ} \mathrm{C}$} \\
\hline & $\lambda_{\max }$ & $\%$ & $\lambda_{\max }$ & $\%$ & $\lambda_{\max }$ & $\%$ \\
\hline$\tau_{0}{ }^{\mathrm{a}}$ & & 20,06 & & 18,31 & & 16,82 \\
\hline$\tau_{1} b$ & 358,9 & 32,83 & 355,0 & 21,85 & 344,7 & 13,9 \\
\hline$\tau_{2}{ }^{b}$ & 358,9 & 41,89 & 358,9 & 52,36 & 358,9 & 58,97 \\
\hline$\tau_{3} b$ & 356,1 & 5,22 & 356,1 & 7,48 & 356,1 & 10,31 \\
\hline
\end{tabular}

a $\tau_{0}$ refere-se ao tempo de vida do D-Nal.

b $\tau_{1}, \tau_{2}$ e $\tau_{3}$ referem-se respectivamente aos tempos longo, intermediário e curto do Trp. 
Tabela 4.3.7 - Comprimento de onda de máxima intensidade $\lambda_{\max }(\mathrm{nm})$ e contribuição percentual (\%) da área integrada das componentes espectrais dos tempos de vida do Trp e DNal presentes no HS-032 em vesículas de DMPG, obtidos a $10^{\circ} \mathrm{C}, 25^{\circ} \mathrm{C}$ e $40^{\circ} \mathrm{C}$, pela análise global de um conjunto de dados no intervalo de 330 a $380 \mathrm{~nm}$.

\begin{tabular}{|c|c|c|c|c|c|c|}
\hline & \multicolumn{2}{|c|}{$10^{\circ} \mathrm{C}$} & \multicolumn{2}{|c|}{$25^{\circ} \mathrm{C}$} & \multicolumn{2}{|c|}{$40^{\circ} \mathrm{C}$} \\
\hline & $\lambda_{\max }$ & $\%$ & $\lambda_{\max }$ & $\%$ & $\lambda_{\max }$ & $\%$ \\
\hline$\tau_{0}{ }^{a}$ & & 48,24 & & 48,85 & & 48,42 \\
\hline$\tau_{1} b$ & & 11,27 & 341,9 & 13,13 & & 9,81 \\
\hline$\tau_{2} b$ & 353,2 & 29,09 & 356,0 & 30,88 & 353,2 & 32,23 \\
\hline$\tau_{3} b$ & 341,9 & 11,40 & & 7,14 & 339,0 & 8,54 \\
\hline
\end{tabular}

a $\tau_{0}$ refere-se ao tempo de vida do D-Nal.

${ }^{\mathrm{b}} \tau_{1}, \tau_{2}$ e $\tau_{3}$ referem-se respectivamente aos tempos longo, intermediário e curto do Trp.

Analisando a Figura 4.3.7, podemos dizer que, se atribuirmos a cada tempo de vida do $\operatorname{Trp}\left(\tau_{1}, \tau_{2}\right.$ e $\left.\tau_{3}\right)$ uma conformação do cromóforo, para o $\alpha$-MSH em solução predomina a conformação associada $\operatorname{com} \tau_{1}$, e em DMPG aquela associada com $\tau_{2}$. É interessante notar que nos peptídeos cíclicos (Figs. 4.3 .8 e 4.3.9), mesmo em tampão, predomina a conformação associada com $\tau_{2}$, parecendo que ele já se encontra na forma mais adequada para penetração na membrana.

Tabela 4.3.8 - Comprimento de onda de máxima intensidade $\lambda_{\max }(\mathrm{nm})$ e contribuição percentual (\%) da área integrada das componentes espectrais dos tempos de vida do Trp e DNal presentes no HS-053 em solução aquosa, obtidos a $10^{\circ} \mathrm{C}, 25^{\circ} \mathrm{C}$ e $40^{\circ} \mathrm{C}$, pela análise global de um conjunto de dados no intervalo de 330 a $380 \mathrm{~nm}$.

\begin{tabular}{|c|c|c|c|c|c|c|}
\hline & \multicolumn{2}{|c|}{$10^{\circ} \mathrm{C}$} & \multicolumn{2}{|c|}{$25^{\circ} \mathrm{C}$} & \multicolumn{2}{|c|}{$40^{\circ} \mathrm{C}$} \\
\hline & $\lambda_{\max }$ & $\%$ & $\lambda_{\max }$ & $\%$ & $\lambda_{\max }$ & $\%$ \\
\hline$\tau_{0}{ }^{a}$ & & 20,95 & & 18,47 & & 16,21 \\
\hline$\tau_{1} b$ & 356,1 & 30,98 & 344,7 & 16,50 & 336,2 & 12,64 \\
\hline$\tau_{2} b$ & 358,9 & 42,61 & 358,9 & 54,93 & 358,9 & 56,87 \\
\hline$\tau_{3}{ }^{b}$ & 356,1 & 5,46 & 353,2 & 10,10 & 358,9 & 14,28 \\
\hline
\end{tabular}

a $\tau_{0}$ refere-se ao tempo de vida do D-Nal.

${ }^{\mathrm{b}} \tau_{1}, \tau_{2}$ e $\tau_{3}$ referem-se respectivamente aos tempos longo, intermediário e curto do Trp. 
Tabela 4.3.9 - Comprimento de onda de máxima intensidade $\lambda_{\max }(\mathrm{nm})$ e contribuição percentual (\%) da área integrada das componentes espectrais dos tempos de vida do Trp e DNal presentes no HS-053 em vesículas de DMPG, obtidos a $10^{\circ} \mathrm{C}, 25^{\circ} \mathrm{C}$ e $40^{\circ} \mathrm{C}$, pela análise global de um conjunto de dados no intervalo de 330 a $380 \mathrm{~nm}$.

\begin{tabular}{|c|c|c|c|c|c|c|}
\hline & \multicolumn{2}{|c|}{$10^{\circ} \mathrm{C}$} & \multicolumn{2}{|c|}{$25^{\circ} \mathrm{C}$} & \multicolumn{2}{|c|}{$40^{\circ} \mathrm{C}$} \\
\hline & $\lambda_{\max }$ & $\%$ & $\lambda_{\max }$ & $\%$ & $\lambda_{\max }$ & $\%$ \\
\hline$\tau_{0} \mathrm{a}$ & & 54,76 & & 53,41 & & 50,00 \\
\hline$\tau_{1} b$ & & 12,7 & & 9,09 & & 9,46 \\
\hline$\tau_{2} b$ & 353,2 & 20,63 & 350,4 & 23,86 & 353,2 & 24,32 \\
\hline$\tau_{3} b$ & & 11,91 & 344,7 & 13,64 & 344,7 & 16,22 \\
\hline
\end{tabular}

a $\tau_{0}$ refere-se ao tempo de vida do D-Nal.

${ }^{\mathrm{b}} \tau_{1}, \tau_{2}$ e $\tau_{3}$ referem-se respectivamente aos tempos longo, intermediário e curto do Trp.

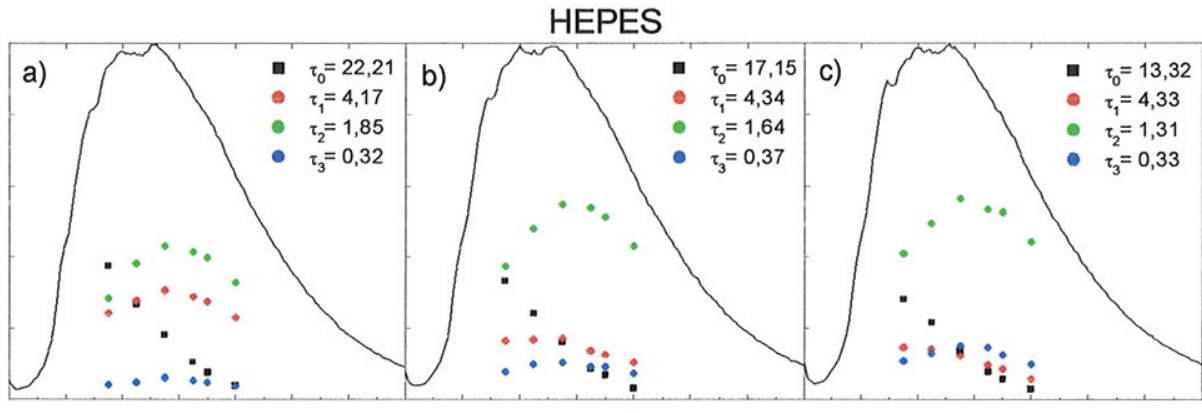

$10^{\circ} \mathrm{C}$

$25^{\circ} \mathrm{C}$

$40^{\circ} \mathrm{C}$

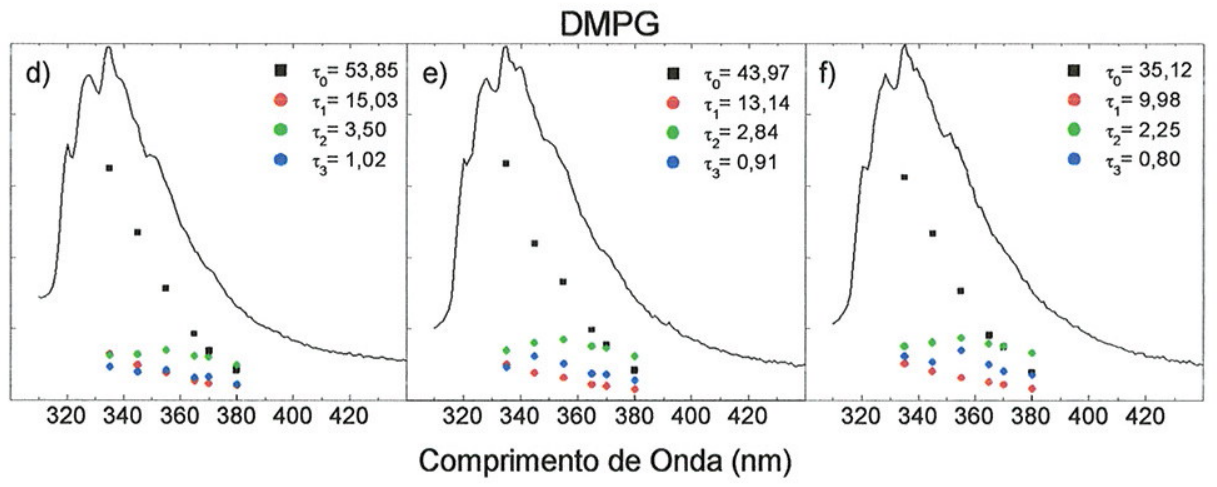

Figura 4.3.9 - Espectros de emissão associados ao decaimento do análogo cíclico HS-053 em solução aquosa (a, b, c) e em presença de vesículas de DMPG (d, e, f) obtidos a $10^{\circ} \mathrm{C}$ (a e d), 25 ${ }^{\circ} \mathrm{C}$ (b e e) e $40{ }^{\circ} \mathrm{C}$ (c e f), relativos aos tempos longo $\tau_{1}(\ominus)$, intermediário $\tau_{2}(\ominus)$ e curto $\tau_{3}(\ominus)$ do Trp, e ao tempo $\tau_{0}$ do D-Nal (घ). O espectro no regime estacionário $(-)$ também é apresentado. 


\subsubsection{Espectros de RPE do $\alpha$-MSH e análogos em dispersões de DMPG}

A interação do $\alpha$-MSH e seus análogos cíclicos com agregados de anfifilicos, também está sendo investigada pela técnica de RPE. A seguir, serão apresentados resultados preliminares, usando o marcador 12-PCSL incorporado à bicamada lipídica de DMPG (agora, a membrana lipídica é que está sendo monitorada). As Figuras 4.3.10 e 4.3.11 apresentam os espectros de RPE do 12-PCSL incorporado em $10 \mathrm{mM}$ de DMPG, na presença ou ausência de $10 \mathrm{~mol} \%$ de $\alpha$-MSH e seus análogos cíclicos, em ambas as fases gel e líquido cristalina da membrana, nas temperaturas de $5{ }^{\circ} \mathrm{C}$ e $40 \circ \mathrm{C}$, respectivamente. Alguns espectros de 12-PCSL apresentam uma pequena contribuição de marcador livre em solução, provavelmente devido à presença do marcador lisado.

Os espectros obtidos com as membranas na fase gel foram analisados através de medidas do parâmetro hiperfino máximo $A_{\text {màx }}$ (ver seção 2.3.3). O aumento deste parâmetro está associado à viscosidade do meio ou empacotamento (para uma discussão maior deste parâmetro ver, por exemplo, Turchiello et al., 2000). Os valores de $A_{\text {máx }}$ mostram que na fase gel os peptídeos HS-024, HS-032 e HS-053 enrijecem muito mais a membrana do que os peptídeos $\alpha$-MSH e HS-014 (Figura 4.3.12). Ao analisarmos estes dados não podemos esquecer que estamos numa concentração fixa de peptídeo/lipídeo (10 mol \%), e os peptídeos podem apresentar diferentes partições na bicamada lipídica. Ainda mais relevante é o fato dos peptídeos $\alpha$-MSH e HS-014 apresentarem, respectivamente, cargas aproximadas de +1 e zero no valor de $\mathrm{pH}$ usado, e os peptídeos HS-024, HS-032 e HS-053 carga +2. Portanto, é possível que o grande efeito observado esteja relacionado com a maior concentração dos peptídeos HS-024, HS-032 e HS-053 na superficie da membrana,favorecendo uma maior partição destes análogos na bicamada lipídica. Entretanto, apesar de neutro, o HS014 torna a membrana mais rígida do que o peptídeo monovalente $\alpha-\mathrm{MSH}$, mostrando, sem dúvida, que os peptídeos cíclicos ou particionam mais na bicamada lipídica em fase gel, ou produzem maior alteração em sua estrutura.

Os resultados obtidos com a membrana na fase fluida são muito diferentes dos descritos acima, para a fase gel. Na Figura 4.3.13 estão mostrados as relações entre as alturas das linhas de campo baixo (correspondendo ao número de spin nuclear do $\mathrm{N}$ $m_{I}=+1$ ) e campo central $h_{+1} / h_{0}$ (correspondendo a $m_{I}=0$ ) (ver seção 2.3.2), por ser um parâmetro mais sensivel para espectros com alta mobilidade do que algum outro parâmetro empírico (Biaggi et al, 1996 e 1997). Em geral, $h_{+1} / h_{0}$ é mais próximo da unidade quando a viscosidade do meio diminui. 


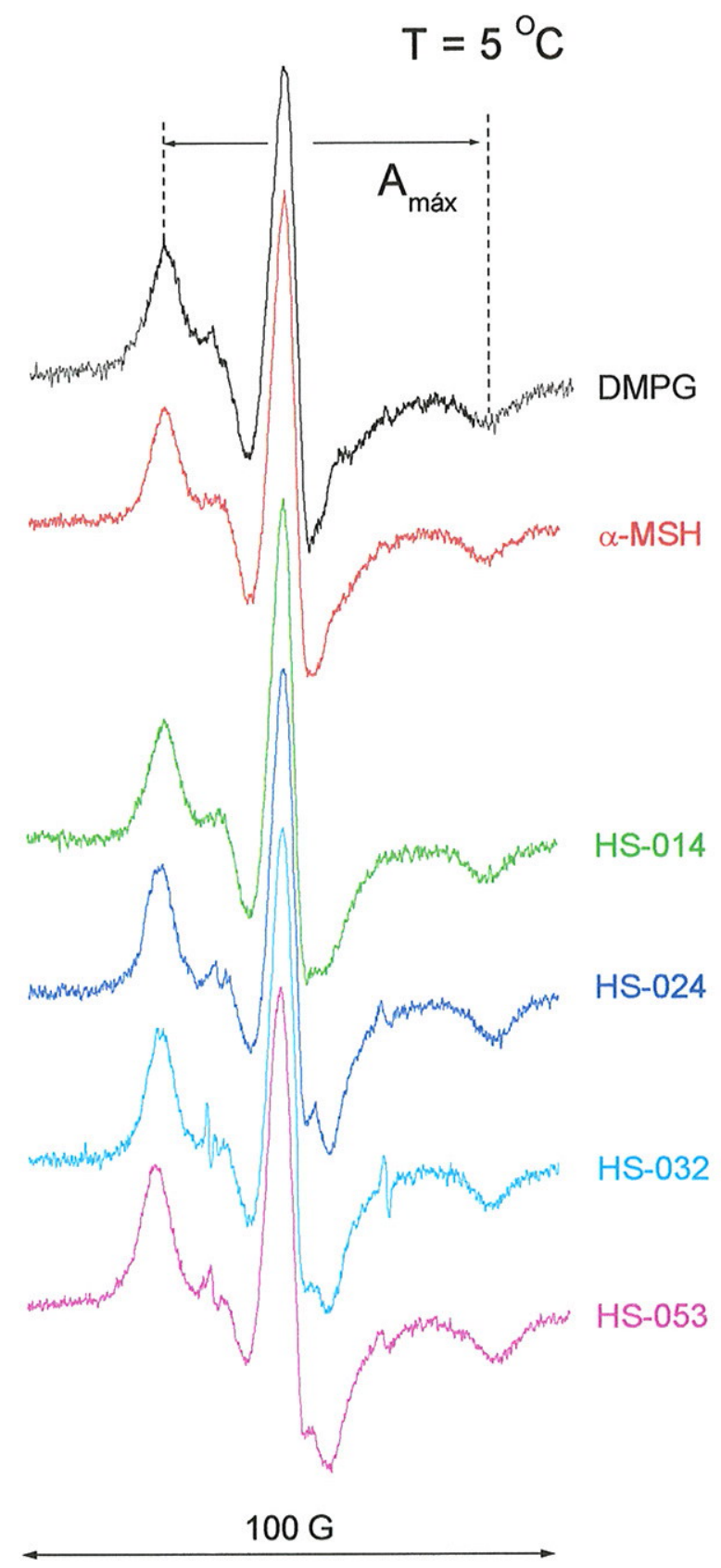

Figura 4.3.10 - Espectros de RPE obtidos com o marcador 12-PCSL (0.8 mol\%) em dispersões de $10 \mathrm{mM}$ de membrana de DMPG, na ausência e presença de $10 \mathrm{~mol} \% \alpha$-MSH e seus análogos cíclicos, à temperatura de $5{ }^{\circ} \mathrm{C}$. Largura total do espectro $100 \mathrm{G}$. 


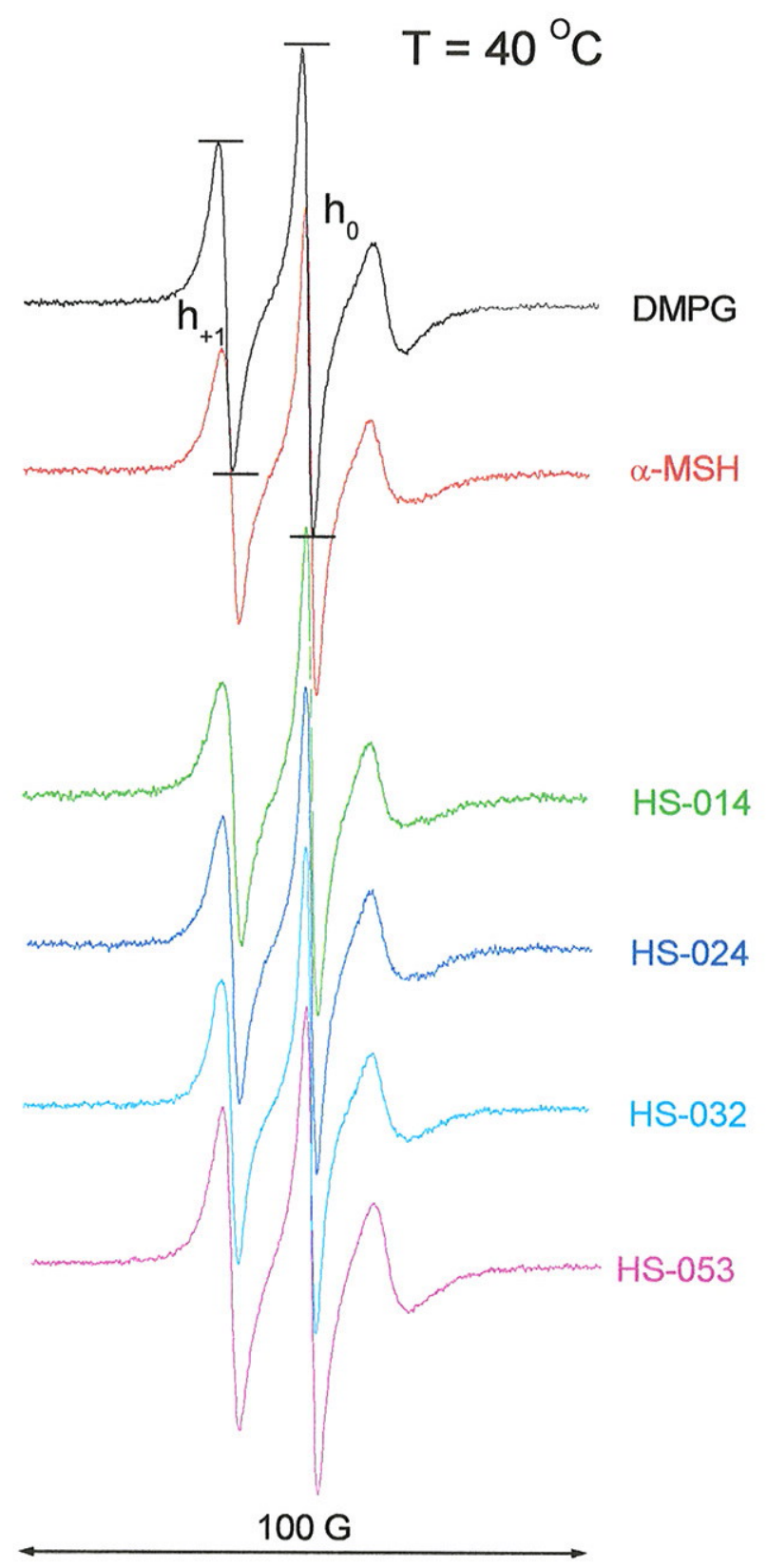

Figura 4.3.11 - Espectros de RPE obtidos com o marcador 12-PCSL (0.8 mol\%) em dispersões de $10 \mathrm{mM}$ de membrana de DMPG, na ausência e presença de $10 \mathrm{~mol} \% \alpha$-MSH e seus análogos cíclicos, à temperatura de $40^{\circ} \mathrm{C}$. Largura total do espectro $100 \mathrm{G}$. 
É interessante notar que, na fase fluida da membrana, o maior efeito (enrijecimento) está relacionado com o $\alpha-\mathrm{MSH}$, sendo que o análogo HS-053 causa a menor perturbação na bicamada. Neste caso, a carga total do peptídeo não parece ser relevante para a interação peptídeo/lipídeo.

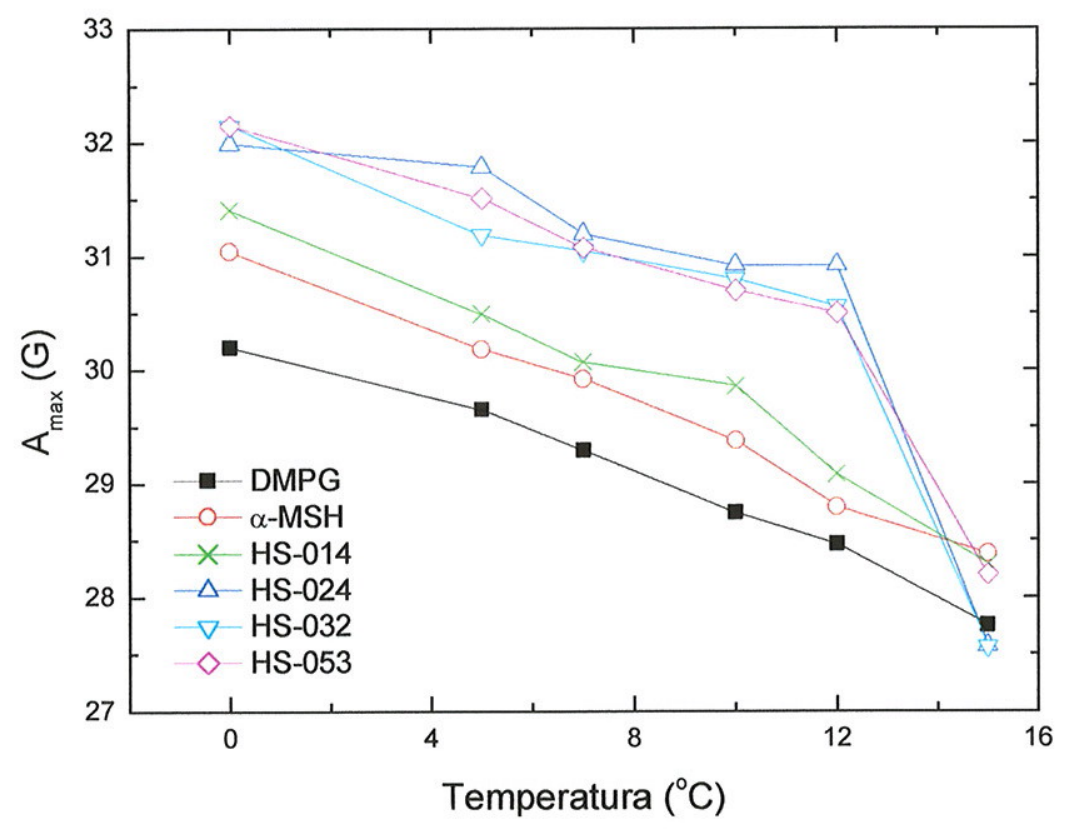

Figura 4.3.12 - Dependência do desdobramento máximo hiperfino $A_{\max }$ com a temperatura, do marcador fosfolipídico 12-PCSL em dispersões de $10 \mathrm{mM}$ de DMPG na ausência e presença de $10 \mathrm{~mol} \%$ de $\alpha$-MSH e seus análogos cíclicos.

Foi também utilizado outro parâmetro, a largura da linha de baixo campo $\Delta H_{+1}$, que pode ser medido nas várias temperaturas, de 0 a 45 ○C (Figura 4.3.14) (Turchiello et al., 2000). Este parâmetro também pode monitorar possiveis alterações causadas pelos peptídeos na transição de fase de bicamadas de DMPG. Quanto mais largo o pico central mais imobilizada se encontra a membrana, ou seja, o meio torna-se menos fluido (ver seção 2.3.1). Na fase gel os resultados são semelhantes aos obtidos com as medidas de $A_{\text {máx}}$ : efeitos análogos produzidos pelos $\alpha$-MSH e HS-014, sendo que os peptídeos HS-024, HS-032 e HS-053 enrijecem mais a membrana. Na fase fluida este não é um bom parâmetro para diferenciar os efeitos produzidos pelos vários peptídeos. Os peptídeos alteram o perfil de tansição de fase do DMPG, sem entretanto alterar muito a queda relativamente brusca, monitorada pelo 12 -PCSL, em torno de $20{ }^{\circ} \mathrm{C}$. 


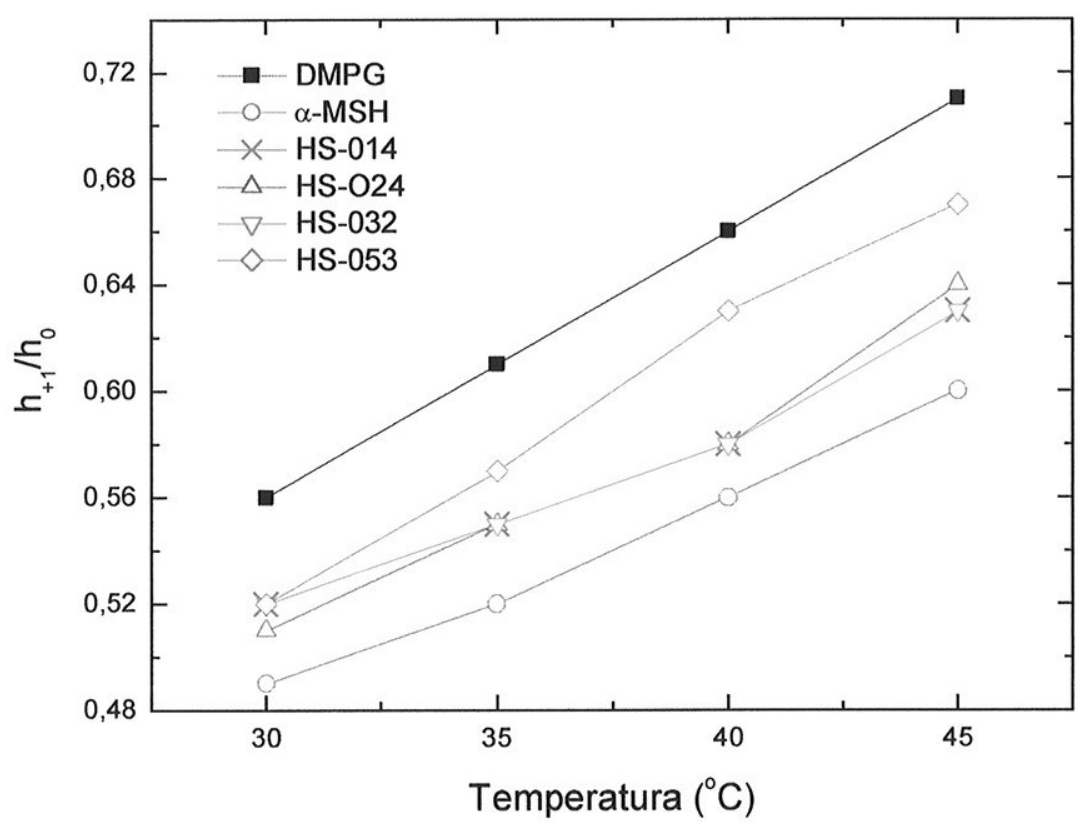

Figura 4.3.13 - Dependência da razão entre as alturas dos picos a campo baixo e campo central $h_{+1} / h_{0}$ com a temperatura, do marcador fosfolipídico 12-PCSL em dispersões $10 \mathrm{mM}$ de DMPG na ausência e presença de $10 \mathrm{~mol} \%$ de $\alpha-\mathrm{MSH}$ e seus análogos cíclicos.

O estudo por RPE de marcadores de spin da interação de peptídeos cíclicos com bicamadas lipídicas ainda encontra-se em fase preliminar. É dificil conciliar os resultados descritos acima com os dados obtidos com medidas de fluorescência dos peptídeos $\alpha$-MSH, HS-032 e HS-053, descritos na seção anterior. Os dados de RPE mostram claramente uma maior interação dos peptídeos cíclicos com a fase gel da bicamada, quando comparados com o $\alpha$-MSH, enquanto que na fase fluida existe uma inversão, sendo que o $\alpha$-MSH enrijece mais a bicamada lipídica. Entretanto, os dados de fluorescência sugerem que, para qualquer temperatura, os peptídeos cíclicos penetram mais na bicamada lipídica. Para completar os estudos por RPE é necessário a utilização de outros marcadores de spin, que monitorem outras profundidades da bicamada lipídica, principalmente próximo à superficie (5-PCSL), e um estudo da partição dos diferentes peptídos na membrana. 


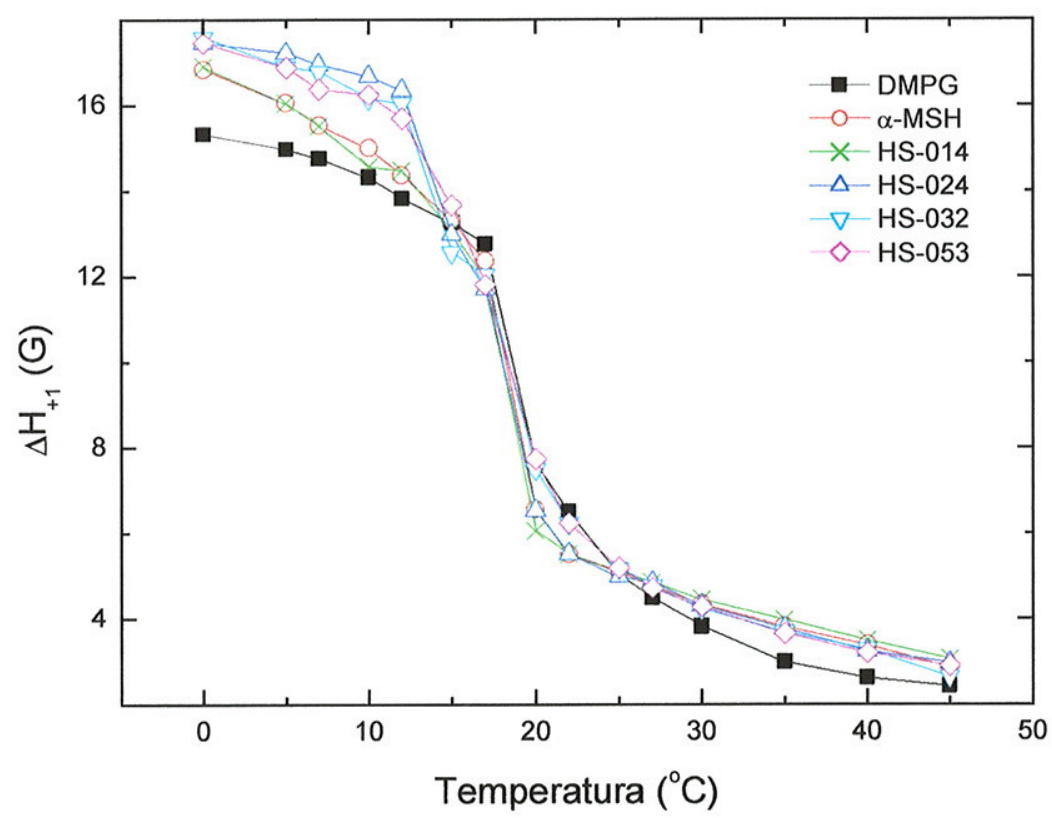

Figura 4.3.14 - Dependência da largura do pico a campo baixo $\Delta H_{+1}$ com a temperatura, do marcador fosfolipídico 12-PCSL em dispersões de $10 \mathrm{mM}$ de DMPG na ausência e presença de 10 mol\% de $\alpha$-MSH e seus análogos cíclicos. 


\section{4 $\alpha$-MSH e o análogo MSH-I marcados com a sonda paramagnética Toac: um estudo em solução}

(Trabalho em colaboração com o Prof. Dr. Clóvis R. Nakaie e o Prof. Dr. Amando S. Ito)

Peptídeos marcados com o Toac têm sido empregados, por exemplo, nos peptídeos vasoativos angiotensina II (AII) e bradicinina (BK), em posições específicas de suas cadeias. Entretanto, foi observada perda de atividade biológica em ambos os peptídeos (Nakaie et al., 1983 e 1996). Recentemente, foi obtida a primeira síntese do $\alpha$-MSH e MSH-I marcados com a sonda paramagnética Toac, porém mantendo sua atividade biológica (Barbosa et al., 1999 e Nakaie et al., 2001). Assim, esse resultado é de grande importância porque cria um potencial de novos estudos conformacionais de peptídeos pela técnica de RPE. A seguir, serão apresentados os resultados preliminares do estudo conformacional comparativo entre o $\alpha-\mathrm{MSH}$ e o seu análogo marcado (acetil-Toac ${ }^{0}-\alpha-\mathrm{MSH}$ ), assim como o MSH-I e seu análogo Ac-Toac ${ }^{0}-\mathrm{MSH}-\mathrm{I}$, em água e em tampão HEPES (ver seção 3.2).

\subsubsection{O Toac visto por RPE}

A estrutura química do Toac é mostrada abaixo. Como dito anteriormente (seção 1.5), por ser uma molécula pequena e fazer ligações peptídicas ele se liga rigidamente nas cadeias de aminoácidos.

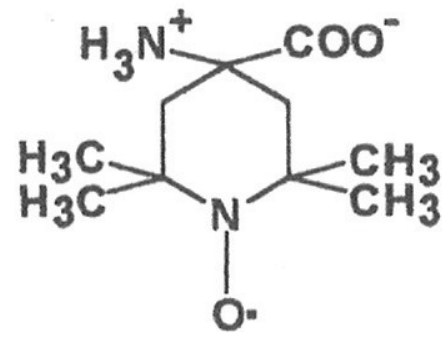

Figura 4.4.1 - Estrutura química do Toac (para nome completo, ver seção 3.1).

Quando comparado com o Ac-Toac ${ }^{0}-\alpha-\mathrm{MSH}$, o espectro de RPE mostra diferentes mobilidades entre o Toac livre e o ligado ao peptídeo (Figura 4.4.2), diluídos em água. Ambos os espectros apresentam linhas finas, como esperado para moléculas pequenas tombando em um solvente não viscoso. Entretanto, os tempos de correlação $\tau_{\mathrm{B}}$ e $\tau_{\mathrm{C}}$ (calculados pela eq. 2.3.17, corrigidas para rotação isotrópica por $\tau_{B}=-1,22 x$ 
$10^{-9} B_{\text {corr }}$ e $\tau_{C}=1,19 \times 10^{-9} C_{\text {corr }}$ (Marsh, 1989) para o Toac ligado no $\alpha$-MSH são uma ordem de magnitude maior que os do Toac livre (Tabela 4.4.1).

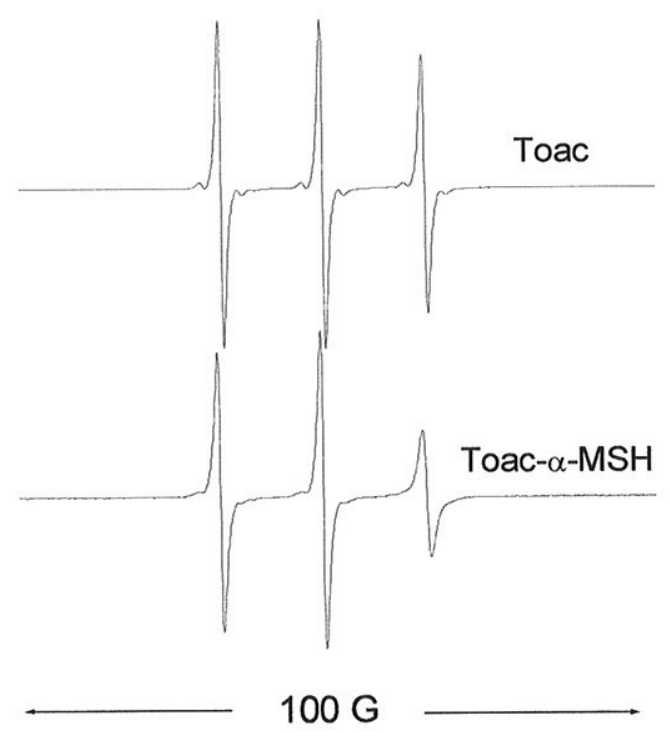

Figura 4.4.2 - Espectros de RPE de $10^{-4} \mathrm{M}$ de Toac e Ac-Toac ${ }^{0}-\alpha-\mathrm{MSH}$ em água (pH 5,0), a $25^{\circ}$ C. Amplitude de modulação do campo de 0,5 G.

O Ac-Toac0-MSH-I apresenta um espectro de RPE similar ao do Ac-Toac ${ }^{0}-\alpha-$ MSH. Os parâmetros gerados pelo seu espectro também são mostrados na Tabela 4.4.1, e comparados com aqueles encontrados no Toac livre. Os diferentes valores entre os tempos de correlação rotacional $\tau_{\mathrm{B}}$ e $\tau_{\mathrm{C}}$, obtidos para os peptídeos marcados indicam um movimento anisotrópico destes em relação ao Toac livre. Os resultados mostrados aqui, obtidos em tampão HEPES, são ligeiramente diferentes dos resultados obtidos em água. Considerando que os espectros de RPE do Toac livre e ligado aos peptídeos são típicos de movimento rápido (motional narrowing), os valores de $\tau_{\mathrm{B}}$ e $\tau_{\mathrm{C}}$ foram calculados. Usando a razão entre os dois tempos de correlação $\tau_{\mathrm{C}} / \tau_{\mathrm{B}}$, como uma estimativa da anisotropia do movimento da molécula (Schreier et al., 1978), é evidente que a ligação aos peptídeos torna o movimento do Toac menos isotrópico (a razão $\tau_{\mathrm{C}} / \tau_{\mathrm{B}}$ para o Toac livre é de aproximadamente 1 ).

Mudanças no $\mathrm{pH}$ do meio afetam o estado de protonação de várias cadeias laterais de resíduos em peptídeos. Assim, estas mudanças podem alterar a conformação dos peptídeos. Para o caso do $\alpha$-MSH (Ac-Ser1-Tyr2-Ser3-Met4-Glu5-His6-

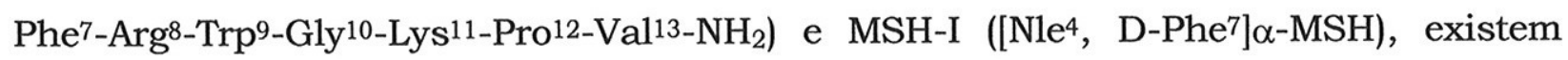


cinco grupos tituláveis: Tyr, Glu, His, Arg e Lys, com pK's para os aminoácidos livres em solução de 10,46, 4,07, 6,04, 12,48 e 10,54, respectivamente (Voet e Voet, 1995).

Tabela 4.4.1 - Parâmetros de RPE para o Toac livre e ligado aos peptídeos, diluídos em água: desdobramento hiperfino isotrópico $a_{0}$, e tempos de correlação rotacional $\tau_{\mathrm{B}} \mathrm{e} \tau_{\mathrm{c}}$.

\begin{tabular}{llcccc}
\hline & & $a_{0}(\mathrm{G})$ & $\tau_{\mathrm{B}}$ & $\tau_{\mathrm{C}}$ & $\tau_{\mathrm{C}} / \tau_{\mathrm{B}}$ \\
\hline \multirow{2}{*}{ pH 5,0 } & Toac & 16,330 & 0,034 & 0,036 & 1,06 \\
& Ac-Toac ${ }^{0}-\alpha-$ MSH & 16,237 & 0,285 & 0,350 & 1,23 \\
& Ac-Toac 0 -MSH-I & 16,241 & 0,320 & 0,395 & 1,23 \\
\hline
\end{tabular}

Os erros estimados nos valores de $a_{0}$ e $\tau_{B}$ ou $\tau_{C}$ são de $0,005 \mathrm{G} \mathrm{e} 0,005 \mathrm{~ns}$, respectivamente.

Em tampão HEPES (conforme as condições experimentais mencionadas na seção 3.2), para os vários valores de $\mathrm{pH}$ estudados, os tempos de correlação rotacional, obtidos dos espectros de RPE do Toac ligado no $\alpha$-MSH e MSH-I, não apresentam diferenças significativas entre eles (Figura 4.4.3). Ambos o Ac-Toac ${ }^{0}-\alpha-$ MSH e o Ac-Toac ${ }^{0}-M S H-I$ têm uma rotação anisotrópica média em torno de $\tau_{c} / \tau_{B}=1,23$.

A análise do desdobramento hiperfino isotrópico $a_{0}$, que é sensível à polaridade do microambiente do grupo nitróxido (Griffith et al., 1974), também mostra uma diferença entre o Toac livre e o ligado aos peptídeos. Essa diferença pode ser atribuída a um ambiente menos polar nas vizinhanças do nitróxido do Toac, quando inserido na estrutura do peptídeo, e/ou a uma distribuição de elétrons desemparelhados diferenciada para o Toac livre e ligado. 


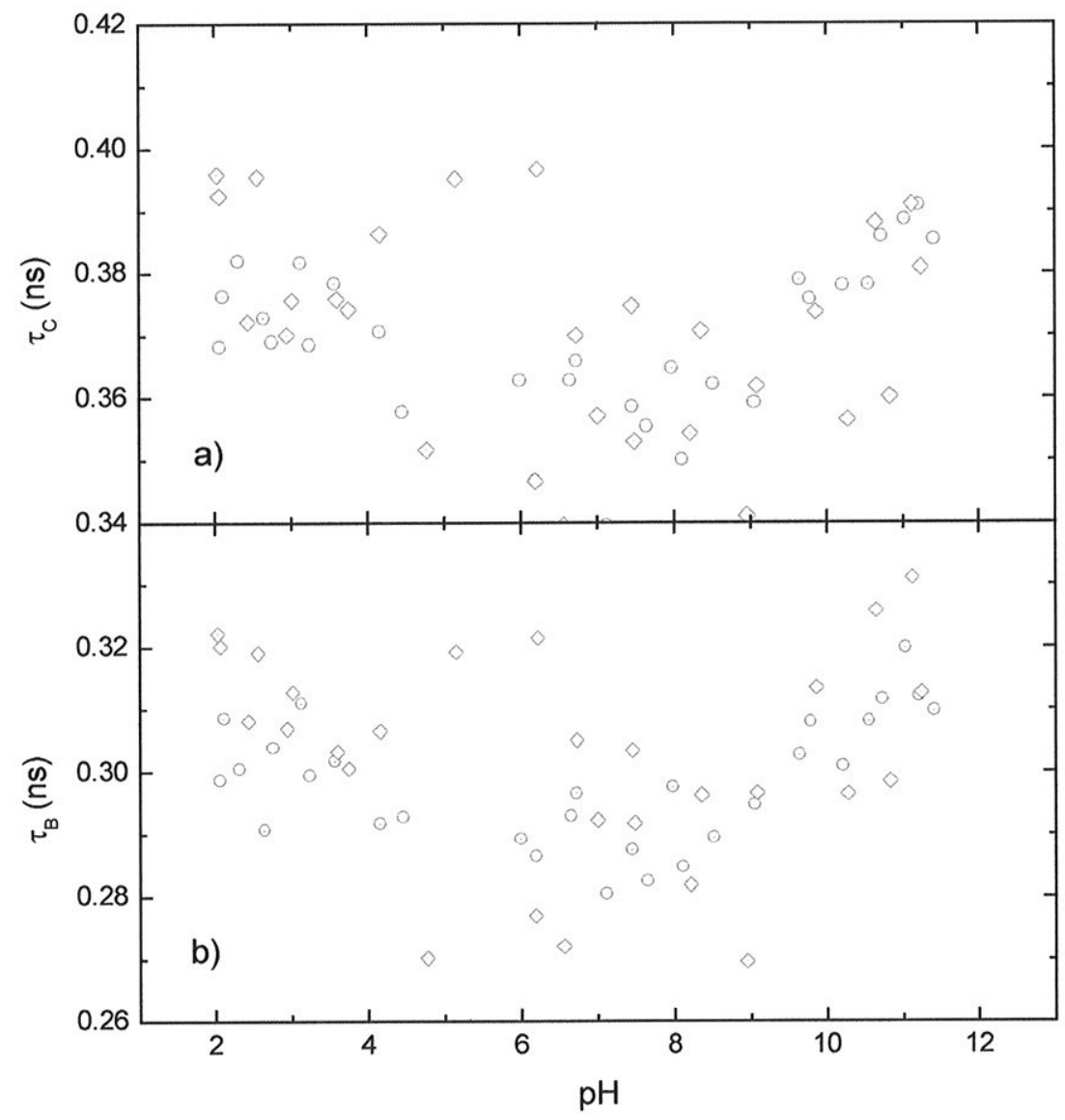

Figura 4.4.3 Dependência dos tempos de correlação $\tau_{\mathrm{C}}(\mathrm{a})$ e $\tau_{\mathrm{B}}$ (b) com o pH do Ac-Toac ${ }^{0}-\alpha-\mathrm{MSH}$ $(\bigcirc)$ e Ac-Toac ${ }^{0}$-MSH-I $(\diamond)$, em tampão HEPES à temperatura ambiente. Os dados apresentados são de duas amostras (simbolos com e sem ponto). Erro médio de 0,02 ns.

É interessante notar que $a_{0}$ apresenta uma forte dependência com o pH da solução (Figura 4.4.4). Embora os pontos da Figura 4.4.4 estejam um pouco dispersos, estes mostram claramente um comportamento equivalente ao observado na titulação da componente $\tau_{1}$ do tempo de vida do Trp, como veremos na seção 4.4.3. O aumento de $a_{0}$ e posterior diminuição com o aumento do $\mathrm{pH}$ sentido pelo Toac, reflete mudanças na polaridade do grupo $\mathrm{N}-\mathrm{O}$ do Toac, que podem estar associadas a alterações conformacionais relacionadas com as titulações de grupos das cadeias laterais dos aminoácidos. Diferenças na polaridade do microambiente monitorado pelo Toac ligado no $\alpha$-MSH e no MSH-I são observadas na região de $\mathrm{pH}$ entre 6,0 e 11,0. Neste intervalo, o nitróxido do Toac ligado no MSH-I sente, em média, um microambiente mais polar do que o ligado no $\alpha-\mathrm{MSH}\left(a_{0}\left(\right.\right.$ Ac-Toac $\left.{ }^{0}-M S H-I\right)>a_{0}(A c-$ $\left.\operatorname{Toac}^{0}-\alpha-M S H\right)$ ). Considerando que a ligação covalente do Toac nos dois peptídeos é 
idêntica, esse diferença somente pode ser atribuída a diferentes ambientes experimentados pelo Toac nos dois peptídeos. Este resultado sugere uma pequena diferença estrutural entre o hormônio e seu análogo MSH-I, mesmo em solução aquosa, com a titulação dos grupos da His, Tyr e Lys.

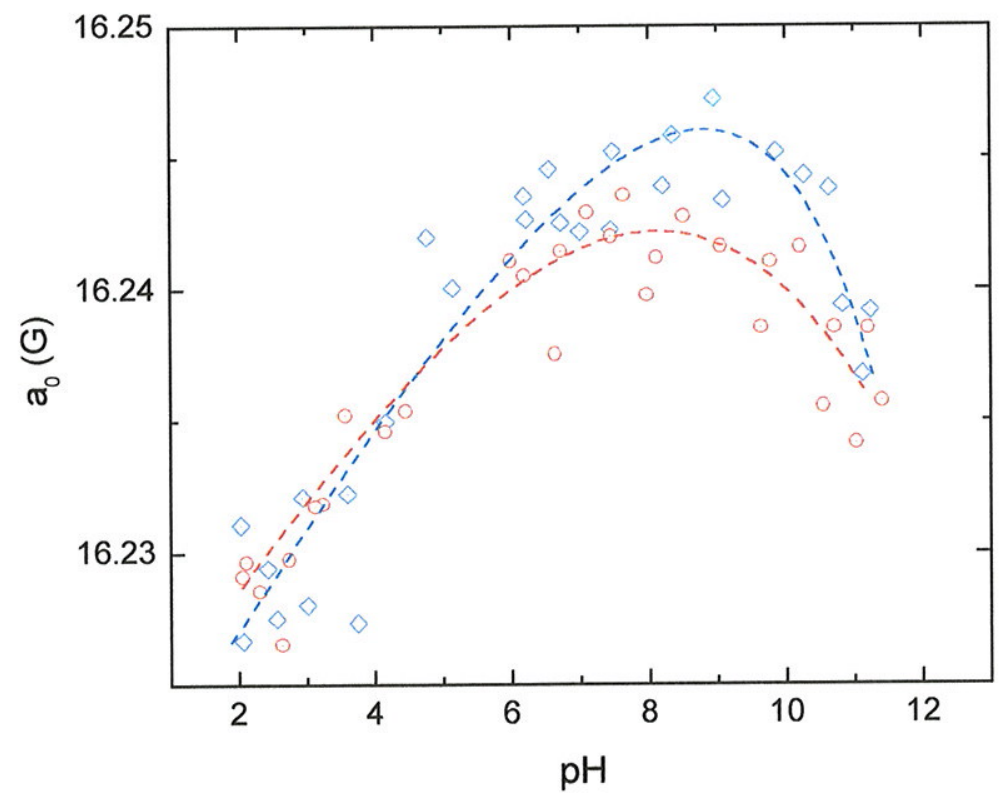

Figura 4.4.4 - Dependência de $a_{0}$ com o pH do Ac-Toac ${ }^{0}-\alpha-\mathrm{MSH}(\circ)$ e Ac-Toac ${ }^{0}$-MSH-I $(\diamond)$, em tampão HEPES à temperatura ambiente. Os dados apresentados são de duas amostras (símbolos com e sem ponto). A linha tracejada serve somente como auxilio visual. Erro médio de $0,03 \mathrm{G}$.

\subsubsection{O efeito supressor do Toac no Trp: um estudo por fluorescência.}

Os espectros de absorção óptica do Toac, $\alpha-\mathrm{MSH}$ e Ac-Toac ${ }^{0}-\alpha-\mathrm{MSH}$ em água à temperatura ambiente, $\mathrm{pH} 7,0$, são mostrados na Figura 4.4.5. Na região próxima do UV, em torno de $280 \mathrm{~nm}$ (coeficiente de extinção $\varepsilon \approx 5700 \mathrm{M}^{-1} . \mathrm{cm}^{-1}$ ), o espectro do peptídeo marcado é dominado pelas transições eletrônicas características do resíduo Trp, superposta à uma pequena contribuição da molécula Toac. O Ac-Toac ${ }^{0}-\alpha-\mathrm{MSH}$ também apresenta uma banda de absorção muito fraca centrada em torno de $410 \mathrm{~nm}$, com $\varepsilon \approx 20 M^{-1} \cdot \mathrm{cm}^{-1}$, como observado recentemente (Pispisa et al., 1998) em peptídeos ligados ao Toac (devido à escala usada, essa banda não é evidente na Figura 4.4.5). As mesmas características são apresentadas no espectro do análogo Ac-Toac0-MSH-I (dados não mostrados). Amostras de Toac puro, excitadas em 295 nm, não mostram nenhuma emissão fluorescente. Entretanto, sob excitação nesse comprimento de INSTITUTODE FÍSICA

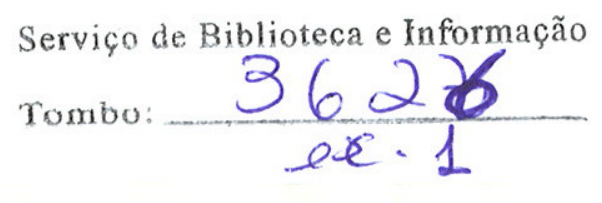


onda, ambos os peptídeos marcados apresentam uma banda de emissão centrada em torno de 355 nm, típica do Trp em água (Figura 4.4.5d). Comparada com os peptídeos não marcados, a intensidade fluorescente do Trp nos peptídeos ligados ao Toac diminui, muito provavelmente devido à supressão pela molécula Toac.

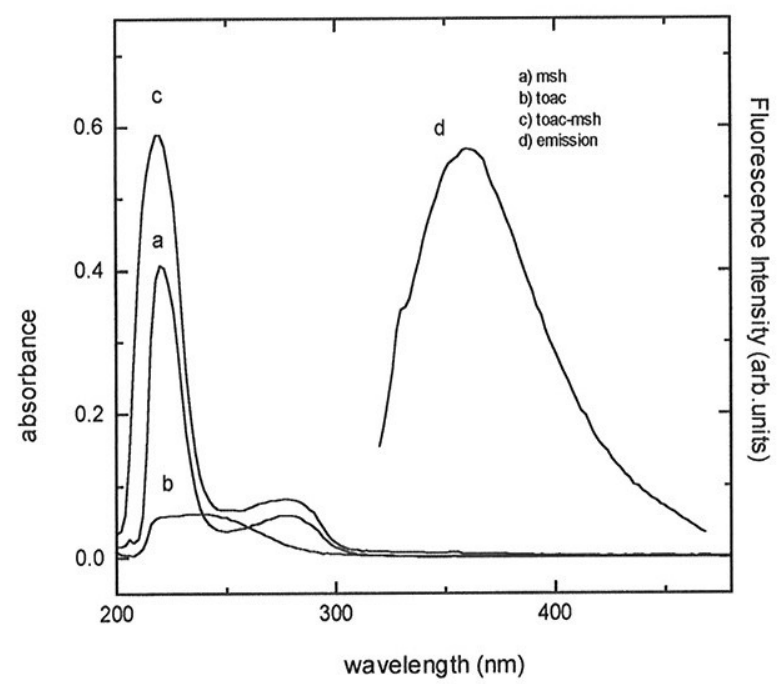

Figura 4.4.5 - Espectros de absorção óptica (caminho óptico $1 \mathrm{~cm}$ ) do $\alpha-\mathrm{MSH}$ (a), Toac (b) e AcToac $^{0}-\alpha-\mathrm{MSH}$ (c), e o espectro de emissão fluorescente de Ac-Toac ${ }^{0}-\alpha-\mathrm{MSH}$ excitado em $295 \mathrm{~nm}$ (d). Concentração dos peptídeos e Toac $2,5 \times 10^{-5} \mathrm{M}$, em água, $\mathrm{pH} 7,0,22^{\circ} \mathrm{C}$.

O decaimento do estado excitado de todos os compostos aqui estudados em água, marcados ou não, são distintos entre eles, como observado antes para os peptídeos não marcados em pH neutro (Ito et al., 1993), e pode ser ajustado com três componentes de tempo de vida. Os tempos de vida do $\alpha$-MSH e do MSH-I para altos valores de $\mathrm{pH}$ são comparáveis àqueles previamente relatados para os peptídeos em tampão fosfato, pH 7,4 (Ito et al., 1993). Entretanto, os peptídeos marcados com o Toac apresentam um decaimento fluorescente mais rápido (Figura 4.4.6), compatível com a supressão de fluorescência do Trp pela sonda paramagnética. A redução no tempo de vida pode ser examinada pelo cálculo do tempo de vida médio $\langle\tau\rangle$, de acordo com a equação 2.2.6 (mais adiante, será mostrado que, em presença do Toac, os três tempos de vida do Trp diminuem, Tabela 4.4.3). Os tempos de vida médios dos peptídeos marcados com o Toac são sistematicamente menores do que aqueles dos peptideos originais, independente do valor de $\mathrm{pH}$ usado (Tabela 4.4.2). 


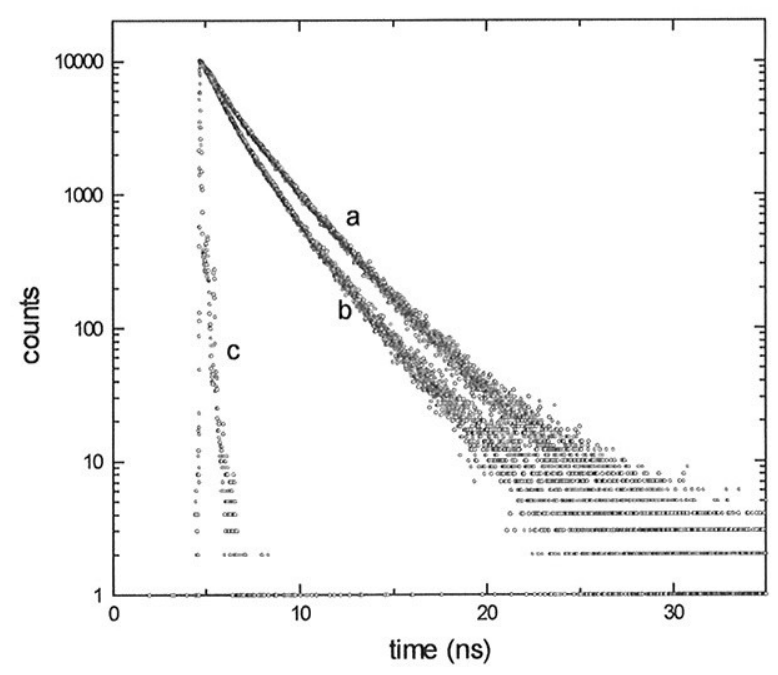

Figura 4.4.6 - Decaimento do estado excitado de $\alpha-\mathrm{MSH}$ (a), e Ac-Toac ${ }^{0}-\alpha-\mathrm{MSH}$ (b) em água, pH 7,0 . Concentração $2,5 \times 10^{-5} \mathrm{M}, 22^{\circ} \mathrm{C}$. A resposta do instrumento, excitado em $297 \mathrm{~nm}$, também é mostrada (c).

O resíduo Trp e o grupo Toac estão longe um do outro na cadeia peptídica e o modelo de Förster foi recentemente aplicado ao estudo de peptídeos marcados com Toac (Pispisa et al., 1998), e uma distância de Förster $\left(R_{0}\right)$ de 9,3 Å foi calculada para o par Trp-Toac. Assim, uma estimativa das distâncias intramoleculares do Toac-Trp em melanotropinas marcadas pode ser feita, baseada nos tempos de vida médios calculados (Tabela 4.4.2). Uma distância doador-aceitador, $r=R_{0}(1 / E-1)^{1 / 6}$, pode ser estimada da eficiência de transferência de energia, dada por $E=1-\left\langle\tau_{d a}\right\rangle /\left\langle\tau_{d}\right\rangle$, onde $<\tau_{\mathrm{da}}>$ e $<\tau_{\mathrm{d}}>$ são os tempos de vida médios para os peptídeos marcado e não marcado com o Toac, respectivamente, e usando o valor de $R_{0}$ calculado por Pispisa (Pispisa et al., 1998). As distâncias estimadas Toac-Trp, dadas na Tabela 4.4.3, foram obtidas sob a suposição de movimento rápido para o doador e aceitador durante o tempo de vida de fluorescência. Como normalmente relatado na literatura, as distâncias doador-aceitador são estimadas com um erro de $20 \%$. Os dados apresentados aqui também são diferentes dos dados obtidos com os peptídeos em água (Nakaie et al., 2001). 
Tabela 4.4.2 - Tempo de vida médio do decaimento do Trp, $<\tau>$, e distâncias estimadas TrpToac em peptídeos ligados ao Toac, $r$.

\begin{tabular}{|c|c|c|c|}
\hline & Sistema & $<\tau>(\mathrm{ns})$ & $r(\AA ̊)$ \\
\hline \multirow[t]{4}{*}{$\mathrm{pH} 3,0$} & $\alpha-\mathrm{MSH}$ & 2,29 & \\
\hline & $\mathrm{Ac}^{-\mathrm{Toac}^{0}-\alpha-\mathrm{MSH}}$ & 1,97 & 12,59 \\
\hline & MSH-I & 2,20 & \\
\hline & Ac-Toac ${ }^{0}-\mathrm{MSH}-\mathrm{I}$ & 1,86 & 12,34 \\
\hline \multirow[t]{4}{*}{$\mathrm{pH} 6,0$} & $\alpha-\mathrm{MSH}$ & 2,62 & \\
\hline & Ac-Toac ${ }^{0}-\alpha-\mathrm{MSH}$ & 2,27 & 12,70 \\
\hline & MSH-I & 2,56 & \\
\hline & Ac-Toac ${ }^{0}-\mathrm{MSH}-\mathrm{I}$ & 2,19 & 12,51 \\
\hline \multirow[t]{4}{*}{$\mathrm{pH} 9,0$} & $\alpha-\mathrm{MSH}$ & 2,86 & \\
\hline & Ac-Toac ${ }^{0}-\alpha-\mathrm{MSH}$ & 2,46 & 12,59 \\
\hline & MSH-I & 2,69 & \\
\hline & Ac-Toac ${ }^{0}-\mathrm{MSH}-\mathrm{I}$ & 2,37 & 12,98 \\
\hline
\end{tabular}

O erro estimado nos valores de $<\tau>$ é $0,05 \mathrm{~ns}$

Os resultados mostram que, a distância Toac-Trp, dentro do erro estimado, é praticamente a mesma, em ambos os peptídeos (Ac-Toac ${ }^{0}-\mathrm{MSH}-\mathrm{I}$ e Ac-Toac ${ }^{0}-\alpha-\mathrm{MSH}$ ), e parece não variar com o $\mathrm{pH}$ do meio. O tempo de vida médio, por sua vez, depende do $\mathrm{pH}$ do meio, como veremos a seguir.

\subsubsection{Dependência do tempo de vida com o pH}

O decaimento do Trp presente no $\alpha$-MSH e MSH-I, em tampão HEPES à temperatura ambiente, observado em $350 \mathrm{~nm}$, com e sem a sonda paramagnética, foi obtido variando-se o $\mathrm{pH}$ da amostra, e calculou-se o tempo de vida médio (equação 2.2.6) resultante de três componentes temporais, baseado no modelo de rotâmeros (Szabo e Rayner, 1980). Decaimentos ajustados com dois tempos de vida também foram obtidos. Entretanto, a análise do $\chi^{2}$ reduzido mostrou resultar num ajuste pobre. A Figura 4.4.7 mostra a variação do tempo de vida médio $<\tau>$ de duas amostras com o pH, para os peptídeos melanotrópicos marcados e não marcados. 


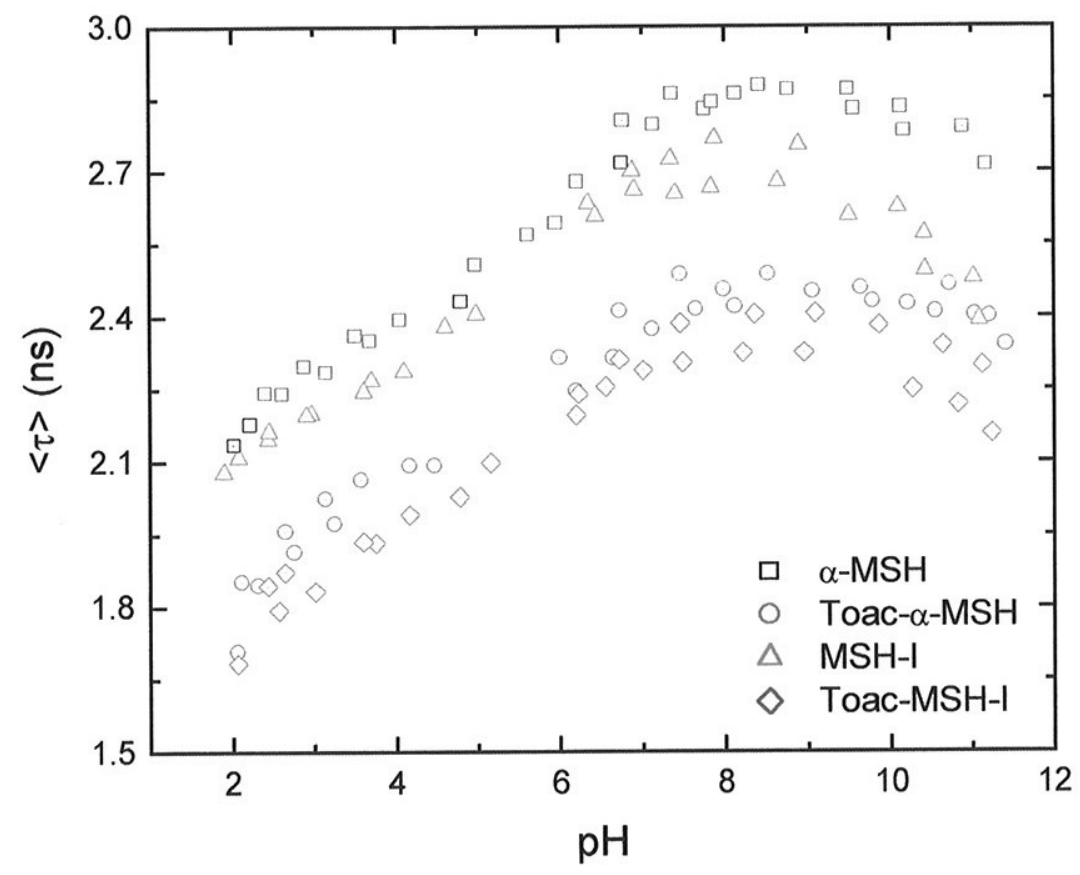

Figura 4.4.7 - Dependência do tempo de vida médio $\langle\tau>$ (em ns) com o pH do (ㅁ) $\alpha-\mathrm{MSH},(\mathrm{O})$ Ac-Toac ${ }^{0}-\alpha-M S H,(\triangle)$ MSH-I e $(\diamond)$ Ac-Toac ${ }^{0}-$ MSH-I, em tampão HEPES a temperatura ambiente, medido em $350 \mathrm{~nm}$. Excitação em $296 \mathrm{~nm}$. Os dados apresentados são de duas amostras (símbolos com e sem ponto).

De maneira geral, todos os peptídeos apresentam um aumento em seus tempos de vida médios $\langle\tau\rangle$ com o aumento do $\mathrm{pH}$ até em torno de 8,5. Após esse valor, um comportamento decrescente é observado (perfil semelhante ao obtido com $a_{0}$, Fig. 4.4.4). Aparentemente, no meio ácido, parece existir dois pontos de inflexão, o que é razoável pois tanto o ácido glutâmico (Glu) quanto a histidina (His) titulam nesta região. Analogamente, no meio alcalino parece existir apenas um ponto de inflexão. Entretanto existem três resíduos que podem titular: a Tyr, a Arg e a Lys, porém, devido ao intervalo de $\mathrm{pH}$ usado, muito provavelmente podemos restringir aos grupos Tyr e Lys. A provável importância da Lys na estabilização da estrutura ativa (Prabhu et al., 1999) e a sua proximidade com o resíduo Trp parece indicar que este é o grupo responsável pela redução do tempo de vida médio do Trp. O efeito da deprotonação da Arg sobre $o<\tau>$ do Trp não foi observado porque nesse valor de $\mathrm{pH}$, a quantidade de cátions $\mathrm{Na}^{+}$é excessivamente grande, alterando drasticamente a força iônica do meio.

Mecanismos como transferência de carga ou supressão colisional podem contribuir para a diminuição da fluorescência do Trp, e conseqüentemente, de seus tempos de vida. Como mencionado antes, os peptídeos com Toac apresentam uma 
banda de absorção muito fraca centrada em torno de $410 \mathrm{~nm}$, sobrepondo-se à banda de emissão do Trp, permitindo a transferência de energia ressonante de fluorescência entre a cadeia lateral do resíduo Trp como doador e o marcador de spin como aceitador.

É possivel achar um conjunto único de tempos de vida para os vários valores de $\mathrm{pH}$, sugerindo que a variação da acidez do meio somente modifique a porcentagem dos três rotâmeros supostos presentes no Trp. Como na análise global dos vários comprimentos de onda de emissão (ver seção anterior), aqui foi feita uma análise global do tempo de vida como função do $\mathrm{pH}$, e observamos a variação percentual das três componentes temporais. A Figura 4.4.8 mostra essa variação dos peptídeos $\alpha$ MSH e MSH-I com e sem o Toac. A Tabela 4.4.3 apresenta os tempos de vida encontrados nesse tipo de análise. O melhor conjunto de tempos para cada peptídeo foi escolhido pelo método dos mínimos quadrados (menor valor do $\chi^{2}$ reduzido, ver seção 2.2.3).

Tabela 4.4.3 - Tempos de vida do Trp (ns), obtidos da análise global dos vários valores de $\mathrm{pH}$, dos peptídeos marcados ou não, em tampão HEPES.

\begin{tabular}{ccccc}
\hline & $\tau_{1}$ & $\tau_{2}$ & $\tau_{3}$ & $\chi^{2} \mathrm{G}$ \\
\hline$\alpha-\mathrm{MSH}$ & $3,68 \pm 0,05$ & $2,28 \pm 0,05$ & $0,54 \pm 0,01$ & 1,17 \\
Toac- $\alpha$-MSH & $3,22 \pm 0,04$ & $2,03 \pm 0,03$ & $0,50 \pm 0,01$ & 1,20 \\
MSH-I & $3,40 \pm 0,10$ & $1,95 \pm 0,05$ & $0,48 \pm 0,03$ & 1,27 \\
Toac-MSH-I & $3,10 \pm 0,10$ & $1,70 \pm 0,06$ & $0,42 \pm 0,02$ & 1,49
\end{tabular}

Obs: os valores de chi-quadrado individuais $\left(\chi^{2}\right.$ i) para cada valor de $\mathrm{pH}$ desviam-se da unidade em no máximo $10 \%$.

De maneira geral, para todos os peptídeos, a porcentagem do rotâmero relacionado à componente de tempo curto $\left(\tau_{3}\right)$ praticamente não varia com o $\mathrm{pH}$, ficando abaixo de $15 \%$ do total de rotâmeros presentes nas amostras. Contrariamente, as porcentagens dos rotâmeros relacionados aos tempos de vida longo $\left(\tau_{1}\right) \mathrm{e}$ intermediário $\left(\tau_{2}\right)$ sofrem mudanças expressivas com o $\mathrm{pH}$. Adicionalmente, esses rotâmeros parecem intercambiar-se um com o outro, uma vez que a porcetagem de $\tau_{3}$ é praticamente constante. Dessa maneira, passaremos a analisar somente a variação da porcentagem do rotâmero relacionado a $\tau_{1}$.

O comportamento de $\tau_{1}$ para todos os peptídeos observados, é bastante similar ao do tempo de vida médio. A curva de titulação desse tempo também mostra, aparentemente, dois grupos tituláveis em $\mathrm{pH}$ ácido e apenas um grupo em $\mathrm{pH}$ 
alcalino. Os resíduos responsáveis pela inflexão nessa curva são a Glu, His e provavelmente a Lys, embora não esteja descartada a possibilidade de titulação da Tyr. Entretanto, é bastante provável que o valor de $\mathrm{pH}$ em que ocorre a protonação e/ou deprotonação desses resíduos seja diferente deles livres da cadeia peptídica, e devemos considerar a interação de todos os grupos tituláveis presentes nas amostras.

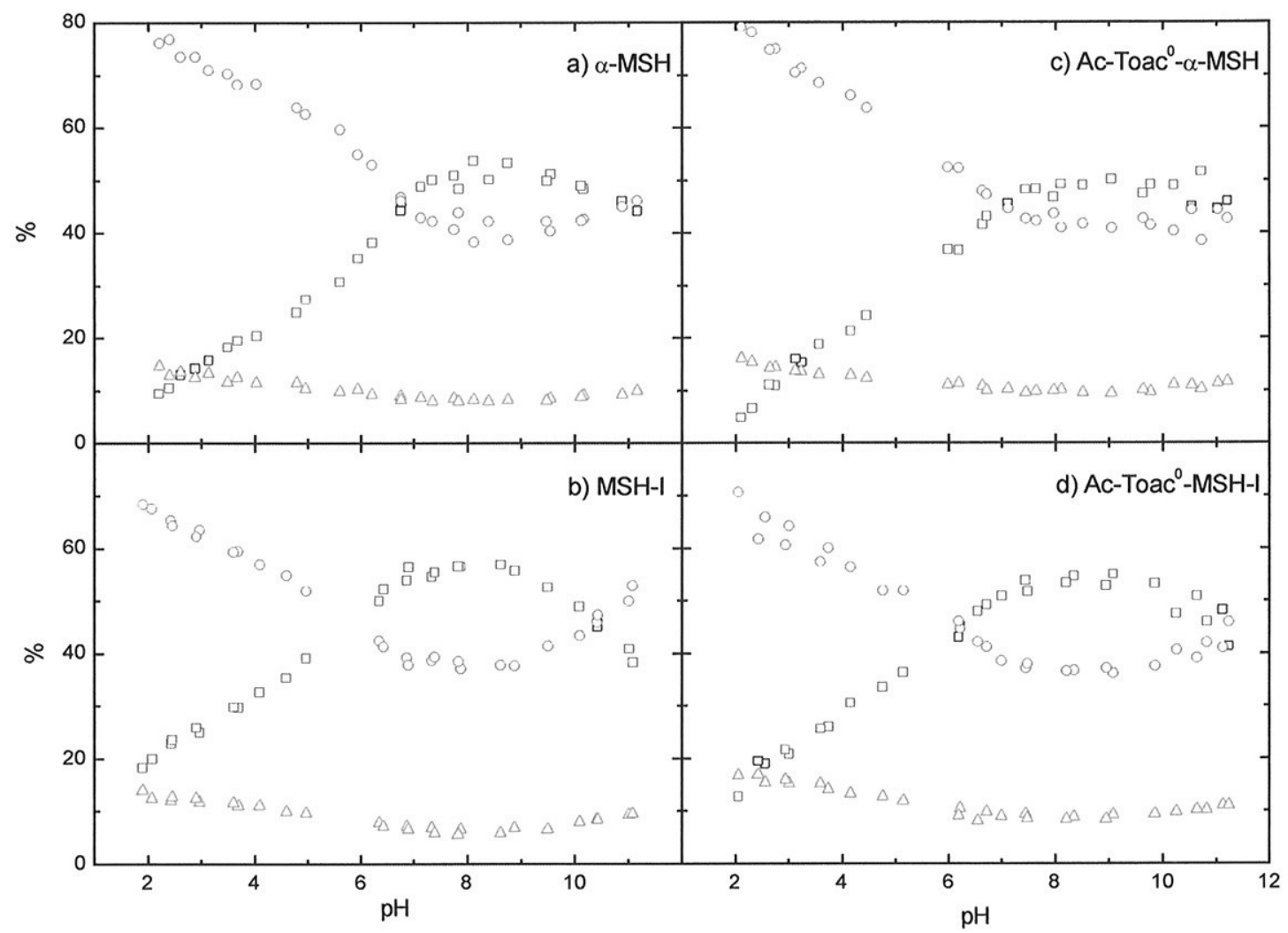

Figura 4.4.8 - Dependência da contribuição percentual associada à $\tau_{1}(\square), \tau_{2}(O)$, e $\tau_{3}(\Delta)$ (em ns) com o pH do (a) $\alpha-\mathrm{MSH}$, (b) MSH-I, (c) Ac-Toac ${ }^{0}-\alpha-\mathrm{MSH}$ e (d) Ac-Toac ${ }^{0}-\mathrm{MSH}-\mathrm{I}$ em tampão HEPES a temperatura ambiente, medido em $350 \mathrm{~nm}$. Os valores das componentes foram obtidas pelo método de análise global (ver Tabela 4.4.3). Os dados apresentados são de duas amostras (simbolos com e sem ponto).

Quando sítios individuais tituláveis numa molécula interagem com outros (como é o caso dos peptídeos aqui estudados), suas titulações podem ser muito mais complexas do que a de um sítio independente, conforme descrita pela equação de Henderson-Hasselbalch (eq. 3.1). Entretanto, essa dificuldade pode ser eliminada se a titulação complexa for decomposta em componentes individuais. Assim, efetuando-se uma somatória ponderada sobre todos os grupos tituláveis (eq. 3.3), os valores de pK dos grupos tituláveis do $\alpha$-MSH e MSH-I podem ser determinados, assim como os seus 
similares marcados com o Toac. A Figura 4.4.9 apresenta os ajustes das curvas de titulação de $\tau_{1}$ das amostras estudadas. A Tabela 4.4.4 mostra os valores de pK e suas contribuições (valores de $a$ ) de cada curva de Henderson-Hasselbalch individual encontradas nesse ajuste.

Tabela 4.4.4 - Valores de pK e $a$ da titulação da componente temporal $\tau_{1}$ do $\alpha-\mathrm{MSH}$, MSH-I, Ac-

Toac $^{0}-\alpha-$ MSH e Ac-Toac ${ }^{0}-$ MSH-I, em tampão HEPES à temperatura ambiente, obtidos pela equação (3.2) ${ }^{1}$. Os índices 1, 2 e 3 referem-se aos resíduos Glu, His e Lys (ou Tyr), respectivamente. As curvas teóricas e experimentais são mostradas na Fig. 4.4.9.

\begin{tabular}{ccccccc}
\hline & $p K_{1}$ & $p K_{2}$ & $p K_{3}$ & $a_{1}$ & $a_{2}$ & $a_{3}$ \\
\hline$\alpha-M S H$ & $3,42 \pm 0,13$ & $6,24 \pm 0,07$ & $10,27 \pm 0,26$ & $16,4 \pm 1,2$ & $27,4 \pm 1,1$ & $8,2 \pm 1,0$ \\
Toac- $\alpha$-MSH & $2,98 \pm 0,16$ & $6,10 \pm 0,09$ & $10,90 \pm 0,25$ & $19,9 \pm 1,9$ & $25,2 \pm 1,5$ & $3,5 \pm 1,8$ \\
MSH-I & $3,59 \pm 0,14$ & $6,20 \pm 0,04$ & $10,24 \pm 0,10$ & $16,9 \pm 1,3$ & $19,4 \pm 1,5$ & $20,1 \pm 0,8$ \\
Toac-MSH-I & $3,52 \pm 0,22$ & $6,20 \pm 0,15$ & $10,97 \pm 0,19$ & $17,9 \pm 2,1$ & $19,6 \pm 2,0$ & $15,7 \pm 1,5$ \\
\hline
\end{tabular}

1 Para simular o comportamento ascendente de $\tau_{1}$, os termos da equação (3.3) que apresentam essa característica $(i=1$ e 2$)$ foram subtraídos da unidade.

Os resultados obtidos para o $\alpha$-MSH mostram que os valores de $\mathrm{pK}$ dos grupos tituláveis (Glu, His, e Lys ou Tyr), encontrados no ajuste (aqui denominados $p K_{1}, p K_{2} \mathrm{e}$ $p K_{3}$, respectivamente), diferem dos seus valores quando isolados de alguma seqüência peptídica. O pK do Glu obtido pelo ajuste $\left(p K_{1}=3,42\right)$ é menor que o dele livre $(4,07)$. Isso é consistente com o caráter positivo do peptídeo, em especial à presença da His ${ }^{+}$ em meio ácido, junto ao Glu, que torna o seu $\mathrm{pH}$ local maior que o $\mathrm{pH}$ da solução. Portanto, a concentração de $\mathrm{H}^{+}$próximo ao Glu é menor devido ao efeito repulsivo eletrostático. A His tem o seu pH local diminuído devido à presença do Glu (que está principalmente carregado negativamente para $\mathrm{pH}>3,42$ ). Assim, espera-se que o seu pK seja maior do que o pK da His livre $(6,04)$, o que está de acordo com o ajuste $\left(p K_{2}=\right.$ 6,24). A Lys, por sua vez, tem o seu pH local aumentado, possivelmente, devido à presença da Arg (positivamente carregada). Conseqüentemente, seu pK é menor do que o dela sozinha $(10,54)$, como encontrado no ajuste $\left(p K_{3}=10,27\right)$. Toda essa discussão dos pK's está melhor esquematizada abaixo. As cargas adquiridas por esses grupos tituláveis no $\alpha$-MSH também são apresentadas abaixo.

\begin{tabular}{cccc}
\hline Grupos & {$\left[\mathbf{H}^{+}\right]$} & pH & pK \\
\hline positivos & local $<$ bulk & local $>$ bulk & diminui \\
negativos & local $>$ bulk & local $<$ bulk & aumenta \\
\hline
\end{tabular}


Ac-Ser-Tyr-Ser-Met-Glu-His+-Phe-Arg+-Trp-Gly-Lys+-Pro-Val- $\mathrm{NH}_{2}$

pH 3,42

Ac-Ser-Tyr-Ser-Met-Glu--His ${ }^{+}-\mathrm{Phe}-\mathrm{Arg}^{+}-\mathrm{Tr}$-Gly-Lys+-Pro-Val-NH $\mathrm{N}_{2}$

$\mathrm{pH} 6,24$

Ac-Ser-Tyr-Ser-Met-Glu--His-Phe-Arg+-Trp-Gly-Lys+-Pro-Val- $\mathrm{NH}_{2}$

$\mathrm{pH} 10,27$

Ac-Ser-Tyr--Ser-Met-Glu--His-Phe-Arg+-Trp-Gly-Lys-Pro-Val- $\mathrm{NH}_{2}$

Analogamente ao $\alpha$-MSH, o MSH-I apresentou o mesmo aspecto variacional. Os seus resíduos polares foram titulados praticamente nos mesmos valores de $\mathrm{pH}$ encontrados para o $\alpha$-MSH (dentro do intervalo de erro das medidas, como indicado na Tabela 4.4.5). Entretanto, o aumento na contribuição da curva de HendersonHasselbalch da Lys $\left(a_{3}=20,1\right)$ (ou Tyr) indica que esse grupo titulável tem um efeito maior na curva de titulação total do peptídeo, estando associado a uma maior redução do tempo de vida médio em meio alcalino, como observada na Figura 4.4.7. Da mesma forma, o Ac-Toac0-MSH-I também apresenta essa característica $\left(a_{3}=15,7\right)$.

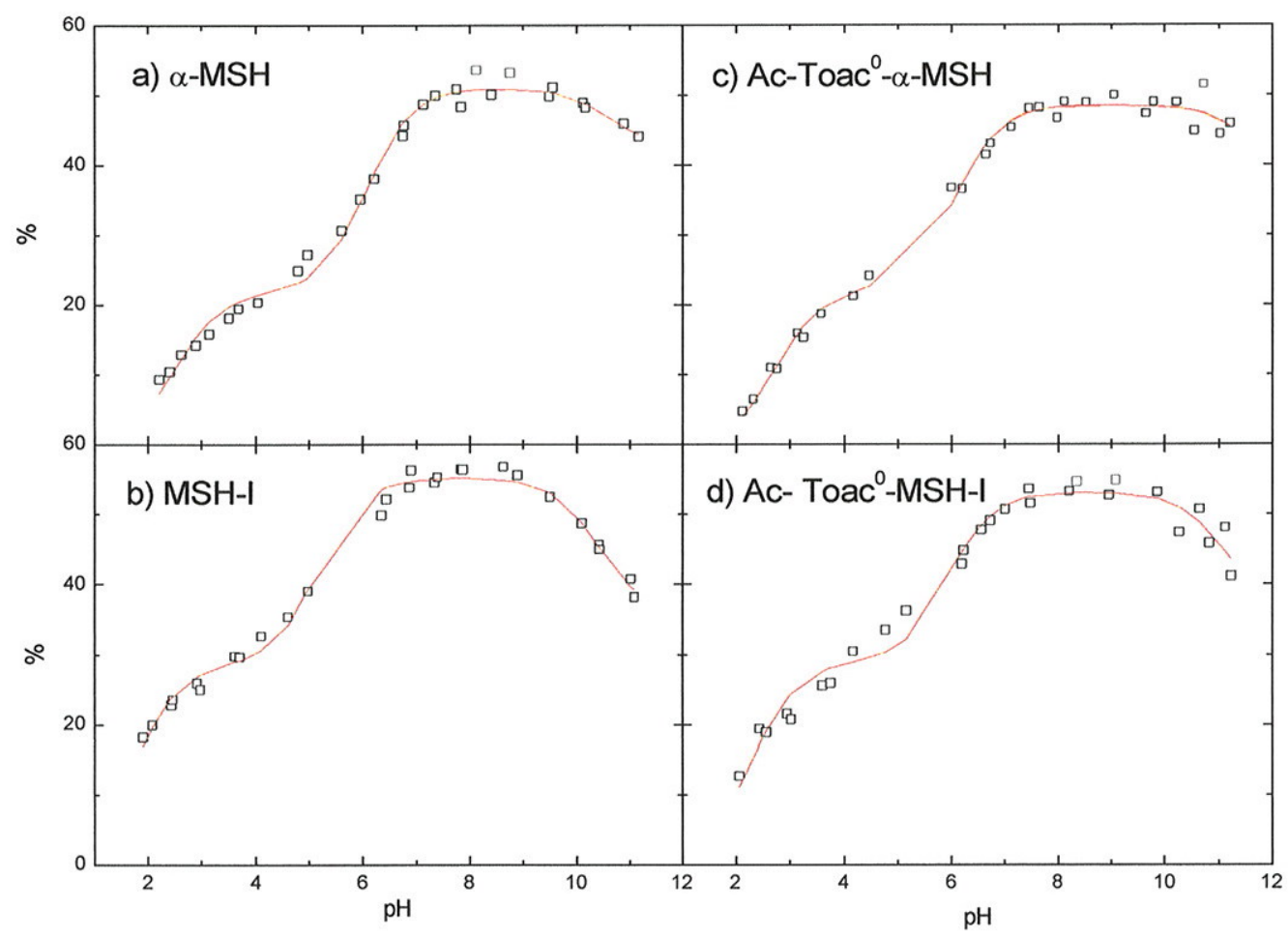

Figura 4.4.9 - Curvas de titulação da componente $\tau_{1}$ do do (a) $\alpha-\mathrm{MSH}$, (b) MSH-I, (c) Ac-Toac ${ }^{0}$ $\alpha$-MSH e (d) Ac-Toac ${ }^{0}$-MSH-I em tampão HEPES a temperatura ambiente. Os ajustes das curvas são mostrados em linha contínua. Os parâmetros resultantes do ajuste são dados na Tabela 4.4.4. Os dados apresentados são de duas amostras (símbolos com e sem ponto). 
O Ac-Toac ${ }^{0}-\alpha-$ MSH tem comportamento semelhante para os resíduos Glu e His do $\alpha$-MSH (redução do pK em relação ao aminoácido livre, 4,07 e 6,04, respectivamente), porém com valores de pK ligeiramente diferentes. Entretanto, o ajuste mostra que a Lys (ou Tyr) tem o seu $\mathrm{pH}$ local diminuído, e portanto seu $\mathrm{pK}$ aumentado (o $p K$ da Lys livre é de 10,54). Comparando o Ac-Toac ${ }^{0}-\alpha-M S H$ com o $\alpha-$ $\mathrm{MSH}$, vemos que o pK do Glu diminui (de 3,42 para 2,98), devido a uma maior influência da proximidade de grupos positivos. A His também tem o seu pK diminuído (de 6,24 para 6,10), porém devido a uma menor influência do Glu- ou à presença de grupos positivos. E a Lys (ou Tyr) tem o seu pK aumentado (de 10,27 para 10,90) devido à proximidade com cargas negativas. Portanto, apesar de apresentarem atividades biológicas semelhantes (Barbosa et al., 1999), o análogo Ac-Toac ${ }^{0}-\alpha-\mathrm{MSH}$ tem, em média, estrutura em solução aquosa ligeiramente diferente do peptídeo natural $\alpha-\mathrm{MSH}$.

O Ac-Toac0-MSH-I e o MSH-I apresentam valores de $p K_{1}$ e $p K_{2}$, relativos aos resíduos Glu e His, aproximadamente iguais (dentro da precisão da medida). Entretanto, o pK da Lys aumenta (de 10,24 para 10,97). Aparentemente, a presença do Toac parece alterar a conformação do peptídeo em tampão HEPES, aproximando a Tyr (carregada principalmente negativa nesse valor de $\mathrm{pH}$ ) da Lys (ou vice-versa), e assim, aumentando a concentração de $\mathrm{H}^{+}$nessa região. Apesar disso, as estruturas desses dois peptídeos são mais semelhantes do que os dos Ac-Toac ${ }^{0}-\alpha-\mathrm{MSH}$ e $\alpha-\mathrm{MSH}$. Isto é consistente com o fato do MSH-I ser uma molécula mais rígida.

Trabalhos em andamento no grupo de Biofisica (Marquezin e Ito), usando dipeptídeos, mostram que os tempos de vida do Trp, em função do $\mathrm{pH}$ do meio, somente em presença dos aminoácidos, Glu, His e Lys, comportam-se de maneira similar aos perfis encontrados para o Trp nos peptídeos aqui estudados (Fig. 4.4.8). Entretanto, os valores encontrados para os pK's são diferentes, sendo que nos dipeptídeos os valores estão muito mais próximos daqueles obtidos com os aminoácidos livres em solução aquosa, encontrados nos livros texto (Voet \& Voet, 1995). Portanto, esta comparação com dipeptídeos reforça nossa discussão da influência dos grupos vizinhos, e também da conformação, nos valores de pK's obtidos para os peptideos pelos ajustes das curvas na Fig. 4.4.9.

Esses resultados serão importantes na discussão das estruturas dos peptídeos, por exemplo, determinadas por medidas de ressonância magnética nuclear (RMN). Além disso, para melhor entender o efeito do Toac na conformação do peptídeo, faz-se necessário o estudo desta sonda em outras posições da cadeia peptídica, em solução aquosa e em agregados de anfifilicos. 


\section{Conclusões}

A variação do perfil de polaridade da bicamada lipídica devido à interação peptídeo-lipídeo é uma informação complementar ao efeito que o $\alpha$-MSH causa na fluidez da membrana (Biaggi et al., 1997). O efeito do peptídeo sobre o empacotamento e o grau de hidratação da fase lipídica, pode levar a um ambiente ideal, favorecendo a interação hormônio-receptor. Por outro lado, o efeito do peptídeo na diminuição da barreira hidrofóbica da membrana pode ser biologicamente relevante. É importante ter em mente que o DMPG está sendo usado aqui como sistema modelo da fase lipídica de membranas biológicas.

Em membranas de DMPG na fase líquido cristalina, o peptídeo melanotrópico aumenta o empacotamento e a polaridade em regiões monitoradas pelo 5- e 16-PCSL, e 5- e 16-SASL (e 12-PCSL, como indicado pelos espectros simulados). Isto é contrário ao efeito causado pela penetração completa de moléculas hidrofóbicas, como o colesterol e carotenóides, na fase fluida da membrana, que aumentam o empacotamento mas diminuem a polaridade da bicamada (Subczynski et al., 1994; Wisniewska e Subczynski, 1998). Este comportamento pode ser específico do $\alpha$-MSH, ou pode ser uma conseqüência geral da interação de membranas aniônicas com peptídeos catiônicos que penetram parcialmente na bicamada lipídica. Por exemplo, a presença de um aminoácido carregado, como a Arg, próximo ao resíduo hidrofóbico Trp, como ocorre no $\alpha$-MSH, pode induzir (ou estabilizar) a presença de moléculas de água dentro da bicamada. Ou então, a interação peptídeo-lipídeo poderia deformar a estrutura da bicamada, permitindo a penetração de uma maior quantidade de água na membrana. É importante notar que, em bicamadas fluidas, isto não é um efeito devido a um aumento de cátions na superficie da membrana de DMPG, porque nenhuma alteração foi observada na presença de $100 \mathrm{mM}$ de $\mathrm{NaCl}$.

Mostrou-se que as mudanças no perfil de polaridade medidas em amostras congeladas não podem ser aplicadas aos lipídeos na fase líquido cristalina. Essa diferença parece ser particularmente relevante na presença de moléculas polares que causam alterações distintas nas fases gel e fluida da membrana. Entretanto, é observada uma certa correlação entre o empacotamento na fase gel, causado pelo $\alpha$ $\mathrm{MSH}$ e $\mathrm{NaCl}$, e o aumento na polaridade (aumento de $\mathrm{A}_{z \mathrm{z}}$ ) medido em amostras congeladas. 
A detecção da coexistência de dois microambientes na fase intermediária de bicamadas de DMPG (Riske et al., 2001), depende de uma posição específica do marcador de spin na bicamada lipídica. Espectros do 16-PCSL parecem apresentar um sinal composto de RPE, proveniente de dois dominios de diferentes viscosidades e polaridades. Em presença de $\alpha-\mathrm{MSH}$, observa-se muito provavelmente o desaparecimento de um dos sinais. Este desaparecimento é atribuído resultar da preferência do peptídeo em localizar-se em regiões de altíssima curvatura, tais como as encontradas em agregados micelares, propiciando uma maior penetração do $\alpha$-MSH para regiões hidrofóbicas, e alterando o sinal dessa população de marcadores 16PCSL, ou expulsando o marcador desta região.

A modificação da estrutura primária do $\alpha-\mathrm{MSH}$, pela introdução do resíduo fluorescente D-Nal e formação de ponte disulfeto intramolecular, parece favorecer a entrada dos peptídeos em ambiente mais hidrofóbico. Usando o modelo de rotâmeros (Szabo e Rayner, 1980), verifica-se que, em solução aquosa, o Trp nos análogos cíclicos tem a sua componente de tempo longo $\tau_{1}$ diminuída devido ou à presença do D-Nal em sua cadeia peptídica, ou à ponte disulfeto, e esta alteração depende do grau de mobilidade do peptídeo, sendo que para baixas temperaturas este efeito não é observável. O D-Nal, por sua vez, parece ter parte de sua fluorescência suprimida pelo Trp, porém para confirmar este resultado, faz-se necessário o estudo com outros peptídeos com D-Nal, mas sem resíduos supressores.

$\mathrm{Na}$ fase lipídica, o aumento nos tempos de vida do Trp presente nos análogos cíclicos, associado à redução da polaridade da região em que este se encontra, indica que, nestes peptídeos, o Trp penetra mais profundamente na membrana do que no $\alpha-$ MSH. Essa penetração é provavelmente induzida pelo D-Nal que, em ambiente hidrofóbico, tem a sua fluorescência altamente favorecida em relação a do Trp. A forma mais adequada para penetração na membrana é a conformação associada ao tempo de vida intermediário $\tau_{2}$ do Trp. Em ambiente aquoso, os peptídeos cíclicos parecem ter uma conformação próxima (na região do Trp) da adquirida pelo $\alpha$-MSH em bicamadas lipídicas, sugerindo que os análogos cíclicos encontram-se, em meio aquoso, em uma forma mais adequada para penetração da membrana. Além disso, o D-Nal também penetra na bicamada lipídica de DMPG, alterando drasticamente seu espectro de fluorescência e o tempo de vida do estado excitado. Assim, o D-Nal parece ser uma sonda muito interessante, pois está presente em peptídeos ativos, e apresenta tempo de vida muito diferente do Trp, podendo, pois, ser monitorada em presença de proteínas que contenham vários $\operatorname{Trp}_{\mathrm{s}}$ (por exemplo, receptores). Além disso, apresenta 
grande variação no espectro de fluorescência, quando vai de um meio aquoso para o interior hidrofóbico de agregados anfifilicos.

A incorporação da sonda paramagnética Toac no início da seqüência peptídica do $\alpha$-MSH, e de seu análogo biologicamente mais ativo (MSH-I), reduz os tempos de vida do Trp no estado excitado, devido à supressão de sua fluorescência pelo Toac. A dependência da conformação do $\alpha$-MSH e MSH-I com o pH do meio, observado tanto por RPE do Toac quanto pela fluorescência do Trp, é atribuído à titulação de cadeias laterais dos peptídeos. A análise das curvas de titulação destes peptídeos, obtidas por fluorescência do Trp, sugere pequenas diferenças conformacionais entre os peptídeos em meio aquoso, sendo o maior efeito observado em pH alcalino. Em meio ácido, a presença do Toac no $\alpha$-MSH e MSH-I parece não causar modificação considerável nas estruturas destes peptídeos. Entretanto, em meio alcalino a presença do Toac parece modificar as estruturas do hormônio natural e seu análogo biologicamente mais ativo (ver Tabela 4.4.4). O Toac modifica a conformação destes peptídeos aproximando a Tyr da Lys, e aumentando a contribuição da Lys na titulação do Ac-Toac ${ }^{0}-\alpha-M S H$ e AcToac0-MSH-I. Estudos em dipeptídeos (Glu-Trp, His-Trp e Lys-Trp) que apresentam perfis de titulação semelhantes aos encontrados nos peptídeos aqui estudados, porém com valores de pK's diferentes, confirmam nosso resultado. Embora esses resultados indiquem mudança conformacional nos peptídeos marcados, tal alteração parece não modificar suas atividades biológicas (Barbosa et al., 1999 e Nakaie et al., 2001). Assim, o Toac como sonda paramagnética, é de grande potencial para uso em diversas aplicações bioquímicas. 


\section{Modelo teórico para o espectro de ressonância magnética de movimento lento}

(Freed et al., 1971; Schneider e Freed, 1989; Budil et al., 1996)

\section{A.1 Considerações teóricas}

De acordo com a teoria, para descrever a evolução temporal do operador magnetização dos spins individuais, foi usada a equação de Liouville estocástica (ELE) através do tratamento quântico do operador densidade dependente da orientação, enquanto que a orientação da molécula é determinada por um processo estocástico clássico. Este último, que modela a reorientação das moléculas, afeta a evolução temporal do sistema de spins, e assim o espectro de RPE resultante. A magnetização macroscópica pode então ser descrita efetuando a média num "ensemble" de spins. O sistema é descrito por uma hamiltoniana $\hbar H$ de volume $\mathrm{V}$ e temperatura T. Quando uma radiação eletromagnética de freqüência $\omega / 2 \pi$ é aplicada, a absorção magnética é determinada pela parte imaginária da susceptibilidade magnética, que pode ser mostrada ser dada por (Abragam, 1989):

$$
\chi^{\prime \prime}(\omega)=\frac{\omega V}{k T} \cdot \frac{1}{\operatorname{Tr}[\varepsilon]} \int_{0}^{\infty} \cos \omega t \cdot \operatorname{Tr}\left[M_{z}(t) M_{z}\right] d t
$$

onde $M_{z}$ é o operador para a componente $z$ da magnetização macroscópica da amostra,

$$
M_{z}(t)=\exp (i H t) \cdot M_{z} \cdot \exp (-i H t)
$$

e $\varepsilon$ é o operador unitário no espaço vetorial representado por $H$. Para a maioria dos propósitos, podemos usar uma formulação semiclássica em que a hamiltoniana total do sistema de spins é dividida em duas partes,

$$
\hbar H=\hbar H_{0}+\hbar H_{1}(t)
$$

A hamiltoniana de ordem-zero $\hbar H_{0}$ é independente do tempo e gera o aparecimento de um espectro de linha fina, enquanto $\hbar H_{1}(t)$ é uma perturbação dependente do tempo que causa relaxação e alargamento de linha. Este último termo 
representa o efeito de tombamento dos radicais livres resultantes da colisão com o solvente, rotação interna e vibração. É esse tombamento molecular que modula as interações dipolares intramoleculares anisotrópicas e a anisotropia do tensor-g. As rotações internas e vibrações modificam a geometria da molécula e a distribuição da densidade de spins do elétron- $\pi$ e conseqüentemente as interações hiperfinas isotrópicas.

A reorientação dinâmica do marcador de spin (assumido ser rígido) é modelado por um super-operador de difusão rotacional simetrizado com um potencial de restauração (também chamado de potencial diretor) da forma,

$$
U(\Omega)=-k_{B} T\left\{\sum_{L=2,4} c_{0}^{L} D_{00}^{L}(\Omega)+c_{2}^{L}\left[D_{02}^{L}(\Omega)+D_{0-2}^{2}(\Omega)\right]\right\}
$$

onde $\Omega=(\alpha, \beta, \gamma)$ representa os ângulos de Euler descrevendo a orientação do radical relativo a um referencial fixo, e $c^{L_{O}}$ e $c^{L_{2}}$ são os coeficientes do potencial diretor. As funções $D_{M K}^{L}(\Omega)$ são os harmônicos esféricos generalizados ou os elementos da matriz de rotação de Wigner. Embora a escolha do processo estocástico usado para modelar a reorientação das moléculas afete a evolução temporal do sistema de spins, e assim o espectro de RPE resultante, o potencial diretor mencionado é apropriado para modelar marcadores de spin.

\section{A.2 Definição dos sistemas de coordenadas}

A seguir serão definidos os sistemas de coordenadas usados. Sejam os seguintes sistemas de eixos utilizados na simulação: o sistema molecular $\left(x^{\prime}, y^{\prime}, z^{\prime}\right)$, o sistema diretor ( $\mathrm{x}, \mathrm{y}, \mathrm{z}$ ), o sistema magnético (x"',y", z"') e o sistema de laboratório $(\mathrm{x}, \mathrm{y}, \mathrm{z})$ que são mostrados esquematicamente na Figura A.1. 


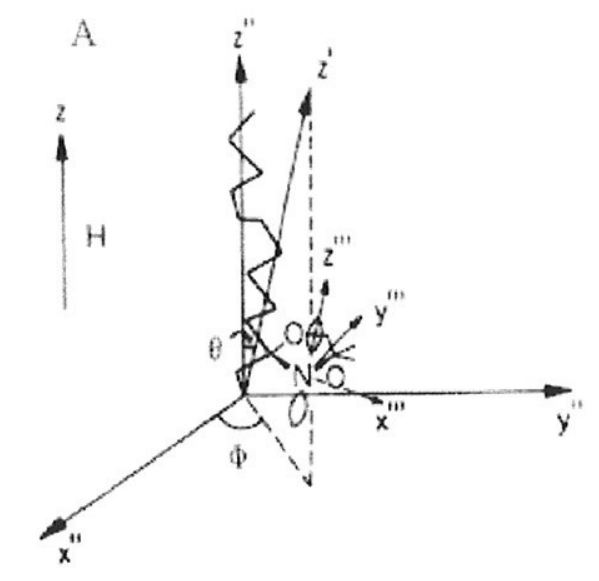

Figura A.1 - Representação esquemática dos quatro sistemas de coordenadas utilizados nas simulações dos espectros de RPE com movimento lento. (Ge e Freed, 1999).

Considere uma cadeia bem ordenada com orientação preferencial ao longo do eixo $z^{\prime}$ do sistema diretor e um radical nitróxido conectado perto do final dessa cadeia (ver Fig. A.1). Agora suponha que o segmento do final da cadeia é dobrada conforme pode ser observado na Figura A.2, sem alterar a orientação preferencial.

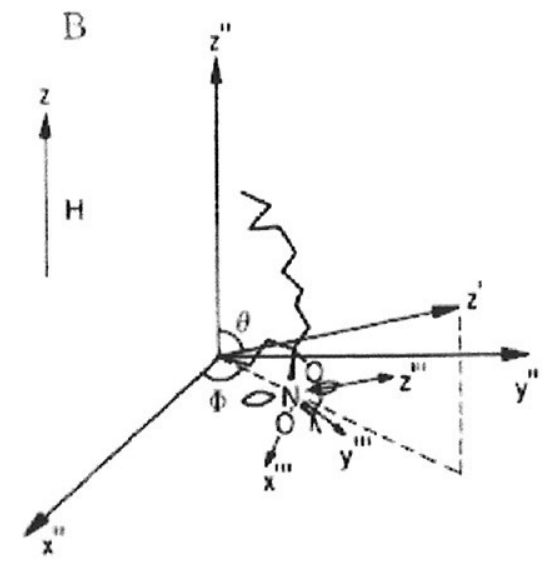

Figura A.2 - Modificação das direções dos sistemas de coordenadas relativas a uma dobra do segmento final da cadeia. (Ge e Freed, 1999).

O sistema molecular ( $\left.\mathrm{x}^{\prime}, \mathrm{y}^{\prime}, \mathrm{z}^{\prime}\right)$ é o sistema em que as constantes de difusão rotacional $R_{\perp}$ e $R_{/ /}$são os valores principais do tensor de difusão rotacional com simetria axial para a mobilidade do nitróxido conectado ao segmento da cadeia. Eles representam as taxas de difusão rotacional sobre o eixo $\perp$ e / / do segmento da cadeia. A ordem da cadeia pode ser representado pelo sistema molecular ( $\left.x^{\prime}, y^{\prime}, z^{\prime}\right)$. O parâmetro de ordem do marcador de spin S é definido como: 


$$
S \equiv\left\langle D_{00}^{2}\right\rangle=\left\langle\frac{1}{2}\left(3 \cos ^{2} \theta-1\right)\right\rangle=\int D_{00}^{2}(\Omega) P(\Omega) d \Omega
$$

que é a medida do alinhamento do eixo molecular z' com relação ao sistema diretor z". $\mathrm{P}(\Omega)$ é a distribuição de probabilidade orientacional e é dado por:

$$
P(\Omega)=\frac{\exp \left\{-U(\Omega) / k_{B} T\right\}}{\int \exp \left\{-U(\Omega) / k_{B} T\right\} d \Omega}
$$

onde $U(\Omega)$ é o potencial diretor (eq. A.4) experimentado pelo radical nitróxido, que pode ser aproximado como

$$
-U(\theta, \Phi) / k_{B} T=\frac{c_{0}^{2}}{2}\left(3 \cos ^{2}-1\right)+\sqrt{\frac{3}{2}} c_{2}^{2} \operatorname{sen}^{2} \theta \cos 2 \theta
$$

onde $\Omega \equiv(\theta, \Phi)$, e $\theta$ e $\Phi$ representam, os ângulos polar e azimutal do eixo de difusão $z$ ' no sistema diretor, e $c^{2}{ }_{o}$ e $c_{2}^{2}$ são os coeficientes adimensionais da energia potencial.

O sistema magnético ( $\mathrm{x}$ "',y"',z"') é o sistema de eixos em que os tensores g e A são diagonalizados. Por convenção, o eixo x"' aponta ao longo da direção N-O, o eixo z"' é paralelo ao orbital $2 \mathrm{P} \pi$ do átomo de Nitrogênio, e o eixo y"' é perpendicular aos outros eixos. O eixo $z$ " do sistema diretor ( $x^{\prime \prime}, y^{\prime \prime}, z$ ) representa a orientação média das cadeias acila num fragmento da bicamada lipídica. O último sistema de eixos é o sistema de laboratório $(\mathrm{x}, \mathrm{y}, \mathrm{z})$ que é definido pelo campo magnético aplicado com o eixo $z$ na direção do campo.

Além desses sistemas, outros dois ângulos também são definidos. O ângulo de inclinação do potencial diretor $\Psi$ é o ângulo entre o potencial diretor (eixo z") e o campo magnético (eixo z). Na Figura A.1, z" é paralelo ao campo magnético e portanto $\Psi=0$. Este ângulo está relacionado à ordem macroscópica das bicamadas lipídicas. Para vesículas lipídicas, o ângulo de inclinação do potencial diretor do fragmento da bicamada é aleatoriamente distribuído no espaço, isto é, macroscopicamente a amostra é desordenada. O segundo ângulo de inclinação, chamado inclinação da difusão $\beta$, é o ângulo entre o eixo magnético $z$ "' e o eixo molecular z', que está relacionado à conformação do segmento da cadeia onde o radical nitróxido está ligado. Assim, se o segmento onde o grupo Doxil está ligado está numa conformação trans, então os sistemas magnético e molecular coincidem um com o outro e portanto $\beta=0$.

Para entender o significado do parâmetro de ordem negativo, Freed et al., 1999, analisaram o potencial diretor ao longo de três direções específicas: $(\theta, \Phi)=\left(90^{\circ}, 0^{\circ}\right)$, 
$\left(90^{\circ}, 90^{\circ}\right),\left(0^{\circ}, 0^{\circ}\right)$ que especifica as orientações dos eixos $x^{\prime}, y^{\prime}, z^{\prime}$ paralelo ao eixo z". Nesse trabalho foi verificado que espectros que são simulados com valores negativos para os coeficientes do potencial diretor, possuem uma distribuição orientacional no plano perpendicular ao eixo $z$ " do sistema diretor. Assim, parâmetros de ordem negativo é um indicativo de dobra da cadeia lipídica onde está conectado o radical nitróxido. 


\section{Referências}

Abragam, A. "Principles of nuclear magnetism". Oxford, Hong Kong, 1989.

Atherton, N.M. "Principles of electron spin resonance". Ellis Horwood, Great Britain, 1993.

Bales, B.L. "Inhomogeneously broadened spin-label spectra, em Biological Magnetic Resonance, vol. 8". Eds. Berliner, L.J. e Reuben, J. Plenum Publishing Corporation, New York, 1989, pág. 77-130.

Barbosa, S.R., Cilli, E.M., Lamy-Freund, M.T., Castrucci, A.M.L. e Nakaie, C.R. "First synthesis of a fully active spin-labeled peptide hormone". FEBS Letters, 446 (1999) 45-48.

Benatti, C.R., Feitosa, E., Fernandez, R.M. e Lamy-Freund, M.T. "Structural and thermal characterization of dioctadecyldimethylammonium bromide dispersions by spin labels". Chem. Phys. Lipids, 111 (2001) 93-104.

Biaggi, M.H., Pinheiro, T.J.T., Watts, A. e Lamy-Freund, M.T. "Spin label and 2H-NMR studies on the interaction of melanotropic peptides with lipid bilayers". Eur. Biophys. J., 24 (1996) 251-259.

Biaggi, M.H., Riske, K.A. e Lamy-Freund, M.T. "Melanotropic peptide-lipid bilayer interactions. Comparison of the hormone $\alpha-\mathrm{MSH}$ to a biologically more potent analog". Biophys. Chem., 67 (1997) 139-149.

Bransden, B.H. e Joachain, C.J. "Physics of atoms and molecules". Longman, London, 1996.

Budil, D.E., Lee, S., Saxena, S. e Freed, J.H. "Nonlinear-least-squares analysis of slow-motion EPR spectra in one and two dimensions using a modified LevenbergMarquardt algorithm”. J. Mag. Res., 120 (1996) 155-189.

Cantor, C.R. e Schimmel, P.R. "Biophysical chemistry. Part II. Techniques for the study of biological structure and function". W.H. Freeman and Company, New York, 1980.

Castrucci, A.M.L., Hadley, M.E., Sawyer, T.K., Wilkes, B.C., Al-Obeidi, F., Staples, D.J., DeVaux, A.E., Dym, O., Hintz, M.E., Riehm, J., Rao, K.R. e Hruby, V.J. "Alpha-melanotropin - the minimal active sequence in the lizard skin bioassay". Gen. Comp. Endocrinol., 73 (1989) 157-163.

Cevc, G. e Marsh, D. “Phospholipid bilayers: Physical principles and models”. John Wiley \& Sons, New York, 1987. 
Chang, M.C., Petrich, J.W., McDonald, D.B. e Fleming, G.R. "Nonexponential fluorescence decay of tryptophan, tryptophylglycine, and glycyltryptophan". $J$. Am. Chem. Soc., 105 (1983) 3819-3824.

de Gennes, P.G. "The physics of liquid crystals”. Oxford University Press, Oxford, 1974.

Earle, K.A., Moscicki, J.K., Ge, M., Budil, D.E. e Freed, J.H. “250-GHz electron spin resonance studies of polarity gradients along the aliphatic chains in phospholipid membranes". Biophys. J., 66 (1994) 1213-1221.

Ellena, J.F., Archer, S.J., Dominey, R.N., Hill, B.D. e Cafiso, D.S. "Localizing the nitroxide group of fatty acid and voltage-sensitive spin-labels in phospholipid bilayers". Biochim. Biophys. Acta, 940 (1988) 63-70.

Feix, J.B., Popp, C.A., Venkataramu, S.D., Beth, A.H., Park, J.H. e Hyde, J.H. "An electron-electron double-resonance study of interactions between [14N]- and [15N] stearic acid spin-label pairs: lateral diffusion and vertical fluctuations in dimyristoylphosphatidylcholine”. Biochemistry, 23 (1984) 2293-2299.

Fernandez, R.M. e Lamy-Freund, M.T. "Correlation between the effects of a cationic peptide on the hydration and fluidity of anionic lipid bilayers: a comparative study with sodium ions and cholesterol". Biophys. Chem., 87 (2000) 87-102.

Freed, J.H., Bruno, G.V. e Polnaszek, C.F. "Electron spin resonance line shapes and saturation in the slow motional region". J. Phys. Chem., 75 (1971) 3385-3399.

Fretten, P., Morris, S.J., Watts, A. e Marsh, D. "Lipid-lipid and lipid-protein interactions in chromaffin granule membranes. A spin label ESR study". Biochim. Biophys. Acta, 598 (1980) 247-259.

Gaffney, B.J. "Practical considerations for the calculation of order parameters for fatty acid or phospholipid spin labels in membranes, em Spin labeling - Theory and applications”. Ed. Berliner, L.J. Academic Press, New York, 1976, pág. 567-571.

Ge, M. and Freed, J.H. "Electron-spin resonance study of aggregation of gramicidin in dipalmitoylphosphatidylcholine bilayers and hydrophobic mismatch". Biophys. J., 76 (1999) 264-280.

Ge, M. e Freed, J.H. "An electron spin resonance study of interactions between gramicidin A' and phosphatidylcholine bilayers". Biophys. J., 65 (1993) 21062123.

Ge, M. e Freed, J.H. "Polarity profiles in oriented and dispersed phosphatidylcholine bilayers are different: an electron spin resonance study". Biophys. J., 74 (1998) 910-917. 
Gennis, R.B. "Biomembranes. Molecular structure and function". Springer-Verlag, New York, 1989.

Griffith, O.H, Dehlinger, P.J. e Van, S.P. "Shape of the hydrophobic barrier of phospholipid bilayers (evidence for water penetration in biological membranes". J. Membr. Biol., 15 (1974) 159-192.

Griffith, O.H. e Jost, P.C. "Lipid spin labels in biological membranes, em Spin labelling-Theory and applications”. Ed. Berliner, L.J. Academic Press, New York, 1976, pág. 453-523.

Hadley, M.E, Sharma, S.D., Hruby, V.J., Levine, N. e Dorr, R.T. "Melanotropic peptides for therapeutic and cosmetic tanning of the skin". Ann. N. Y. Acad. Sci., 680 (1993) 424-439.

Halpern, H.J., Peric, M., Yu, C. e Bales, B. "Rapid quantitation of parameters from inhomogeneously broadened EPR-spectra”. J. Mag. Res., 103 (1993) 13-22.

Hanson, P., Millhauser, G., Formaggio, F., Crisma, M. E Toniolo, C. "ESR characterization of hexameric, helical peptides using double Toac spin labeling”. J. Am. Chem. Soc., 118 (1996) 7618-7625.

Harris, J., Power, T.J., Bieber, A.L. e Watts, A. "An electron-spin-resonance spin-label study of the interaction of purified Mojave toxin with synaptosomal membranes from rat brain". Eur. J. Biochem., 131 (1983) 559-565.

Hauser, H. "Effect of inorganic cations on phase transitions". Chem. Phys. Lipids, 57 (1991) 309-325.

Heimburg, T. e Biltonen, R.L. "Thermotropic behavior of dimyristoylphosphatidyl glycerol and its interaction with cytochrome C". Biochemistry, 33 (1994) 94779488.

Ho, C., Slater, S.J. e Stubbs, C.D. "Hydration and order in lipid bilayers". Biochemistry, 34 (1995) 6188-6195.

Hruby, V.J., Wilkes, B.C., Hadley, M.E., al-Obeidi, F., Sawyer, T.K., Staples, D.J., DeVaux, A.E., Dym, O., Castrucci, A.M.L., Hintz, M.E., Riehm, J.P. e Rao, K.R. "Alpha-melanotropin - the minimal active sequence in the frog-skin bioassay". J. Med. Chem., 30 (1987) 2126-2130.

Hruby, V.J., Lu, D., Sharma, S.D., Castrucci, A.L., Kesterson, R.A., al-Obeidi, F.A., Hadley, M.E. e Cone, R.D. "Cyclic lactam alpha-melanotropin analogues of AcNle4-cyclo[Asp5, D-Phe7, Lys10] $\alpha$-MSH-(4-10)- $\mathrm{NH}_{2}$ with bulky aromatic amino acids at position 7 show high antagonist potency and selectivity at specific melanocortin receptors". J. Med. Chem., 38 (1995) 3454-3461. 
Hubbell, W.L. e McConnell, H.M. "Molecular motion in spin-labeled phospholipids and membranes". J. Am. Chem. Soc., 93 (1971) 314-326.

Ito, A.S., Castrucci, A.M.L., Hruby, V.J., Hadley, M.E., Krajcarski, D.T. e Szabo, A.G. "Structure-activity correlations of melanotropin peptides in model lipids by tryptophan fluorescence studies". Biochemistry, 32 (1993) 12264-12272.

Jacobs, R.E. e White, S.H. "The nature of the hydrophobic binding of small peptides at the bilayer interface: implications for the insertion of transbilayer helices". Biochemistry, 28 (1989) 3421-3437.

Johnson, M.E. “Apparent hydrogen bonding by strongly immobilized spin-labels.". Biochemistry, 20 (1981) 3319-3328.

Kask, A., Mutulis, F., Muceniece, R., Pähkla, R., Mutule, I., Wikberg, J.E.S, Rägo, L. e Schiöth, H.B. "Discovery of a novel superpotent and selective melanocortin-4 receptor antagonist (HS024): evaluation in vitro and in vivo". Endocrinology, 139 (1998) 5006-5014.

Knutson, J.R., Beechem, J.M. e Brand, L. "Simultaneous analysis of multiple fluorescence decay curves - a global approach". Chem. Phys. Lett., 102 (1983) 501-507.

Lakowicz, J.R. "Principles of Fluorescence Spectroscopy", 2nd Edition. Kluwer Academic/Plenum Publishers, New York, 1999.

Lawaczeck, R. "Permeability of water-molecules across vesicular lipid bilayers". J. Membr. Biol., 51 (1979) 229-261.

Macedo, Z.S., Furquim, T.A. e Ito, A.S. "Estimation of average depth of penetration of melanotropins in dimyristoylphosphatidylglycerol vesicles". Biophys. Chem., 59 (1996) 193-202.

Marsh, D. "Membrane Spectroscopy”. Ed. Ernst Grell, Springer Verlag, Berlin, 1981.

Marsh, D. "Experimental methods in spin-label spectra analysis, em Biological Magnetic Resonance, vol. 8”. Eds. Berliner, L.J. e Reuben, J. Plenum Publishing Corporation, New York, 1989, pág. 255-303.

Marsh, D. e Schorn, K. “Corrections for anisotropically averaged hyperfine splittings and order parameters from pseudopowder electron paramagnetic resonance (EPR) line shapes, em Biological Magnetic Resonance, vol. 14”. Ed. Berliner, L.J. Plenum Press, New York, 1998, pág. 405-410.

Nakaie, C.R., Goissis, G., Schreier, S. e Paiva, A.C.M. "pH dependence of EPR spectra of nitroxides containing ionizable groups". Brazilian J. Med. Biol. Res., 14 (1981) 173-180. 
Nakaie, C.R., Schreier, S. e Paiva, A.C.M. "Synthesis and properties of spin-labeled angiotensin derivatives". Biochim. Biophys. Acta, 742 (1983) 63-71.

Nakaie, C.R., Sila, E.G., Cilli, E.M., Marchetto, R., Oliveira, E., Carvalho, R.S.H., Jubilut, G.N., Miranda, A., Tominaga, M., Schreier, S., Paiva, T.B. e Paiva, A.C.M. "Peptides". Eds. Ramage, R. e Epton, R. Mayflower Scientific, 1996, pág. 673-674.

Nakaie, C.R, Barbosa, S.R., Vieira, R.F.F., Fernandez, R.M., Cilli, E.M., Castrucci, A.M.L., Visconti, M.A., Ito, A.S. e Lamy-Freund, M.T. "Comparative EPR and fluorescence conformational studies of fully active spin-labeled melanotropic peptides". FEBS Letters, 497 (2001) 103-107.

Onufriev, A., Case, D.A. e Ullmann G.M. "A novel view of $\mathrm{pH}$ titration in biomolecules". Biochemistry, 40 (2001) 3413-3419.

Prabhu, N.V., Perkyns, J.S., Pettitt, B.M. e Hruby, V.J. "Structure and dynamics of $\alpha-$ MSH using DRISM integral equation theory and stochastic dynamics". Biopolymers, 50 (1999) 255-272.

Petrich, J.W., Chang, M.C., McDonald, D.B. e Fleming, G.R. "On the origin of nonexponential fluorescence decay in tryptophan and its derivatives". J. Am. Chem. Soc., 105 (1983) 3824-3832.

Pispisa, B., Palleschi, A., Stella, L., Venanzi, M. e Toniolo, C. "A nitroxide derivative as a probe for conformational studies of short linear peptides in solution. Spectroscopic and molecular mechanics investigation". J. Phys. Chem. B, 102 (1998) 7890-7898.

Ptak, M., Egret-Charlier, M., Sanson, A. e Boloussa, O. "A NMR study of the ionization of fatty acids, fatty amines and $\mathrm{N}$-acylamino acids incorporated in phosphatidylcholine vesicles”. Biochim. Biophys. Acta, 600 (1980) 387-397.

Riske, K.A., Politi, M.J., Reed, W.F. e Lamy-Freund, M.T. "Temperature and ionic strength dependent light scattering of DMPG dispersions". Chem. Phys. Lipids, 89 (1997) 31-44.

Riske, K.A., Nascimento, O.R., Peric, M., Bales, B. e Lamy-Freund, M. T. "Probing DMPG vesicle surface with a cationic aqueous soluble spin label". Biochim. Biophys. Acta, 1418 (1999) 133-146.

Riske, K.A., Amaral, L.Q. e Lamy-Freund, M.T. "Thermal transitions of DMPG bilayers in aqueous solution: SAXS structural studies". Biochim. Biophys. Acta, 1511 (2001) 297-308.

Ross, J.B.A., Wyssbrod, H.R., Porter, R.A., Schwartz, G.P., Michaels, C.A. e Laws, W.R. "Correlation of tryptophan fluorescence intensity decay parameters with $1 \mathrm{H}$ NMR- 
determined rotamer conformations: [tryptophan2]oxytocin". Biochemistry, 31 (1992) 1585-1594.

Schindler, H. e Seelig, J. "EPR-spectra of spin labels in lipid bilayers". J. Chem. Phys., 59 (1973) 1841-1850.

Schiöth, H.B. "Discovery of novel selective ligands, expression and structural characterisation of the melanocortin receptor subtypes". Tese de Doutorado apresentada à Universidade de Uppsala, Uppsala, 1997.

Schiöth, H.B., Muceniece, R., Mutulis, F., Prusis, P., Lindeberg, G., Sharma, S.D., Hruby, V.J. e Wikberg, J.E.S. "Selectivity of cyclic [D-Nal7] and [D-Phe $\left.{ }^{7}\right]$ substituted MSH analogues for the melanocortin receptor subtypes". Peptides, 18 (1997) 1009-1013.

Schiöth, H.B., Mutulis, F., Muceniece, R., Prusis, P. e Wikberg, J.E.S. "Discovery of novel melanocortin 4 receptor selective MSH analogues". Brit. J. Pharm., 124 (1998) 75-82.

Schneider, D.J. e Freed, J.H. "Calculating slow motional magnetic resonance spectra A user's guide, em Biological Magnetic Resonance, vol. 8”. Eds. Berliner, L.J. e Reuben, J. Plenum Publishing Corporation, New York, 1989, pág. 1-76.

Schreier-Muccilo, S., Marsh, D., Dugas, H., Schneider, H. e Smith, I.C.P. "Spin probe study of influence of cholesterol on motion and orientation of phospholipids in oriented multibilayers and vesicles". Chem. Phys. Lipids, 10 (1973) 11-27.

Schreier, S., Polnaszek, C.F. e Smith, I.C.P. "Spin labels in membranes. Problems in practice”. Biochim. Biophys. Acta, 515 (1978) 375-436.

Schwartz, R.N., Peric, M., Smith, S.A. e Bales, B.L. "Simple test of the effect of an electric field on the ${ }^{14} \mathrm{~N}$-hyperfine coupling constant in nitroxide spin probes". $J$. Phys. Chem., 101 (1997) 8735-8739.

Stryer, L. "Biochemistry", 2nd Edition. W.H.Freeman and Company, San Francisco, 1981.

Subczynski, W.K., Wisniewska, A., Yin, J.J., Hyde, J.S. e Kusumi, A. "Hydrophobic barriers of lipid bilayer membranes formed by reduction of water penetration by alkyl chain unsaturation and cholesterol”. Biochemistry, 33 (1994) 7670-7681.

Szabo, A.G. e Rayner, D.M. "Fluorescence decay of tryptophan conformers in aqueous solution". J. Am. Chem. Soc., 102 (1980) 554-563.

Tanford, C. "The hydrophobic effect: formation of micelles and biological membranes", 2nd Edition. John Wiley \& Sons, New York, 1980.

Toniolo, C., Valente, E. ,Formaggio, F., Crisma, M., Pilloni, G., Corvaja, C., Toffoletti, A., Martinez, G.V., Hanson, M.P., Millhauser, G.L., George, C. e Flippen- 
Anderson, J.L. "Synthesis and conformational studies of peptides containing Toac, a spin-labelled C $C^{\alpha, \alpha}$-disubstituted glycine”. J. Peptide Sci., 1 (1995) 45-57.

Toniolo, C., Crisma, M. e Formaggio, F. “Toac, a nitroxide spin-labeled, achiral C ${ }_{-}$ tetrasubstituted $\alpha$-amino acid, is an excellent tool in material science and biochemistry". Biopolymers, 47 (1998) 153-158.

Turchiello, R.F., Juliano, L., Ito, A.S., Lamy-Freund, M.T. "How bradykinin alters the lipid membrane structure: a spin label comparative study with bradykinin fragments and other cations". Biopolymers, 54 (2000) 211-221.

van Holde, K.E., Johnson, W.C. e Ho P.S. "Principles of physical biochemistry". Prentice-Hall, New Jersey, 1998.

Vaudry, H. e Eberle, A.N. "The melanotropic peptides". Ann. N.Y. Acad. Sci., 680, 1993. Voet, D. e Voet, J.G. "Biochemistry”, 2nd Edition. John Wiley \& Sons, New York, 1995. Volke, F. e Pampel, A. "Membrane hydration and structure on a subnanometer scale as seen by high-resolution solid-state nuclear-magnetic-resonance - POPC and POPC/C(12)EO(4) model membranes". Biophys. J., 68 (1995) 1960-1965.

Redfield, A.G. "The theory of relaxation processes, em Advances in magnetic resonance”. Ed. Waugh, J.S. Academic Press, New York, 1965, pág. 1-32.

Willis, K.J. e Szabo, A.G. "Conformation of parathyroid hormone: time-resolved fluorescence studies". Biochemistry, 31 (1992) 8924-8931.

Winner, M.C. e White, S.H. "Structure of a fluid dioleoylphosphatidylcholine bilayer determined by joint refinement of $\mathrm{x}$-ray and neutron diffraction data. II. Distribution and packing of terminal methyl groups". Biophys. J., 61 (1992) 428433.

Wisniewska, A. e Subczynski, W.K. "Effects of polar carotenoids on the shape of the hydrophobic barrier of phospholipid bilayers". Biochim. Biophys. Acta, 1368 (1998) 235-246.

Zhou, Z., Sayer, B.G., Hughes, D.W., Stark, R.E. e Epand, R.M. "Studies of phospholipid hydration by high-resolution magic-angle spinning nuclear magnetic resonance". Biophys. J., 76 (1999) 387-399. 